\title{
Turtles and Tortoises of the World During the Rise and Global Spread of Humanity: First Checklist and Review of Extinct Pleistocene and Holocene Chelonians
}

\section{Turtle Extinctions Working Group*}

*Authorship of this article is by this joint Working Group of the IUCN SSC Tortoise and Freshwater Turtle Specialist Group and specialists in Chelonian Paleontology, which for the purposes of this document consisted of the following contributors:

\section{Anders G.J. Rhodin ${ }^{1}$, Scott Thomson ${ }^{2}$, Georgios L. Georgalis ${ }^{3,4}$,} Hans-Volker KarL ${ }^{5}$, Igor G. Danilov ${ }^{6}$, AKio TAKahashi ${ }^{7}$,

Marcelo S. de la Fuente ${ }^{8}$, Jason R. Bourque ${ }^{9}$, Massimo Delfino $^{4,10}$, Roger Bour ${ }^{11}$, John B. Iverson ${ }^{12}$, H. Bradley Shaffer ${ }^{13}$, and Peter Paul van Dijk ${ }^{14}$

${ }^{1}$ Chairman Emeritus, IUCN SSC Tortoise and Freshwater Turtle Specialist Group,

Chelonian Research Foundation, 168 Goodrich St., Lunenburg, Massachusetts 01462 USA [rhodincrf@aol.com];

${ }^{2}$ Museu de Zoologia da Universidade de São Paulo, Divisão de Vertebrados (Herpetologia), Ipiranga,04263-000 São Paulo, Brazil [scott.thomson321@gmail.com];

${ }^{3}$ Department of Geosciences, UniversityofFribourg/Freiburg,Chemindu Musée 6,1700 Fribourg, Switzerland [dimetrodon82@yahoo.gr]; ${ }^{4}$ Dipartimento di Scienze della Terra, Università di Torino, Via Valperga Caluso 35, 10125 Torino, Italy [massimo.delfino@unito.it];

${ }^{5}$ Department of Prehistoric and Early Historic Archaeology, Friedrich-Schiller-University Jena, Löbdergraben 24a,07743 Jena, Germany [hvkarl@icloud.com];

${ }^{6}$ Department of Herpetology, Zoological Institute of the Russian Academy of Sciences,

Universitetskaya Emb. 1, St.Petersburg, 199034, Russia [igordanilov72@gmail.com]; ${ }^{7}$ Department of Zoology, Faculty of Science, Okayama University of Science,

Ridaicho 1-1, Kitaku, Okayama 700-0005, Japan [takahashi@zool.ous.ac.jp];

${ }^{8}$ Departamento de Paleontología, Museo de Historia Natural de San Rafael,

Parque Mariano Moreno s/n, (5600) San Rafael, Provincia de Mendoza, Argentina [mdelafuente1910@gmail.com];

${ }^{9}$ Division of Vertebrate Paleontology, Florida Museum of Natural History,

Dickinson Hall, University of Florida, 1659 Museum Rd., Gainesville, Florida 32611 USA [jbourque@flmnh.ufl.edu];

${ }^{10}$ Institut Català de Paleontologia Miquel Crusafont, Universitat Autònoma de Barcelona,

Edifici ICP, Campus de la UAB s/n, 08193 Cerdanyola del Vallès, Barcelona, Spain;

${ }^{11}$ Laboratoire des Reptiles et Amphibiens, Muséum National d'Histoire Naturelle, Paris, France [bour.roger@gmail.com];

${ }^{12}$ Department of Biology, Earlham College, Richmond, Indiana 47374 USA [johni@earlham.edu];

${ }^{13}$ Department of Ecology and Evolutionary Biology and Institute of the Environment and Sustainability,

University of California, Los Angeles, California 90095 USA [brad.shaffer@ucla.edu];

${ }^{14} \mathrm{Co}$-Chair, IUCN SSC Tortoise and Freshwater Turtle Specialist Group,

Conservation International, 2011 Crystal Drive, Suite 500, Arlington, Virginia 22202 USA [pvandijk@conservation.org]

Abstract. - We provide a first checklist and review of all recognized taxa of the world's extinct Pleistocene and Holocene (Quaternary) turtles and tortoises that existed during the early rise and global expansion of humanity, and most likely went extinct through a combination of earlier hominin (e.g., Homo erectus, $H$. neanderthalensis) and later human (H. sapiens) exploitation, as well as being affected by concurrent global or regional climatic and habitat changes. This checklist complements the broader listing of all modern and extant turtles and tortoises by the Turtle Taxonomy Working Group (2014). We provide a comprehensive listing of taxonomy, names, synonymies, and stratigraphic distribution of all chelonian taxa that have gone extinct from approximately the boundary between the Late Pliocene and Early Pleistocene, ca. 2.6 million years ago, up through $1500 \mathrm{AD}$, at the beginning of modern times. We also provide details on modern turtle and tortoise taxa that have gone extinct since $1500 \mathrm{AD}$. This checklist currently includes 100 fossil turtle and tortoise taxa, including 84 named and apparently distinct species, and 16 additional taxa that appear to represent additional valid species, but are only identified to genus or family. Modern extinct turtles and tortoises include 8 species, 3 subspecies, and 1 unnamed taxon, for 12 taxa. Of the extinct fossil taxa, terrestrial tortoises of the family Testudinidae (including many large-bodied island forms) are the most numerous, with 60 taxa. When the numbers for fossil tortoises are combined with the 61 modern (living and extinct) species of tortoises, of the 121 tortoise species that have existed at some point since the beginning of the Pleistocene, $69(57.0 \%)$ have gone extinct. This likely reflects the high vulnerability of these large and slow terrestrial (often insular) species primarily to human exploitation. The other large-bodied terrestrial turtles, the 
giant horned turtles of the family Meiolaniidae, with 7 taxa (also often insular), all went extinct by the Late Holocene while also exploited by humans. The total global diversity of turtles and tortoises that has existed during the history of hominin utilization of chelonians, and that are currently recognized as distinct and included on our two checklists, consists of 336 modern species and 100 extinct Pleistocene and Holocene taxa, for a total of $\mathbf{4 3 6}$ chelonian species. Of these, 109 species $(25.0 \%)$ and 112 total taxa are estimated to have gone extinct since the beginning of the Pleistocene. The chelonian diversity and its patterns of extinctions during the Quaternary inform our understanding of the impacts of the history of human exploitation of turtles and the effects of climate change, and their relevance to current and future patterns.

KEY WORDS. - Reptilia, Testudines, turtle, tortoise, chelonian, taxonomy, distribution, extinction, fossils, paleontology, archaeology, humanity, hominin, exploitation, chelonophagy, megafauna, island refugia, climate change, Pliocene, Pleistocene, Holocene, Anthropocene, Quaternary

As an addition to the annual checklist of extant modern turtle taxa (Turtle Taxonomy Working Group [TTWG] 2014), we here present an annotated checklist of extinct Pleistocene and Holocene turtle and tortoise species that existed in relatively recent times, prior to $1500 \mathrm{AD}$, during the history of the rise and global spread of humanity and concurrent global climatic and habitat changes. These species, recorded from archaeological and paleontological sites from the Pleistocene and Holocene epochs (Quaternary period), approximately the last 2.6 million years, are currently considered to be valid, and not synonymous with modern (post-1500 AD) taxa.

These fossil species, including some unnamed taxa of indeterminate or undescribed generic or specific allocation, represent the majority of the chelonian diversity that has gone extinct relatively recently. Many of these taxa were likely extirpated by anthropogenic exploitation over the relatively long prehistory of earlier hominin (e.g., Homo erectus, H. neanderthalensis, and others) and later human (H. sapiens) exploitation of turtles and tortoises. In addition, many were also likely affected by global and regional climate change and cycles of warming and cooling and habitat alterations, such as those associated with glacial and interglacial periods and sea level changes and aridification, or stochastic events such as volcanism. As such, these recently extinct fossil species and taxa are eminently relevant to our understanding of distribution and extinction patterns among modern chelonians. Additionally, they broaden our awareness of the baseline and extent of turtle richness and diversity that existed at the early beginnings of humanity's utilization and consumption of turtles - exploitation that greatly increased with the rapid global expansion of humanity.

Of notable interest in this fossil checklist are the very recent, apparently human-induced extinctions of giant tortoises of the family Testudinidae, as well as giant horned terrestrial turtles of the extinct family Meiolaniidae. Among the Testudinidae are the Madagascan giant tortoises, Aldabrachelys abrupta and A. grandidieri, that went extinct in about 1200 $\mathrm{AD}$ and $884 \mathrm{AD}$, respectively, not long after humans reached Madagascar ca. 2000 years ago (Pedrono 2008). Additionally, some large insular species of Chelonoidis from the Bahamas region of the Caribbean West Indies were eaten into extinction by pre-Columbian natives as late as ca. 1170-1400 AD (Carlson 1999; Franz et al. 2001; Hastings et al. 2014).

Among the Meiolaniidae, we have the remarkable giant terrestrial horned turtle, Meiolania damelipi from Vanuatu in the southern Pacific Ocean, also eaten into extinction by humans by about $810 \mathrm{BC}$ (White et al. 2010), as well as an unnamed giant horned turtle from nearby New Caledonia, that went extinct as recently as about $531 \mathrm{AD}$ (Gaffney et al. 1984). This unnamed and vanished species was apparently the last surviving member of this most impressively distinct and ancient family of giant horned terrestrial turtles. Several recent phylogenies suggest that the Meiolaniidae branched off as a separate clade of turtles before the CryptodiraPleurodira split (e.g., Joyce 2007; Sterli and de la Fuente 2013), but others (e.g., Gaffney 1996; Gaffney et al. 2007; Gaffney and Jenkins 2010) place them among the Cryptodira. In either case, their recent extinction was indeed major, not just for their disparate and bizarre morphology, but also because had they persisted, they would have been one of the most evolutionarily and phylogenetically distinct lineages of surviving chelonians - truly a monumental loss.

It is our hope that this additional checklist will increase our focus and understanding of these turtles and tortoises lost to extinction during relatively recent times, and that we will gain a greater appreciation for chelonian diversity and a greater sense of loss that so many giant tortoises and horned turtles and other amazing species have been lost forever to extinction. Hopefully this will increase our resolve to assure that we lose no more, whether to anthropogenic means or climate change, and increasingly inspire our conservation ethic to continue to work together for their preservation and protection. 


\section{METHODS}

This is a checklist and review of turtle and tortoise species that existed and went extinct from approximately the beginning of the Pleistocene, ca. 2.6 million years before present (ybp), up through the Holocene (see Table 1), to the beginning of modern times (1500 AD), that are not currently considered synonymous with modern taxa. We also include species recorded and described from the Plio-Pleistocene boundary and the Late Pliocene from ca. 3.5-2.6 million ybp, since these may well have persisted into the Early Pleistocene. This list therefore represents those chelonian species that existed and went extinct during the early rise and global spread of humanity (Table 2), during the period of increasing hominin exploitation of turtles and tortoises, while also being affected by concurrent global and regional climatic and habitat changes, as well as sea level change and volcanism.

A source of some confusion in the literature is that the formal definition of when the Pleistocene began changed a few years ago (Gibbard et al. 2010), when the definition was shifted from about 1.8 million ybp to about 2.6 million ybp. Therefore many records that were previously considered as Late Pliocene in the older literature are now defined as Early Pleistocene. This creates some uncertainty, as one has to check older papers that deal with the Late Pliocene to determine if the described material is still Pliocene or should now be considered Early Pleistocene.

We include information regarding the original authorities and publication details for each taxon, subsequent changes in classification, stratigraphic period of occurrence (Table 1), and location and approximate date of extinction (last recorded date of occurrence), when available, and list other previously synonymized fossil names. For specific, generic, and suprageneric names that include extant taxa, full synonymies are listed in TTWG (2014), for exclusively fossil entities we provide those synonymies here. We try to include known subsequent combination names for each taxon (in lighter gray text), but these may not be complete. As common names are important in discussions regarding modern turtles, we have chosen to also record or suggest common English names for all these recognized fossil taxa. We also try to document the authorities responsible for taxonomic changes, and provide commentary about controversies or details about taxa as appropriate.

Whether extinctions of these fossil chelonian taxa were primarily caused by prehistoric hominin and human overexploitation or climate change, or both working in concert, remains uncertain in most cases. For mammals these questions have generally been analyzed in associa- tion with body size, with mammalian megafauna (defined as having a body mass either $\geq 10 \mathrm{~kg}$ or $\geq 44 \mathrm{~kg}$ [100 lbs]) much more likely to have been overexploited by humans (Dirzo et al. 2004; Barnosky et al. 2004; Sandom et al. 2014). Since body size of turtle species is therefore relevant to this question (i.e., which chelonians could also be considered "megafauna"), we record approximate straight-line carapace length (CL) or a descriptive size of the species when available.

As a comparative reference, extant giant Aldabra Tortoises (Aldabrachelys gigantea) with a CL of ca. 39$40 \mathrm{~cm}$ have a body mass of about $10 \mathrm{~kg}$, those with a CL of ca. 59-60 cm have a body mass of about $44 \mathrm{~kg}$, and those with a CL of ca. $100 \mathrm{~cm}$ have a body mass of about $156 \mathrm{~kg}$, with large individuals of about $127 \mathrm{~cm} \mathrm{CL}$ reaching a body mass of about $280 \mathrm{~kg}$ (Aworer and Ramchurn 2003).

In order to provide complete coverage in this checklist of all extinct turtle and tortoise taxa from the PlioPleistocene boundary through the Holocene and into the present (what many are calling the Anthropocene), we provide several additional appendices.

Appendix I is a list of the turtle and tortoise taxa that have gone extinct in modern times, since $1500 \mathrm{AD}$. We provide commentaries regarding each of these extinctions. We include one unnamed extinct modern species among these that is not included on our list of named modern taxa (TTWG 2014).

Appendix II lists all named fossil taxa that are currently synonymized with modern species; these taxa are also further detailed in the checklist of modern turtles (TTWG 2014). Synonymizations in this appendix have usually been made by other authorities, and we list them here with only limited commentaries. We expect that some or possibly several of these synonymized fossil taxa may potentially be resurrected as valid and distinct taxa as new material becomes available and/or the taxa are reassessed.

Appendix III lists a few taxa that have sometimes been considered to be of possible Pleistocene or PlioPleistocene boundary origin, but are currently suspected to actually represent older (earlier Pliocene or Miocene) taxa, and may or may not be considered valid or distinct.

Appendix IV lists a few Pleistocene fossil taxa that are fragmentary and considered to be relatively unidentifiable nomina dubia. With further analysis or discovery of more material some of these may eventually be recognized as distinct.

We do not at this time list occurrences of extant modern species from Pleistocene or Holocene deposits, although such information is also clearly important and relevant to our understanding of distributional patterns and evolutionary history of those taxa, as well as human 
Table 1. Geological epochs, ages, and human cultural periods of the Quaternary (see http://en.wikipedia.org/wiki/Quaternary and associated links). Ages given are all approximate and slightly rounded off and recorded as ybp (= years before present), which by convention use 1950 as the zero point. The Pleistocene is defined as starting at 2,588,000 $\pm 5000 \mathrm{ybp}$; we round it off to ca. $2,600,000 \mathrm{ybp}$. The Anthropocene is not yet officially defined.

Modern (historic, “Anthropocene"): 1500 AD-present

Holocene: $12,000-450$ ybp (10,050 BC-1500 AD) Late Holocene: 4200-450 ybp (2250 BC-1500 AD) Middle Holocene: 8200-4200 ybp (6250 BC-2250 BC) Early Holocene: $12,000-8200$ ybp (10,050-6250 BC)

Holocene Climatic Phases:

Subatlantic: $2500-0$ ybp (550 BC-1950 AD)

Subboreal: 5000-2500 ybp (3050-550 BC)

Atlantic: $7500-5000$ ybp (5550-3050 BC)

Boreal: 9000-7500 ybp (7050-5550 BC)

Preboreal: 10,300-9000 ybp (8350-7050 BC)

Pleistocene: 2,600,000-12,000 ybp

Late Pleistocene (Tarantian): 125,000-12,000 ybp

Middle Pleistocene (Ionian): 780,000-125,000 ybp

Early Pleistocene: 2,600,000-780,000 ybp

Calabrian: 1,800,000-780,000 ybp

Gelasian: 2,600,000-1,800,000 ybp

North American Pleistocene Glacial Stages:

Wisconsinan: 80,000-12,000 ybp

Late Wisconsinan: 30,000-12,000 ybp

Middle Wisconsinan: 65,000-30,000 ybp

Early Wisconsinan: 80,000-65,000 ybp

Sangamonian Interglacial: 130,000-80,000 ybp

Illinoian: 300,000-130,000 ybp

Aftonian Interglacial: 1,300,000-900,000 ybp

Pre-Illinoian: 2,600,000-300,000 ybp

North American Pleistocene Land Mammal Faunal Ages:

Rancholabrean: 300,000-12,000 ybp

Irvingtonian: 1,800,000-300,000 ybp

Blancan: 4,750,000-1,800,000 ybp

Late Blancan: 2,600,000-1,800,000 ybp

Early Blancan: (Late Pliocene) > 2,600,000 ybp

South American Pleistocene Land Mammal Faunal Ages:

Lujanian: 780,000-12,000 ybp

Ensenadan: 1,200,000-780,000 ybp

Uquian: 2,600,000-1,200,000 ybp

European Pleistocene Land Mammal Faunal Ages:

Toringian: $500,000-126,000 \mathrm{ybp}$

Biharian: 1,200,000-500,000 ybp

Villafranchian: 3,600,000-1,200,000 ybp

Late Villafranchian:

Mammal Neogene biozone MN 17:

(Early Pleistocene) 2,600,000-1,200,000 ybp

Early Villafranchian:

Mammal Neogene biozone MN 16:

(Late Pliocene) $>$ 2,600,000 ybp

Human Cultural Periods: (vary widely by site)

Old World:

Neolithic: 13,000-5000 ybp

Mesolithic (Epipaleolithic): 20,000-7000 ybp

Paleolithic: 2,600,000-10,000 ybp

New World:

Archaic: 10,000-3000 ybp

Paleoindian: 20,000-10,000 ybp
Table 2. Approximate timeline of the rise and global spread of humanity (see http://en.wikipedia.org/wiki/Timeline_of_human_ evolution, http://en.wikipedia.org/wiki/Early_human_migrations, and associated links; see also Beyin 2011, Bellwood 2013).

15,000,000 ybp: The family Hominidae (hominids) appeared, as great apes speciated from lesser apes, arose in Africa.

13,000,000 ybp: The subfamily Homininae (hominins) appeared and became increasingly human, remained in Africa.

3,600,000 ybp: The australopithecine hominins (Ardipithecus, Australopithecus, Kenyanthropus) began to appear in South Africa and East Africa; upright bipedalism developed; remained in Africa and persisted into the early Pleistocene, ca. 2,000,000 ybp.

$\mathbf{2 , 8 0 0 , 0 0 0}$ ybp: Late Pliocene to Early Pleistocene; the hominin genus Homo appeared in East Africa (Gibbons 2015); Homo habilis occurred from ca. 2,800,000 to $1,400,000 \mathrm{ybp}$, remained in Africa; Oldowan Paleolithic stone technology begins to develop around 2,600,000 ybp

1,900,000 ybp: Early Pleistocene; the hominins Homo ergaster and Homo erectus appeared in Africa; by ca. 1,800,000 ybp $H$. erectus migrated out and spread widely through the Middle East, the Caucasus, southern Europe, southern and eastern Asia (mainland China, possibly differentiating as H. pekinensis), and the Indo-Australian Archipelago as far as Flores (possibly differentiating as $H$.floresiensis), survived on Java until ca. $70,000 \mathrm{ybp}$ (possibly differentiating as $H$. soloensis); did not reach Japan or Australia.

1,200,000 ybp: Early Pleistocene; the hominin Homo antecessor appeared in southern Europe, and survived until ca. 800,000 ybp.

600,000 ybp: Middle Pleistocene; the hominin Homo heidelbergensis occurred in Europe, Africa, and western Asia, and survived until ca. 200,000 ybp.

350,000 ybp: Middle Pleistocene; the hominin Homo neanderthalensis appeared in Europe and survived until ca. 25,000 ybp, apparently eventually interbreeding with later-arriving humans, $H$. sapiens.

200,000 ybp: Middle Pleistocene; modern humans, Homo sapiens, first appeared in East Africa, remained there at first, then at about 160,000 ybp began to migrate out of Africa, gradually apparently replacing, interbreeding with, or extirpating $H$. neanderthalensis and $H$. erectus, reaching the Middle East at ca. 125,000-100,000 ybp, South Asia at ca. 75,000-70,000 ybp, Europe at ca. 40,000 ybp, Australia and New Guinea at about 60,000-50,000 ybp, Japan at ca. 35,000 ybp, the South Pacific islands between about 30,000-4000 ybp, North Americas sometime between ca. 20,000-15,000 ybp, South America at about 15,000 ybp, the Caribbean Archipelago at ca. 7000 ybp, and Madagascar at ca. 2000-1500 ybp (see older simplified schematic map below by Burenhult 2000).

74,000 ybp: Late Pleistocene; the unusually small endemic hominin species Homo floresiensis occurred on Flores island in the Indo-Australian Archipelago at about 74,000 ybp; but may have differentiated from $H$. erectus as early as $1,000,000 \mathrm{ybp}$, and survived until ca. 17,000 ybp.

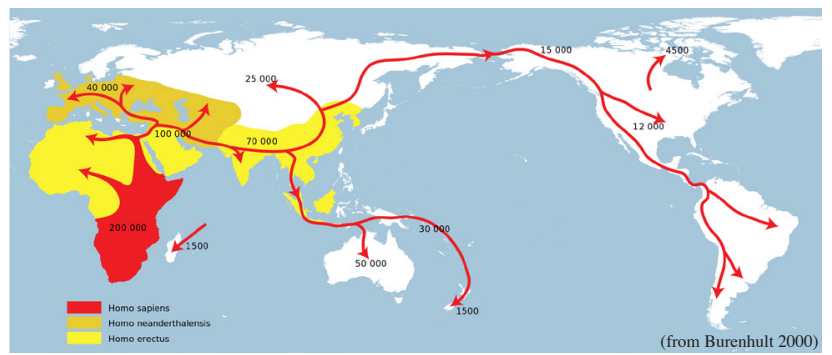




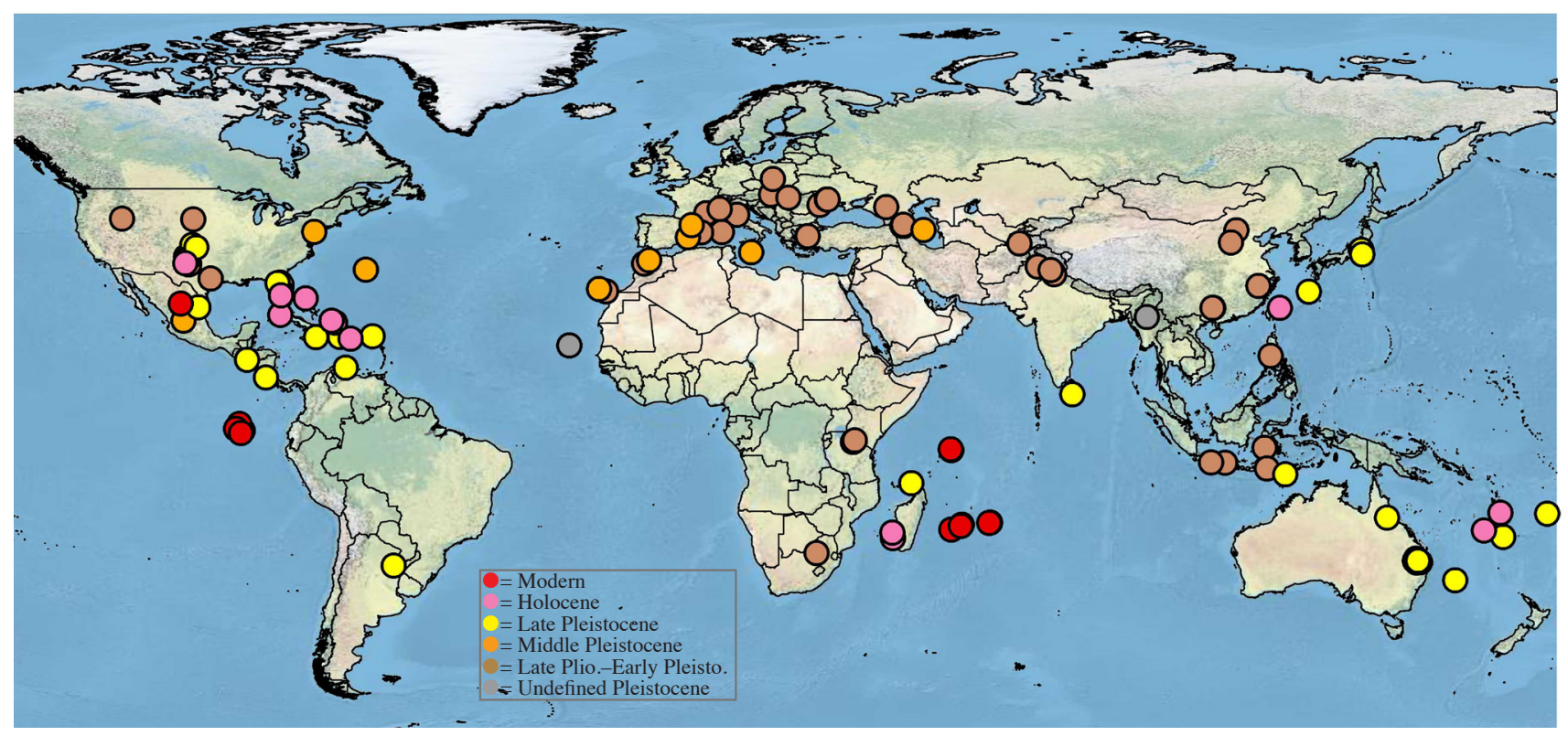

Figure 1. Global distribution of all 112 extinct turtle and tortoise taxa from the Plio-Pleistocene boundary through Modern times that are currently recognized as distinct on this checklist. Brown dots $\bigcirc=$ Plio-Pleistocene boundary and Early Pleistocene taxa $(2,600,000$ $780,000 \mathrm{ybp})$; orange dots $=$ Middle Pleistocene taxa $(780,000-125,000 \mathrm{ybp})$; yellow dots $=$ Late Pleistocene taxa $(125,000-12,000$ ybp); pink dots $=$ Holocene taxa (12,000-450 ybp, prior to $1500 \mathrm{AD})$; red dots $=$ Modern extinct taxa (since $1500 \mathrm{AD})$; gray dots = undefined "Pleistocene" taxa. Each point represents one taxon, but several points are too close together to differentiate from each other; see Figs. 2-5 for close-up detail. Points represent either the most recent known occurrence record for Late Pleistocene, Holocene, and Modern taxa, or the type locality for earlier or undefined Pleistocene taxa.

consumption and exploitation and climate change affecting those species. We intend that future editions of either this or the regular checklist of modern taxa (TTWG 2014) will record such occurrences, and we encourage our readers and colleagues to send us citations and references to help complete that effort.

We attempt to record the most recent time period from which these fossil species have been recorded or inferred, and when possible, the approximate age of last known occurrence, both in traditional uncalibrated ${ }^{14} \mathrm{C}$ radiocarbon ages and updated calibrated ages. Published traditional uncalibrated radiocarbon dates are given as ${ }^{14} \mathrm{C}$ age, and updated calibrated ages are noted as published or have been calculated here for the first time using OxCal 4.2 (https://c14.arch.ox.ac.uk/), and noted with an asterisk (*). Ages given are approximate and slightly rounded off and recorded as ybp (= years before present), which by convention use 1950 as the zero point.

The taxonomy of the fossil species on our checklist is far from resolved, and our list should not be considered authoritative. Many taxa described from fragmentary fossils are not readily attributable to a specific genus or a recognized species and are instead listed as "sp." (= undescribed species) or "gen. indet." (genus indeterminate), or as nomina dubia. Some of these taxa that have been described from fragmentary fossils may eventually be synonymized with other more completely preserved and valid taxa, or additional finds of fossil material may clarify their apparent distinctiveness.
The phylogeny and higher taxonomy of turtles continue to be subjects of extensive debate and competing arrangements, resulting not only from the use or emphasis on different data sets (morphological vs. molecular) but also different analytical approaches and nomenclatural practices (traditional Linnaean vs. phylocode). Major contributions to this topic include Gaffney (1984), Gaffney and Meylan (1988), Joyce (2007), Gaffney et al. (2007), Danilov and Parham (2008), Sterli (2008, 2010), Joyce et al. (2009, 2013), Barley et al. (2010), Gaffney and Jenkins (2010), Sterli and de la Fuente (2013), and Crawford et al. (2015).

For the purposes of this paper, with its wide authorship and equally wide range of phylogenetic views, we have adopted a taxonomic framework of convenience that is a mildly modified version of that used in TTWG (2014). The modifications consist mainly of the addition of two higher groupings to the framework: Meiolaniformes for the extinct family Meiolaniidae, and the extinct subfamily Chelydropsinae under the extant family Chelydridae. Their hierarchical placement in our checklist is simply intended to be pragmatic and conveniently consistent with that of TTWG (2014), and does not imply support for, or disagreement with, any of the phylogenies proposed in the literature. Our focus in this paper is on the extinct taxa themselves, rather than on their higher-level phylogenetic relationships.

We have attempted to record all distinct fossil species that are currently considered valid, but we have no 


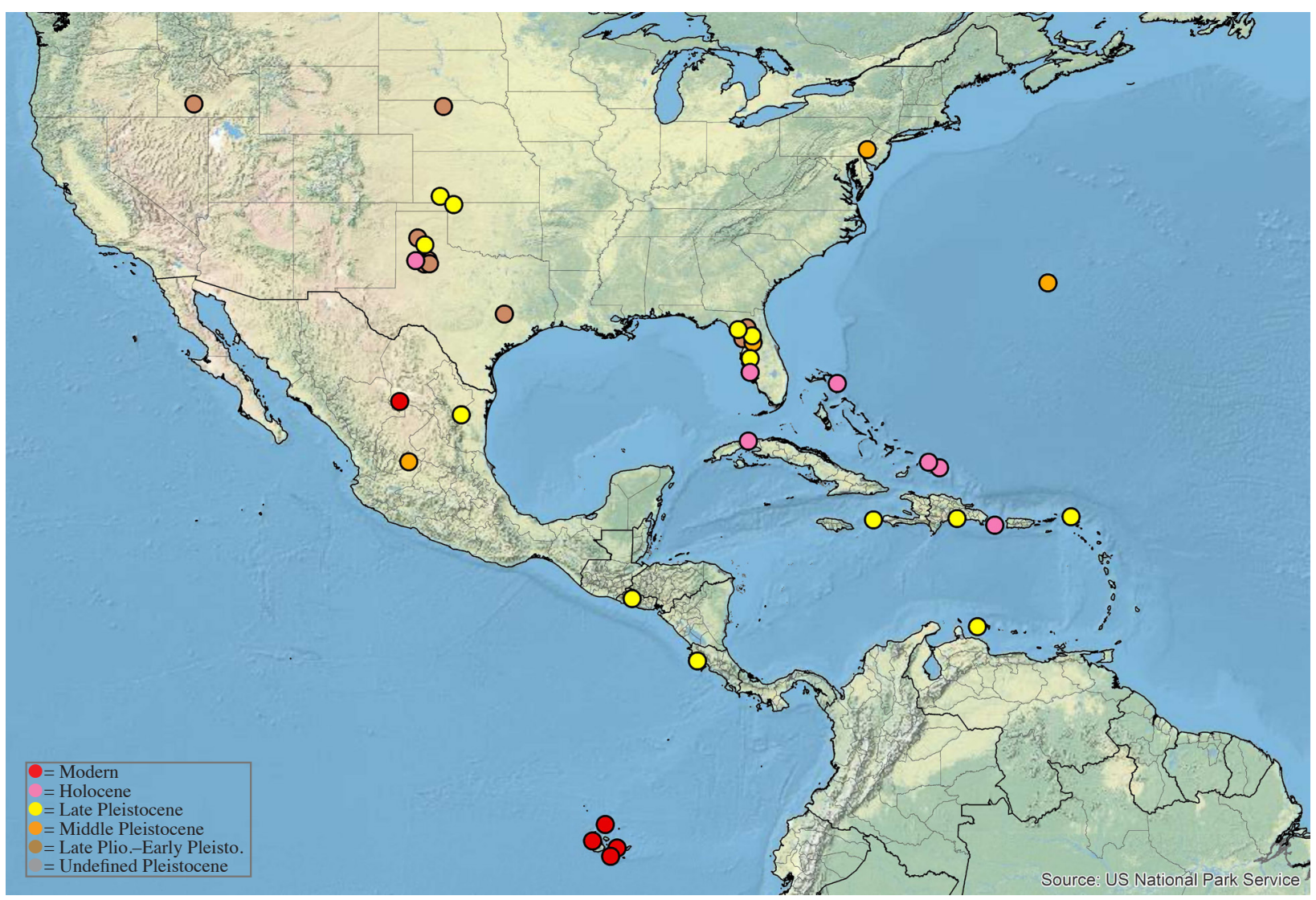

Figure 2. Close-up of northern Western Hemisphere extinct turtle and tortoise taxa as depicted and described in Fig. 1. See also Fig. 13.

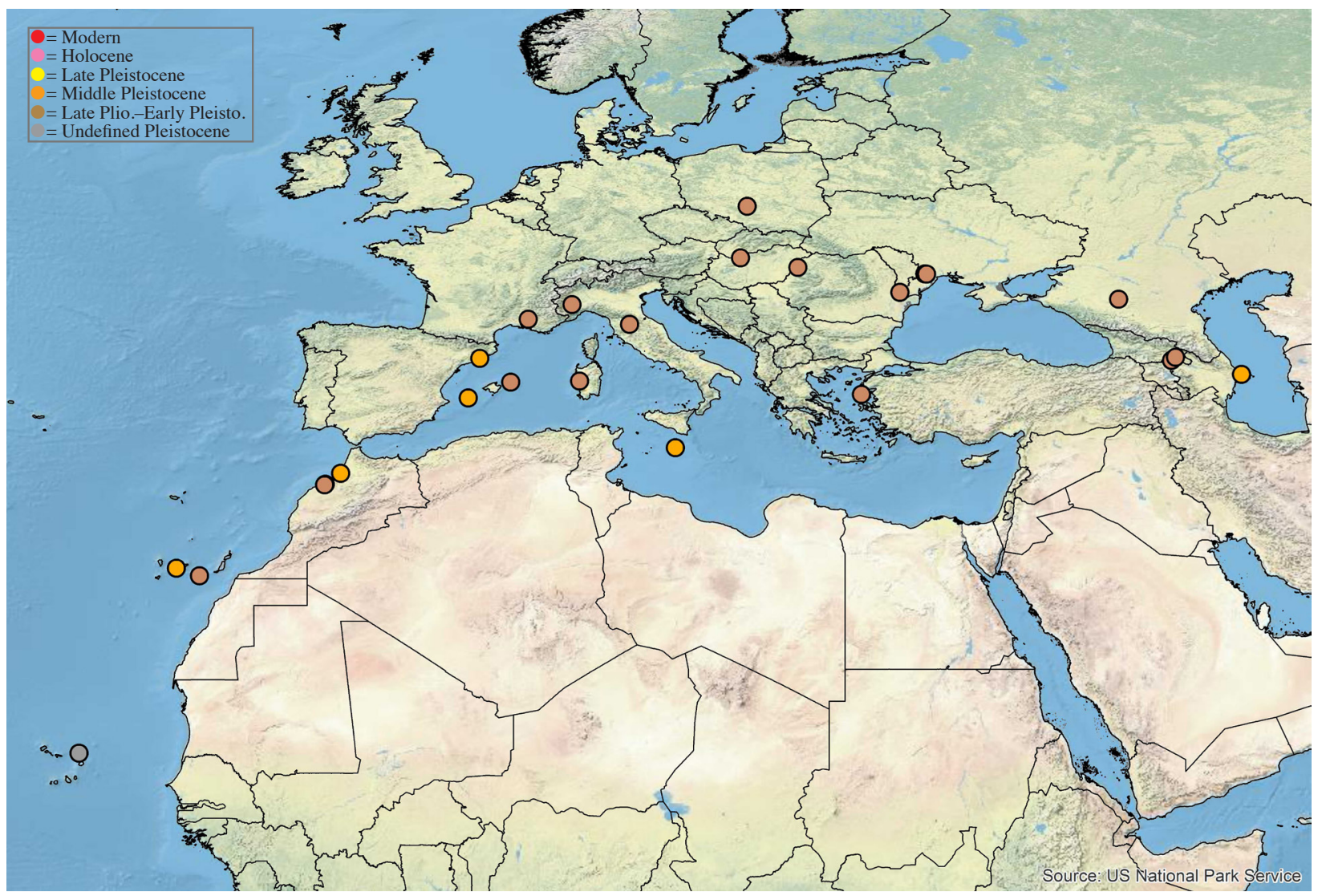

Figure 3. Close-up of northern Eastern Hemisphere extinct turtle and tortoise taxa as depicted and described in Fig. 1. 


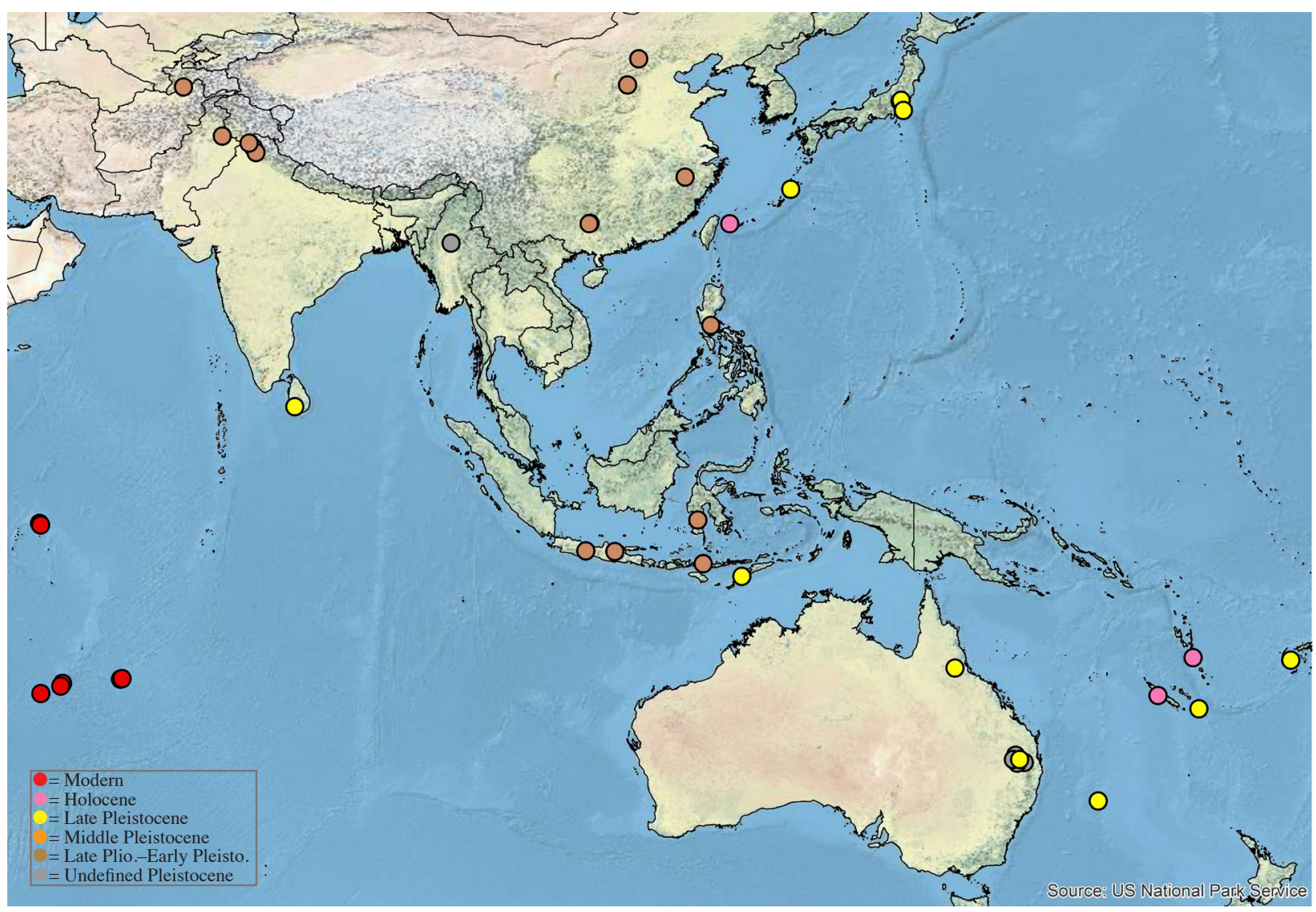

Figure 4. Close-up of southeastern Eastern Hemisphere extinct turtle and tortoise taxa as depicted and described in Fig. 1.

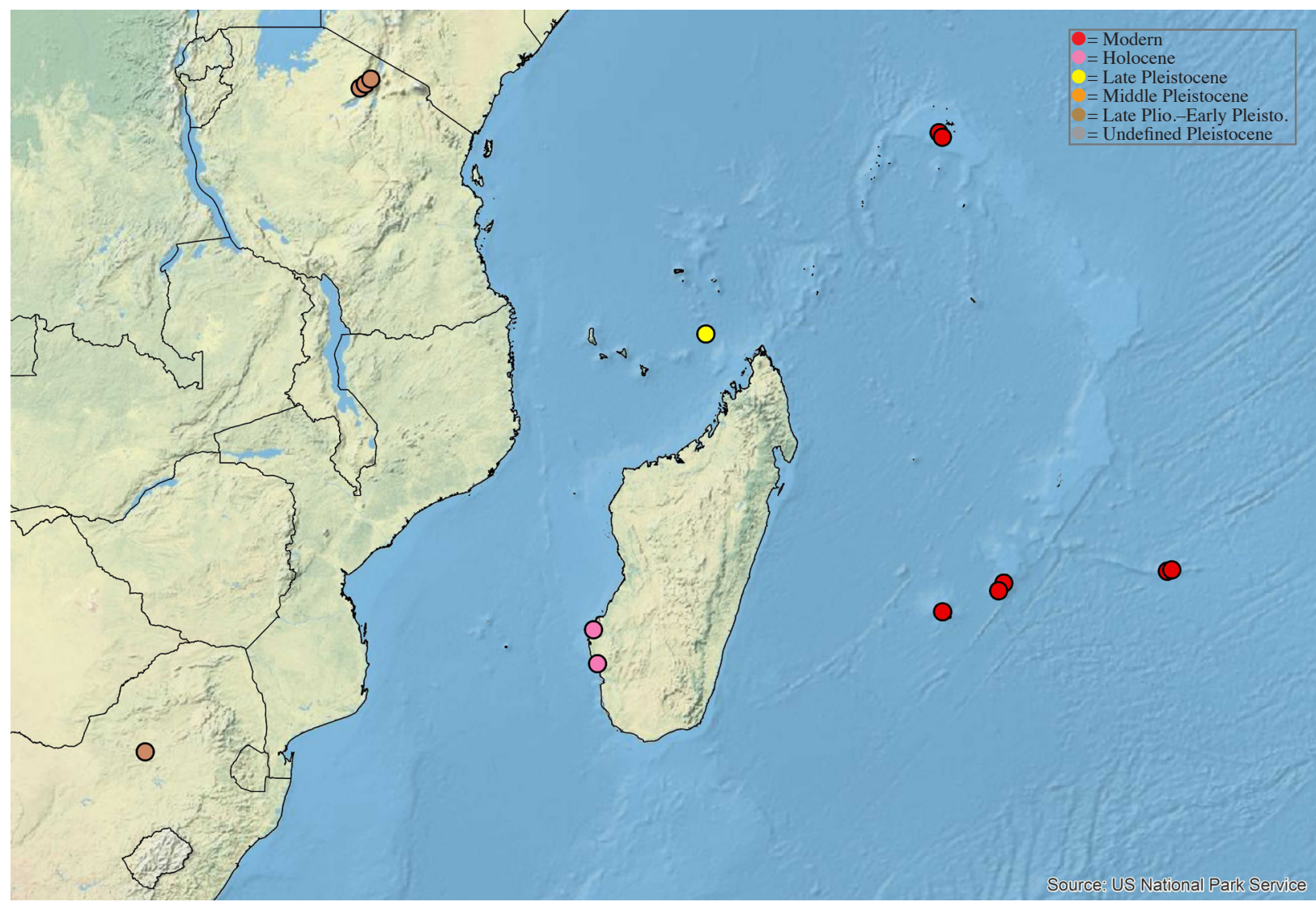

Figure 5. Close-up of southern Africa and Indian Ocean extinct turtle and tortoise taxa as depicted and described in Fig. 1. 
doubt occasionally erred by listing some taxa that may have been synonymized by other researchers, or synonymized some that are considered valid by others. A few apparently valid fossil taxa described or previously treated as subspecies have here been listed as species (and so indicated), as we do not believe that subspecies (or paleosubspecies) designations are adequately definable or appropriate for fossil turtle taxa. We have made no significant attempt at this time to determine whether some of the recognized species that we list may represent ancestral chronospecies or paleospecies that subsequently evolved into modern taxa.

We list a few unnamed Pleistocene and Holocene taxa that we or other authorities have hypothesized to represent distinct taxa, based on comparative patterns of morphology and zoogeographic distribution of closely related species. We have done this only for some undescribed taxa of Testudinidae (tortoises) and Meiolaniidae (horned turtles), terrestrial taxa that are typically characterized by a notable degree of restricted zoogeographic distinctiveness, especially for isolated island taxa. We are also aware of other undescribed and apparently distinct Pleistocene taxa of Emydidae and Geoemydidae, but since these freshwater and semi-terrestrial taxa tend not to be as zoogeographically isolated as tortoises, we have chosen not to list them until formal descriptions are published.

We consider this checklist to be a work in progress, and may have missed some previously documented extinct species, or listed some that are no longer considered valid by some authorities. We will continue to update the list with subsequent editions as new information comes to our attention, and we encourage our readers and colleagues to help us improve this checklist by providing information and references for any oversights or possible misinterpretations, as well as new published information as it becomes available.

Decisions regarding which extinct species to include and recognize as valid or not in this checklist, and which names to synonymize or not, were elucidated from the primary taxonomic references listed in the comments and the following references: Kuhn (1964), Auffenberg (1974), Młynarski (1976), Jackson (1988), Bour (1994), Ye (1994), Holman (1995), Meylan (1995), Gaffney (1996), Huttereret al. (1998), de la Fuente (1999), Lapparent de Broin (2000, 2001), Dodd (2001), Franz and Quitmyer (2005), Lapparent de Broin et al. (2006b,c), Steadman et al. (2007), Pedrono (2008), Takahashi et al. (2008), and Hansen et al. (2010).

\section{RESULTS}

This checklist of extinct Plio-Pleistocene,Pleistocene, and Holocene turtles and tortoises currently includes 100 distinct taxa, including 84 named and apparently valid spe-

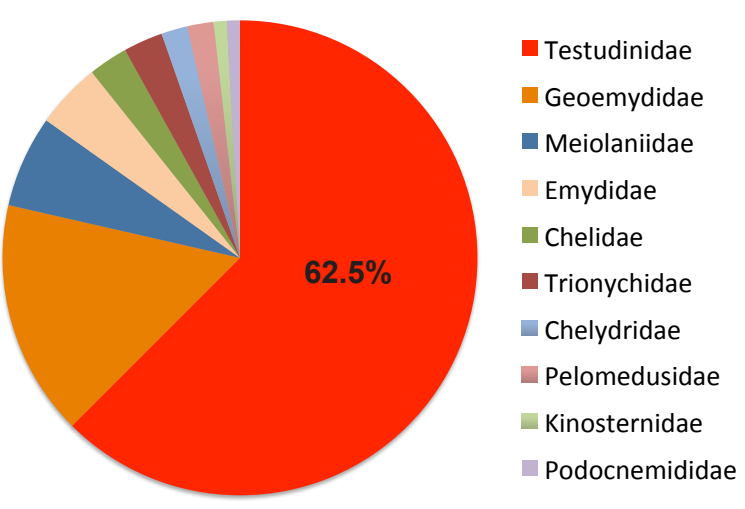

Figure 6. Percentage distribution by family of the 112 extinct Pleistocene through Modern turtle and tortoise taxa documented in this checklist. Testudinidae constitute 70 taxa (62.5\%).

cies, plus 16 additional unnamed fossil taxa (13 Testudinidae and 3 Meiolaniidae) that appear likely to represent valid species, but have so far not been formally diagnosed beyond genus or family. Definitions of valid species boundaries or decisions regarding possible synonymization with other taxa can be difficult with fossils, especially when dealing with incomplete and fragmentary specimens, and these numbers are at most reasonable estimates of the actual or known diversity.

Figures 1-5 depict distribution maps of all 100 extinct turtle and tortoise taxa from the Plio-Pleistocene boundary through the Pleistocene and the Holocene, and also include 12 taxa that went extinct during Modern times (see Appendix I), for a total of 112 extinct taxa. Table 3 provides an approximate chronologic sequential listing of the most recent extinctions during Modern, Holocene, Late and Middle Pleistocene times.

We record a total of 220 taxonomic names that have been used to describe and name various fossil and subfossil Plio-Pleistocene, Pleistocene, and Holocene chelonian taxa, including primary description names, secondary nomina nova, and nomina nuda. We currently consider 84 of these names to represent valid or possibly valid extinct species; 35 other names have been synonymized under these extinct species, 83 names describing fossil specimens have been synonymized under extant modern taxa (see Appendix II), and 18 are considered to be older than the Plio-Pleistocene boundary taxa and/or questionable or unidentifiable nomina dubia (Appendices III and IV).

The total diversity of turtles and tortoises in the world that has apparently existed since the Plio-Pleistocene boundary, during the relatively long history of humanity's association with chelonians, and currently recognized as distinct and included on the two checklists, now consists of 335 modern named species (TTWG 2014) plus one unnamed extinct modern species (see Appendix I) and about 100 extinct fossil Holocene and Pleistocene taxa, for a total of about 436 chelonian species that have existed during this 


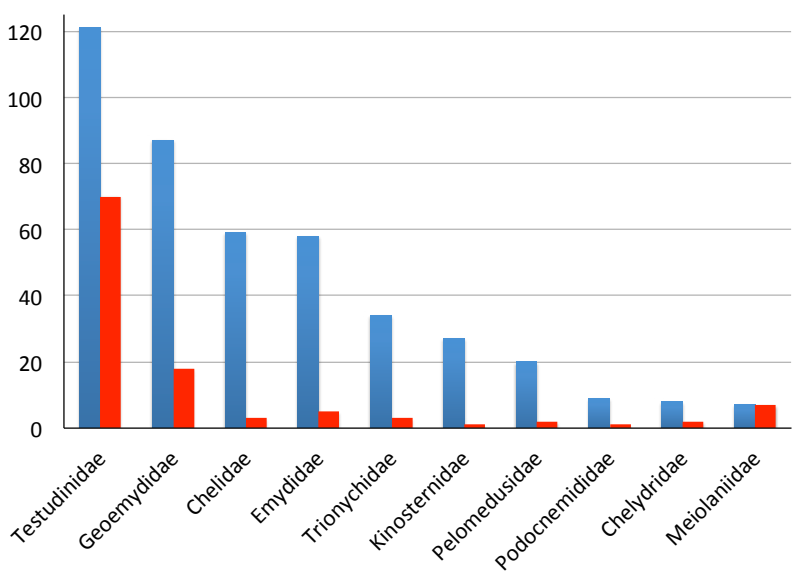

Figure 7. Total number of taxa per family of turtles and tortoises that have existed (blue bars) and gone extinct (red bars) between the Plio-Pleistocene boundary and the present.

time frame. If we count all chelonian taxa, which includes 453 modern named species and subspecies (TTWG 2014), one unnamed modern extinct species (Appendix I), and the 100 fossil species and taxa, then there have been 554 chelonian taxa that have occurred at some point since the Plio-Pleistocene boundary and the beginning of the Pleistocene through the present.

If we include the 9 species of modern turtles and tortoises that have gone extinct since $1500 \mathrm{AD}$ (Appendix I), then 109 (25.0\%) of 436 turtle species that have existed at some point during the time since the Plio-Pleistocene boundary, have gone extinct. This assumes (probably partially inaccurately) that all Modern species already occurred at the beginning of the Pleistocene, and that our counts of definable and valid taxa are correct and complete. Indeed, some species in recent radiations, e.g., Galapágos Chelonoidis tortoises on younger volcanic islands (Poulakakis

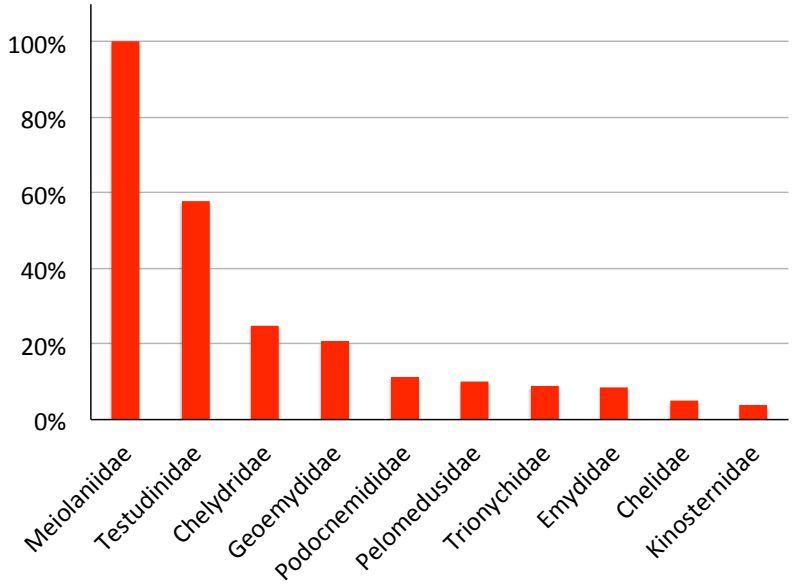

Figure 8. Percentage of species per family that went extinct between the Plio-Pleistocene boundary and the present, as a percentage of all the taxa that existed per family from that period.

et al. 2012), and Graptemys freshwater turtle species in various southeastern USA drainage basins (Ehret and Bourque 2011), probably did not exist at the beginning of the Pleistocene, and our numbers have not been corrected for this possibility. If we count all taxa and include the 12 modern extinct taxa ( 8 named species, 1 unnamed species, and 3 named subspecies), then 112 (20.2\%) of all 554 known chelonian taxa that have occurred at some point since the beginning of the Pleistocene, have gone extinct. Of these, 65 were continental taxa and less than half, $47(42.0 \%)$, were insular.

If we add the 109 extinct turtle species to the 107 Critically Endangered or Endangered extant species of turtles (www.iucnredlist.org; TTWG 2014), then 216 $(49.5 \%)$ of all 436 known turtle species that have occurred at some point since the beginning of the Pleistocene are either already extinct or on the verge of extinction. If we

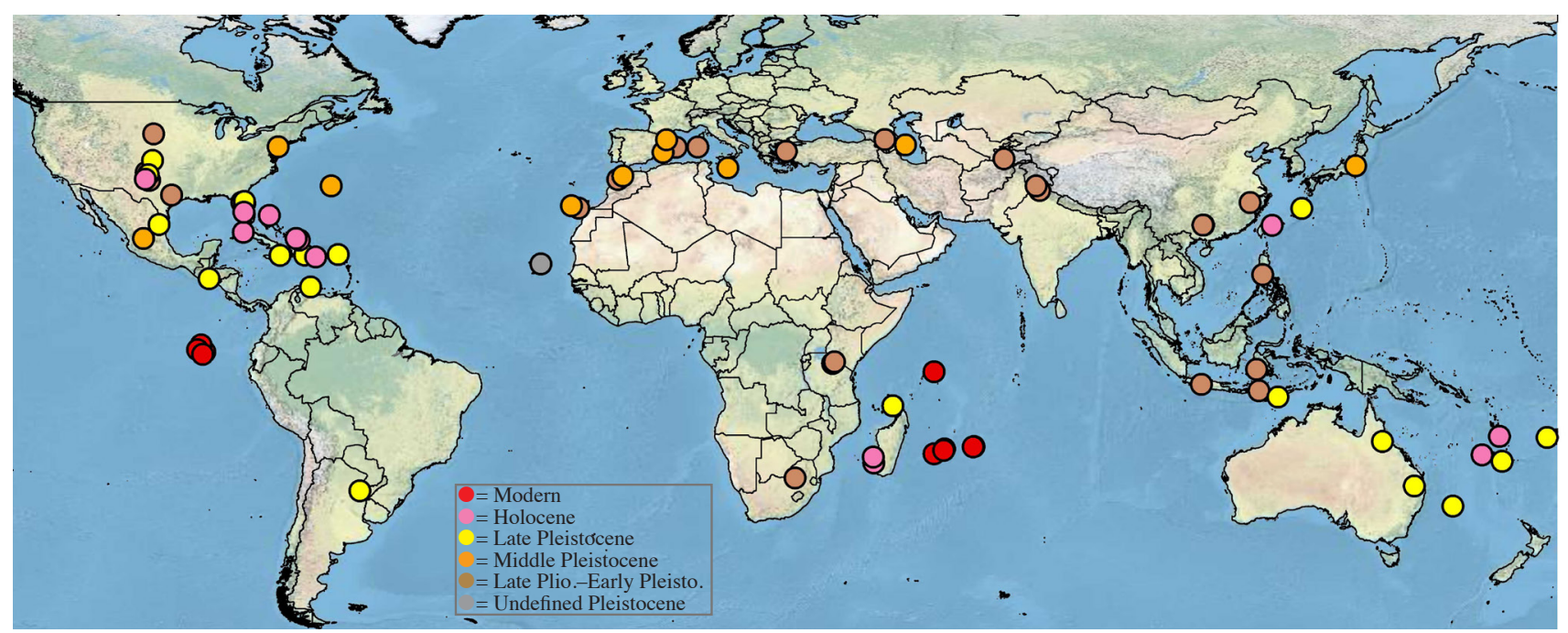

Figure 9. Global distribution of all 81 terrestrial turtle and tortoise taxa of the families Testudinidae (70), Meiolaniidae (7), Geoemydidae (3), and Pelomedusidae (1) that have gone extinct since the Plio-Pleistocene boundary, many of them giant and insular forms. Brown dots = Plio-Pleistocene boundary and Early Pleistocene taxa $(2,600,000-780,000 \mathrm{ybp})$; orange dots $=$ Middle Pleistocene taxa $(780,000-125,000 \mathrm{ybp})$; yellow dots $=$ Late Pleistocene taxa $(125,000-12,000 \mathrm{ybp})$; pink dots $=$ Holocene taxa $(12,000-450 \mathrm{ybp}$, prior to $1500 \mathrm{AD}$ ); red dots $=$ Modern extinct taxa (since $1500 \mathrm{AD}$ ); gray dots $=$ undefined "Pleistocene" taxa. 


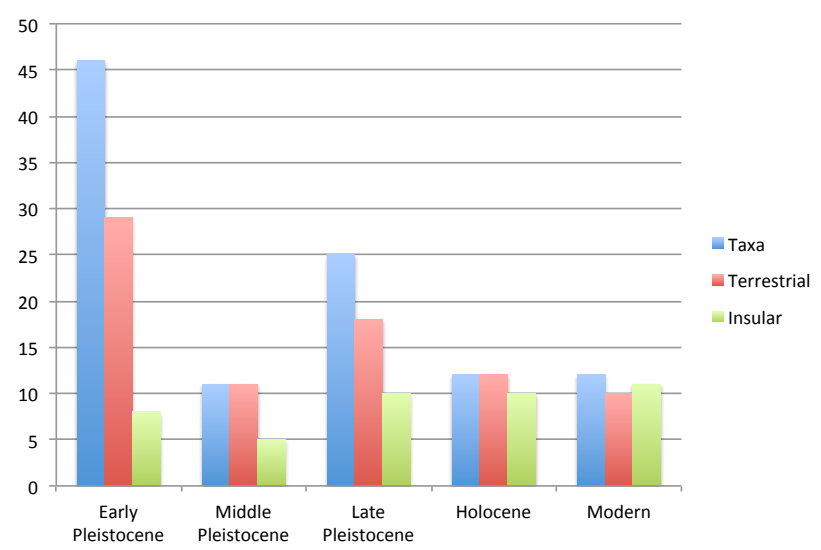

Figure 10. Total number of taxa by age of 106 extinct taxa from the Early Pleistocene (including the Plio-Pleistocene boundary) through Modern times (excluding 6 undefined "Pleistocene" taxa).

add the 167 Threatened extant species of turtles (includes Critically Endangered, Endangered, and Vulnerable; www. iucnredlist.org; TTWG 2014), then fully $276(63.3 \%)$ of all 436 known turtle species that have occurred at some point since the beginning of the Pleistocene are either already extinct or threatened with extinction.

Of the 112 extinct Pleistocene, Holocene, and Modern taxa, terrestrial tortoises of the family Testudinidae (including many giant and large-bodied island forms), are by far the most numerous, with 60 fossil taxa and 10 modern extinct taxa for a total of 70 taxa (62.5\%) (Fig. 6). The second-most numerous are the Geoemydidae, with 18 taxa, several of which were also terrestrial or semi-terrestrial. The third-most numerous are the giant horned terrestrial turtles, the Meiolaniidae, with 7 taxa. Combined, these three families constitute $84.8 \%$ of the 112 extinct turtle and tortoise taxa during this time frame.

If we add the 60 fossil tortoise taxa (Testudinidae) to the 61 modern (52 extant and 9 extinct) species of tortoises (TTWG 2014; Appendix I), we find that of 121 known species of tortoises that have occurred at some point since the beginning of the Pleistocene, $69(57.0 \%)$ have already gone extinct (Figs. 7-8). For the Meiolaniidae, 7 of 7 taxa $(100 \%)$ that occurred at some point since the beginning of the Pleistocene have gone extinct. For the generally smaller and more aquatic Geoemydidae, 18 of 87 taxa (20.7\%) that occurred at some point since the beginning of the Pleistocene have gone extinct. For the testudinids and meiolaniids, their high extinction percentages likely reflect the high vulnerability of these large and slow terrestrial species to both hominin exploitation and climate change.

If we add the 69 extinct tortoise species to the 25 Critically Endangered or Endangered extant species of Testudinidae (TTWG 2014), we find that 94 (77.7\%) of all 121 known tortoises that have occurred at some point since the beginning of the Pleistocene are either already

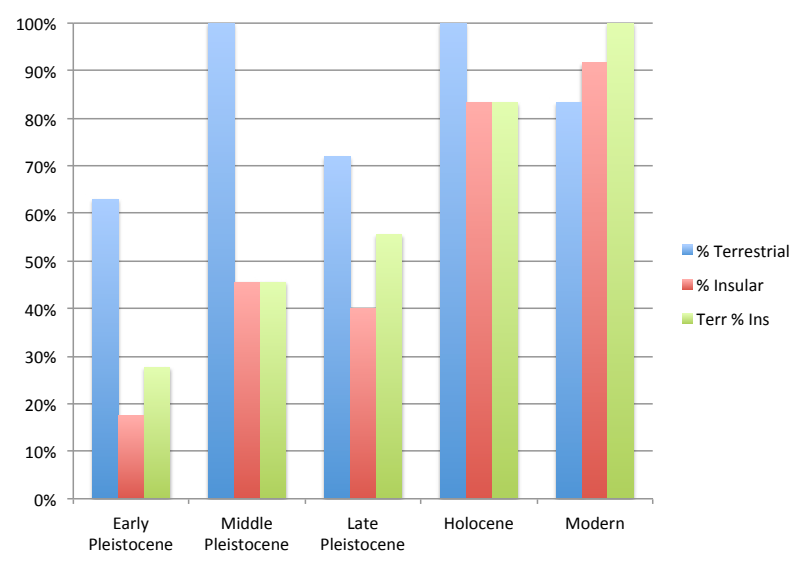

Figure 11. Percentage of taxa by age of 106 extinct taxa from the Early Pleistocene (including the Plio-Pleistocene boundary) through Modern times (excluding 6 undefined "Pleistocene" taxa).

extinct or on the verge of extinction. Finally, if we add the 42 Threatened species, we find that 111 (91.7\%) of all known tortoise species that have occurred at some point since the beginning of the Pleistocene are either already extinct or threatened with extinction.

In terms of the greater vulnerability of terrestrial tortoises and turtles to hominin and human exploitation, we note that more than two-thirds of the extinct taxa that have occurred at some point from the Plio-Pleistocene boundary through the present are from the terrestrial families Testudinidae and Meiolaniidae (77 of 112 taxa, 68.8\%). A few extinct species from other families were also terrestrial: Cuora miyatai, Cuora tungia, and Geoemyda amamiensis of the Geoemydidae, and Latisternon microsulcae of the Pelomedusidae. If we add these four, it brings the number of extinct terrestrial taxa to nearly three-fourths of the total (81 of 112 taxa, $72.3 \%$ ).

Figure 9 shows the distribution of all these 81 terrestrial taxa that have gone extinct since the Plio-Pleistocene boundary through the present. Of these, 37 were continental taxa, and over half $(44,54.3 \%)$ were insular, with the most recently extinct taxa (Late Pleistocene, Holocene, and Modern) closely associated with the known patterns and chronologies of hominin and human migration routes out of Africa and into various island archipelagos (see Table 2), where many of these taxa went extinct in conjunction with or shortly after the arrival of humanity. Especially noteable are the sequential extinctions spreading through the Indo-Australian Archipelago and across Australia and into the southwestern Pacific islands, in Japan and the Ryukyu Archipelago, the pattern in southeastern USA expanding into the Caribbean West Indies, and the recent spread across Madagascar and into the Mascarene islands.

Also of note regarding terrestrial turtles and tortoises are the age-related totals and percentages of terrestrial vs. aquatic, and insular vs. continental extinctions (Figs. 10-11). During the Early Pleistocene and Plio-Pleistocene 
Table 3. Approximate sequential chronology of the most recent turtle and tortoise extinctions, as estimated based on dated or inferred last recorded occurrences for Modern, Late Holocene, Early Holocene, Late Pleistocene, and Middle Pleistocene taxa (60 taxa total).

\begin{tabular}{|c|c|c|c|c|c|}
\hline Taxon & Common Name & Family & Location & Age & Date \\
\hline Chelonoidis abingdonii & Pinta Giant Tortoise & Testudinidae & Ecuador (Galápagos: Pinta) & Modern & $2012 \mathrm{AD}$ \\
\hline Chelonoidis phantastica & Fernandina Giant Tortoise & Testudinidae & Ecuador (Galápagos: Fernandina) & Modern & ca. $1970 \mathrm{AD}$ \\
\hline Kinosternon h.megacephalum & Viesca Mud Turtle & Kinosternidae & Mexico (Coahuila) & Modern & ca. $1970 \mathrm{AD}$ \\
\hline Pelusios c. seychellensis & Seychelles Mud Turtle & Pelomedusidae & Seychelles (Mahé) & Modern & ca. $1950 \mathrm{AD}$ \\
\hline Chelonoidis sp. & Santa Fé Giant Tortoise & Testudinidae & Ecuador (Galápagos: Santa Fé) & Modern & ca. $1890 \mathrm{AD}$ \\
\hline Aldabrachelys g.daudinii & Daudin's Giant Tortoise & Testudinidae & Seychelles (Mahé?) & Modern & ca. $1850 \mathrm{AD}$ \\
\hline Chelonoidis nigra & Floreana Giant Tortoise & Testudinidae & Ecuador (Galápagos: Floreana) & Modern & ca. $1850 \mathrm{AD}$ \\
\hline Cylindraspis indica & Reunion Giant Tortoise & Testudinidae & Réunion & Modern & ca. $1840 \mathrm{AD}$ \\
\hline Cylindraspis peltastes & Rodrigues Domed Tortoise & Testudinidae & Mauritius (Rodrigues) & Modern & ca. $1800 \mathrm{AD}$ \\
\hline Cylindraspis vosmaeri & Rodrigues Giant Saddleback Tortoise & Testudinidae & Mauritius (Rodrigues) & Modern & ca. $1800 \mathrm{AD}$ \\
\hline Cylindraspis inepta & Mauritius Giant Domed Tortoise & Testudinidae & Mauritius (Mauritius) & Modern & ca. $1735 \mathrm{AD}$ \\
\hline Cylindraspis triserrata & Mauritius Giant Flat-shelled Tortoise & Testudinidae & Mauritius (Mauritius) & Modern & ca. $1735 \mathrm{AD}$ \\
\hline Chelonoidis sp. & Caicos Giant Tortoise & Testudinidae & Turks and Caicos (Middle Caicos) & Late Holocene & ca. $1400 \mathrm{AD}$ \\
\hline Chelonoidis sp. & Turks Tortoise & Testudinidae & Turks and Caicos (Grand Turk) & Late Holocene & ca. $1200 \mathrm{AD}$ \\
\hline Aldabrachelys abrupta & Madagascar Giant Tortoise & Testudinidae & Madagascar & Late Holocene & ca. $1200 \mathrm{AD}$ \\
\hline Chelonoidis alburyorum & Abaco Tortoise & Testudinidae & Bahamas (Abaco) & Late Holocene & ca. $1170 \mathrm{AD}$ \\
\hline Aldabrachelys grandidieri & Grandidier's Giant Tortoise & Testudinidae & Madagascar & Late Holocene & ca. $884 \mathrm{AD}$ \\
\hline Meiolaniidae sp. & New Caledonia Giant Horned Turtle & Meiolaniidae & New Caledonia & Late Holocene & ca. $531 \mathrm{AD}$ \\
\hline Meiolania damelipi & Efate Giant Horned Turtle & Meiolaniidae & Vanuatu (Efate) & Late Holocene & ca. $810 \mathrm{BC}$ \\
\hline Chelonoidis monensis & Mona Tortoise & Testudinidae & Puerto Rico (Mona Island) & Late Holocene & ca. $1050 \mathrm{BC}$ \\
\hline Hesperotestudo wilsoni & Wilson's Tortoise & Testudinidae & USA (southwestern states) & Early Holocene & ca. $9050 \mathrm{BC}$ \\
\hline Manouria oyamai & Ryukyus Tortoise & Testudinidae & Japan (Ryukyu Archipelago) & Early Holocene & ca. 9050 BC \\
\hline Hesperotestudo crassiscutata & Southeastern Giant Tortoise & Testudinidae & USA (southern states) & Early Holocene & ca. 9515 BC \\
\hline Chelonoidis cubensis & Cuban Giant Tortoise & Testudinidae & Cuba & Early Holocene & unknown \\
\hline Graptemys kerneri & Kerner's Map Turtle & Emydidae & USA(Florida) & Late Pleistocene & ca. 15,000 ybp \\
\hline Chelonoidis lutzae & Lutz's Giant Tortoise & Testudinidae & Argentina (Corrientes) & Late Pleistocene & ca. 22,000 ybp \\
\hline Meiolania sp. & Wyandotte Giant Horned Turtle & Meiolaniidae & Australia (Queensland) & Late Pleistocene & ca. 45,000 ybp \\
\hline Aldabrachelys sp. & Glorieuse Giant Tortoise & Testudinidae & Glorieuses Islands & Late Pleistocene & unknown \\
\hline Chelonoidis sombrerensis & Sombrero Giant Tortoise & Testudinidae & Anguilla (Sombrero Island) & Late Pleistocene & unknown \\
\hline Chelonoidis sp. & Curaçao Giant Tortoise & Testudinidae & Curaçao & Late Pleistocene & unknown \\
\hline Chelonoidis sp. & Hispaniola Tortoise & Testudinidae & Dominican Republic & Late Pleistocene & unknown \\
\hline Chelonoidis sp. & Navassa Tortoise & Testudinidae & Navassa Island (Caribbean) & Late Pleistocene & unknown \\
\hline Chelydra floridana & Giant Florida Snapping Turtle & Chelydridae & USA(Florida) & Late Pleistocene & unknown \\
\hline Geoemyda amamiensis & Amami Leaf Turtle & Geoemydidae & Japan (Ryukyu Archipelago) & Late Pleistocene & unknown \\
\hline Gopherus donlaloi & Don Lalo's Gopher Tortoise & Testudinidae & Mexico (Tamaulipas) & Late Pleistocene & unknown \\
\hline Gopherus laticaudatus & Broad-tailed Gopher Tortoise & Testudinidae & USA(Texas) & Late Pleistocene & unknown \\
\hline Hesperotestudo equicomes & Kansas Tortoise & Testudinidae & USA (Kansas, Nebraska) & Late Pleistocene & unknown \\
\hline Hesperotestudo incisa & Incised Tortoise & Testudinidae & USA(Florida, Georgia) & Late Pleistocene & unknown \\
\hline Hesperotestudo sp. & Mesoamerican Giant Tortoise & Testudinidae & El Salvador & Late Pleistocene & unknown \\
\hline Megalochelys sp. & Timor Giant Tortoise & Testudinidae & Indonesia (Timor) & Late Pleistocene & unknown \\
\hline Meiolania mackayi & Walpole Giant Horned Turtle & Meiolaniidae & New Caledonia (Walpole Island) & Late Pleistocene & unknown \\
\hline Meiolania platyceps & Lord Howe Giant Horned Turtle & Meiolaniidae & Australia (Lord Howe Island) & Late Pleistocene & unknown \\
\hline Meiolaniidae sp. & Viti Levu Giant Horned Turtle & Meiolaniidae & Fiji (Viti Levu Island) & Late Pleistocene & unknown \\
\hline Melanochelys sinhaleyus & Sinhalese Pond Turtle & Geoemydidae & Sri Lanka & Late Pleistocene & unknown \\
\hline Mauremys nipponica & Nipponese Pond Turtle & Geoemydidae & Japan (Honshu) & Late Pleistocene & unknown \\
\hline Mauremys yabei & Yabe's Pond Turtle & Geoemydidae & Japan (Honshu) & Late Pleistocene & unknown \\
\hline Ninjemys oweni & Owen's Giant Horned Ninja Turtle & Meiolaniidae & Australia (Queensland) & Late Pleistocene & unknown \\
\hline Pseudemys hibbardi & Hibbard's Cooter & Emydidae & USA(Oklahoma, Kansas) & Late Pleistocene & unknown \\
\hline Rhinoclemmys nicoyana & Nicoya Wood Turtle & Geoemydidae & Costa Rica & Late Pleistocene & unknown \\
\hline Centrochelys burchardi & Tenerife Giant Tortoise & Testudinidae & Canary Islands (Tenerife) & Middle Pleistocene & ca. 200,000 ybp \\
\hline Titanochelon sp. & Ibiza Tortoise & Testudinidae & Spain (Balearic Islands) & Middle Pleistocene & ca. 200,000 ybp \\
\hline Hesperotestudo bermudae & Bermuda Tortoise & Testudinidae & Bermuda & Middle Pleistocene & ca. $310,000 \mathrm{ybp}$ \\
\hline Centrochelys robusta & Maltese Giant Tortoise & Testudinidae & Malta (Valletta) & Middle Pleistocene & unknown \\
\hline Cuora miyatai & Japanese Box Turtle & Geoemydidae & Japan (Honshu, Kyushu) & Middle Pleistocene & unknown \\
\hline Gopherus pargensis & Cedazo Gopher Tortoise & Testudinidae & Mexico (Aguascalientes) & Middle Pleistocene & unknown \\
\hline Hesperotestudo mlynarskii & Mlynarski's Tortoise & Testudinidae & USA(Florida) & Middle Pleistocene & unknown \\
\hline Hesperotestudo percrassa & Port Kennedy Tortoise & Testudinidae & USA(Pennsylvania) & Middle Pleistocene & unknown \\
\hline Testudo binagadensis & Binagady Tortoise & Testudinidae & Azerbaijan & Middle Pleistocene & unknown \\
\hline Testudo kenitrensis & Kenitra Tortoise & Testudinidae & Morocco & Middle Pleistocene & unknown \\
\hline Testudo lunellensis & Gracia Tortoise & Testudinidae & Spain (Catalonia) & Middle Pleistocene & unknown \\
\hline
\end{tabular}


boundary, 29 of 46 (63.0\%) extinctions were terrestrial, 8 of $46(17.4 \%)$ were insular, and 8 of $29(27.6 \%)$ terrestrial extinct taxa were insular. During the Middle Pleistocene, 11 of $11(100.0 \%)$ extinctions were terrestrial, 5 of 11 $(45.5 \%)$ were insular, and 5 of $11(45.5 \%)$ terrestrial extinct taxa were insular. During the Late Pleistocene, 18 of $25(72.0 \%)$ extinctions were terrestrial, 10 of 25 $(40.0 \%)$ were insular, and 10 of $18(55.6 \%)$ terrestrial extinct taxa were insular. During the Holocene, 12 of 12 (100.0\%) extinctions were terrestrial, 10 of $12(83.3 \%)$ were insular, and 10 of $12(83.3 \%)$ terrestrial extinct taxa were insular. Finally, in Modern times, 10 of 12 (83.3\%) taxa that went extinct were terrestrial, 11 of $12(91.7 \%)$ were insular, and 10 of $10(100.0 \%)$ terrestrial extinct taxa were insular.

Although a greater number of taxa went extinct at the Plio-Pleistocene boundary and Early Pleistocene than in later times, there is a clear pattern of gradually increasing percentages of extinctions of terrestrial and insular turtle and tortoise species through time, most notably showing a gradual age-related increase in the percentage of extinctions of insular terrestrial taxa (Fig. 11 , green bars). This pattern is consistent with generally more continental terrestrial taxa becoming extinct in PlioPleistocene and earlier Pleistocene times and generally more insular terrestrial taxa becoming extinct later into the Late Pleistocene, Holocene, and Modern times. This pattern is reflective of the known pattern and chronology of the spread of humanity across the globe from continental to insular sites, suggesting a high likelihood of gradual hominin and human exploitation and extirpation first of continental terrestrial turtle and tortoise faunas and later of insular terrestrial turtles and tortoises.

In terms of whether extinct turtles and tortoises represent megafauna as defined by mammologists, we note that the average carapace length (CL) of all 96 extinct terrestrial turtle and tortoise species for which we have at least estimated sizes, was $63.9 \mathrm{~cm}$, which would correspond to an animal of body mass of ca. $53 \mathrm{~kg}$ (based on Aworer and Ramchurn 2003). For terrestrial tortoises and turtles, 70 taxa averaged $77.3 \mathrm{~cm} \mathrm{CL}=\mathrm{ca} .90 \mathrm{~kg}$ body mass and for aquatic turtles, 26 taxa averaged $28.0 \mathrm{~cm} \mathrm{CL}=$ ca. 5.0 $\mathrm{kg}$ body mass (data for aquatic turtles from Iverson et al. 1997 and Rhodin, unpubl. data). For terrestrial species, for 25 Plio-Pleistocene and Early Pleistocene taxa, the average $\mathrm{CL}$ was $84.2 \mathrm{~cm}=\mathrm{ca} .115 \mathrm{~kg}$, for 8 Middle Pleistocene taxa CL was $45.1 \mathrm{~cm}=\mathrm{ca} .20 \mathrm{~kg}$, for 15 Late Pleistocene taxa CL was $77.1 \mathrm{~cm}=$ ca. $90 \mathrm{~kg}$, for 12 Holocene taxa, CL was $78.2 \mathrm{~cm}=$ ca. $95 \mathrm{~kg}$, and for 9 Modern taxa, average $\mathrm{CL}$ was $89.9 \mathrm{~cm}=\mathrm{ca} .130 \mathrm{~kg}$. Extinct terrestrial tortoises in our listing were generally large and heavy and would be considered megafauna; aquatic turtles were generally smaller and not considered megafauna.

\section{DISCUSSION}

There is an abundance of literature on the prehistoric Pleistocene and Holocene use and consumption of turtles and tortoises by earlier hominins and later humans, with many documented finds of turtle bones from archaeological sites and kitchen middens and inhabited caves (see below). It is beyond the scope of this checklist at present to document all of these records, although such a compilation would be extremely valuable. However, we make some noteworthy observations from this literature.

One of the more striking results of our survey of Pleistocene and Holocene turtle and tortoise extinctions is that fossil taxa of terrestrial species, notably the Testudinidae and Meiolaniidae, are disproportionately represented, a factor that we link to the consumption of turtles (chelonophagy) by earlier hominins and later humans.

As is true today in most tropical human subsistence hunter-gatherer societies, it was also likely true during the earlier days of humanity: any tortoise encountered was a tortoise collected and consumed. These slowmoving and non-threatening shelled terrestrial animals required minimal effort to find and, even when giant and heavy, were easily collected by bands of huntergatherers and could be stored alive for long periods of time to be eaten in times of need. Tortoises were, essentially, the earliest pre-industrial version of "canned food", and early hominins began to collect and eat them as they developed the transformational ability to open their shells and butcher them using primitive stone tools (Oldowan Paleolithic technology), the earliest version of "can-openers".

Turtles and tortoises were an excellent dietary source of protein and were an important component of the subsistence diet of many early hominins (Steele 2010; Thompson and Henshilwood 2014). Bigger tortoises and larger-bodied species were more visible in the landscape and were probably preferentially collected, yielding more food for consumption, and probably gradually extirpated more rapidly as a result, leaving smaller tortoise species and the more elusive freshwater turtles to survive longer.

Our working hypothesis is that many of the giant tortoises of the family Testudinidae and the giant horned turtles of the family Meiolaniidae that went extinct during these times were primarily extirpated by hominin and human overexploitation during the relatively long rise and global spread of humanity from the end of the Pliocene through the Pleistocene and Holocene and into the present. However, many of these giant species were also no doubt affected to varying degrees by the relatively sudden global cooling that began towards the end of the Pliocene at about 3.2 million ybp, leading to the Northern 
Hemisphere Glaciation and beginning of the Pleistocene (Zachos et al. 2001).

Additionaly, we hypothesize that most smaller tortoises and freshwater turtles that went extinct during these times were probably not necessarily primarily extirpated by humanity, but possibly more likely as a result of climate and habitat change, though probably also while being exploited to a lesser degree. In addition, many of the early Plio-Pleistocene "extinctions" may instead represent evolutionary phylogenetic transitions from earlier to subsequent chronospecies or paleospecies, with many of these possibly primarily affected by global cooling and glaciation (Zachos et al. 2001).

These patterns of early human exploitation have been corroborated by the studies of Stiner et al. (1999, 2000) on the subsistence use of large vs. small game, including Greek Tortoises (Testudo graeca), from the Paleolithic of Israel. Their studies demonstrated a significant chronologic decrease in the size of tortoises utilized, with those collected from 150,000 to 100,000 ybp being very much larger than those collected between 100,000 to 11,000 ybp, reflecting the effect of constant human exploitation pressures on tortoise sizes over long periods of time. Further extensive analyses of the same and additional material by Speth and Tchernov (2003) confirmed that human exploitation was directly correlated with decrease in tortoise size, particularly during a sudden human population growth pulse at around 44,000 ybp. Smaller and faster freshwater turtles, which probably required greater effort to collect, were apparently not exploited as frequently by early hominin hunter-gatherer societies, as the slower terrestrial tortoises were (Stiner et al. 2000; O'Reilly et al. 2006; Blasco et al. 2011).

Human exploitation of marine turtles also started long ago, with the earliest archaeological records of marine turtle bones from middens in the Arabian Peninsula and the Persian Gulf dating back to approximately $7000 \mathrm{ybp}$, or ca. 5000 BC (Beech 2000, 2002). Indeed, the earliest historical written documentation of people eating turtles was by the Greek historian and geographer Agatharchides of Cnidus, who lived in ca. 250 BC. He described a tribe of primitive people that he called the "Chelonophagi"

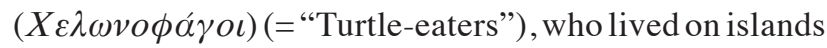
in the southern Red Sea area between Africa and Arabia and ate giant sea turtles, using their shells for building shelters and as boats (Burstein 1989).

We do not attempt to summarize the extensive literature on the history of human exploitation of marine turtles, well done already by Frazier (2003). We note, however, that despite the fact that most extant marine turtle species are currently assessed on the IUCN Red List as being Threatened (Vulnerable, Endangered, and Critically Endangered), there are no data to suggest that hominins or humans have yet contributed to the extinction of any marine turtle species. This would also have been unlikely, given 1) the generally global or at least widespread regional ranges of most sea turtle species, 2) their propensity to nest on offshore islands (like many seabirds), and 3 ) their developmental and/or foraging habitats often including the open ocean, making them relatively inaccessible to exploitation by humans. Hopefully, these factors and a continued conservation ethic will help prevent any anthropogenic extinctions of sea turtles.

\section{Hominin Chelonophagy}

Our review indicates that hominin consumption of turtles and tortoises has occurred since the earliest development of Oldowan stone technology in eastern and southern Africa and that it has gradually spread out of Africa in conjunction with the evolution of the genus Homo and the gradual migratory global spread of humanity. Turtles and tortoises have comprised an important component of the subsistence diet of evolving humanity.

Africa. - The broad pattern of extinction outlined above is born out by the turtle fossil record from Olduvai Gorge in Tanzania, at the very heart of modern human origins. Studies by Auffenberg (1981), based on archaeological excavations by the Leakeys, demonstrated that the Early Pleistocene Australopithecus, and other early hominins, Homo habilis and probably H. erectus, gathered large numbers of chelonians. At these and slightly older Late Pliocene levels at some of these sites, there were a few remains of an extinct giant tortoise ("Aldabrachelys" laetoliensis), an extinct smaller tortoise (Stigmochelys brachygularis), and an extinct terrestrial pelomedusid (Latisternon microsulcae) mixed in with many still-extant freshwater turtles (Pelusios sinuatus) and a few still-extant medium-sized tortoises (Stigmochelys pardalis). Later, in the Middle Pleistocene, there were mainly large numbers of $P$. sinuatus and only an occasional $S$. pardalis. This pattern of utilization is consistent with early overexploitation and extirpation of the terrestrial tortoises leading to later availability of mainly freshwater turtles.

This pattern is repeated throughout the continent. Several finds of Plio-Pleistocene giant tortoises have been recovered from continental Africa, often assigned to Centrochelys or Stigmochelys (Harrison 2011), including from Hadar, Ethiopia (3.4-3.2 million ybp), Omo, Ethiopia (3.5-2.5 million ybp), Bahr el Ghazal, Chad (3.5-3.0 million ybp), Kaiso Beds, Uganda (2.3-2.0 million ybp), and Olduvai, Tanzania (4.42.6 million ybp). Giant tortoises somewhat similar to extant Stigmochelys pardalis, but more likely an 
undescribed species, have also been found at Rawi, the Early Pleistocene Oldowan site (ca. 2.5 million ybp) on the Homa Peninsula in Kenya (Broin 1979; F. Lapparent de Broin, pers. comm.). The extinction of these and several other giant forms in Africa occurred almost simultaneously at around 2.6-2.5 million ybp, coinciding with the evolution of Homo in Africa and the early Oldowan use of stone tools for butchering (Harrison 2011). While there are numerous records of Late Pliocene to Early Pleistocene fossil giant tortoises from continental Africa, none except for the somewhat smaller extant Centrochelys sulcata and Stigmochelys pardalis have been reported from more recent deposits (Lapparent de Broin 2000; Wood 2003).

Though many earlier Pleistocene records of turtles associated with hominin archaeological sites have not yet shown specific taphonomic indicators of butchering, there is no doubt that turtles and tortoises have been exploited for a long time. Indeed, in addition to the circumstantial evidence from Olduvai Gorge and other parts of Africa, evidence from the Plio-Pleistocene of the Chiwondo Beds in Malawi (3,750,000 to 2,000,000 ybp) indicate that early hominins, such as Paranthropus boisei and Homo rudolfensis, crushed freshwater turtle shells (Karl 2012). Additionally, a tortoise shell from the Early Pleistocene Sterkfontein Australopithecus site in South Africa $(2,000,000$ to $1,600,000 \mathrm{ybp})$ appears as if it may have been butchered (Broadley 1997).

At Lake Turkana in Kenya, Early Pleistocene hominins at about 1,950,000 ybp (pre-dating Homo erectus) butchered and consumed many turtles, in addition to small and large mammals (notably hippopotamus), crocodiles, and fish (notably air-breathing catfish) (Braun et al. 2010). Stone tool marks recorded from the insides of turtle carapacial fragments found there have indicated that they were actively butchered (Braun et al. 2010; Archer et al. 2014).

Similarly, Thompson and Henshilwood (2014) documented butchering and the high nutritional value and high levels of exploitation of still-extant Angulate Tortoises (Chersina angulata) in the Middle Stone Age of South Africa at ca. 100,000 to 70,000 ybp. Also in the Middle and Late Stone Age of South Africa (ca. 70,000-2000 ybp), Klein and Cruz-Uribe (1983, 2000) and Steele and Klein (2006) documented the gradual decrease in size of $C$. angulata harvested and consumed by humans in the region. Though habitat and climate deterioration could have played a role in the decreasing size of the tortoises, these authors concluded that hunting pressure was significantly greater in the Late Stone Age when the human population density had grown significantly and the increased exploitation affected the size of tortoises available for harvesting. Avery et al. (2004) noted accumulations of burned tortoise shells in Paleolithic Early Holocene South African huntergatherer sites from 10,700 to $9600 \mathrm{ybp}$ and later, that were suggestive of focused collection and consumption of tortoises burned in bush fires.

We also note the description by Broadley (2007) of what he suggested was an "anomalous" specimen of Kinixys, most similar to extant $K$. spekii, from an Early Holocene (ca. 9400 ybp) cave site in Zimbabwe. We have not listed this testudinid as an unnamed extinct taxon, but based on the morphological characteristics of the limited fragmentary material, it might be.

Middle East and Europe. - The Early Pleistocene Dmanisi site in Georgia in the Caucasus, dated at ca. $1,800,000 \mathrm{ybp}$, represents the earliest known occurrence of Homo outside of Africa. This site includes many tortoise bones identified as the Greek Tortoise, Testudo graeca, in association with the primitive hominin (probably $H$. erectus) that occurred there (Blain et al. 2014).

In Eurasia, remains of the widespread species of the genera Testudo, Emys, Mauremys and further south, also of Rafetus and Trionyx, are common in archaeological sites of Homo sapiens and $H$. neanderthalensis. Documented evidence of active butchering and exploitation of turtles and tortoises has been shown from the Early Pleistocene of Spain, approximately 1,200,000 ybp (Blasco et al. 2011), where a taphonomic analysis of turtle bones demonstrated that cave-dwellers (Homo sp.) used stone tools to prepare and consume many medium-sized Hermann's Tortoises, Testudo hermanni, and occasionally the smaller European Pond Turtle, Emys orbicularis. Stiner et al. (1999, 2000) also demonstrated the significance of freshwater turtles ( $E$. orbicularis) and tortoises (Testudo spp.) in Paleolithic subsistence economies for up to $120,000 \mathrm{ybp}$ in Italy and 200,000 ybp in Israel, respectively. Also in Spain, in the Middle Pleistocene at ca. 228,000 ybp, hominins at Bolomor Cave butchered, burned, and consumed large numbers of T. hermanni tortoises (Blasco 2008).

In the Middle East, during a later timeframe, the late Epipaleolithic Natufian culture in Israel also utilized T. graeca extensively for symbolic and consumptive feasting, and perhaps for medicinal purposes (Grosman et al. 2008; Munro and Grosman 2010). These authors documented a Natufian female shaman's ceremonial grave from 12,000 ybp containing over 50 sacrificed whole tortoises placed next to her body (with her head resting on a tortoise shell), and over 5500 bone fragments from over 70 butchered and roasted tortoises interred around her burial site. Clearly, tortoises were highly favored consumption resources in this early prehistoric society. 
Asia. - Modern chelonophagy and exploitation by humans in many Asian countries, notably China, represents one of the main current threats to turtle biodiversity around the world (van Dijk et al. 2000; Turtle Conservation Coalition 2011). Originally coined the "Asian Turtle Crisis," extensive consumption in China leading to widening trade routes from Southeast Asia and rapid trade globalization have extended the reach of Chinese demand beyond Asia, to all other continents where turtles occur.

However, chelonophagy in Asia did not start in China, but rather with the first migrations of hominins and humans into southern Asia. In fact, the sequential extirpation of giant Megalochelys tortoises from various islands in the Indo-Australian Archipelago during the Pleistocene is generally interpreted as a specific indicator for the migratory arrival of early hominins, Homo erectus, gradually spreading across the Archipelago (Sondaar 1981, 1987; van den Bergh 1999; van den Bergh et al. 2009). All continental taxa of giant Megalochelys tortoises in the Sivaliks of India went extinct by the Early Pleistocene, and insular taxa also went gradually extinct in most of the Archipelago, surviving into the Middle Pleistocene only on Timor.

By the Late Pleistocene, there were evidently no more giant tortoises anywhere in the South Asia and Southeast Asia regions. At a rockshelter site in peninsular Thailand dated at ca. 43,000 to 27,000 ybp, extensive remains of exploited chelonians revealed only still-extant species, with nearly all of them freshwater turtles of the families Geoemydidae (including Cuora amboinensis, a semi-terrestrial species) and aquatic Trionychidae (Mudar and Anderson 2007). There were only a few individuals of Indotestudo elongata, a smaller terrestrial tortoise with a carapace length of only about $27 \mathrm{~cm}$. The proportion of chelonian bones in relation to other mammalian remains indicated that turtles and tortoises formed a very significant portion of the diet of these people, but easily-collected tortoises were no longer apparently as abundant in the local fauna.

By the Holocene, smaller semi-terrestrial leaflitter turtles and aquatic turtles were sometimes the only chelonians found in some archaeological sites, such as in late Pleistocene archaeological deposits (ca. 13,000-7000 ybp) at Niah Cave in the lowlands of Borneo (Pritchard et al. 2009). Their analysis revealed that of the several identifiable turtle species utilized there at that time, all were geoemydids (Cyclemys dentata, Notochelys platynota, Heosemys spinosa) and trionychids (Amyda cartilaginea, Dogania subplana). There were no tortoise bones found in the deposits, probably a good indicator that large tortoises (Manouria emys, carapace length to ca. $60 \mathrm{~cm}$ ) had either already been extirpated or did not occur in these lowland regions. In tropical forested Cambodia, from 2450 to $1450 \mathrm{ybp}$ (500 BC to 500 AD), people at Phum Snay gathered and utilized many more large and easilycollected forest tortoises (Manouria emys) than more elusive river turtles, such as Batagur borneoensis and Amyda cartilaginea (O'Reilly et al. 2006).

The most striking associations come from China, which affirm the longstanding cultural importance of turtles in that country. In early Neolithic China, at about 8550-8150 ybp (6600-6200 BC), turtle shells of the extant terrestrial geoemydid turtle, Cuora flavomarginata, were often associated with human burials (Li et al. 2003). Several turtle plastra inscribed with primitive proto-writing or reconstructed shells filled with colored pebbles that seemed to denote a special status were often placed strategically around the head or legs of buried people. One adult man whose head was missing instead had eight turtle shells (carapace and plastron) placed where the head should have been ( $\mathrm{Li}$ et al. 2003). Turtles have long been revered and utilized in Chinese culture, and this pattern has extended and expanded into the present. Turtles and tortoises in modern China are now venerated and exploited not only for food consumption, but also for conversion into traditional medicinal products and use as high-end status pets, leading unfortunately to increasingly severe threat levels to their continued survival and a growing globalization of unsustainable turtle trade (van Dijk et al. 2000; Turtle Conservation Coalition 2011).

Australia and the Pacific. - The giant horned turtles of the family Meiolaniidae were similarly apparently affected primarily by human overexploitation. Although the continental species in Australia may have also been affected by the gradual aridification of their habitat, they were probably affected more by human exploitation, similarly to the documented extirpation of the Australian continental megafauna at around 46,000 ybp (Flannery 1994). On their last Pacific island refugia, the last of the Meiolaniidae went extinct as a result of consumptive exploitation by humans, as noted by White et al. (2010), who documented finds of butchered meiolaniid bones in midden deposits from the Late Holocene.

North America and the Caribbean. - As in Asia and Australasia, the disappearance of large terrestrial tortoises in the New World coincided with the arrival of humans. In addition to circumstantial evidence, Late Pleistocene and Early Holocene extinctions of giant North American continental tortoises, such as Hesperotestudo crassiscutata, were often associated with evidence of human exploitation, including a find from 12,000 ybp of a large individual killed by 
a wooden stake (Clausen et al. 1979; Holman and Clausen 1984).

In addition, there was human exploitation of Gopherus tortoises by various Paleo-Indian cultures, including Clovis people, at about 11,200 ybp (Tuma and Stanford 2014). Not only did Clovis people exploit turtles and tortoises, but they constituted the fifth most frequent animal type found at their sites (found in 30\% of sites), after mammoths (in 79\% of sites), bison (52\%), ungulates $(45 \%)$, and rodents $(39 \%)$, indicating the importance of chelonians in Clovis diet (Waguespack and Surovell 2003). Concurrent climate change may also have contributed to the vulnerability of these species by first reducing their populations before humans delivered the final extinction blow, but they were definitely exploited.

A similar scenario of worsening climate with colder winters associated with human exploitation has been hypothesized for the extinction of the smaller southwestern tortoise species Hesperotestudo wilsoni at about 11,000 ybp (Moodie and Van Devender 1979). On the other hand, extirpation of the somewhat larger stillextant Bolson Tortoise, Gopherus flavomarginatus, from its Pleistocene distributional extent in Texas, Arizona, and New Mexico, was most likely caused by human exploitation (Morafka 1988; Truett and Phillips 2009), leaving it restricted and endangered in its current refuge in Mapimí in Mexico.

In addition to tortoises, many species of aquatic turtles and small terrestrial box turtles were utilized by native Paleo-Indians of the North American Holocene (Archaic Period). These turtles were common in shell heap middens located in regions more northerly than the northern-most distributional extent of tortoises, in colder climatic zones such as around the Great Lakes and in New England (Adler 1968, 1970; Rhodin and Largy 1984; Rhodin 1986, 1992, 1995). Further, Adler (1970) also documented the gradual regional extirpation of terrestrial Box Turtles (Terrapene carolina) by Native Americans in northern New York State from about 3500 BC through ca. 1700 AD. Of all the Emydidae, Terrapene spp. are the most tortoiselike and terrestrial, reinforcing the pattern of easier and preferential human exploitation and chelonophagy of terrestrial chelonians.

In the Caribbean, the stratigraphic and geographic distribution of tortoises suggests wide Pleistocene dispersal throughout the area, followed by extirpation on the larger Greater Antilles islands, with relictual Holocene species remaining only on smaller and isolated or inhospitable islands such as Mona, Navassa, Sombrero, Middle Caicos, Grand Turk, and the Bahamas (Pregill 1981; Franz and Franz 2009; Steadman et al. 2014; Hastings et al.
2014). For example, Pregill (1981) documented no Late Pleistocene tortoises present on Puerto Rico; however, giant tortoises persisted into the Late Pleistocene or possibly the early Holocene on nearby Mona as well as several other small isolated islands. In the Bahamas, on Abaco Island, Lucayan Taíno people arrived at ca. 950 ybp and the endemic tortoise, Chelonoidis alburyorum, was consumed into extinction by ca. 780 ybp (1170 AD) (Steadman et al. 2014; Hastings et al. 2014). In the Turks and Caicos islands, giant tortoises persisted into near-historic times, as late as ca. 1200 and $1400 \mathrm{AD}$, respectively, and were extirpated through direct human consumption by the Taíno and Meillac people (Carlson 1999; Franz et al. 2001).

MesoAmerica and South America. - There are few records of Pleistocene and Holocene fossil turtles or tortoises from MesoAmerica or South America. There is an undescribed giant Hesperotestudo recorded from El Salvador in MesoAmerica, and an undescribed giant Chelonoidis from Curaçao offshore from Venezuela, but neither was associated with human habitation sites. Only one distinct fossil species has been verified from continental South America, Chelonoidis lutzae from the Late Pleistocene of Argentina, at ca. 22,000 ybp, probably preceding the arrival of humans. However, the Early Holocene habitation site of Caverna da Pedra Pintada, dated at ca. 11,700-9880 ybp and located along the Rio Amazonas in the lower Amazon basin, contained many bones of exploited turtles and tortoises (Roosevelt et al. 1996; Oliver 2008). Unfortunately, these bones have apparently not yet been identified, being described simply as Testudinidae (in our opinion, probably extant Chelonoidis carbonaria and/or $C$. denticulata) and Pleurodira (probably extant Podocnemis expansa and/or P. unifilis).

\section{Giant Tortoises as Megafauna}

Recent extensive global Pleistocene and Holocene megafaunal mammalian extinction modelling analysis by Sandom et al. (2014) has provided strong evidence of the predominant association of these extinctions with hominin and human paleobiogeography rather than climate change. This was especially striking for the Americas and Australia, areas where modern humans (H. sapiens) arrived without prior presence of prehuman hominins ( $H$. erectus, $H$. neanderthalensis). In Eurasia there was at most some weak additional glacialinterglacial climate-associated influence on these extinction patterns.

The patterns of giant tortoise extinctions are similar in scope and details to the widespread mammalian megafaunal extinctions of the Pleistocene 
and Holocene, and also suggestive of significant human influence. For analytical reviews and examples of the dynamics and specifics of these extinction events and human-induced extirpation patterns among other vertebrates, notably mammalian herbivores and other megafauna, see the following works (MacPhee 1999; Barnosky et al. 2004; Haynes 2009; Turvey 2009; van der Geer et al. 2010). Although none of these reviews provide any in-depth discussion concerning the similar extinction patterns of tortoises, they are useful in reviewing data regarding the competing (but not mutually exclusive) theories of Pleistocene human exploitation and overkill vs. climate change as causes for these extinctions. Extinctions of non-chelonian reptiles during the Pleistocene and Holocene have been documented by Case et al. (1998), who reported extensive patterns of reptilian extinctions over the last 10,000 years, but focused primarily on lizards, with only brief passing reference to a few tortoises that also went extinct.

Our hypothesis regarding exploitation of giant tortoises is supported by the work of Surovell et al. (2005), who analyzed similar patterns of exploitation of giant proboscideans (elephants and mammoths). Their conclusion was that the archaeological record of human subsistence hunting of proboscideans was primarily located along the advancing edges of the human range, suggesting that human range expansion was associated with regional and global overkill of these animals, and that proboscideans succeeded in surviving essentially only in refugia inaccessible to humans. In our opinion, giant tortoises were probably extirpated in much the same way, being easier than giant proboscideans to collect and process, leading to the relatively rapid and expanding extinction of these species in the face of spreading humanity, surviving into Modern times only

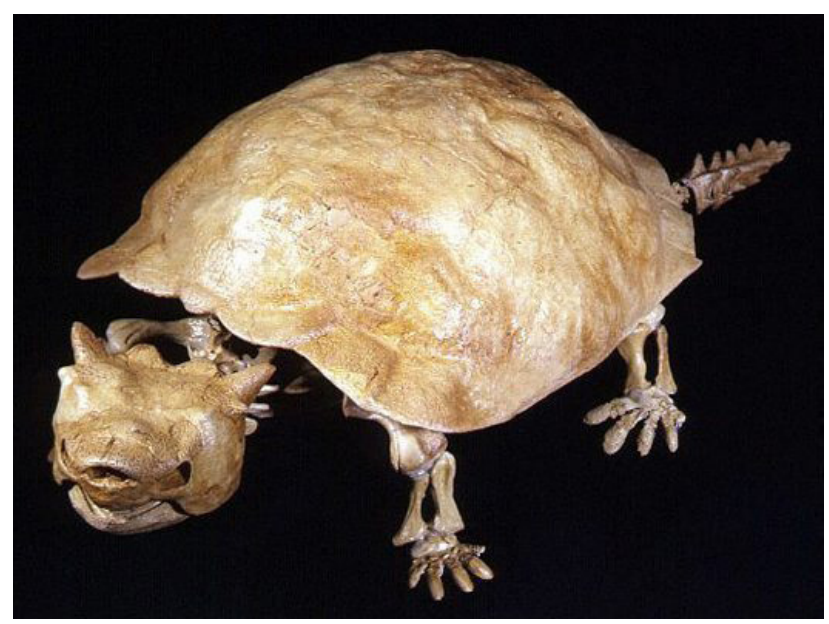

Figure 12. Meiolania platyceps from Lord Howe Island. Reconstructed skeleton by Burke et al. (1983) and the American Museum of Natural History. on a few isolated and distant oceanic islands beyond the reach of early hominins.

However, there are clear differences between the ecology of mammalian megafauna and of large tortoises. The poikilotherm physiology of tortoises not only allows them to survive extended periods without food, water or optimal temperatures, but also allows a much larger "standing crop" or biomass of tortoises than mammals for the same amount of primary production by the vegetation (Iverson 1982). Large compact aggregations of up to thousands of now-extinct giant Cylindraspis tortoises were described from Rodrigues in the Mascarenes upon first arrival of humans (Leguat 1707) (see Fig. 14), and present populations of Chersina angulata on Dassen Island in South Africa (Stuart and Meakin 1983), and Aldabrachelys gigantea on Aldabra (Coe et al. 1979), indicate a high potential biomass and carrying capacity for tortoises, particularly in the absence of mammalian herbivore competitors.

Associated with this physiology, however, are slow growth rates and late maturity, usually on the order of 10 to 25 years for medium and large tortoises. High hatchling and juvenile mortality rates are offset by longevity and persistent reproduction, often for several decades, of the individuals that reach maturity (Bourn and Coe 1978; Swingland and Coe 1979). Population modeling has, however, documented that such life histories are highly susceptible to the impacts of increased mortality of mature adults (Doroff and Keith 1990; Congdon et al. 1993, 1994), in effect leading to depleted populations within a few generations of exploitation. Migration and movement patterns of tortoises are generally insufficient to repopulate such depleted populations if adult tortoise mortality rates remain elevated through continued offtake by human hunter-gatherers, as evidenced by the failure of Amazonian tortoises (Chelonoidis denticulata and $C$. carbonaria) to persist within the daily hunting perimeter $(8-10 \mathrm{~km})$ around Amerindian villages (Souza-Mazurek et al. 2000; Peres and Nascimento 2006). Considering that an individual tortoise is at risk of detection by a human hunter effectively any day throughout its entire life, and that humans (and their hunting dogs) tend to look out for tortoises even when focused on hunting or gathering other species, few tortoises are likely to escape detection and predation by humans, with population collapse and species extinction only a matter of time.

\section{Island Refugia}

The fact that giant tortoises were once abundant on continental land masses, but survived into historic times essentially only on remote and isolated islands such as Aldabra, the Mascarenes, and the Galapágos, 


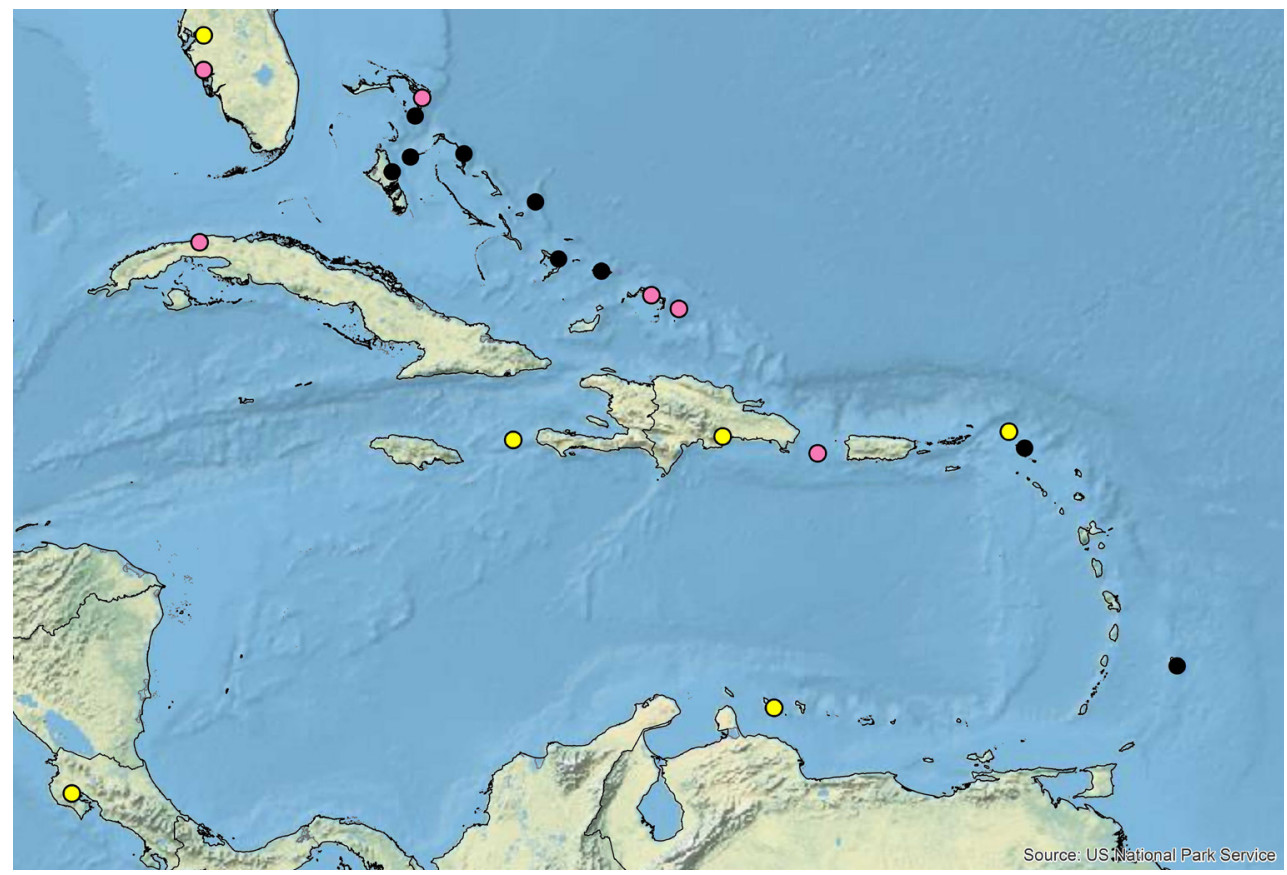

Figure 13. Close-up of the Caribbean region depicted in Fig. 2. Yellow dots $=$ Late Pleistocene taxa $(125,000-12,000$ ybp); pink dots = Holocene taxa (12,000-450 ybp, prior to 1500 AD). Black dots $9=$ unidentified Pleistocene Chelonoidis spp. material not included on any other maps or graphs. See more detailed description of Chelonoidis spp. incertae on p. 31.

adds credence to our hypothesis that giant tortoises were susceptible to extinction by hominin chelonophagy.

Humans did not reach Aldabra and the Mascarenes until the 1500 s, but when they arrived tortoises were rapidly exploited and driven into extinction by the late 1700s (Gerlach 2004; Bour 2007; Gerlach et al. 2013). In the Galapágos, a similar scenario unfolded after humans reached these islands in 1535 , with two species exploited into extinction in the 1800 s, one exploited into virtual extinction in the 1900s (but surviving as a single individual into this century), and one going extinct in the 1900s as an appparent result of habitat loss and volcanism (Pritchard 1996; Poulakakis et al. 2012).

The other large-bodied terrestrial chelonians, the giant horned turtles of the family Meiolaniidae (Fig. 12), with seven Pleistocene taxa, all went extinct during these times, their final demise associated with evidence of human exploitation on small remote South Pacific islands during the Late Holocene (Gaffney et al. 1984; White et al. 2010).

In the Caribbean West Indies, several taxa of giant, large, and medium-sized tortoises of the genus Chelonoidis existed throughout the archipelago prior to human arrival at about 7000 ybp (Pregill 1981; Franz and Franz 2009). Those on the Greater Antilles islands were generally extirpated first, with relictual species remaining into the Holocene only on smaller and isolated islands. On Abaco Island in the Bahamas, C. alburyorum persisted until about $1170 \mathrm{AD}$ and was exploited into extinction shortly after the arrival of Lucayan Taíno people (Steadman et al. 2014; Hastings et al. 2014). In the Turks and Caicos Islands, giant and medium-sized tortoises persisted into late preColumbian times, being found in Taíno and Meillac habitation sites from as late as ca. $1400 \mathrm{AD}$, and were extirpated through direct human consumption (Carlson 1999; Franz et al. 2001). On Curaçao, giant tortoises apparently persisted until the Late Pleistocene. Several unidentified Chelonoidis spp. have also been found in Pleistocene deposits on several of the Bahamas banks islands, as well as limited material from Anguilla and Barbados (Fig. 13).

In the Indo-Australian Archipelago, the stratigraphic and geographic distributions of extinct Megalochelys giant tortoises also indicate a likely scenario of early hominin and human exploitation leading to extinction of multiple species on many islands (Sondaar 1981, 1987; van den Bergh 1999; van den Bergh et al. 2009). The association between the various insular taxa of Megalochelys and the hominin Homo erectus has been well documented and supports a scenario of overexploitation.

On Mauritius island in the Mascarenes in the Indian Ocean, the giant tortoises there (Cylindraspis triserrata and $C$. inepta) were able to endure climatic changes (markedly increased aridity) $4200 \mathrm{ybp}$ through altered drought-adaptive ability to change their metabolic processes (van der Sluis et al. 2014). However, human arrival in the 17 th century changed the original habitat to 


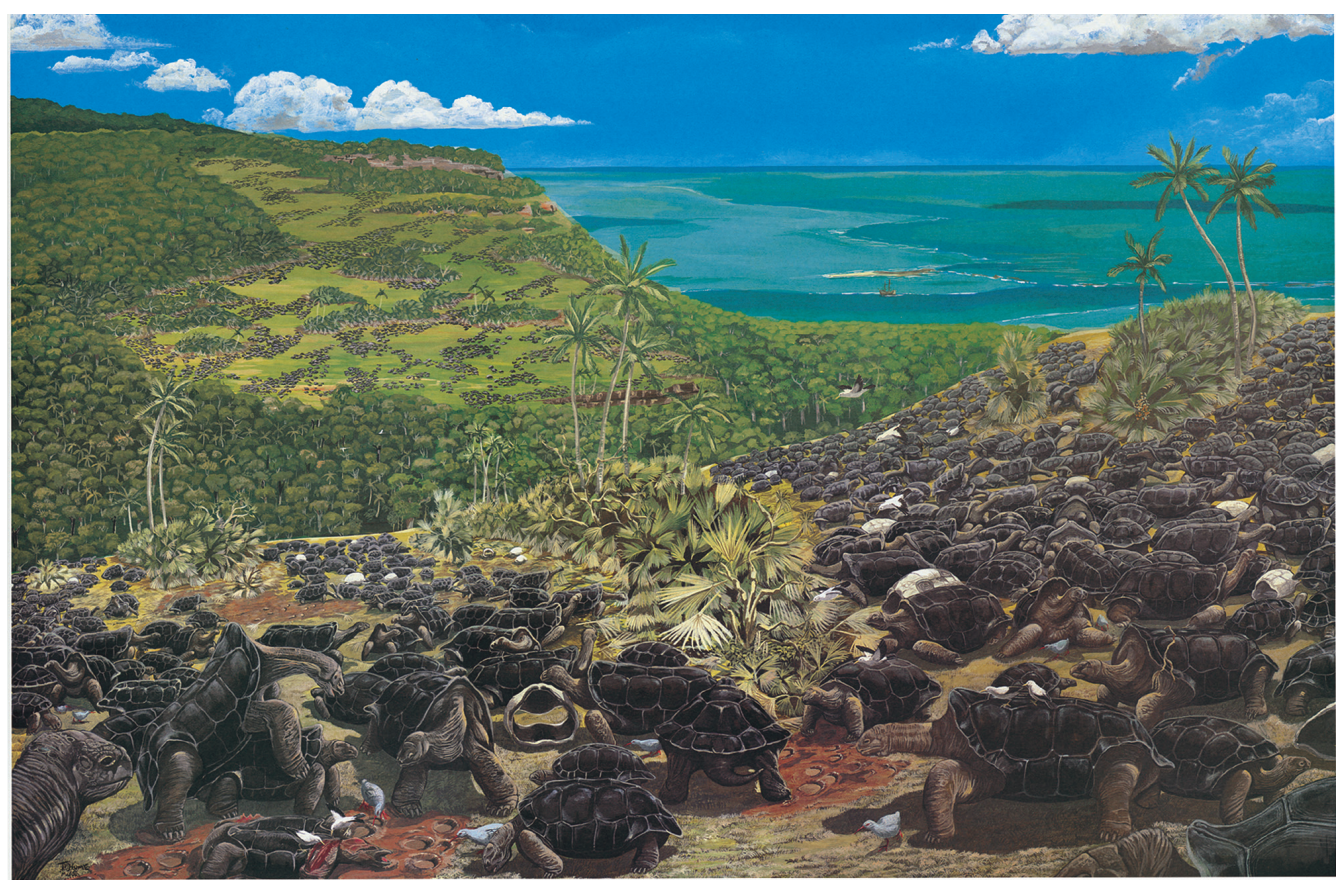

Figure 14. Artist's rendition of two species of extinct giant tortoises, Cylindraspis vosmaeri (larger, saddlebacked) and $C$. peltastes (smaller, domed) in their native habitat on Rodrigues Island in the late 1600s when accounts indicate the herds of tortoises were so large and dense that it was possible to walk for long distances on their backs without touching the ground (Leguat 1707). Painting by Julian Pender Hume (from Griffiths et al. 2013).

such an extent that, in combination with overexploitation and the impacts of introduced species such as rats, pigs, and macaques, which continue to impact native birds (Durrell 1977), it resulted in the rapid extinction of both of the giant tortoise species.

Hansen et al. (2010) discussed and documented extinction patterns of many species of giant tortoises on continental land masses in contrast to islands since the late Pleistocene, noting several cases of human exploitation as well as instances more likely influenced by climate change. They also recommended and noted on-going ecological replacement efforts (rewilding) of extant giant (Aldabran Aldabrachelys gigantea) and smaller (Madagascan Astrochelys radiata) regional tortoises onto some of these islands that previously had giant Cylindraspis tortoises (e.g., on Ile aux Aigrettes and Round Island in Mauritius, and on Rodrigues). Rewilding efforts for tortoises on these islands are already showing excellent progress (Griffiths et al. 2013b; Griffiths 2014), and plans are underway to also consider rewilding A. gigantea to Madagascar itself, where two giant tortoises went extinct in the Late Holocene (Griffiths 2014).

Rewilding or assisted migration are potentially promising lines of conservation management strategies that may help restore vanished or threatened ecosystems to islands or continental regions that no longer harbor the tortoises that previously existed there, but were driven into extinction by human exploitation (Truett and Phillips 2009; Griffiths et al. 2010, 2011, 2013a; Pedrono et al. 2013). These strategies are particularly pertinent in the Mascarene Islands and on Madagascar, as well as in the Galápagos. Rewilding and restoration efforts for giant tortoises in the Galápagos are increasingly being evaluated in the context of conservation genetics and the phylogenetic analysis of extant and extinct species (Poulakakis et al. 2008, 2012; Parham 2008; Russello et al. 2010; Garrick et al. 2012; Hennessy 2014). In the Mascarenes and Seychelles, genetic analysis of the various Cylindraspis and Aldabrachelys taxa, whether classified as species, subspecies, evolutionarily significant units (ESUs), or management units (MUs), has suggested rapid adaptive evolution of these various isolated insular taxa (Austin and Arnold 2001; Austin et al. 2003; Gerlach and Rioux Paquette 2014).

There is also increasing evidence building of the major ecological impact that grazing herds of giant tortoises have on ecosystem characteristics, especially on islands (Gibbs et al. 2010, 2014; Hunter et al. 2013; Froyd et al. 2014) (see Fig. 14). The loss of tortoises from island ecosystems has had a profound effect on those ecosystems, leading also to a cascade effect of extinctions of and increased threat levels to additional species dependent on the tortoise-modified habitat (Froyd et al. 2014). Restoration of giant tortoises to islands as "ecosystem engineers" may help restore those threatened ecosystems. 


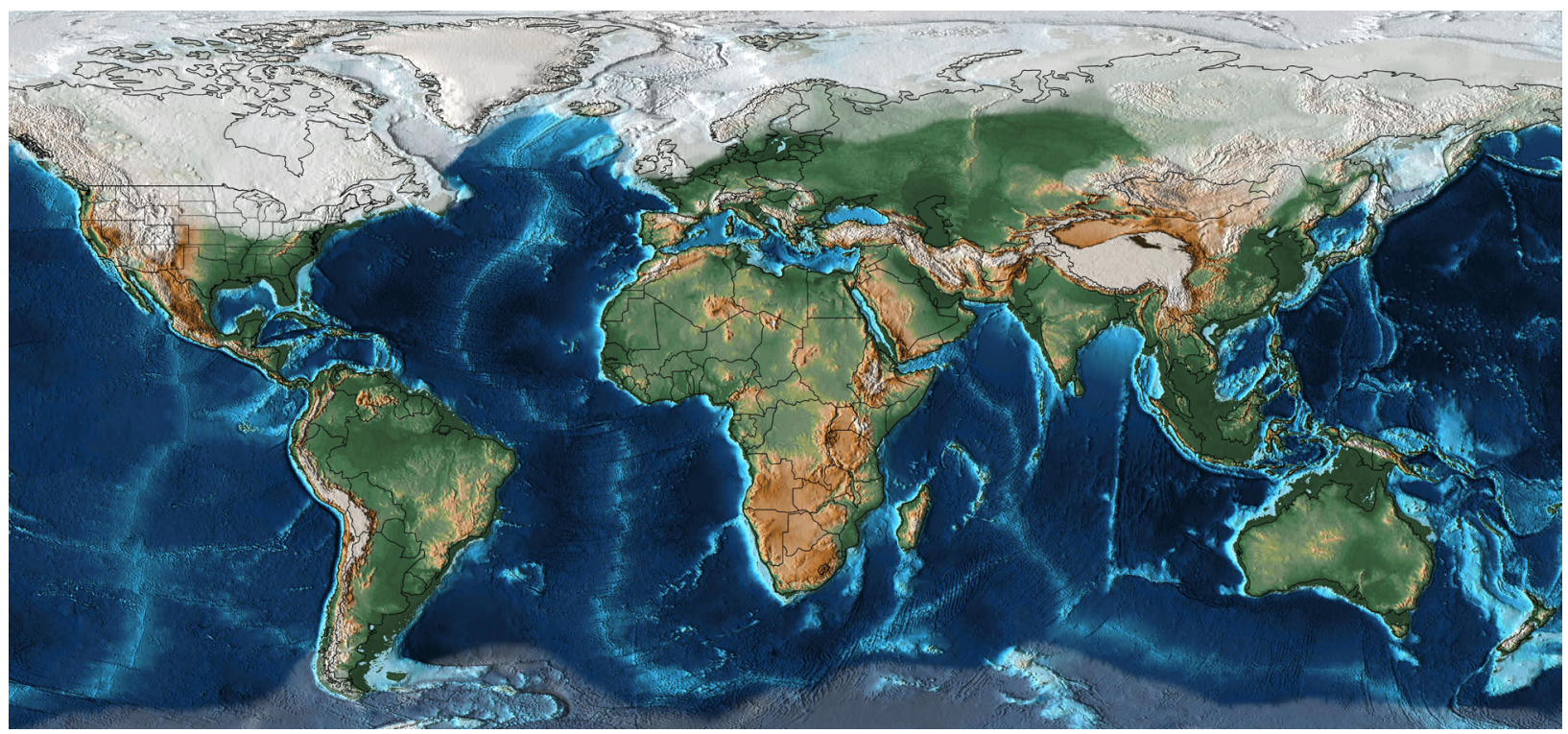

Figure 15. Global extent of glaciation during the Last Glacial Maximum during the Late Pleistocene, ca. 21,000 ybp, with associated maximum lowered sea levels creating land bridges across many island archipelagos (from Scotese 2013).

\section{Climate and Habitat Change}

In terms of the effects of global or regional climate change and habitat alteration on the diversity and distribution of turtle and tortoise species, periods of Pleistocene and Holocene glaciation (e.g., the Last Glacial Maximum in the Late Pleistocene, ca. 21,000 ybp; Fig. 15) and interglacial warming periods and changes leading to landscape aridification and sea level changes have caused fluctuating distributions of many species and created refugia where speciation has occurred.

Rödder et al. (2013) modeled range extensions and contractions of 59 extant North American freshwater and semi-terrestrial turtle species through three Quaternary glacial and interglacial cycles from 320,000 ybp through the present. They found that although fossils of these species usually occurred within predicted thermal niches, based on extant populations of the same species, they sometimes occurred outside these niches, suggesting that the species' thermal niches might be much more flexible and less directly climate-dependent than previously assumed.

As such, to what extent climate and habitat changes have also caused actual species extinctions rather than just regional extirpations remains uncertain and somewhat conjectural. We hypothesize that climate changes may have contributed to the extinctions of many species, perhaps playing a secondary role in the case of the insular giant tortoises, and more of a primary role in others. These climate changes may especially have influenced the difference in patterns of chelonian species richness in North America between the Pleistocene and modern times (Jass et al. 2014).
In a major phylogeographic study of the widespread small North American freshwater Painted Turtles (Chrysemys picta subspecies and C. dorsalis), Starkey et al. (2003) found evidence of at least two independent range expansions into previously glaciated regions of North America, including massive extirpation and recolonization across the Great Plains and Rocky Mountain region. The timing and extent of this recolonization was consistent with regional aridification as the last glaciers receded approximately 14,000 years ago, and Starkey et al. (2003) tentatively proposed this paleoclimatological event as a major factor shaping genetic variation and evolution in Chrysemys.

During the Early, Middle, and most of the Late Pleistocene of North America, before the arrival of Homo sapiens at ca. 20,000-18,000 ybp, the evolutionary patterns and extinctions of the various large tortoise species of Gopherus and Hesperotestudo were likely also influenced primarily by climate and habitat changes, with relatively abrupt periods of cooling and warming associated with changing patterns of continental glaciation and interglacial warming periods, as well as changing aridification of the landscapes (Morafka and Berry 2002; Reynoso and Montellano-Ballesteros 2004).

In South America, Cione et al. (2003) postulated that most of the megafaunal mammalian and giant tortoise extinctions at the Pleistocene-Holocene interphase were impacted by a combination of early human exploitation and extreme and frequent periodic climate changes that they termed the "zig-zag effect", which led to changes in temperature, humidity, and habitat modification that adversely impacted the species involved. 
In Europe, continental glaciation patterns and interglacial warming periods with associated climate change affected the Pleistocene and Holocene distributional fluctuations of the European Pond Turtle, Emys orbicularis, as documented by Sommer et al. (2007, 2009, 2011). The wide distributional range of this small freshwater turtle species has shifted as far north as into Sweden in Scandinavia during thermal maxima (at ca. 9800-5500 ybp, but now no longer present there, see Sommer et al. 2009) and far south into Mediterranean refugia during glaciation events. Despite this, only subspecific distinctiveness has evolved as a result (see ancient DNA analysis of subfossil material by Sommer et al. 2009), and no taxa are known to have gone extinct. Further, being a small freshwater turtle and perhaps not so preferentially collected, it was not as commonly exploited by early humans as larger sympatric terrestrial tortoises (Blasco et al. 2011), although it does appear in human-associated archaeological contexts, especially in areas north of the natural distribution of tortoises (Sommer et al.2009). In addition, judging by the presence of the closely related insular species Emys trinacris on Sicily, there could potentially also exist unrecognized extinct Emys species on other Mediterranean islands. Further analysis of chelonian archaeological material from sites on Cyprus, Crete, Sardinia, and other islands may help answer this question.

Jiménez Fuentes et al. (1999) documented extensive human exploitation of Hermann's Tortoise, Testudo hermanni, in Portugal in the Late Pleistocene, ca. 29,000-22,000 ybp, outside of this species' current range. This indicates either extirpation due to overexploitation or climate and habitat change. Analysis of human use patterns of $T$. hermanni during the Pleistocene and Holocene of the southeastern Iberian Peninsula (Morales Pérez and Sanchis Serra 2009), also outside the species' current range, suggested climate change as the primary driver for the extirpation of the species in that region, although it was also clearly utilized by humans. How much each of the concurrent and complementary threats of climate change vs. human overexploitation have affected the survival of this and many other chelonian species is difficult to determine.

Regional climate and habitat deterioration and warming or cooling may also contribute to a change in size of turtle and tortoise species, although decreasing size of individuals in a population is most generally interpreted as resulting from human density-dependent exploitation (Steele and Klein 2006). Even if it is not clear how the 'temperature-size rule' applies to reptiles, from empirical evidence it seems likely that body size of turtles varies in relation to temperature, and the study of this phenomenon could be very promising (Delfino and de Vos 2014).

Anadón et al. (2015) studied the phylogeography of Testudo graeca subspecies in the Mediterranean region and found varying degrees of climate-associated range contractions and expansions in conjunction with recent glaciation events. They hypothesized that in taxa limited by precipitation and aridification the response to glacial cycles and climate change was more unpredictable than in those limited by temperature.

\section{Concluding Remarks}

We do not claim to have provided definitive evidence of the relative importance of hominin and human overexploitation vs. climate or habitat change as the primary cause of any of the Pleistocene and Holocene extinctions that we list here, but we believe we have documented some compelling circumstantial evidence that humanity has greatly affected the survival of many of these species, especially the insular giant tortoises and terrestrial horned turtles.

There is no doubt that hominins have been gathering, storing, and consuming slow-moving and protein-rich turtles and tortoises, especially the larger terrestrial species, for as long as our respective life forms have co-existed, probably dating back to the very dawn of humanity. Undoubtedly, concurrent climate and habitat change, as well as mammalian predation and geological and stochastic events such as sea level change and volcanism, have also played roles as causative factors in many turtle and tortoise extinctions - the question is, to what proportional extent for which species, and when and where.

A likely scenario potentially causing extinction for many species would be deleterious climate or habitat change (cooling, warming, aridification, sea level change, volcanism) leading to habitat deterioration and increasingly vulnerable and stressed populations of chelonians that are then further diminished and finally extinguished by a combination of mammalian predation and human overexploitation. We urge and challenge our colleagues in the turtle and paleontology communities to further analyze and investigate these patterns more fully so as to help clarify and increase our understanding of these processes.

We believe that by increasing our awareness and understanding of the dynamics and specifics of these numerous Pleistocene and Holocene turtle and tortoise extinctions, we will gain an increased appreciation of and understanding of the tremendous chelonian diversity that we have lost and continue to lose, and what it may take to help reverse the present patterns of 
threats to the continued survival of these ancient and iconic animals. Whether caused by human exploitation or climate and habitat changes, these past extinctions can inform our understanding of the impacts of the long history of human exploitation of turtles and the effects of climate change, and their relevance to current and future patterns, a view also shared by the new discipline of conservation paleobiology (Dietl and Flessa 2011).

Further, an increased understanding of the important effects of the prior ecological engineering roles of these vanished giant tortoises, especially on islands, may help us formulate and implement improved conservation management programs involving ecological analogues (rewilding) to help restore some of those threatened ecosystems, while also creating benefits for countless other species. We need to learn from what we have lost, and work to retain and restore as much as possible of what we still have.

Acknowledgments. - The original impetus to compile this checklist and review of fossil turtles that went extinct during the early rise and global spread of humanity emanated from discussions between Rhodin and James Parham, and we gratefully thank him for his contributions. We also thank the following colleagues for their input and other help with gathering data, obtaining publications, and reviewing earlier drafts of the manuscript: Donald Broadley, Chuck Crumly, Indraneil Das, Anslem de Silva, Richard Franz, Jack Frazier, Eugene Gaffney, Ren Hirayama, Julia Horrocks, Dale Jackson, Walter Joyce, Benjamin Kear, France de Lapparent de Broin, Hidetoshi Ota, James Parham, José Rosado, Erick Setiyabudi, Christopher Scotese, Gert van den Bergh, and Evangelos Vlachos. We thank Julian Pender Hume for the painting of extinct Cylindraspis tortoise herds on Rodrigues.

\section{CHECKLIST}

\section{Diversity Contents of this Checklist of Extinct Pleistocene and Holocene Chelonians}

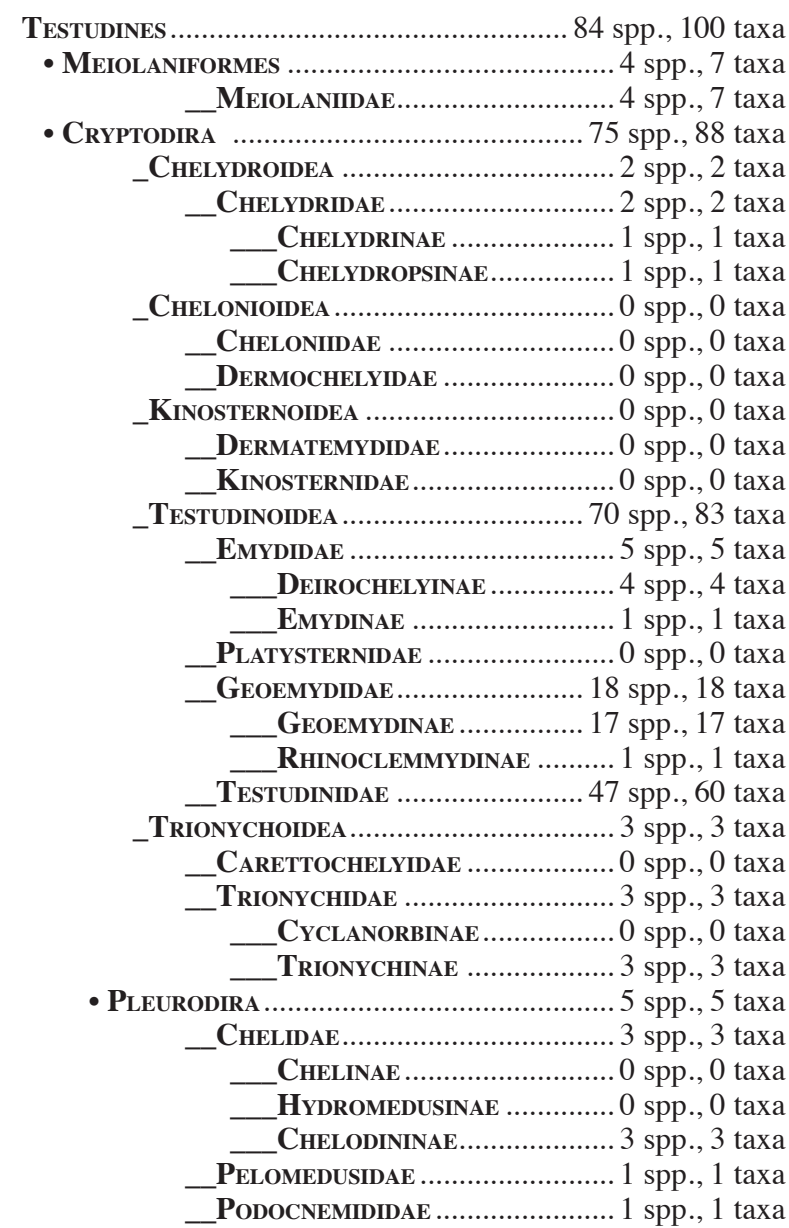

\section{Testudines Batsch 1788}

- Meiolaniformes Sterli and de la Fuente 2013

Meiolaniformes Sterli and de la Fuente 2013:839

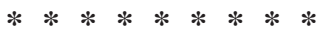

_ MeiolaniIDae Boulenger 1887

Miolaniidae Boulenger 1887:554

Meiolaniidae Simpson 1937:2

Comment: Phylogenetic placement of the family Meiolaniidae remains somewhat controversial. Several authors place it on the stem of crown turtles, branching off before the Cryptodira-Pleurodira split (e.g., Joyce 2007; Sterli 2010; Sterli and de la Fuente 2013), but others (e.g., Gaffney 1983, 1985, 1996; Gaffney et al. 2007; Gaffney and Jenkins 2010) place it among the Cryptodira. We list it here under Meiolaniformes, as recommended by Sterli and de la Fuente (2013), but the hierarchical placement in our checklist is simply intended to be functional, and does not imply specific support for, or disagreement with, either proposed phylogeny. 
Meiolania Owen 1886a

Meiolania Owen 1886a:315

Ceratochelys Huxley 1887:232 (nomen novum)

Miolania Boulenger 1887:554 (nomen novum)

Meiolania damelipi White, Worthy, Hawkins, Bedford, and Spriggs 2010

(Late Holocene, until ca. 810 BC, 2760 ybp)

Efate Giant Horned Turtle

Vanuatu (Efate Island)

Size: CL ca. $135 \mathrm{~cm}$

Meiolania damelipi $\uparrow$ White, Worthy, Hawkins, Bedford, and Spriggs 2010:15512 [Late Holocene (archaeological midden), Vanuatu (Efate: Teouma Lapita site)], ${ }^{14} \mathrm{C}$ age: $2733-2741 \pm 30 \mathrm{ybp}$, calibrated age: $2890-2760$ ybp (940-810 BC)

Comment: This is the most recently extinct named taxon of Meiolaniidae, extirpated by modern humans of the Lapita culture. The midden specimens consisted primarily of limb elements, rather than carapace or plastron bones, supporting the direct evidence of butchering and transportation by humans (White et al. 2010). Further analysis has shown that fruit bats, marine turtles, and Meiolania were initially heavily targeted for exploitation in close proximity to the Lapita site, resulting in local resource depletion and a resultant subsistence change towards harvest of more mobile foraging individuals further afield (Kinaston et al. 2014; S. Hawkins, unpubl. data). The species was only tentatively assigned to the genus Meiolania with a question mark, pending analysis of additional material (White et al. 2010).

Meiolania mackayi Anderson 1925

(Late Pleistocene or Holocene?)

Walpole Giant Horned Turtle

New Caledonia (Walpole Island)

Size: CL ca. $70 \mathrm{~cm}$

Meiolania mackayi $\uparrow$ Anderson 1925:239 [Late Pleistocene or Holocene, New Caledonia (Walpole Island)]

Comment: Specimens occur in phosphatic guano deposits in coral rock, generally presumed to be Late Pleistocene or possibly Holocene.

Meiolania platyceps Owen 1886a (see Fig. 12)

(Early to Late Pleistocene)

Lord Howe Giant Horned Turtle

Australia (Lord Howe Island)

Size: CL ca. $100 \mathrm{~cm}$

Meiolania platyceps $\dagger$ Owen 1886a:315 [Late Pleistocene, Australia (Lord Howe Island)], Miolania platyceps

Meiolania minor $\uparrow$ Owen 1886b:471 [Late Pleistocene, Australia (Lord Howe Island)], Miolania minor

Ceratochelys sthenurus $\dagger$ Huxley 1887:232 (partim, nomen novum) [Late Pleistocene, Australia (Queensland)]

Comment: Carapace length of most meiolaniids is uncertain, with online resources generally listing ca. 250 $\mathrm{cm}$ as the body size of $M$. platyceps (but this apparently includes head, neck, and tail). Gaffney (1996) provided no CL measurements, but indicated relative shell sizes of platyceps (1.0), mackayi (0.7), and the Wyandotte sp. $(2.0+)$ based on relative bone sizes. The most complete shell of M. platyceps (AMF 61110) measures ca. 63.5 $\mathrm{cm}$ in CL (based on a photo with $\mathrm{cm}$ scale supplied by E. Gaffney, pers. comm.). Comparing measured lengths of the femur of this specimen (Gaffney 1996) and the largest femur known, the estimated maximum CL of $M$. platyceps is ca. $100 \mathrm{~cm}$. Fossilized eggs from what is presumably this species measure anywhere from 7.2 to ca. $9.0 \mathrm{~cm}$ in diameter (Anderson 1925; Gaffney 1996; Lawver and Jackson 2014). The species evidently went extinct before human settlement, possibly as a result of postglacial sea level rise (White et al. 2010).

\section{Meiolania sp. [Wyandotte]}

(Late Pleistocene, until ca. 45,000 ybp)

Wyandotte Giant Horned Turtle

Australia (Queensland)

Size: CL ca. $200 \mathrm{~cm}$

Meiolania $\mathrm{cf}$. M. platyceps $\dagger$ (Gaffney and McNamara 1990) [Late Pleistocene, Wyandotte Formation, Australia (Queensland), ca. 200,000-45,000 ybp]

Comment: The described material consisted of only three horn cores and one caudal vertebrae, noted to be most similar to $M$. platyceps from Lord Howe Island and distinct from $M$. oweni (= Ninjemys oweni) from Queensland. As such, there were clearly two separate species of Meiolaniidae in the Late Pleistocene of Queensland.

Ninjemys Gaffney 1992

Ninjemys Gaffney 1992:1

Ninjemys oweni (Woodward 1888)

(Late Pleistocene)

Owen's Giant Horned Ninja Turtle

Australia (Queensland)

Size: CL ca. $100 \mathrm{~cm}$

Meiolania oweni $\dagger$ Woodward 1888:89 [Late Pleistocene, Australia (Queensland: Darling Downs)], Miolania oweni, Ninjemys oweni

Ceratochelys sthenurus $\dagger$ Huxley 1887:232 (partim, nomen novum) [Late Pleistocene, Australia (Queensland)]

Comment: Described in detail by Gaffney (1992), who established the genus Ninjemys for this species, honoring the Teenage Mutant Ninja Turtles of entertainment fame: "in allusion to that totally rad, fearsome foursome epitomizing shelled success". Unfortunately, that shelled success did not lead to survival into the present.

\section{Meiolaniidae sp. [New Caledonia]}

(Late Holocene, until ca. 531 AD, 1419 ybp)

New Caledonia Giant Horned Turtle

New Caledonia

Size: CL ca. $70 \mathrm{~cm}$

Meiolaniidae, gen. et sp. indet. $\dagger$ (Gaffney et al. 1984) [Late Holocene, New Caledonia (Pindai Cave, Nepoui Peninsula)], ${ }^{14} \mathrm{C}$ age: $1720 \pm 70$ ybp, $230 \mathrm{AD} \pm 70$ (160-300 AD), calibrated age*: 1820-1419 ybp (130-531 AD)

Comment: This is apparently the most recently extinct 
000e.24 Conservation Biology of Freshwater Turtles and Tortoises • Chelonian Research Monographs, No. 5

(but unnamed) taxon of Meiolaniidae, extirpated by modern humans.

Meiolaniidae sp. [Fiji]

(Late Pleistocene)

Viti Levu Giant Horned Turtle

Fiji (Viti Levu Island)

Size: undetermined

Meiolaniidae, gen. et sp. indet. $\dagger$ (Worthy et al.

1999) [Late Pleistocene, Fiji (Viti Levu Island)]

Comment: Discussed by White et al. (2010); we hypotesize this taxon to be distinct based on biogeographic separation from other recorded insular Meiolaniidae.

\section{- Cryptodira Cope 1868b}

\section{_Chelydroidea Gray 1831b}

\section{_Chelydridae Gray 1831b}

\section{Chelydrinae Gray 1831b}

Chelydra Schweigger 1812

Chelydra floridana (Hay 1907)

(Late Pleistocene)

Giant Florida Snapping Turtle

USA (Florida)

Size: undetermined

Macrochelys floridana $\dagger$ Hay 1907:847 [Late Pleistocene (Rancholabrean), USA (Florida)], Chelydra floridana

Comment: Thomas et al. (2014) examined type material of this taxon and determined that it most likely represented a giant species of Chelydra, rather than being synonymous with Macrochelys temmincki, as previously hypothesized.

\section{Chelydropsinae Młynarski 1980}

Chelydropsinae Młynarski 1980:1

Chelydropsis Peters 1868

Chelydropsis Peters 1868:72

Chelydropsis nopcsai (Szalai 1934)

(Late Miocene to Early Pleistocene)

Nopcsa's Snapping Turtle

Romania, Hungary, Slovakia, Poland, Germany, Ukraine Size: CL ca. $70 \mathrm{~cm}$

Trionyx nopcsai $\uparrow$ Szalai 1934:134 (partim) [Miocene, Tataros, Bihar, Hungary (now = Brusturi, Bihor, Transylvania, Romania)], Chelydropsis nopcsai

Macrocephalochelys pontica $\uparrow$ Pidoplichko and Tarashchuk 1960:105 [Plio-Pleistocene boundary, Ukraine], Chelydropsis pontica

Chelydra strausi Schmidt 1966:25 [Late Pliocene, Willershausen, Lower Saxony, Germany], Chelydra straussi, Chelydropsis strausi

Comment: The type material consisted of a lower jaw fragment later identified by Młynarski (1966) as a chelydrid and some carapacial bones of a trionychid (Farkas
1995). Further discussed by Hutchison (2008). Karl et al. (2012) synonymized $C$. strausi with $C$.nopscai .

\section{_Testudinoidea Fitzinger 1826}

\section{EMYdidae Rafinesque 1815}

\section{Deirochelyinae Agassiz 1857}

Graptemys Agassiz 1857

Graptemys kerneri Ehret and Bourque 2011

(Late Pleistocene, until ca. 15,000 ybp)

Kerner's Map Turtle

USA (Florida)

Size: CL ca. $30 \mathrm{~cm}$

Graptemys kerneri $\uparrow$ Ehret and Bourque 2011:578

[Late Pleistocene, Rancholabrean, USA (Flori-

da)], Rare Earth Elements age: ca. 15,000 ybp

Comment: Described as being most similar to the broadheaded extant Graptemys barbouri. The species exhibiting sexual dimorphism, with females much larger than males, and represents the furthest southeastern distribution of the genus. Jackson (1975) previously described Pleistocene specimens of this taxon that he referred to Graptemys cf. G. barbouri.

Pseudemys Gray 1856a

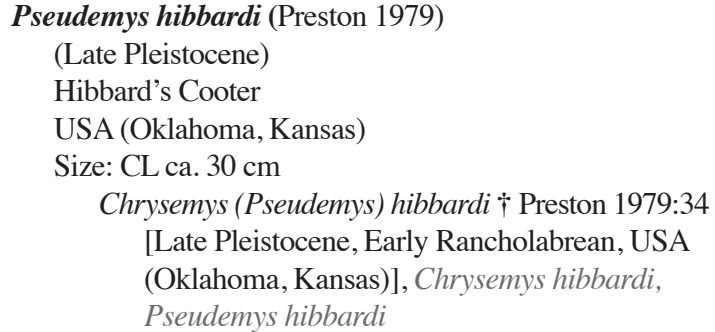

Comment: Holman $(1991,1995)$ questioned the validity of this species, indicating that it appeared similar to extant $P$. concinna and $P$. floridana, and recommended that it be considered a "species inquirendae" (a nomen dubium).

\section{Trachemys Agassiz 1857}

Trachemys idahoensis (Gilmore 1933)

(Late Pliocene to Early Pleistocene)

Idaho Slider

USA (Idaho, Kansas, Nebraska, Texas)

Size: CL ca. $>30 \mathrm{~cm}$

Pseudemys idahoensis Gilmore 1933:1 † [Late

Pliocene-Early Pleistocene, Blancan, Glenns

Ferry Formation, USA (Idaho)], Trachemys

idahoensis

Comment: The original generic assignment by Gilmore (1933) was uncertain as to whether this taxon was a Pseudemys, Chrysemys, or Graptemys. Weaver and Robertson (1967) suggested it was closest to extant Pseudemys rubriventris, but Zug (1969), based on additional material, concluded it was more similar to extant Trachemys scripta. Jackson (1988) concluded that the taxon was a Trachemys rather than a Pseudemys and that 
T. idahoensis and T. platymarginata (see below) were synonymous. Joyce et al. (2013) placed "Pseudemys" idahoensis as more closely related to extant Graptemys than to Trachemys, but its generic relationships remain uncertain.

Trachemys platymarginata (Weaver and Robertson 1967)

(Late Pliocene to Early Pleistocene)

Florida Slider

USA (Florida)

Size: CL ca. $35 \mathrm{~cm}$

Chrysemys platymarginata $\dagger$ Weaver and Robertson 1967:58 [Late Pliocene-Early Pleistocene, Blancan, USA (Florida)], Trachemys platymarginata

Comment: Jackson (1988) synonymized this species with Trachemys idahoensis, but Bourque (unpubl. data) notes that it is quite distinctive and represents a separate species.

Emydinae Rafinesque 1815

Emys Duméril 1805

Emys antiqua Khosatzky 1956

(Early Pliocene to Early Pleistocene)

Ancient European Pond Turtle

Russia, Ukraine, Moldavia

Size: CL ca. $20 \mathrm{~cm}$.

Emys orbicularis antiqua $\dagger$ Khosatzky 1956:325

[Early Pliocene, Kosyakino, Stavropol, Russia], Emys antiqua, Emydoidea antiqua

Emys semjonovi † Chkhikvadze 1983:57 [Late Pliocene to Early Pleistocene, Kotlovina, Odessa, Ukraine]

Mauremys salčiensis $\dagger$ Redkozubov 1988:74

[Pleistocene, Salchiya, Moldavia], Mauremys salciensis, Emys salciensis

Comment: Originally described as a subspecies, this taxon was elevated to a species by Khosatzky (1982). Chkhikvadze (1983) referred it to Emydoidea, but Fritz (1995b) returned it to Emys as a subspecies (E. o. antiqua) and synonymized Clemmys mehelyi Kormos 1911 and Emys semjonovi Chkhikvadze 1983 with it. Later, Fritz and Farkas (1996) assigned Clemmys mehelyi to Clemmydopsis (see below). Here we list the taxon as a species and also place Mauremys salciensis Redkozubov 1988 into its synonymy (Danilov, unpubl. data), although Chkhikvadze (2007) recognized salciensis as a separate species of Emys. Emys antiqua may represent a chronospecies or paleospecies precursor to modern Emys orbicularis.

\section{_GEOEMYDIDAE Theobald 1868}

\section{GeoemydinaE Theobald 1868}

\section{Clemmydopsis Boda 1927}

Clemmydopsis Boda 1927:375

Comment: Subfamilial placement of this genus is unclear; in some recent works (Hervet 2004, 2006) it is included in the family Ptychogasteridae along with Echmatemys, Geiselemys, Hummelemys, and Ptychogaster.
Clemmydopsis mehelyi (Kormos 1911)

(Late Pliocene to Early Pleistocene)

Mehely's Pond Turtle

Hungary, Austria, France

Size: undetermined

Clemmys mehelyi $\uparrow$ Kormos 1911:506 [Late

Pliocene or Early Pleistocene, Süttö, KomáromEsztergom, Hungary], Clemmydopsis mehelyi

Clemmydopsis sopronensis $\dagger$ Boda 1927:375

[Late Pliocene or Early Pleistocene, Hungary], Geoemyda sopronensis

Comment: Fritz and Farkas (1996) reassessed C. mehelyi and resurrected it from its previous synonymy under either extant Emys orbicularis or Mauremys caspica, assigning it to Clemmydopsis and also synonymizing C. sopronensis with $C$. mehelyi. Gross (2004) suggested that $C$. sopronensis was distinct from C. mehelyi.

Cuora Gray 1856a

Cuora miyatai (Shikama 1949)

(Middle Pleistocene)

Japanese Box Turtle

Japan (Honshu, Kyushu)

Size: CL ca. $12 \mathrm{~cm}$

Cyclemys miyatai $\uparrow$ Shikama 1949:179 [Middle Pleistocene, Middle Kuzuüan, Japan (Honshu, Kyushu)], Cuora miyatai

Cyclemys akiyoshiensis $\uparrow$ Shikama and Okafuji 1964:59 [Middle Pleistocene, Lower Isa Bed (Lower Kuzuüan), Choukoutienian, Japan (Honshu)]

Comment: Hasegawa and Ota (1980) synonymized $C$. akiyoshiensis with $C$. miyatai. The species was likely terrestrial and most closely related to modern Cuora flavomarginata, as discussed by Hasegawa (1981), but the two are clearly morphologically differentiated (Hirayama 2007).

\section{Cuora tungia (Yeh 1963b)}

(Early Pleistocene)

Liucheng Box Turtle

China (Guangxi)

Size: CL ca. $14-15 \mathrm{~cm}$

Testudo tungia $\uparrow$ Yeh 1963b:224 [Early Pleistocene, China (Guangxi: Liucheng, Liuzhou)], Cuora tungia

Comment: Described as a testudinid from a shell from Early Pleistocene deposits in a cave possibly used by Homo erectus and also associated with Gigantopithecus blacki, a giant ape that went extinct about 100,000 ybp. Referred instead to the geoemydid genus Cuora by Auffenberg (1974). The species was reassessed by Naksri et al. (2014), who verified its taxonomic distinction from other extant Cuora and the Japanese Pleistocene $C$. miyatai, while noting that it was most closely related to $C$. flavomarginata. They also concluded that the species was terrestrial based on its high-domed shell morphology. The specific epithet tungia is derived from the Chinese word for "cave". 
Geoemyda Gray 1834b

Geoemyda amamiensis Takahashi, Kato, and Ota 2007

(Late Pleistocene)

Amami Leaf Turtle

Japan (Ryukyu Archipelago)

Size: CL ca. 6-12 cm

Geoemyda amamiensis $\uparrow$ Takahashi, Kato, and Ota 2007:3 [Late Pleistocene, Tokunoshima

Formation, Japan (Tokunoshima Island, Amami Group, Ryukyu Archipelago)]

Comment: This species was probably terrestrial and is most closely related to modern Geoemyda japonica, a terrestrial species that occurs in the Ryukyu Archipelago.

\section{Mauremys Gray 1869b}

Mauremys alekperovi Chkhikvadze 1989

(Early Pleistocene)

Azerbaijan

Size: CL ca. $25-28 \mathrm{~cm}$.

Mauremys alekperovi $\dagger$ Chkhikvadze 1989:27

[Early Pleistocene, Kushkuna, Azerbaijan], Mauremys alekperovi

\section{Mauremys etrusca (Portis 1890)}

(Late Pliocene to Middle Pleistocene?)

Etruscan Pond Turtle

Italy

Size: CL ca. $16 \mathrm{~cm}$

Emys aniensis $\dagger$ Indes 1869:16 (nomen nudum and nomen dubium) [Middle Pleistocene, Rome, Italy]

Emys etrusca $\uparrow$ Portis 1890:12 [Late Pliocene to Early Pleistocene, Villafranchian, Italy], Emys (Ocadia) etrusca, Mauremys etrusca

Comment: Rook et al. (2013) recognized this species as valid and distinct, citing a reassessment by Chesi (2009) in an unpublished thesis. Chesi et al. (2007) described a Late Pleistocene Mauremys sp. from Sardinia that may also represent this taxon, or an undescribed form, or possibly a fossil of extant Mauremys leprosa or M. rivulata.

Mauremys fenhoense (Chow 1961)

(Early Pleistocene)

Fen River Turtle

China (Shanxi)

Size: CL ca. $17 \mathrm{~cm}$

Chinemys fenhoense $\uparrow$ Chow 1961:426 [Early Pleistocene, Nihewan Formation, China (Shanxi)], Mauremys fenhoense

\section{Mauremys gaudryi (Depéret 1885)}

(Late Pliocene to Early Pleistocene)

Gaudry's Pond Turtle

France, Italy

Size: CL ca. $22 \mathrm{~cm}$

Emys gaudryi $\uparrow$ Depéret 1885:117 [Pliocene,

France], Clemmys gaudryi, Clemmys (Ocadia) gaudryi, Mauremys gaudryi

Comment: Early Pleistocene occurrence of this species in Italy was noted by Chesi et al. (2009).
Mauremys isoclina (Dubois 1908)

(Early Pleistocene)

Trinil Pond Turtle

Indonesia (Java)

Size: CL ca. $31 \mathrm{~cm}$

Hardella isoclina $\dagger$ Dubois 1908:1270 [Early Pleistocene, Trinil Beds, Indonesia (Java)], Clemmys isoclina, Mauremys isoclina

Comment: Redescribed and reassessed as Clemmys by Williams (1957), treated as Mauremys by Das (1997) and Hoogmoed et al. (2010). However, its generic allocation needs further reassessment owing to the presence of several morphological differences from Mauremys (Karl and Philippen, Takahashi, unpubl. data). The species is a component of the Trinil HK Fauna (e.g., Joordens et al. 2009), considered to be $1,500,000$ to 900,000 ybp in age.

Mauremys nipponica (Hirayama, Kaneko, and Okazaki 2007)

(Middle to Late Pleistocene)

Nipponese Pond Turtle

Japan (Honshu)

Size: CL ca. $33 \mathrm{~cm}$

Ocadia nipponica $\dagger$ Hirayama, Kaneko, and Okazaki 2007:3 [Middle Pleistocene, Kiyokawa Formation, Shimosa Group, ca. 220,000 ybp, Japan (Honshu)], Mauremys nipponica

Comment: Hirayama and Isaji (2010) mentioned occurrences of this taxon from the Early to Late Pleistocene of Honshu (Late Pleistocene of Kanagawa and Shizuoka, Honshu [Hasegawa et al. 2007], and Early Pleistocene of Hyogo, Ishikawa, and Osaka of Honshu, and Nagasaki of Kyushu [Hirayama, unpubl. data]). However, these materials have not been adequately described and conspecificity with $M$. nipponica is uncertain.

Mauremys yabei (Shikama 1949)

(Middle to Late Pleistocene)

Yabe's Pond Turtle

Japan (Honshu)

Size: CL ca. $22 \mathrm{~cm}$

Clemmys yabei $\uparrow$ Shikama 1949:169 [Late Pleistocene, Upper Kuzuü Formation, Japan (Honshu)], Mauremys yabei

Comment: Hirayama and Isaji (2010) reported occurrence of this species from the Middle Pleistocene, Kiyokawa Formation (ca. 220,000 ybp), Honshu, Japan.

Melanochelys Gray 1869a

Melanochelys etuliensis Khosatzky and Redkozubov 1986 (Early Pliocene to Early Pleistocene)

Etulia Pond Turtle

Moldavia

Size: CL ca. $25 \mathrm{~cm}$.

Melanochelys etuliensis $\dagger$ Khosatzky and Redkozubov 1986:74 [Early Pliocene, Etulia, Moldavia], Sakya etuliensis, Sarmatemys etuliensis Comment: Late Pliocene to Early Pleistocene material of this species was also reported from Salchiya, Moldavia, by Redkozubov (1994). Generic placement uncertain, sometimes referred to as "Melanochelys". 
Melanochelys mossoczyi (Młynarski 1964)

(Late Miocene to Early Pleistocene)

Mossoczy's Pond Turtle

Poland, Moldavia, Russia, Slovakia, Ukraine, Germany Size: CL ca. $20 \mathrm{~cm}$

Geoemyda mossoczyi $\uparrow$ Młynarski 1964:335 [Pliocene to Lower Pleistocene, Poland)], Geoemyda (Heosemys) mossoczyi, Sakya mossoczyi, Clemmydopsis mossoczyi, Melanochelys mossoczyi

Geoemyda (Heosemys) boristhenica $\uparrow$ Tarashchuk 1971:56 [Middle to Late Pliocene, Ukraine]

Geoemyda (Heosemys) mossoczyi wetterauensis $\dagger$ Karl 1983:375 [Late Pliocene, Wetterau, Hesse, Germany], Melanochelys mossoczyi wetterauensis

Comment: Lapparent de Broin (2001) indicated that this taxon from the Plio-Pleistocene boundary might be referred to either Sakya Bogachev 1960 or Clemmydopsis Boda 1927. It was referred to Melanochelys by Chkhikvadze (1989) and Danilov et al. (2012, 2013). Generic placement uncertain, sometimes referred to as "Melanochelys". The Late Pliocene taxa Geoemyda boristhenica and Geoemyda wetterauensis may or may not be distinct, but are tentatively listed for now as synonyms under M. mossoczyi.

Melanochelys pidoplickoi (Khosatzky 1946)

(Early Pliocene to Early Pleistocene?)

Pidoplichko's Pond Turtle

Ukraine, Moldavia, Russia

Size: CL ca. $20 \mathrm{~cm}$

Clemmys pidoplickoi $\uparrow$ Khosatzky 1946:617 [Early

Pliocene, Kuchurgan, Ukraine], Geoemyda

pidoplickoi, Melanochelys pidoplickoi, Clemmys pidoplickai, Melanochelys pidoplickai, Geoemyda (Spinemys) pidoplickai, Melanochelys pidoplichkoi

Comment: The following fossil taxa have sometimes been synonymized with this species: Geoemyda mossoczyi Młynarski 1964, Clemmys malustensis Macarovici and Vancea 1960, and Geoemyda (Heosemys) boristhenica Tarashchuk 1971 (Khosatzky and Redkozubov 1989). This species was used as a type for the subgenus Geoemyda (Spinemys) by Khosatzky and Młynarski (1966a). Undescribed material of this species was reported from the Late Pliocene to Early Pleistocene Kotlovina locality of Ukraine by Chkhikvadze (1983). The species name was unjustifiably emended twice: first from pidoplickoi to pidoplickai (Telepneva 1964), and then to pidoplichkoi (Chkhikvadze 2007). Generic placement uncertain, sometimes referred to as "Melanochelys".

Melanochelys sinhaleyus Deraniyagala 1953

(Late Pleistocene)

Sinhalese Pond Turtle

Sri Lanka

Size: CL ca. $35-40 \mathrm{~cm}$

Melanochelys trijuga sinhaleyus $\uparrow$ Deraniyagala 1953:4 [Late Pleistocene, Ratnapura Beds, Sri Lanka], Geoemyda trijuga sinhaleya, Melanochelys sinhaleyus

Comment: This taxon was described from fragmentary carapacial material showing slight differences from modern
Melanochelys trijuga parkeri. Taxonomic distinction is uncertain, but we list it pending further analysis.

Pangshura Gray 1856b

Pangshura tatrotia Joyce and Lyson 2010

(Late Pliocene to Early Pleistocene)

Tatrot Pond Turtle

Pakistan

Size: CL ca. $27 \mathrm{~cm}$

Pangshura tatrotia $\dagger$ Joyce and Lyson 2010:451

[Late Pliocene, Tatrot, Siwaliks, Pakistan)]

Comment: Stratigraphically noted to be from the Tatrot

Formation at an age of between $3,590,000$ to $2,590,000$ ybp, possibly placing it at the Plio-Pleistocene boundary. The species is most closely related to extant Pangshura tecta.

Sakya Bogachev 1960

Sakya Bogachev 1960:88

Sakya riabinini (Khosatzky 1946)

(Late Miocene to Early Pleistocene)

Riabinin's Pond Turtle

Ukraine, Moldavia, Russia

Size: CL ca. $27 \mathrm{~cm}$

Clemmys riabinini $\uparrow$ Khosatzky 1946:617 [Early Pliocene, Kuchurgan, Ukraine], Sakya riabinini, Geoemyda (Spinemys) riabinini

Sakya pontica $\uparrow$ Bogachev 1960:1988 [Late Miocene, Naumovka, Crimea, Russia]

Comment: Sakya pontica was synonymized with Clemmys riabinini by Chkhikvadze (1983). However, Lapparent de Broin (2001) considered S. pontica to be a valid taxon. Late Pliocene to Early Pleistocene material of this species was reported from Salchiya, Moldavia, by Redkozubov (1994).

Rhinoclemmydinae Le and McCord 2008

Rhinoclemmys Fitzinger 1835

Rhinoclemmys nicoyana Acuña-Mesen and LauritoMora 1996

(Late Pleistocene)

Nicoya Wood Turtle

Costa Rica

Size: CL ca. 31-32 cm

Rhinoclemmys nicoyana $\dagger$ Acuña-Mesen and Laurito-Mora 1996:271 [Late Pleistocene, Costa Rica]

\section{Testudinidae Batsch 1788}

Aldabrachelys Loveridge and Williams 1957

Aldabrachelys abrupta (Grandidier 1868)

(Late Holocene, until ca. 1200 AD, 750 ybp)

Madagascar Giant Tortoise

Madagascar

Size: CL ca. $115 \mathrm{~cm}$

Testudo abrupta $\uparrow$ Grandidier 1868:377 [Late Holocene, Madagascar] ${ }^{14} \mathrm{C}$ age: $750 \pm$ 
$370 \mathrm{ybp}, 1200 \mathrm{AD} \pm 370(830-1570 \mathrm{AD})$, calibrated age*: 1358-55 ybp (592-1895 AD), Geochelone abrupta, Asterochelys abrupta,

Dipsochelys abrupta, Aldabrachelys abrupta Comment: This species went extinct shortly after the first arrival of humans from continental Africa, who reached Madagascar approximately 2000 years ago (Pedrono 2008). Radiocarbon dating of bones from the species indicate a range of dates that suggest possible, but unlikely, persistence of occurrence into the very earliest part of the modern era, just after $1500 \mathrm{AD}$. Three uncalibrated ${ }^{14} \mathrm{C}$ aged specimens are known: 1) the youngest, at $750 \pm$ 370 ybp (ca. $1200 \mathrm{AD} \pm 370 \mathrm{yrs}=830-1570$ AD; Burleigh and Arnold 1986); 2) an intermediate specimen, $1910 \pm 120 \mathrm{ybp}(\mathrm{ca} .40 \mathrm{AD} \pm 120 \mathrm{yrs}=80 \mathrm{BC}-160 \mathrm{AD}$; Mahé and Sourdat 1972); and 3) the oldest, at $2035 \pm$ $35 \mathrm{ybp}$ (ca. $85 \mathrm{BC} \pm 35 \mathrm{yrs}=120-50 \mathrm{BC}$; Burleigh et al. 1982). The calibrated ages for these three specimens, respectively, calculate as: 1) 592-1895 AD [less precise range due to younger age]; 2) $197 \mathrm{BC}-390 \mathrm{AD}$; and 3) $163 \mathrm{BC}-52 \mathrm{AD}$. Although it is conceivable that the youngest of these specimens was from a tortoise that actually lived in the 1500 s or later, this is unlikely, and we assume that the species probably went extinct sometime between 1200 and $1300 \mathrm{AD}$. The skull was redescribed by Gerlach (2008), who noted also that this species was apparently sympatric with $A$. grandidieri.

Aldabrachelys grandidieri (Vaillant 1885)

(Late Holocene, until ca. 884 AD, 1066 ybp)

Grandidier's Giant Tortoise

Madagascar

Size: CL ca. $125 \mathrm{~cm}$

Emys gigantea $\uparrow$ Grandidier in Milne-Edwards 1868:1167 [Late Holocene, Madagascar], Testudo gigantea

Testudo grandidieri $\uparrow$ Vaillant 1885:876 (nomen novum) [Late Holocene, Madagascar], ${ }^{14} \mathrm{C}$ age: $1250 \pm 50$ ybp (650-750 AD), calibrated age*: 1282-1066 ybp (668-884 AD), Geochelone grandidieri, Dipsochelys grandidieri, Aldabrachelys grandidieri, Megalochelys grandidieri

Testudo madagascariensis $\uparrow$ Rothschild 1915:pl.34 [Late Holocene, Madagascar]

Comment: This species went extinct shortly after the first arrival of humans from continental Africa, who reached Madagascar approximately 2000 years ago (Pedrono 2008). The most recent dated specimen recorded was from ca. $1250 \mathrm{ybp}$ (Burleigh and Arnold 1986).

\section{Aldabrachelys sp. [Glorieuse]}

(Late Pleistocene, until ca. 100,000 ybp)

Glorieuse Giant Tortoise

Glorieuse Islands (Grande Glorieuse)

Size: undetermined

Unidentified tortoise $\uparrow$ (Battistini and Cremers 1972) [Late Pleistocene, Karimbolian limestone inclusion fill, Cap Vert, Grande Glorieuse], Dipsochelys sp., Aldabrachelys sp.

Comment: Fragmentary fossil bones of giant tortoises have been excavated on uninhabited Glorieuse Island between Madagascar and Aldabra by Battistini and Cremers (1972). The bones were deposited in multiple areas of solution-hole inclusion fill in eroded Karimbolian reef limestone dated to ca. 125,000 ybp, but the inclusion fill with tortoise bones would be younger than the limestone, perhaps ca. 100,000 ybp, similar in age to tortoise bones on Aldabra in inclusion fill in Aldabra limestone (Taylor et al. 1979). These bones most likely represent a distinct insular giant tortoise of the genus $\mathrm{Al}$ dabrachelys, most likely closely related to extinct Madagascan taxa or extant A. gigantea from Aldabra (Bour 1994). There has also been some question as to whether extinct Aldabrachelys tortoises ever occurred in the Comoros (Anjouan and Mayotte islands) west of Glorieuse (Austin et al. 2003). Although Broin (1990) and Boivin et al. (2013) documented archaeological remains of transported specimens of extant Madagascan Astrochelys yniphora and Erymnochelys madagascariensis in human habitation sites on Mayotte dated from ca. 800-900 AD, no fossil Aldabrachelys have yet been confirmed to have occurred in the Comoros. Bour (1994) hypothesized that the Glorieuse tortoise went extinct as a result of sea level change and marine incursion (possibly at about 120,000-100,000 ybp) and that the island was not repopulated by tortoises after sea levels receded and the island re-emerged, as was the case at least twice in the last 125,000 years for Aldabra (Braithwaite et al. 1973; Taylor et al. 1979). Of note is that some fossils of Aldabrachelys from the Late Pleistocene of Aldabra appear to represent a different morphotype from extant A. gigantea (Bour 1994). A humerus from Point Hodoul inclusion deposits in the Aldabra limestone layer from ca. 100,000-80,000 ybp is quite different in appearance from fossil or extant A. gigantea (Bour 1994). We consider it possibly distinct from $A$. gigantea and perhaps reflective of one of the earlier iterations of tortoises appearing on Aldabra after a marine incursion and inundation (Braithwaite et al. 1973; Taylor et al. 1979; Bour 1988, 1994). Further analysis of this material is clearly needed.

“Aldabrachelys” laetoliensis (Meylan and Auffenberg 1987)

(Late Pliocene to Early Pleistocene)

Laetoli Giant Tortoise

Tanzania

Size: CL ca. $100 \mathrm{~cm}$

Geochelone (Aldabrachelys) laetoliensis $\uparrow$ Meylan and Auffenberg 1987:1167 [Late Pliocene,

Laetoli Beds, Olduvai Gorge, Tanzania], Geochelone laetoliensis, Aldabrachelys laetoliensis, Stigmochelys laetoliensis

Comment: This species was recorded from hominin habitation sites in Olduvai from about 3,800,000-2,600,000 ybp and was exposed to early human exploitation (Harrison 2011). This species has tentatively been assigned to both Aldabrachelys and Stigmochelys (to which it may be closer; F. Lapparent de Broin, pers. comm.), but further material and new analysis may well indicate that it belongs to a new genus.

Centrochelys Gray 1872b

Centrochelys atlantica (López-Jurado, Mateo, and García-
Márquez 1998)
(Pleistocene)
Sal Island Tortoise


Cape Verde (Sal)

Size: CL ca. $40 \mathrm{~cm}$

Geochelone atlantica $\dagger$ López-Jurado, Mateo, and

García-Márquez 1998:111 [Pleistocene (Middle Quaternary), Cape Verde (Sal: Pedra Lume crater)], Centrochelys atlantica

Comment: The occurrence of this taxon in the volcanic crater on Sal was first recorded by Chevalier et al. (1935) who identified it as comparable to extant Testudo calcarata (= Centrochelys sulcata) and assigned it to the Middle Quaternary in association with freshwater Phragmites, no longer present anywhere in the Cape Verde islands. López-Jurado et al. (1998) redescribed it as a new species differentiated from $C$. sulcata by its smaller size and lesser robusticity. There is no evidence of human contact with tortoises on Cape Verde in any early travel accounts.

Centrochelys burchardi (Ahl 1926)

(Middle Pleistocene, until ca. 200,000 ybp)

Tenerife Giant Tortoise

Canary Islands (Tenerife)

Size: CL ca. $80-95 \mathrm{~cm}$

Testudo burchardi $\uparrow$ Ahl 1926:575 [Middle Pleistocene, Canary Islands (Tenerife: Adeje)], Geochelone (Geochelone) burchardi, Geochelone burchardi, Centrochelys burchardi

Comment: Originally described as simply Tertiary in origin, later work by Bravo and Coello (1975) demonstrated that the strata from which these and other tortoise bones were recovered were actually from the Middle Pleistocene, ca. 670,000 to $200,000 \mathrm{ybp}$. This was also noted by Hutterer et al. (1998), who described fossil eggs of what was apparently this species.

Centrochelys marocana Gmira, Lapparent de Broin, Geraads, Lefèvre, Mohib, and Raynal 2013

(Late Pliocene to Early Pleistocene)

Moroccan Giant Tortoise

Morocco

Size: CL ca. 180-200 cm

Centrochelys marocana $\uparrow$ Gmira, Lapparent de Broin, Geraads, Lefêvre, Mohib, and Raynal 2013:715 [Late Pliocene, Casablanca, Morocco]

Centrochelys robusta (Adams 1877)

(Middle Pleistocene)

Maltese Giant Tortoise

Malta (Valletta)

Size: CL ca. $85 \mathrm{~cm}$

Testudo robusta $\uparrow$ Adams 1877:178 [Middle Pleistocene, Valletta, Malta], Geochelone (Geochelone) robusta, Geochelone robusta, Centrochelys robusta

Testudo spratti $\uparrow$ Adams 1877:186 [Middle Pleistocene, Valletta, Malta], Geochelone spratti, Centrochelys spratti

Testudo robustissima $\uparrow$ Tagliaferro 1914:77 [Middle Pleistocene, Valletta, Malta], Geochelone robustissima, Centrochelys robustissima

Comment: It is possible that this species will be referred to Titanochelon on the basis of the coeval and more informative remains of giant tortoises from Alcamo, Sicily
(Bonfiglio et al. 1999), that likely belong to this genus (Delfino, unpubl. data).

Centrochelys vulcanica (López-Jurado and Mateo 1993)

(Late Pliocene to Early Pleistocene?)

Gran Canaria Tortoise

Canary Islands (Gran Canaria)

Size: CL ca. $60-65 \mathrm{~cm}$

Geochelone vulcanica $†$ López-Jurado and Mateo 1993:109 [Late Pliocene, Canary Islands (Gran Canaria)], Centrochelys vulcanica

Comment: Though described as simply Pliocene in origin, earlier analysis by Hirsch and López-Jurado (1987) of fossil eggs of this presumed species (prior to its description) had concluded that it occurred in the Late Pliocene, between 4,500,00 and 3,500,000 ybp, as also further documented by Hutterer et al. (1998). Whether the species persisted into the Early Pleistocene remains undocumented, but we list it here as a possible PlioPleistocene boundary taxon.

\section{Chelonoidis Fitzinger 1835}

Chelonoidis alburyorum Franz and Franz 2009

(Late Holocene, until ca. 1110 AD, 840 ybp)

Abaco Tortoise; Albury's Tortoise

Bahamas

Size: CL ca. $47 \mathrm{~cm}$

Chelonoidis alburyorum $\uparrow$ Franz and Franz 2009:5

[Late Holocene, Bahamas (Abaco Island)], ${ }^{14} \mathrm{C}$ age: $960-910$ ybp (550-1040 AD), calibrated age: $920-780$ ybp (1170 AD)

Comment: Described from remarkably intact shells from an underwater sinkhole, with ${ }^{14} \mathrm{C}$ age of $2720-2580 \pm$ 50 ybp (820-580 BC); calibrated age: $2770-2500$ ybp (820-550 BC). Recent finds of charred fragments of this species from Lucayan Taíno culture middens in peat deposits at Gilpin Point, Abaco Island (Steadman et al. 2014; Hastings et al. 2014), are calculated to ${ }^{14} \mathrm{C}$ age of 960-910 ybp and 920-780 cal. ybp (ca. 1170 AD), shortly after the arrival of humans on Abaco at ca. $950 \mathrm{ybp}$. Other tortoise fragments from the Pleistocene or Holocene of Bahamas (Banana Hole on New Providence and on Andros), described by Auffenberg (1967a) as Geochelone sp., may represent the same species. At least two other similar undescribed species occur in the Bahamas region (Franz and Franz 2009).

Chelonoidis cubensis (Leidy 1868b)

(Pleistocene to Early Holocene)

Cuban Giant Tortoise

Cuba (Santa Clara)

Size: CL ca. $90 \mathrm{~cm}$

Testudo cubensis $\uparrow$ Leidy 1868b:179 [Pleistocene, Cuba (Ciego-Montero, Cienfuegos, Santa Clara)], Testudo (Chelonoidis) cubensis, Geochelone cubensis, Hesperotestudo cubensis, Chelonoidis cubensis

Comment: Redescribed by Williams (1950). Auffenberg (1967a) discussed this species; Meylan and Sterrer (2000) treated it as Chelonoidis. Karl (1995) described fosssils of smaller (CL ca. $40 \mathrm{~cm}$ ) individuals of what might be this species from Late Pleistocene to Early 
Holocene deposits in San José de la Lamas, La Habana; this population apparently went extinct through human exploitation.

Chelonoidis lutzae Zacarías, de la Fuente, Fernández, and Zurita 2013

(Late Pleistocene, ca. 55,000 to 22,000 ybp)

Lutz's Giant Tortoise

Argentina (Corrientes)

Size: CL ca. $83 \mathrm{~cm}$

Chelonoidis lutzae $†$ Zacarías, de la Fuente,

Fernández, and Zurita 2013:306 [Late

Pleistocene, Lujanian, Argentina (Corrientes)]

Comment: According to Zacarías et al. (2013) the strict consensus tree showed a polytomy among $C$. lutzae, $C$. gallardoi, and $C$. australis, and the extant and extinct species of the clades for $C$. chilensis and $C$. carbonaria. Using the pruned tree option of phylogenetic analysis, $C$. lutzae and C.australis were recovered as a monophyletic clade.

Chelonoidis monensis (Williams 1952)

(Late Pleistocene to Late Holocene, possibly until ca. $1050 \mathrm{BC}, 3000 \mathrm{ybp}$ )

Mona Tortoise

USA (Puerto Rico: Mona Island)

Size: CL ca. $50 \mathrm{~cm}$

Testudo (Monachelys) monensis $\dagger$ Williams 1952:547 [Pleistocene, USA, Puerto Rico (Mona Island)], Testudo monensis, Geochelone (Monachelys) monensis, Geochelone monensis, Monachelys monensis, Chelonoidis monensis, Chelonoidis (Monachelys) monensis

Comment: Mona Island is small and isolated, halfway between the larger islands of Hispaniola and Puerto Rico. Stone tools found on Mona date back to ca. 3000 ybp. An ancient cave drawing representing what appears to be a tortoise (not a sea turtle) also occurs there, suggesting the possibility that the species may have survived until early humans arrived (see http://blog.britishmuseum.org/2013/07/09/new-discoveries-of-cave-art-in-thecaribbean/; Jago Cooper, unpubl. data).

Chelonoidis sombrerensis (Leidy 1868b)

(Late Pleistocene)

Sombrero Giant Tortoise

Anguilla (Sombrero Island)

Size: CL ca. $90-100 \mathrm{~cm}$

Emys sombrerensis $\uparrow$ Leidy 1868b:180 [Late

Pleistocene, guano deposits, Anguilla (Sombrero Island)], Testudo sombrerensis, Testudo

(Geochelone) sombrerensis, Geochelone sombrerensis, Geochelone (Chelonoidis) sombrerensis, Chelonoidis sombrerensis

Comment: Julien (1878) provided additional details on the original material, and Auffenberg (1967a) described more recently collected material.

\section{Chelonoidis sp. [Caicos]}

(Late Holocene, until ca. 1200-550 ybp, ca. 750-1400 AD)

Caicos Giant Tortoise

Turks and Caicos (Middle Caicos Island)

Size: CL ca. 60-90 cm
Geochelone sp. $\dagger$ (Franz et al. 2001) [Late Holocene, subfossil, Turks and Caicos (Middle Caicos Island: Indian Cave)]

Comment: The Caicos tortoise bones were associated with human habitation, including Meillac style pottery dated to ca. 1200-500 ybp. Many of the bones were charred, indicating they had been consumed. Franz et al. (2001) hypothesized that the species had been extirpated by human predation in the late pre-Columbian historic period. The Caicos Islands are separated from the Turks Islands by a deep strait and were never connected, even during the last glacial maximum at the end of the Pleistocene.

\section{Chelonoidis sp. [Turks]}

(Late Holocene, until ca. 1200 AD)

Turks Tortoise

Turks and Caicos (Grand Turk Island)

Size: CL ca. $35-40 \mathrm{~cm}$

Geochelone sp. $\dagger$ (Carlson 1999:82) [Late Holocene, subfossil, Turks and Caicos (Grand Turk Island: Coralie)]

Comment: This undescribed but distinct small tortoise species appears closely related to C. alburyorum, but is only about half its size (Carlson 1999; R. Franz, pers. comm.). Charred tortoise bones have been found in conjunction with an early Taíno habitation site at Coralie that was occupied from ca. 705 to 1170 AD (Carlson 1999; Franz et al. 2001). No tortoise bones have been found in later habitation sites on the island (Carlson 1999). The Turks Islands are separated from the Caicos Islands by a deep strait and were never connected, even during the last glacial maximum at the end of the Pleistocene.

\section{Chelonoidis sp. [Navassa]}

(Late Pleistocene)

Navassa Tortoise

USA Territory: Navassa Island

Size: CL ca. $40 \mathrm{~cm}$

Geochelone sp. $\dagger$ (Auffenberg 1967a) [Late Pleistocene, USA Territory: Caribbean, Navassa Island)]

Comment: Navassa Island, between Hispaniola and Jamaica, is very small and isolated, and also had an endemic iguana (Cyclura onchiopsis) that apparently went extinct through human exploitation.

\section{Chelonoidis sp. [Hispaniola]}

(Late Pleistocene to Early Holocene?)

Hispaniola Tortoise

Dominican Republic

Size: CL ca. $60 \mathrm{~cm}$

Geochelone sp. $\uparrow$ (Franz and Woods 1983) [Late Pleistocene to Early Holocene?, Dominican Republic (San Cristobal: Los Haitises)]

Comment: Specimens were found in a cave and were not dated. Similar deposits on Hispaniola have been dated from ca. 20,000 to less than 10,000 ybp (Franz and Woods 1983).

\section{Chelonoidis sp. [Curaçao] \\ (Middle to Late Pleistocene) \\ Curaçao Giant Tortoise}


Curaçao

Size: CL ca. $80 \mathrm{~cm}$

Geochelone sp. $\dagger$ (Hooijer 1963) [Pleistocene, Curaçao]

Comment: Hooijer (1963) described two humeri and a femur from a giant tortoise species from depositional fissures in two separate Pleistocene cave sites (San Pedro and Tafelberg Santa Barbara) in fossil coral reef terraces on the island of Curaçao. He noted that they were similar to extant tortoises from the Galápagos, but differentiated from the fossil Caribbean tortoises known at the time (C. cubensis, $C$. monensis, and $C$. sombrerensis) and estimated that the animals had carapace lengths of ca. 60,75 , and $80 \mathrm{~cm}$. Associated extinct rodent bones (Megalomys curazensis) from the cave at San Pedro (in the second-highest reef terrace on Curaçao, at ca. 55 $\mathrm{m}$ above current sea level) have since been inferred as being of late Middle Pleistocene origin, ca. 400,000 to 130,000 ybp (McFarlane and Lundberg 2002). The second cave at Tafelberg Santa Barbara (in the highest reef terrace at ca. $160 \mathrm{~m}$ above current sea level) has not been dated. However, although this high-level reef terrace was formed earlier than the lower one (Muhs et al. 2012), it was never inundated again, and fissure deposits in the cave also contained bones from two recently occurring rodent species: one that was extirpated from Curaçao in approximately the 1500s AD (Oryzomys curasoae $=O$. gorgasi), and, in the most superficial depositional layers, black rats (Rattus rattus) that were introduced with first European contact in 1499 AD (McFarlane and Debrot 2001). As such, this second site includes deposits extending into Modern times. It is unclear from what layer within these deposits the tortoise bones were found, but presumably at least as recently as the Late Pleistocene. Although relatively close to the northern shore of Venezuela, Curaçao has been an isolated island since at least the Tertiary (McFarlane and Debrot 2001), and based on Hooijer's description and the currently known zoogeography of Chelonoidis species (Franz and Franz 2009), we tentatively recognize this taxon as distinct. Hopefully more material will be found and analyzed.

\section{Chelonoidis spp. incertae}

Other materials of Pleistocene tortoises of this genus have also been found on other Caribbean islands (see map, Fig. 13). Very limited fragmentary material has been found on Barbados ("Geochelone sp.", CL ca. $60 \mathrm{~cm}$; Ray 1964) and Anguilla ("Tortoise cf. Geochelone carbonaria", CL ca. 46 cm; Lazell 1993). More extensive material has been found on Andros, New Providence, and Eleuthera on Great Bahama Bank in the Bahamas ("Geochelone sp.", CL ca. 60 cm; Auffenberg 1967a; "Chelonoidis sp."; Franz and Franz 2009). Pleistocene specimens referable to Chelonoidis sp. have also been collected from San Salvador Bank (Olson et al. 1982), as well as CrookedAcklins Bank and Mayaguana Bank (Franz and Franz 2009), plus an apparently older and larger giant tortoise species from Abaco Island, preceding C. alburyorum (Franz and Albury, unpubl. data). How many distinct taxa are involved remains to be determined, and we have not at this time included these separate insular populations in our count of apparently valid taxa. However, since most tortoises on isolated islands represent separate species, there has likely been more tortoise diversity in the Caribbean. Indeed, the situation in the Bahamas region suggests that different species inhabited different banks of island groups that were exposed and connected during the last glacial maximum ca. 21,000 ybp (see map in Olson and Pregill 1982), but separated by deep oceanic channels. Chelonoidis alburyorum occurred on Abaco, on Little Bahama Bank; the Chelonoidis sp. on nearby Great Bahama Bank (Andros, New Providence, and Eleuthera) was very similar, perhaps representing the same species or perhaps a paleosubspecies (R. Franz, pers. comm.). The taxa from Caicos Bank and the separate Turks Bank are recognized as distinct but unnamed (Franz and Albury, unpubl. data). The other unidentified taxa from other banks need further analysis and hopefully additional material to better elucidate their relationships.

Gopherus Rafinesque 1832

Gopherus donlaloi Reynoso and Montellano-Ballesteros 2004

(Late Pleistocene)

Don Lalo's Gopher Tortoise

Mexico (Tamaulipas)

Size: CL ca. $58 \mathrm{~cm}$

Gopherus donlaloi $\uparrow$ Reynoso and MontellanoBallesteros 2004:823 [Late Pleistocene, Rancholabrean, Mexico (Tamaulipas)]

Comment: Reynoso and Montellano-Ballesteros (2004) regarded this taxon as most closely related to extant $G$. polyphemus and extinct $G$. pertenuis (but used the junior synonym $G$. canyonensis).

Gopherus pargensis Mooser 1980

(Middle Pleistocene)

Cedazo Gopher Tortoise

Mexico (Aguascalientes)

Size: undetermined

Gopherus pargensis $\uparrow$ Mooser 1980:65 [Middle

Pleistocene, Cedazo local fauna, Mexico

(Aguascalientes)]

Comment: Reynoso and Montellano-Ballesteros (2004) regarded this taxon as a nomen vanum and felt that it was not diagnosable, but did not formally synonymize it. We list it tentatively.

Gopherus laticaudatus (Cope 1893)

(Middle to Late Pleistocene)

Broad-tailed Gopher Tortoise

USA (Texas)

Size: CL ca. $35-40 \mathrm{~cm}$

Testudo laticaudata $\uparrow$ Cope 1893:75 [Late Pleistocene, Early Rancholabrean, USA (Texas)], Geochelone laticaudata, Gopherus laticaudatus, Gopherus laticaudata

Testudo hexagonata $†$ Cope 1893:77 [Middle Pleistocene, Irvingtonian, USA (Texas)], Gopherus hexagonatus, Gopherus hexagonata Comment: Auffenberg (1974) listed both Gopherus laticaudatus and G. hexagonatus as valid, but suggested 
that they were probably synonymous. Preston (1979) reassessed the taxa and synonymized $G$. hexagonatus under G. laticaudatus. Reynoso and Montellano-Ballesteros (2004) instead synonymized G. laticaudatus under $G$. hexagonatus, and referred to the taxon as an undiagnosable nomen vanum, but did not formally synonymize it. The name laticaudata has page and usage priority over hexagonata and was chosen by Preston (1979) as the valid name in his revision, and is therefore the valid name for this taxon. Whether it is distinct or synonymous with other Gopherus sp. remains unresolved, and we list it tentatively.

Gopherus pertenuis (Cope 1892b)

(Early Pleistocene)

Texas Giant Gopher Tortoise

USA (Arizona, Texas)

Size: CL ca. $105-110 \mathrm{~cm}$

Testudo pertenuis $\dagger$ Cope 1892b:228 [Early

Pleistocene, Blancan, USA (Texas)], Gopherus pertenuis

Bysmachelys canyonensis $\uparrow$ Johnston 1937:440

[Early Pleistocene, Late Blancan, USA (Texas)],

Gopherus canyonensis

Comment: Cope (1892b) described G. pertenuis as the largest tortoise then known in North America, the very thin $(6-7 \mathrm{~mm})$ shell measuring 3.5 feet $(107 \mathrm{~cm})$ in length. Auffenberg (1974) recognized G. pertenuis as distinct, and Preston (1979) agreed, adding G. canyonensis (Johnston 1937) to its synonymy. Bramble (1982) agreed that $G$. canyonensis and $G$. pertenuis were synonymous, but used the junior synonym $G$. canyonensis, as did Reynoso and Montellano-Ballesteros (2004) and Bramble and Hutchison (2014). However, Cope's name G. pertenuis has nomenclatural priority over G. canyonensis and is not a nomen oblitum; we therefore resurrect it here.

\section{Gopherus sp. [Florida]}

(Late Pliocene to Early Pleistocene, until ca. 1,900,000 ybp)

Inglis Gopher Tortoise

USA (Florida)

Size: CL ca. 18-26 cm

Gopherus cf. polyphemus $\uparrow$ Franz and Quitmyer 2005:185 [Late Pliocene (= Early Pleistocene), Late Blancan, USA (Inglis, Citrus County, Florida)]

Comment: This small Gopherus taxon was described from a Late Blancan site dated at ca. 1,900,000 ybp. It was described as distinct and much smaller than the closely related extant $G$. polyphemus, as was also noted by Franz (2014).

Hesperotestudo Williams 1950

Eupachemys Leidy 1877 (nomen oblitum)

Hesperotestudo Williams 1950:25

Caudochelys Auffenberg 1963:69

Hesperotestudo annae (Hay 1923)

(Early Pleistocene)

Ann's Tortoise

USA (Texas)
Size: undetermined

Testudo annae $\dagger$ Hay 1923:114 [Early Pleistocene, Irvingtonian, USA (Texas)], Geochelone annae, Geochelone (Caudochelys) annae, Hesperotestudo (Caudochelys) annae

Testudo francisi $\dagger$ Hay 1923:116 [Early Pleistocene, USA (Texas)], Geochelone (Caudochelys) francisi, Hesperotestudo (Caudochelys) francisi

Comment: These two taxa (H. annae and $H$. francisi) are sometimes synonymized under $H$. crassiscutata, but Auffenberg (1974) recognized them both as distinct though similar to $H$. crassiscutata, and Franz (unpubl. data) tentatively recognizes both as valid.

Hesperotestudo bermudae Meylan and Sterrer 2000

(Middle Pleistocene, until ca. 310,000 ybp)

Bermuda Tortoise

Bermuda

Size: CL ca. $50 \mathrm{~cm}$

Hesperotestudo bermudae $\uparrow$ Meylan and Sterrer 2000:51 [Middle Pleistocene, Bermuda], ca. $310,000 \mathrm{ybp}$

Comment: This species is hypothesized to have originally reached Bermuda by oceanic drifting or rafting from southeastern North America. A second specimen of this tortoise was recorded by Olson and Meylan (2009).

Hesperotestudo campester (Hay 1908a)

(Late Pliocene to Early Pleistocene)

Plains Giant Tortoise

USA (Kansas, Texas)

Size: CL ca. $>100 \mathrm{~cm}$

Testudo campester $\dagger$ Hay 1908a:455 [Late Pliocene to Early Pleistocene, Blancan, USA (Texas)], Gopherus campester, Geochelone campester, Hesperotestudo campester

Testudo rexroadensis $\dagger$ Oelrich 1952:301 [Late Pliocene, Early Blancan, USA (Kansas)], Geochelone rexroadensis, Geochelone (Hesperotestudo) rexroadensis

Comment: Auffenberg (1974) synonymized T. rexroadensis under H. campester.

Hesperotestudo crassiscutata (Leidy 1889b)

(Middle Pleistocene to Early Holocene, until ca. 9515 BC, 11,465 ybp)

Southeastern Giant Tortoise

USA (Alabama, Florida, Georgia, Louisiana, Mississippi, South Carolina)

Size: CL ca. $120-125 \mathrm{~cm}$

Eupachemys obtusus † Leidy 1877:232 [Pleistocene, USA (South Carolina)] (nomen oblitum), Eupachemys obtusa, Testudo obtusa

Eupachemys rugosus $\dagger$ Leidy 1889b:29 [Late Pleistocene-Early Holocene, Rancholabrean, USA (Florida)] (ex errore for Eupachemys obtusus)

Testudo crassiscutata $\uparrow$ Leidy 1889b:31 [Late Pleistocene-Early Holocene, Rancholabrean, USA (Florida)], ${ }^{14} \mathrm{C}$ age: $12,030 \pm 200$ ybp, calibrated age*: 12,896-11,465 ybp (10,946 BC-9515

$\mathrm{BC})$, Geochelone crassiscutata, Geochelone (Caudochelys) crassiscutata, Caudochelys crassiscutata, Hesperotestudo crassiscutata, 
Hesperotestudo (Caudochelys) crassiscutata

Testudo ocalana $\dagger$ Hay 1916a:45 [Late Pleistocene, USA (Florida)], Gopherus ocalana, Geochelone ocalana

Testudo distans $\dagger$ Hay 1916a:48 [Late Pleistocene, USA (Florida)], Geochelone distans

Testudo sellardsi $\uparrow$ Hay 1916a:49 [Late Pleistocene, USA (Florida)], Geochelone sellardsi

Testudo luciae $\dagger$ Hay 1916a:52 [Late Pleistocene,

USA (Florida)], Geochelone luciae

Comment: Hay (1908a) noted that Eupachemys obtusus was most similar to Testudo crassiscutata, and possibly synonymous and that E. rugosus was an erroneous name for $E$. obtusus; the names were subsequently synonymized by Auffenberg $(1963,1974)$. The specific name obtusus is a nomen oblitum, not having been used since 1908, and should not replace the name crassiscutata through priority. The species $T$. crassiscutata was well described by Loomis (1927) and Auffenberg (1963), who synonymized T. sellardsi, T. luciae, T. ocalana, and T. distans with T. crassiscutata. Clausen et al. (1979) and Holman and Clausen (1984) reported the find of a large specimen of $H$. crassiscutata (CL $94 \mathrm{~cm}$ ) from a PaleoIndian site in Florida aged ca. 12,030 ybp that had been killed by humans. The specimen was associated with a large wooden stake that was still inside the body cavity.

Hesperotestudo equicomes (Hay 1917a)

(Late Pleistocene)

Kansas Tortoise

USA (Kansas, Nebraska)

Size: CL ca. $34 \mathrm{~cm}$

Testudo equicomes $\uparrow$ Hay 1917a:41 [Late Pleistocene, Rancholabrean, Sangamonian, USA (Kansas)], Geochelone equicomes, Geochelone (Hesperotestudo) equicomes, Hesperotestudo equicomes

Hesperotestudo incisa (Hay 1916a)

(Late Pleistocene)

Incised Tortoise

USA (Florida, Georgia)

Size: CL ca. $29 \mathrm{~cm}$

Testudo incisa † Hay 1916a:46 [Late Pleistocene,

Rancholabrean, Sangamonian, USA

(Florida)], Gopherus incisa, Geochelone incisa, Geochelone (Hesperotestudo) incisa, Hesperotestudo incisa

Hesperotestudo johnstoni (Auffenberg 1962)

(Early Pleistocene)

Johnston's Tortoise

USA (Texas)

Size: CL ca. $24 \mathrm{~cm}$

Geochelone johnstoni $\uparrow$ Auffenberg 1962:627

[Early Pleistocene, Late Blancan, Pre-

Nebraskan glaciation, USA (Texas)],

Geochelone (Hesperotestudo) johnstoni, Geochelone johnstoni, Hesperotestudo johnstoni

Hesperotestudo mlynarskii (Auffenberg 1988)

(Middle Pleistocene)

Mlynarski's Tortoise
USA (Florida)

Size: CL ca. $20 \mathrm{~cm}$

Geochelone mlynarskii $\dagger$ Auffenberg 1988:592

[Middle Pleistocene, Late Irvingtonian, USA

(Florida)], Geochelone (Hesperotestudo)

mlynarskii, Hesperotestudo mlynarskii

Comment: Most closely related to H. incisa, but smaller (Auffenberg 1988). The largest type specimen measured $188 \mathrm{~mm}$ in plastral length (PL); CL is estimated here from known CL/PL dimensions of $H$. johnstoni (Auffenberg 1962).

Hesperotestudo oelrichi (Holman 1972)

(Early Pleistocene)

Oelrich's Tortoise

USA (Nebraska)

Size: CL ca. $28 \mathrm{~cm}$

Geochelone (Hesperotestudo) oelrichi $\uparrow$ Holman

1972:59 [Pleistocene, Long Pine and Keim

Formations, Pre-Nebraskan glaciation, USA(Nebraska)], Geochelone oelrichi, Hesperotestudo oelrichi

Hesperotestudo percrassa (Cope 1899)

(Middle Pleistocene)

Port Kennedy Tortoise

USA (Pennsylvania)

Size: "not large"

Clemmys percrassus $\dagger$ Cope 1899:194 [Middle

Pleistocene, Late Irvingtonian, USA (Penn-

sylvania: Port Kennedy)], Testudo percrassa Geochelone (Hesperotestudo) percrassa, Hesperotestudo percrassa

Comment: Hay (1908a) redescribed the species and concluded that it was more similar to Testudo than Clemmys. Parris and Daeschler (1995) further redescribed the species and assigned it to the genus Geochelone and subgenus Hesperotestudo.

Hesperotestudo turgida (Cope 1892a)

(Early Pleistocene)

Plains Tortoise

USA (Kansas, Nebraska, Oklahoma, Texas)

Size: CL ca. $23 \mathrm{~cm}$

Testudo turgida † Cope 1892a:127 [Late Pliocene to Early Pleistocene, Blancan, USA (Texas)], Gopherus turgida, Geochelone turgida, Geochelone (Hesperotestudo) turgida, Hesperotestudo turgida

Comment: Both Kuhn (1964) and Auffenberg (1974) mistakenly cited Emys turgidus Cope 1870b as the original name for this tortoise, but that name described a Cretaceous dermatemyid turtle from New Jersey, now synonymized under Agomphus (Hutchison and Weems 1998; Knauss et al. 2011).

Hesperotestudo wilsoni (Milstead 1956)

(Late Pleistocene to Early Holocene, until ca. 9050 BC, ca. $11,000 \mathrm{ybp})$

Wilson's Tortoise

USA (New Mexico, Oklahoma, Texas)

Size: CL ca. $23 \mathrm{~cm}$

Testudo wilsoni $\dagger$ Milstead 1956:168 [Late Pleisto- 
000e.34 Conservation Biology of Freshwater Turtles and Tortoises • Chelonian Research Monographs, No. 5

cene, Late Wisconsinan, USA (Texas)], ${ }^{14} \mathrm{C}$ age: ca. 11,040 ybp, $9090 \mathrm{BC}$, Geochelone wilsoni, Geochelone (Hesperotestudo) wilsoni, Hesperotestudo wilsoni

Comment: Discussed by Moodie and Van Devender (1979) who noted radiocarbon dating of specimens from ca. 25,000 ybp in the Late Pleistocene to ca. 11,000 ybp in the Early Holocene of Texas, between Clovis and Folsom cultural horizons (Early Archaic). Preston (1979) noted specimens found associated with early man from the Plano Culture of Oklahoma at ca. 11,000 ybp.

\section{Hesperotestudo sp. [El Salvador]}

(Early to Late Pleistocene)

Mesoamerican Giant Tortoise

El Salvador

Size: CL ca. $150 \mathrm{~cm}$

Hesperotestudo sp. $\uparrow$ (Webb and Perrigo 1984)

[Late Pleistocene, El Hormiguero, El Salvador]

Hesperotestudo crassiscutata $\dagger$ (Cisneros 2005)

[Early to Middle Pleistocene, Río Tomayate,

Apopa, El Salvador]

Comment: Described by Cisneros (2005) as being very thin-shelled. This taxon probably represents a distinct species (R. Franz, pers. comm.).

\section{Manouria Gray 1854}

Manouria punjabiensis (Lydekker 1889b)

(Late Pliocene to Early Pleistocene)

Punjab Giant Tortoise

India (Punjab)

Size: CL ca. $90 \mathrm{~cm}$

Testudo punjabiensis $\dagger$ Lydekker 1889b:87 [Late Pliocene to Early Pleistocene, Siwaliks, India (Punjab)], Geochelone (Manouria) punjabiensis, Geochelone punjabiensis, Manouria punjabiensis, Protestudo punjabensis, Manouria punjabensis

Comment: Lydekker (1889b) suggested that this species was close to Manouria emys. Karl and Staesche (2007) recognized this taxon as a valid species of Manouria, but without comparative or diagnostic characters, and misspelled the specific epithet as punjabensis. Further verification of its generic and specific allocation is needed.

Manouria oyamai Takahashi, Otsuka, and Hirayama 2003 (Late Pleistocene to Early Holocene, until ca. 9050 BC, ca. 11,000 ybp)

Ryukyus Tortoise

Japan (Ryukyu Archipelago)

Size: CL ca. $45 \mathrm{~cm}$

Manouria oyamai $\uparrow$ Takahashi, Otsuka, and Hirayama 2003:198 [Late Pleistocene, Japan (Ryukyu Archipelago: Okinawa, Tokunoshima)], ca. 28,000-23,000 ybp

Comment: The youngest known age of this species has been reported as ca. 11,000 ybp from Yonagunijima Island, Ryukyu Archipelago (Otsuka et al. 2008). Recorded from Okinawa, Tokunoshima, Iejima, Miyakojima, and Yonagunijima islands in the Ryukyus. Migration patterns into the Ryukyu Archipelago of this and other Pleistocene taxa has been documented by Otsuka and
Takahashi (2000) and Takahashi et al. (2008).

Megalochelys Falconer and Cautley 1837

Megalochelys Falconer and Cautley 1837:358 (senior homonym; not Megalochelys Fitzinger 1843:29)

Colossochelys Falconer and Cautley 1844:54 (nomen novum)

Cautleya Theobald 1879:186

Megalochelys atlas (Falconer and Cautley 1844)

(Late Pliocene to Early Pleistocene)

Siwaliks Giant Tortoise

India (Punjab), Myanmar, Thailand (?)

Size: CL ca. $180-210 \mathrm{~cm}$

Megalochelys sivalensis $\uparrow$ Falconer and Cautley 1837:358 (nomen nudum) [Late Pliocene to Early Pleistocene, Siwaliks, India (Punjab)], Testudo sivalensis, Testudo (Megalochelys) sivalensis, Megalochelys siwalensis

Colossochelys atlas $\dagger$ Falconer and Cautley 1844:54 [Late Pliocene to Early Pleistocene, Siwaliks, India (Punjab)], Megalochelys atlas, Testudo (Colossochelys) atlas, Testudo (Megalochelys) atlas, Testudo atlas, Geochelone atlas

Megalochelys sivalensis $\uparrow$ Falconer in Murchison 1868:359 [Late Pliocene to Early Pleistocene, Siwaliks, India (Punjab)]

Comment: The original specific name sivalensis in Falconer and Cautley (1837) was not accompanied by any description or illustration, and is a nomen nudum. However, the original generic name Megalochelys Falconer and Cautley 1837 is nonetheless valid (ICZN Code, Article 11.4.1), and was also validated by Cautley (1838), and therefore antedates the use of the homonym by Fitzinger (1843) for Testudo gigantea, as well as the later invalid nomen novum, Colossochelys. In Falconer and Cautley (1844) the specific name atlas was accompanied by a valid description, and that name is nomenclaturally available. Murchison (1868) published many of Falconer's previously unpublished manuscripts, one of which, originally commenced in 1837, but never finished, included a valid description of sivalensis, but since this was not actually published until 1868, it is a junior synonym of atlas. Williams (1952) and Auffenberg (1974) did not designate the name sivalensis as a nomen nudum, but stated instead that it had been withdrawn by the original authors in favor of the well-described later name, atlas (as noted by Murchison 1868). Williams (1952) mistakenly accepted the name sivalensis as valid, and some recent authors have again begun to use it (e.g., Lapparent de Broin 2002; Karl and Staesche 2007 [misspelled as siwalensis]; Setiyabudi 2009; Claude et al. 2011); however, the valid and available name for this taxon is Megalochelys atlas. Claude et al. (2011) described specimens of a large Megalochelys sp. (CL ca. $150 \mathrm{~cm}$ ) from Thailand, inferred to most likely be Pliocene, but potentially Late Miocene or even Pleistocene, that was differentiated from $M$. sivalensis (=M.atlas).

Megalochelys cautleyi (Lydekker 1889b)

(Late Pliocene to Early Pleistocene)

Cautley's Giant Tortoise 
India (Punjab)

Size: "ca. same size as Aldabra tortoise"

Cautleya annuliger Theobald 1879:186 (nomen dubium and nomen oblitum) [Pliocene, Upper Siwaliks, India (Punjab)]

Testudo cautleyi $\dagger$ Lydekker 1889b:86 [Pliocene, Upper Siwaliks, India (Punjab)], Geochelone (Megalochelys) cautleyi, Geochelone cautleyi, Megalochelys cautleyi

Comment: Auffenberg (1974) recognized this taxon as a valid species of Megalochelys without certainty of its generic allocation, and Karl and Staesche (2007) considered it a valid species of the genus without verification. Auffenberg (1974) listed Cautleya annuliger as a nomen nudum; however, the name was accompanied by an adequate description and illustration of a single marginal bone and was therefore a valid description, although clearly a nomen dubium, and by now, a nomen oblitum. Further analysis of the generic allocation of this taxon is needed. Specimens of what may be this species have also been found in Siwalik deposits on Perim Island, Gulf of Cambay, Gujrat, India.

Megalochelys margae (Hooijer 1948)

(Early Pleistocene, until ca. 2,000,000 ybp)

Sulawesi Giant Tortoise

Indonesia (Sulawesi)

Size: CL ca. 140-190 cm

Testudo margae † Hooijer 1948:1169 [Pleistocene, Indonesia (Sulawesi)], Geochelone (Manouria) margae, Geochelone margae, Manouria margae, Megalochelys margae

Comment: This tortoise is a member of the Walanae Fauna, dated as ca. 2,500,000-2,000,000 ybp (e.g., van den Bergh et al. 2001). Tentatively placed in Manouria by Auffenberg (1974), but different from that genus at least in its humerus (Takahashi et al. 2003). Hooijer (1972, 1982) synonymized it under Geochelone atlas and Karl and Staesche (2007) synonymized it under Megalochelys siwalensis; however, it is more likely distinct (Sondaar 1981; Setiyabudi 2009; Takahashi, unpubl. data). A range-wide revision of the taxa that have been placed in or otherwise associated with the genus Megalochelys is clearly needed.

Megalochelys sondaari (Karl and Staesche 2007)

(Early Pleistocene, until ca. 1,700,000 ybp)

Luzon Giant Tortoise

Philippines (Luzon)

Size: CL ca. $70-90 \mathrm{~cm}$

Manouria sondaari $\dagger$ Karl and Staesche 2007:178

[Early Pleistocene, Laguna Formation, Philippines (Luzon), ca. 1,7000,000 ybp], Megalochelys sondaari

Comment: This species was first described in the genus Manouria, but current analysis places it in closer relationship to the genus Megalochelys (Karl, unpubl. data), and we therefore list it as such.

Megalochelys sp. [Timor]

(Middle to Late Pleistocene, until ca. 120,000 ybp)

Timor Giant Tortoise

Indonesia (Timor)
Size: "giant"

Geochelone atlas $\dagger$ (Hooijer 1971) [Middle

Pleistocene, Indonesia (Timor)]

Comment: Considered by Sondaar $(1981,1987)$ and Setiyabudi (2009) to probably be a distinct species. According to Sondaar (1981) and van der Geer et al. (2010), the age of the fossil-bearing beds containing these tortoises and the pygmy proboscidean, Stegodon timorensis, is ca. 800,000 to $120,000 \mathrm{ybp}$.

\section{Megalochelys sp. [Java]}

(Early Pleistocene, until ca. 1,200,000 ybp)

Javan Giant Tortoise

Indonesia (Java)

Size: CL > ca. $175 \mathrm{~cm}$

Geochelone sp. $\uparrow$ (Sondaar 1981) [Early Pleistocene, Kali Glagah Formation, Bumiayu, Indonesia (Java)]

Megalochelys cf. sivalensis $\dagger$ (Setiyabudi 2009)

[Early Pleistocene, Kali Glagah Formation,

Bumiayu, Indonesia (Java)]

Comment: Considered by Sondaar $(1981,1987)$ and Setiyabudi (2009) to probably be a distinct species. The presence of a giant tortoise on Java between 2,000,000 and 1,200,000 ybp was considered by van den Bergh (1999) to be indirect evidence that Homo erectus had not yet reached the island at that time, since giant tortoises were easy prey for hunter-gatherers and rapidly became extinct on islands where hominins settled, as noted by Sondaar $(1981,1987)$. Homo erectus apparently arrived in Java ca. 1,500,000 ybp (see Joordens et al. 2009 for a review), and very likely caused the extinction of the species sometime thereafter.

Megalochelys sp. [Flores]

(Early Pleistocene, until ca. 900,000 ybp)

Flores Giant Tortoise

Indonesia (Flores)

Size: CL ca. $100-140 \mathrm{~cm}$

Megalochelys sp. $\dagger$ (Sondaar et al. 1994) [Early Pleistocene, Indonesia (Flores)]

Collossochelys azizi $\uparrow$ Setiyabudi in Geer et al. 2010:197 (nomen nudum)

Comment: Considered by Setiyabudi $(2006,2009)$ to probably be a distinct species. Sondaar et al. (1994) documented bones of this taxon in association with hominin fossils (probably Homo erectus) from the lower part of the Ola Bla Formation, dated as no later than ca. 900,000 ybp (Morwood et al. 1998). Brumm et al. (2010) documented stone artefacts from ca. 1,020,000 ybp as the earliest evidence of hominin arrival on Flores. No tortoise bones have been found from layers younger than ca. 900,000 ybp, nor in association with Homo floresiensis at Liang Bua from ca. 95,000 to 17,000 ybp or later-appearing H. sapiens (van den Bergh et al. 2009; Brumm et al. 2010). The absence of tortoise bones in these younger strata suggests the intervening extirpation of the species by earlier $H$. erectus (or $H$. floresiensis) exploitation and possibly also impaction by climate change, volcanic eruptions, or other non-anthropogenic processes (Brumm et al. 2010). The tortoise on Flores was hypothesized by van den Bergh (1999) to be about half the size of those on Timor and Sulawesi, but this was 
000e.36 Conservation Biology of Freshwater Turtles and Tortoises • Chelonian Research Monographs, No. 5

based on only a few bone fragments. Setiyabudi (2006), in an unpublished thesis, described and proposed a name for the Flores species, which was unfortunately published (and misspelled) as a nomen nudum (Collossochelys azizi) by Geer et al. (2010).

\section{Psammobates Fitzinger 1835}

Psammobates antiquorum Broadley 1997

(Early Pleistocene, until ca. 1,600,000 ybp)

Sterkfontein Tent Tortoise

South Africa

Size: CL ca. $11 \mathrm{~cm}$

Psammobates antiquorum $\uparrow$ Broadey 1997:111

[Early Pleistocene, South Africa (Gauteng:

Sterkfontein)], ca. 2,000,000 to $1,600,000 \mathrm{ybp}$

Comment: A specimen of this species was recorded from Drimolen Cave in Sterkfontein, an early hominin site known as the Cradle of Humankind, with skeletons of Australopithecus dating back to ca. 3,600,000 ybp. The reasonably intact specimen was missing a portion of its most posterior carapace (Broadley 1997), possibly opened and removed through hominin butchering. Most closely related to extant Psammobates oculifer, of which it might be an ancestral chronospecies.

Stigmochelys Gray $1873 \mathrm{c}$

Stigmochelys brachygularis (Meylan and Auffenberg 1987)

(Late Pliocene to Early Pleistocene, until ca. 2,600,000 ybp)

Laetoli Leopard Tortoise

Tanzania

Size: undetermined

Geochelone (Geochelone) brachygularis $\uparrow$ Meylan and Auffenberg 1987:66 [Late Pliocene, Laetoli Beds, Olduvai Gorge, Tanzania], Stigmochelys brachygularis

Comment: Most closely related to extant Stigmochelys pardalis. This species was recorded from hominin habitation sites in Olduvai at about 3,800,000-2,600,000 ybp and was exposed to early human predation and exploitation (Harrison 2011).

Testudo Linnaeus 1758

Testudo binagadensis Khosatzky in Alekperov 1978 (Middle Pleistocene)

Binagady Tortoise

Azerbaijan (Baku)

Size: undetermined

Testudo graeca binagadensis $\uparrow$ Khosatzky in Alekperov 1978:180 [Middle Pleistocene, Binagady, Baku, Azerbaijan], Testudo binagadensis

Comment: Originally described as a subspecies distinguished by thicker bones of the shell and limbs, and hypothesized to be ancestral to modern Caucasian subspecies of $T$. graeca, we tentatively list this taxon as a distinct species, but its validity needs further assessment (Danilov, pers. comm.). The taxon occurred in the geographic region now occupied by $T$. $g$. armeniaca (including its junior synonym, T. g. pallasi), as determined genetically (Fritz et al. 2007; Mashkaryan et al. 2013;
Mikulíček et al. 2013), and may be ancestral to that or one of the other subspecies in the general Caucasus region, T. g. ibera or T. g. buxtoni.

Testudo changshanensis Wei, Wu, Xu, and Zhang 1975

(Early Pleistocene)

Changshan Tortoise

China (Zhejiang)

Size: CL ca. $33 \mathrm{~cm}$

Testudo changshanensis $\dagger$ Wei, Wu, Xu, and Zhang 1975:118 [Early Pleistocene, China (Zhejiang: Changshan)]

Comment: Generic placement uncertain (Danilov, pers. comm.).

Testudo kenitrensis Gmira 1993

(Middle Pleistocene)

Kenitra Tortoise

Morocco

Size: CL ca. $13 \mathrm{~cm}$

Testudo kenitrensis $\uparrow$ Gmira 1993:702 [Middle

Pleistocene, Middle Sicilien, Morocco]

Comment: More closely related to T. graeca and T. marginata than to T. hermanni (Gmira 1993; Gmira et al. 2013).

Testudo lunellensis Almera and Bofill 1903

(Middle Pleistocene)

Gracia Tortoise

Spain (Catalonia)

Size: CL ca. $25-30 \mathrm{~cm}$

Testudo lunellensis $\uparrow$ Almera and Bofill 1903:106 [Middle Pleistocene, Toringian, Spain (Catalonia: Barcelona)], Testudo hermanni lunellensis, Eurotestudo lunellensis

Testudo lunellensis iberica $\uparrow$ Bergounioux 1958:208 [Middle Pleistocene, Catalonia, Spain]

Comment: Previously occasionally synonymized under either extant $T$. graeca or $T$. hermanni, the taxonomic distinction of this species from Cova de Gràcia was validated by Lapparent de Broin et al. (2006b,c) and Delfino et al. (2012), who both determined that it is most closely related to extant $T$. hermanni. Delfino et al. (2012) also noted that it was the most recent named species of Testudo known to have gone extinct, but other unnamed, possibly distinct, taxa of Pleistocene tortoises closely related to T. hermanni also occur in France (Lunel-Viel) and Italy (Soave), as noted by Lapparent de Broin et al. (2006a,b,c). We do not list these other possibly distinct taxa at this time, pending further analysis of this material. Auffenberg (1974) suggested that Testudo lunellensis var. iberica Bergounioux 1958 was intended as the designation of a morphotype, not a subspecies, and concluded that the name had no validity as a trinomial, whereas Delfino et al. (2012) treated T. l. iberica as a valid subspecific name, but synonymized it under T. lunellensis after examining specimens of both morphotypes.

Testudo oughlamensis Gmira, Lapparent de Broin, Geraads, Lefèvre, Mohib, and Raynal 2013

(Late Pliocene to Early Pleistocene)

Oughlam Tortoise

Morocco 
Size: CL ca. $12 \mathrm{~cm}$

Testudo oughlamensis $\dagger$ Gmira, Lapparent de Broin, Geraads, Lefèvre, Mohib, and Raynal 2013:695 [Late Pliocene, Morocco]

Comment: Described as most closely related to T. kenitrensis, possibly its ancestral chronospecies (Gmira et al. 2013).

Testudo pecorinii Delfino in Abbazzi, Carboni, Delfino, Gallai, Lecca, and Rook 2008

(Late Pliocene to Early Pleistocene)

Sardinia Tortoise

Italy (Sardinia)

Size: CL ca. 22-23 cm

Testudo pecorinii $\uparrow$ Delfino in Abbazzi, Carboni, Delfino, Gallai, Lecca, and Rook 2008:123 ["Late Pliocene" (= Early Pleistocene), Capo Mannu Formation, Villafranchian, Italy (Sardinia)]

Comment: Described as being from the Late Pliocene prior to the redefinition of the base of the Pleistocene; now considered Early Pleistocene.

Testudo transcaucasica Chkhikvadze 1979

(Late Pliocene to Early Pleistocene)

Transcaucasian Tortoise

Georgia (Caucasus)

Size: CL ca. $15 \mathrm{~cm}$

Testudo černovi transcaucasica $†$ Chkhikvadze 1979:545 [Late Pliocene, Middle Akchagylian, Kvabebi, Georgia]; Testudo cernovi transcaucasica, Testudo chernovi transcaucasica, Testudo transcaucasica

Comment: Described as a subspecies of Testudo cernovi Khosatzky 1948 [Pliocene of Ukraine] from the Kvabebi hominin habitation site in eastern Georgia, prior to the redefinition of the base of the Pleistocene. The Akchagylian stage has generally been interpreted as extending from ca. 3,400,000 to $1,800,000 \mathrm{ybp}$, and the Kvabebi site dated at ca. 3,110,000-3,004,000 ybp (Agustí et al. 2009). Testudo cernovi was noted to be Middle Pliocene, from biozones MN 13-14 (Danilov 2005; Danilov et al. 2012), and T. c. transcaucasica was elevated to full species level by Chkhikvadze (2010). We tentatively list this taxon as a distinct species, but its validity needs further assessment.

Testudo Linnaeus 1758 or

Agrionemys Khosatzky and Młynarski 1966b

Testudo or Agrionemys ranovi Amiranashvili, Chkhikvadze, and Sharapov in Sharapov, Amiranashvili, and Chkhikvadze 1988

(Late Pliocene to Early Pleistocene)

Ranov's Steppe Tortoise

Tajikistan (Khatlon)

Size: CL ca. $20 \mathrm{~cm}$

Agrionemys ranovi $\uparrow$ Amiranashvili, Chkhikvadze, and Sharapov in Sharapov, Amiranashvili, and Chkhikvadze 1988:545 [Late Pliocene (= Early Pleistocene), Karamaydan, Fayzabad, Khatlon, Tajikistan]; Agrionemys (Agrionemys) ranovi, Testudo ranovi
Comment: Described as being from the Late Pliocene prior to the redefinition of the base of the Pleistocene. Apparently closely related to extant Testudo or Agrionemys horsfieldii, possibly a chronospecies precursor; also recognized as distinct by Chkhikvadze (2007). As noted in TTWG (2014) and earlier TTWG checklists, whether Agrionemys is distinct from Testudo or not remains unclear. We tentatively list this taxon as a distinct species, but its validity needs further assessment.

Titanochelon Pérez-García and Vlachos 2014

Titanochelon Pérez-García and Vlachos 2014:657

Comment: This fossil genus of large European tortoises from the Miocene and Pliocene, possibly extending into the Early Pleistocene, was recently separated from the older broad genus Cheirogaster (Bergounioux 1935), now considered to be restricted to the Eocene.

Titanochelon gymnesica (Bate 1914)

(Pliocene to Early Pleistocene?)

Menorca Giant Tortoise

Spain (Balearic Islands [Gymnesic Islands: Menorca])

Size: CL ca. $110-130 \mathrm{~cm}$

Testudo gymnesicus † Bate 1914:102 [Late Pliocene-Early Pleistocene, Spain (Balearic Islands: Menorca)], Testudo gymnesica, Geochelone (Geochelone) gymnesica, Geochelone gymnesica, Cheirogaster gymnesica, Cheirogaster gimnesica, Titanochelon gymnesicus, Titanochelon gymnesica

Comment: Endemic to Menorca in the Gymnesic Islands of the eastern Balearics, this species has been believed to have occurred mainly in the late Pliocene, but may have persisted into the Early Pleistocene (Bover et al. 2008). Additional material was discussed by Mercadal and Pretus Real (1980). Recent studies have challenged the age of the associated T. gymnesica fauna; Quintana et al. (2011) suggested a Lower Pliocene age, based on rodents and lagomorphs. We tentatively include it on our checklist despite the uncertainty regarding its age. Pérez-García and Vlachos (2014) tentatively referred it to their new genus as T. gymnesicus; we amend the specific name to the correct spelling gymnesica, as the name Titanochelon is feminine.

\section{Titanochelon sp. [Ibiza]}

(Middle Pleistocene, until ca. 200,000 ybp)

Ibiza Tortoise

Spain (Balearic Islands: Pityusic Islands)

Size: CL ca. $48-56 \mathrm{~cm}$

Testudinidae, gen. et sp. indet. $\dagger$ (Bour 1985a)

[Pleistocene, Spain (Balearic Islands: Ibiza

(Eivissa)], Cheirogaster sp. indet., Titanochelon cf. gymnesicus

Comment: Endemic to the Pityusic Islands (Ibiza [Eivissa] and Formentera) of the western Balearics. Bour (1985a) described specimens of this distinctive insular taxon, but did not name or diagnose it, while noting that it shared some characters with continental Cheirogaster (now Titanochelon) perpiniana (Late Pliocene, France), and some apparently convergent with insular Cylindraspis (Modern, Mascarenes). Filella-Subirà et al. (1999) described fossil tortoise eggs from the Middle Pleisto- 
000e.38 Conservation Biology of Freshwater Turtles and Tortoises • Chelonian Research Monographs, No. 5

cene (ca. 2000,000 ybp) from Formentera that they hypothesized belonged to this taxon, and that they thought might be Cheirogaster (now Titanochelon). Bover et al. (2008) designated the Ibiza taxon as Cheirogaster sp. (= Titanochelon) and noted that humans did not settle in the Pityusic Islands until ca. $5000 \mathrm{ybp}$, but that when they did, most of the endemic fauna that had evolved there in isolation went extinct. Pérez-García and Vlachos (2014) tentatively referred this taxon to Titanochelon cf. gymnesicus, but we retain it as a separate and distinct unnamed taxon based on the earlier work of Bour (1985a).

Titanochelon sp. [Lesvos]

(Late Pliocene to Early Pleistocene)

Lesvos Giant Tortoise

Greece (Lesvos [Lesbos])

Size: CL ca. $186 \mathrm{~cm}$

Cheirogaster aff. schafferi $\uparrow$ (Lapparent de Broin 2002) [Late Pliocene, Vatera Formation, Greece (Lesvos)]

Comment: The Vatera Formation from Lesvos is now considered to be Early Pleistocene (MN17), and though Lesvos is now an island, during those times it was continental rather than insular. The taxon was noted by Lapparent de Broin (2002) to be one of the world's largest tortoises; however, it is different from Cheirogaster (now Titanochelon) schafferi (Kear and Georgalis 2009; Georgalis and Kear 2010,2013) and appears to be a distinct species. Specimens of a similar but smaller species have also been found in Middle Pleistocene deposits at Petralona Cave, Chalikidiki, northern Greece (Kretzoi and Poulianos 1981), where hominin remains (possibly Homo heidelbergensis) dated at ca. 240,000-160,000 ybp (Hennig et al. 1981) have also been found.

\section{Testudinidae sp. [China]}

(Early Pleistocene)

Liuzhou Giant Tortoise

China (Guangxi)

Size: CL ca. $>90 \mathrm{~cm}$

Testudo sp. $†$ Yeh 1963a:102 [Early Pleistocene,

China (Guangxi: Liucheng, Liuzhou)]

Comment: Described from Early Pleistocene deposits in a cave possibly used by Homo erectus and also associated with Gigantopithecus blacki, a giant ape that went extinct about 100,000 ybp. Bones very thick at 11-16 mm. Suggested by Karl (pers. comm.) to possibly be similar to Titanochelon.

\section{_TRIONYCHOIDEA Gray 1825}

\section{Trionychidae Gray 1825}

\section{TrionyChinae Gray 1825}

Trionyx Geoffroy Saint-Hilaire 1809

Trionyx pliopedemontanus Sacco 1889 (Late Pliocene to Early Pleistocene) Piemont Softshell Italy (Piemont) Size: undetermined
Trionyx pliopedemontana $\uparrow$ Sacco 1889:458 [Pliocene, Santo Stefano Roero, Italy (Piemont)], Trionyx pliopedemontanus

Comment: Originally described as being similar to extant Trionyx aegyptiaca (= Trionyx triunguis). Kotsakis (1980) referred other specimens of Trionyx sp. described by Portis (1890) from the Late Pliocene to Early Pleistocene of Valdarno, Tuscany, Italy, to Trionyx cf.pliopedemontanus. Karl (1999) synonymized T. pliopedemontanus and all other Eurasian trionychine fossil taxa back through the Miocene into the Oligocene with the widespread extant morphospecies Trionyx triunguis. However, Rook et al. (2013) recognized T. pliopedemontanus as possibly distinct, and we list it here, pending further analysis.

TrionychinaE gen. indet.

“Aspideretes” sinuosus (Chow and Yeh 1958)

(Late Pliocene to Early Pleistocene)

Shanxi Softshell

China (Shanxi)

Size: CL ca. $14-15 \mathrm{~cm}$

Trionyx (Aspideretes) sinuosus $\uparrow$ Chow and Yeh 1958:51 [Late Pliocene or Early Pleistocene, Shanxi, China], Aspideretes sinuosus

Comment: Taxonomic reassessment of this species has not been undertaken, but it was considered valid by Ye (1994). Brinkman et al. (2008) noted that the presence of a preneural, though highly probable, could not be recognized with certainty, making generic assignment of the species difficult. We note that all living Aspideretes have been referred to Nilssonia based on genetics, but we hesitate to do so for this fossil species.

“Trionyx" australiensis De Vis 1894

(Pleistocene)

Darling Downs Softshell

Australia (Queensland)

Size: undetermined

Trionyx australiensis $\uparrow$ De Vis 1894:125 [Pleistocene, Australia (Queensland)], Pelochelys australiensis

Comment: Taxonomic reassessment of the original specimens by Gaffney and Bartholomai (1979) was inconclusive, with allocation only to Trionychidae, gen. indet. They compared the taxon to Pelochelys from New Guinea, the only Pleistocene or Holocene trionychid genus that has been recorded from the region, but found that it differed significantly and was more similar to Rafetus. White (2001) described an Eocene trionychid, Murgonemys braithwaitei, also from Queensland, Australia, that had a shell and 8th pleural bones similar to T.australiensis, suggesting that these taxa represent a previously unknown radiation of the Trionychidae.

\section{- Pleurodira Cope 1864}

_Chelidae Gray 1825

Chelodininae Baur 1893 
Chelodina Fitzinger 1826

Chelodina (Macrochelodina) Wells and Wellington 1985

Chelodina (Macrochelodina) insculpta De Vis 1897

(Pleistocene)

Darling Downs Snake-neck Turtle

Australia (Queensland)

Size: CL ca. $25-30 \mathrm{~cm}$

Chelodina insculpta $\uparrow$ De Vis 1897:5 [Pleistocene, Australia (Queensland)]

Comment: Analysis of original specimens and taxonomic validation of the species by Thomson (2000), who noted that it was most closely related to $C$. expansa. The size of the intergular would indicate a species of CL ca 25-30 $\mathrm{cm}$, making it similar in size to extant $C$. oblonga $(=C$. rugosa), but smaller than C. expansa (Thomson, unpubl. data).

Elseya Gray 1867

Elseya uberrima (De Vis 1897)

(Pleistocene)

Darling Downs Short-necked Turtle

Australia (Queensland)

Size: CL ca. 55-60 cm

Chelymys uberrima $\dagger$ De Vis 1897:1 [Pleistocene, Australia (Queensland)], Elseya uberrima, Elseya uberima

Chelymys antiqua $\uparrow$ De Vis 1897:4 (partim) [Pleistocene, Australia (Queensland)], Elseya antiqua

Chelymys arata $\dagger$ De Vis 1897:5 [Pleistocene, Australia (Queensland)], Elseya arata

Pelocomastes ampla $\dagger$ De Vis 1897:6 [Pleistocene, Australia (Queensland)], Elseya ampla

Comment: Thomson (2000) reassessed the original material, validated the species, and synonymized the other taxa, but misspelled the name as uberima. This was a large species with the anterior section of the carapace approximately $20 \%$ larger than the largest specimens of extant E. albagula (CL ca. $42 \mathrm{~cm}$ ), corresponding to a CL of ca. 55-60 cm (Thomson, unpubl. data).

Rheodytes Legler and Cann 1980

Rheodytes devisi Thomson 2000

(Pleistocene)

De Vis' Short-necked Turtle

Australia (Queensland)

Size: CL ca. $20 \mathrm{~cm}$

Chelymys antiqua $\dagger$ De Vis 1897:4 (partim) [Pleistocene, Australia (Queensland)]

Rheodytes devisi † Thomson 2000:595 [Pleistocene, Australia (Queensland)]

Comment: The type series of Chelymys antiqua consisted of two taxa: Elseya uberrima and this new species (Thomson 2000). Since a lectotype had already been set for $C$. antiqua by Gaffney (1981) and that specimen represented E. uberrima, it was not possible to reassign the name antiqua to Rheodytes. In terms of size of this species, a first pleural was the same size as the same element from extant $R$. leukops with a CL of 20 $\mathrm{cm}$ (Thomson, unpubl. data).

\section{Pelomedusidae Cope 1868 a}

Latisternon Auffenberg 1981

Latisternon Auffenberg 1981:511

Latisternon microsulcae Auffenberg 1981

(Early Pleistocene, until ca. 1,700,000 ybp)

Olduvai Side-necked Turtle

Tanzania

Size: "medium-sized"

Latisternon microsulcae $\dagger$ Auffenberg 1981:511

[Early Pleistocene, Serengetian, Olduvai,

Tanzania]

Comment: This terrestrial species was based on only a few fragmentary specimens; its relationships within the Pelomedusidae are unclear (Lapparent de Broin 2000), and Gaffney et al. (2011) considered it a nomen dubium. It has been compared to the Pliocene pelomedusid $\mathrm{Ke}$ nyemys williamsi (Wood 1983), but is apparently not closely related to it. The few fragments of $L$. microsulcae were found associated with large numbers of specimens of the still-extant freshwater turtle, Pelusios sinuatus, and two tortoise species, the still-extant Stigmochelys pardalis, and a few fragments of an unidentified extinct giant tortoise. Auffenberg (1981) hypothesized that $L$. microsulcae and the giant tortoise had apparently been extirpated by hominins living at the site, and that after the large terrestrial species had been extirpated, the abundant aquatic species was collected instead.

\section{Podocnemididae Cope $1868 \mathrm{~b}$}

Shweboemys Swinton 1939

Shweboemys Swinton 1939:548

Shweboemys pilgrimi Swinton 1939

(Pliocene or Pleistocene)

Pilgrim's Side-necked Turtle

Myanmar

Size: skull length ca $12.5 \mathrm{~cm}$, CL undetermined

Shweboemys pilgrimi $\uparrow$ Swinton 1939:548 [Pliocene or Pleistocene, Irrawaddy Beds, Myanmar (Burma)]

Comment: This taxon was described from material collected from the Irrawaddy Formation near Mauktet, Shwebo District, Myanmar. Unfortunately, the stratigraphic positions of the two known fossils of this taxon were not recorded (Wood 1970), and since there are Upper (Pleistocene) and Lower (Pliocene) Irrawaddy strata, the taxon could have come from either, or even possibly from underlying Miocene deposits. Other taxa previously included in this genus are all Miocene to Pliocene in age (Wood 1970; Jain 1986; Gaffney et al. 2011). The Irrawaddy Formation has also yielded the Plio-Pleistocene giant tortoise Megalochelys atlas, as well as trionychid and geoemydid turtles (Chhibber 1934).

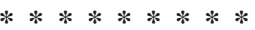




\section{APPENDIX I \\ Extinct Modern Taxa}

Modern freshwater turtle and tortoise taxa ( 8 species, 3 subspecies, and 1 unnamed taxon $=12$ taxa) that have gone extinct since $1500 \mathrm{AD}$, with approximate or known extinction dates. We include one unnamed extinct modern species that is not included on our list of named modern taxa (TTWG 2014).

\section{- Cryptodira}

\section{KINOSTERNIDAE}

Kinosternon hirtipes megacephalum Iverson 1981

(Modern, until ca. 1970)

Viesca Mud Turtle

Mexico (Coahuila)

Size: CL ca. $12 \mathrm{~cm}$

Kinosternon hirtipes megacephalum Iverson 1981:52

[Coahuila, Mexico], Kinosternon megacephalum Comment: This extremely range-restricted taxon was described by Iverson (1981) based on eight specimens collected in two spring-fed drying ponds in 1961. No further specimens have been found. By 1978 no permanent water habitats remained in the area, because the aquifer had been tapped for irrigation purposes (Iverson 1981). ReyesVelasco et al. (2013) revisited the area and confirmed that no permanent aquatic habitats exist in the area, and that this distinctive taxon is certainly extinct.

\section{Testudinidae}

Aldabrachelys gigantea daudinii (Duméril and Bibron 1835) (Modern, until ca. 1850)

Daudin's Giant Tortoise

Seychelles (Mahé?)

Size: CL ca. $79 \mathrm{~cm}$

Testudo daudinii Duméril and Bibron 1835:123 [Seychelles], Testudo gigantea daudinii, Geochelone gigantea daudinii, Dipsochelys daudinii, Geochelone daudinii, Aldabrachelys daudinii, Aldabrachelys gigantea daudinii, Dipsochelys dussumieri daudinii

Comment: This taxon, along with A. g. arnoldi and A.g. hololiss $a$, is one the morphotypes of tortoises believed to originate from the central or granitic Seychelles (Bour 1985b, 1988), variously referred to as distinct species vs. subspecies of the Aldabra Tortoise (TTWG 2014). Its identity, still to be precisely clarified, rests only upon an adult skeleton of unknown origin with a carapace with scutes (but the skull is unfortunately lost), and a young in alcohol (Bour 2006). Little is known about the origin of these two specimens, but subfossil remains from Mahé Island display some similarities with the carapace of the skeleton. However, the taxon is distinctive enough, whether considered to be a species or subspecies, that its extinction is certain. The lost skull was originally described and pictured by Cuvier (1824), the big specimen in its whole described and named by Duméril and Bibron (1835); the same authors only briefly alluded to the young specimen. A tentative study of the DNA of both specimens failed (Austin and Arnold 2001; Gerlach 2004, 2014).

\section{Chelonoidis abingdonii (Günther 1877)}

(Modern, until 2012)

Pinta Giant Tortoise

Ecuador (Galápagos: Pinta)

Size: CL ca. $98 \mathrm{~cm}$

Testudo ephippium Günther 1875:271 (partim, misidentified type) [Charles Island (= Floreana) (in error), Galápagos, Ecuador]

Testudo abingdonii Günther 1877:85 [Abingdon Island (= Pinta), Galápagos, Ecuador], Testudo elephantopus abingdonii, Geochelone abingdonii, Geochelone elephantopus abingdonii, Chelonoidis abingdonii, Chelonoidis elephantopus abingdonii, Geochelone (Chelonoidis) nigra abingdonii, Geochelone nigra abingdonii, Chelonoidis nigra abingdonii, Chelonoidis elephantopus abingdonii

Comment: This species was exposed to intense exploitation by whalers in the early 1800 s collecting animals as provisions for their long Pacific voyages, with the last large loads of tortoises from Pinta recorded as occurring between 1833 and 1848 (Townsend 1925; Pritchard 1996). From then until 1906, no more than a handful of animals were found, and by 1957 only a few dead animals could be found trapped in ravines and crevices (Snow 1964). The habitat had also been severely degraded by introduced goats and intermittent slaughter of a last few animals still occurred. However, one last living male of this species, known as Lonesome George, was found in the wild in 1971 and brought into captivity at the Charles Darwin Research Station on Santa Cruz in 1972 (Pritchard 1996). Though intensive efforts were made to cross-breed him with closely related species for many years, he died in captivity in June 2012 without siring any successful offspring. However, a few animals with partial C. abingdonii genotype hybridized with $C$. becki have been located onVolcan Wolf on Isabela (Russello et al. 2007); evidently a number of $C$. abingdonii were released there inadvertently by whalers in the past, suggesting that the taxon may not yet be fully extinct (Edwards et al. 2013). Some authorities treat this taxon as a subspecies of $C$. nigra.

Chelonoidis nigra (Quoy and Gaimard 1824b)

(Modern, until ca. 1850)

Floreana Giant Tortoise

Ecuador (Galápagos: Floreana)

Size: CL ca. $96 \mathrm{~cm}$

Testudo californiana Quoy and Gaimard 1824a:90 (nomen oblitum) [California, USA (in error)]

Testudo nigra Quoy and Gaimard 1824b:174 (nomen novum) [California, USA (in error)], Chelonoidis nigra, Geochelone nigra, Geochelone nigra nigra, Chelonoidis nigra nigra, Geochelone elephantopus nigra

Testudo galapagoensis Baur 1889:1044 [Charles Island (= Floreana), Galápagos, Ecuador], Testudo elephantopus galapagoensis, Geochelone elephantopus galapagoensis, Chelonoidis galapagoensis, Chelonoidis elephantopus galapagoensis, Geochelone (Chelonoidis) nigra galapagoensis, Geochelone nigra galapagoensis, Chelonoidis nigra galapagoensis

Comment: This species was also exposed to intense exploitation by whalers in the early 1800 s collecting animals 
as provisions, with the last large loads of tortoises from Floreana recorded as occurring between 1831 and 1837 (Townsend 1925; Pritchard 1996). Charles Darwin saw no live tortoises when he visited in 1835 and only a handful of tortoises appear to have been collected between 1840 and 1847, with final rapid exinction estimated to have occurred in about 1850 (Broom 1929; Steadman 1986). However, hybrid specimens of $C$. nigra and $C$. becki have recently been discovered on Volcan Wolf on Isabela, probably as a result of $C$. nigra being inadvertently released there by whalers prior to the 1830 s (as with $C$. abingdonii), suggesting that the taxon may not yet be fully extinct (Poulakakis et al. 2008; Parham 2008; Garrick et al. 2012). Some authorities treat this taxon as the nominotypical subspecies of $C$. nigra, and it has also been referred to variously as $C$.galapagoensis and C. elephantopus.

Chelonoidis phantastica (Van Denburgh 1907)

(Modern, until ca. 1970)

Fernandina Giant Tortoise

Ecuador (Galápagos: Fernandina)

Size: CL ca. $88 \mathrm{~cm}$

Testudo phantasticus Van Denburgh 1907:4 [Narborough Island (= Fernandina), Galápagos, Ecuador], Testudo phantastica, Testudo elephantopus phantastica, Geochelone elephantopus phantastica, Geochelone phantastica, Chelonoidis phantastica, Geochelone phantasticus, Chelonoidis elephantopus phantastica, Geochelone (Chelonoidis) nigra phantastica, Geochelone nigra phantastica, Chelonoidis nigra phantastica

Comment: There are no reliable records of whalers exploiting this species (Townsend 1925; Pritchard 1996). Only the single distinctive holotype of the species has been found, a large male collected alive in 1905 . No other specimens have been seen since, but in 1964 helicopter-assisted surveys of remote areas on Fernandina discovered a large tortoise scat and a few cactus pods with tortoise bite marks (Hendrickson 1965). The species may have survived until ca. 1970, succumbing finally to the frequent volcanic lava flows that nearly cover the island. Genetic work by Poulakakis et al. (2012) has suggested that this species may be most closely related to $C$. porteri on Santa Cruz. Some authorities treat this taxon as a subspecies of $C$. nigra.

\section{Chelonoidis sp. [Santa Fé]}

(Modern, until ca. 1890)

Santa Fé Giant Tortoise

Ecuador (Galápagos: Santa Fé)

Size: "very large"

Testudo sp. (Van Denburgh 1914:365) [Barrington

Island (= Santa Fé), Galápagos, Ecuador]

Comment: There are only a few records of whalers exploiting tortoises from Santa Fé (= Barrington), with shipments noted for about 20 animals taken in 1839 and a single one in 1853 (Townsend 1925), followed by a few more taken informally in about 1876 and one last one in about 1890 (Pritchard 1996). No living animals were found in 1906 when Van Denburgh (1914) searched the island and collected several old appendicular bones from 14 separate individuals. Four of these individuals have recently been genotyped by Poulakakis et al. (2012), who determined that they represent an unnamed extinct species distinct from any other living or extinct Galápagos tortoise species. This unnamed species is not included on our current list of modern species (TTWG 2014).

Cylindraspis indica (Schneider 1783)

(Modern, until ca. 1840)

Reunion Giant Tortoise

Réunion

Size: CL ca. $120 \mathrm{~cm}$

Testudo indica Schneider 1783:355 [Réunion], Chelonura indica, Cylindrapis indica, Megalochelys indica, Geochelone indica, Cylindraspis indica

Testudo tabulata africana Schweigger 1812:322 [Réunion]

Chersine retusa Merrem 1820:29 (nomen novum) [Réunion], Testudo retusa

Testudo perraultii Duméril and Bibron 1835:126 (nomen novum) [Réunion], Geochelone (Cylindraspis) perraultii, Testudo indica perraultii

Testudo graii Duméril and Bibron 1835:135 (nomen novum) [Réunion], Geochelone graii, Cylindraspis graii

Chersina grayi Strauch 1865:36 (nomen novum) [Réunion], Geochelone grayi, Geochelone (Cylindraspis) grayi

Cylindraspis borbonica Bour 1978:491 [Réunion] Comment: The largest of the Mascarene Tortoises, some as large as big tortoises from Aldabra and Galápagos, but narrower and lighter. These tortoises occurred mostly on the western and southern parts of the island; apparently two morphotypes existed, suggesting that perhaps a second species was also present. Tortoises were extirpated from coastal regions between 1700 and 1770, while isolated populations survived until about 1840 in remote mountainous areas. At the time of first colonization during the middle of the $1600 \mathrm{~s}$, tortoises were so numerous that the French settlers, besides eating them regularly, used them to feed their pigs. A large number were sold to visiting ships, usually several hundred at a time. In the meantime several introduced species, especially rats and pigs, consumed eggs and young. From time to time the local administration enacted rulings to forbid or regulate hunting, probably among the first acts anywhere in the world to protect a species (Stoddart et al. 1979; Bour 1981; Bour et al. 2014b; Cheke and Bour 2014).

Cylindraspis inepta (Günther 1873)

(Modern, until ca. 1735)

Mauritius Giant Domed Tortoise

Mauritius (Mauritius)

Size: CL ca. $100 \mathrm{~cm}$

Testudo neraudii Gray 1831b:14 (nomen oblitum) [Mauritius]

Testudo inepta Günther 1873:397 [Mauritius], Geochelone inepta, Cylindraspis inepta

Testudo boutonii Günther 1875:297 [Mauritius]

Testudo sauzieri Gadow 1894:315 [Mauritius], Geochelone sauzieri

Comment: As Mauritius was the first of the Mascarene Islands to be settled, in the early 1600 s, its tortoises were the first to be exterminated, but well after the extinction of the Dodo. By ca. 1700 tortoises were extirpated on the main island and by ca. 1735 also on the surrounding islets. Accord- 
ing to some early Dutch settlers, many tortoises were killed only for their fat. From their numerous remains, one can assume that the largest Mauritian tortoises reached a length of nearly one meter. Their range covered the whole island as well as all the satellite islets (e.g., Flat Island, Ile aux Cerfs, Round Island) (Stoddart et al. 1979; Bour 1984; Cheke and Hume 2008; Bour et al. 2014b; Cheke and Bour 2014; Hume 2014).

Cylindraspis peltastes (Duméril and Bibron 1835) (see Fig. 14) (Modern, until ca. 1800)

Rodrigues Domed Tortoise

Mauritius (Rodrigues)

Size: CL ca. $46 \mathrm{~cm}$

Testudo rotunda Latreille in Sonnini and Latreille 1801:107 (partim, nomen dubium) [Unknown], Chersine rotunda, Geochelone (Geochelone) rotunda

Testudo peltastes Duméril and Bibron 1835:138

[Rodrigues], Geochelone peltastes, Geochelone (Cylindraspis) peltastes, Cylindraspis peltastes

Comment: The two species of Rodrigues tortoises $(C$. peltastes and $C$. vosmaeri) are the best known among the Mascarene species, thanks to several non-fossil remains, including stuffed and alcoholic specimens, and because there are several detailed records by witnesses of their existence (e.g., Leguat 1707), as well as some illustrations. Rodrigues was the last of the Mascarene Islands to be discovered, in 1528 , later occupied by tortoise harvesters starting in 1735 , and permanently settled by about 1792 . The bulk of the tortoise population was extirpated between 1735 and 1770. The last two live tortoises were documented in 1795 and both species were probably extinct by 1800 (Bour et al. 2014a). Contrary to Réunion and Mauritius, the tortoises on Rodrigues were not eaten on site, but harvested and transported by the thousands aboard special boats, destined to supply primarily the garrison and hospital on Mauritius. Precise logbooks indicate that at least ca. 300,000 tortoises were exported. Furthermore, because of their very thin and fragile shells, many died during the journey. After the end of this period of trade, feral cats, rats, and fires eliminated the remaining individuals (Arnold 1979; Stoddart et al. 1979; Bour 1984; North-Coombes 1986; Bour et al. 2014b; Cheke and Bour 2014). Recent finds of intact subfossil shells from caverns (Hume 2014) should increase our knowledge of this recently extinct species.

Cylindraspis triserrata (Günther 1873)

(Modern, until ca. 1735)

Mauritius Giant Flat-shelled Tortoise

Mauritius (Mauritius)

Size: CL ca. $100 \mathrm{~cm}$

Testudo schweigeri Gray 1830b:3 (nomen oblitum) [Unknown]

Testudo schweiggeri Duméril and Bibron 1835:108 (nomen novum et oblitum) [Unknown]

Testudo triserrata Günther 1873:397 [Mauritius], Geochelone triserrata, Cylindraspis triserrata

Testudo leptocnemis Günther 1875:297 [Mauritius], Geochelone leptocnemis, Cylindraspis leptocnemis

Testudo microtympanum Boulenger 1891:4 [Mauritius], Geochelone microtympanum
Testudo guentheri Gadow 1894:320 (senior homonym) [Mauritius]

Testudo güntheri Gadow in Van Denburgh 1914:257 (nomen novum, invalid name, junior homonym) [Mauritius], Testudo guntheri

Testudo gadowi Van Denburgh 1914:257 (nomen novum) [Mauritius], Geochelone (Megalochelys) gadowi, Geochelone (Cylindraspis) gadowi

Comment: This species lived on Mauritius with C. inepta, reaching about the same shell size. The remains of $C$. triserrata are less numerous, roughly $25-30 \%$, but perhaps only because their skeleton and flattened shell were not as strong, with thinner, loosely articulated bones. The Mauritius tortoises were also differentiated by their cranial anatomy, $C$. triserrata having a second bony ridge on the upper jaw, and three on the mandible (hence its name). These features were probably associated with distinct dietary specialization, which could explain the sympatry of two species of similar size. Further research could elucidate more on their ecology (Bour et al. 2014b; Cheke and Bour 2014; Hume 2014).

Cylindraspis vosmaeri (Suckow 1798) (see Fig. 14)

(Modern, until ca. 1800)

Rodrigues Giant Saddleback Tortoise

Mauritius (Rodrigues)

Size: CL ca. $110 \mathrm{~cm}$

Testudo indica vosmaeri Suckow 1798:57 [Rodrigues], Testudo vosmaeri, Geochelone (Cylindraspis) vosmaeri, Geochelone vosmaeri, Cylindraspis vosmaeri

Testudo rotunda Latreille in Sonnini and Latreille 1801:107 (partim, nomen dubium) [Unknown], Chersine rotunda, Geochelone (Geochelone) rotunda

Testudo rodericensis Günther 1873:397 [Rodrigues]

Testudo commersoni Vaillant 1898:138 [Rodrigues], Geochelone commersoni, Cylindraspis commersoni

Comment: As in Mauritius, two tortoises species occurred on Rodrigues. However, they differed greatly in size, with $C$. peltastes only reaching a length of $46 \mathrm{~cm}$, while the larger $C$. vosmaeri sometimes exceeded one meter, up to $110 \mathrm{~cm}$. Actually, the giants, perhaps the dominant males, were rare and referred to as "carrosses" (as in Réunion). The smaller $C$. peltastes had a domed convex shell, and was a grazer of the grassy litter. The larger $C$. vosmaeri, with its carapace widely opened in front, more or less upturned, and long limbs and long neck, was a browser, able to reach leaves and fruits up to about $120 \mathrm{~cm}$ in height. The ecological niches of the two sympatric species were clearly distinct. The extraordinary morphological convergence of $C$. vosmaeri with several saddlebacked Galápagos tortoise species is quite notable (Arnold 1979; North-Coombes 1986; Bour et al. 2014b; Cheke and Bour 2014; Hume 2014).

\section{- Pleurodira}

\section{- Pelomedusidae}

Pelusios castaneus seychellensis (Siebenrock 1906)

(Modern, until ca. 1950)

Seychelles Mud Turtle

Seychelles (Mahé) 
Size: CL ca. $17 \mathrm{~cm}$

Sternothaerus nigricans seychellensis Siebenrock 1906:38 [Seychelles (Mahé)], Pelusios subniger seychellensis, Sternothaerus castaneus seychellensis, Pelusios castaneus seychellensis, Pelusios seychellensis

Comment: Only the type series of this taxon was ever collected, in 1895, but isolated individuals may have persisted until the mid-20th century. Based on genetic analysis, Stuckas et al. (2013) found that the lectotype of P. seychellensis was nested among specimens of West African $P$. castaneus, and concluded that $P$. seychellensis was most likely based on introduced specimens, and recommended the synonymy of $P$. seychellensis with P. castaneus. However, Bour (1983) had identified significant morphological differences between these two taxa, and argued (Bour 2013) that $P$. seychellensis might represent an ancient prehistoric introduction of $P$. castaneus that had subsequently diverged morphologically. He recommended the use of the subspecific designation $P$. castaneus seychellensis until additional comparisons could be made between the taxa, which was followed by TTWG (2014).

$* * * * * * * * *$.

\section{APPENDIX II \\ Fossil Taxa Synonymized with Modern Taxa}

The following named fossil taxa are currently either considered synonymous with extant taxa or to represent actual extant taxa. Determinations and synonymizations have been made by a variety of earlier authorities that we list here, or tentatively by ourselves. We list the fossil names under the extant species that they are synonymized with; for further details and the original citations for the extant species, please refer to our regular checklist (TTWG 2014). We expect that with further reassessments, some of these synonymized taxa may be resurrected as valid and distinct species, either fossil or extant. A few taxa not included on TTWG (2014) are included here for the first time; these are appropriately annotated. As many of these species were synonymized with little or any in-depth analysis by the authorities involved, we urge that a more thorough comparative morphological analysis be undertaken by our paleontological colleagues. We suspect that some of these taxa are actually valid.

\section{- Cryptodira}

\section{_Chelydridae}

Chelydra serpentina (Linnaeus 1758)

Chelydra laticarinata $\dagger$ Hay 1916a:72 (nomen suppressum) [Pleistocene, USA (Florida)]

Comment: Name suppressed by ICZN (1986) in order to not be given nomenclatural precedence over Chelydra osceola Stejneger 1918 whenever the names are synonymous.

Chelydra sculpta $\dagger$ Hay 1916a:73 (nomen suppressum)

[Pleistocene, USA (Florida)]

Comment: Further described by Hay (1917b). Name suppressed by ICZN (1986) in order to not be given nomenclatural precedence over Chelydra osceola Stejneger 1918 whenever the names are synonymous.

\section{_KINOSTERNIDAE}

Kinosternon arizonense Gilmore 1923

Kinosternon arizonense $†$ Gilmore 1923:2 [Pleistocene to Modern, USA (Arizona)], Kinosternon flavescens arizonense

Comment: Recognized as representing a valid extant subspecies by Iverson (1979), who also synonymized Kinosternon flavescens stejnegeri Hartweg 1938 with this taxon. It was later elevated to species status by Serb et al. (2001).

\section{EMYdidAe}

\section{DeIrochelyinae}

Chrysemys picta bellii (Gray 1830b)

Chrysemys timida $\uparrow$ Hay 1908a:345 [Pleistocene, USA (Nebraska)]

Comment: Described by Hay (1908a) as being somewhat similar to Chrysemys bellii and C. picta, the taxon has never been adequately compared to extant Chrysemys picta subspecies. Galbreath (1948) noted that his new Early Pliocene species, $C$. limnodytes, differed from $C$. timida, but did not compare it or C. timida with C. picta. Many fossils of $C$. picta have been described from as far back as the Late Miocene (Ernst 1988), and although $C$. timida may be distinct, we tentatively synonymize it with C. picta bellii pending further analysis.

Pseudemys nelsoni Carr 1938a

Deirochelys floridana $\uparrow$ Hay 1908a:346 (nomen dubium)

[Pleistocene, USA (Florida)]

Comment: Jackson (1964) noted that this species was not a Deirochelys, but most similar to Pseudemys nelsoni or Pseudemys floridana; Jackson (1978) synonymized it with Chrysemys nelsoni (= Pseudemys nelsoni).

Trachemys jarmani $\uparrow$ Hay 1908a:351 (nomen dubium) [Late Pleistocene, USA (Florida)], Pseudemys jarmani Comment: Weaver and Robertson (1967) synonymized this species with extant Deirochelys reticularia. It was reassessed by Jackson (1974) as Chrysemys sp. indet., and synonymized with Chrysemys nelsoni (= Pseudemys nelsoni) by Jackson (1978).

\section{Pseudemys peninsularis Carr 1938b}

Pseudemys floridana persimilis † Hay 1916a:71 (nomen dubium) [Pleistocene, USA (Florida)], Pseudemys floridanus persimilis

Comment: Described as being very similar to Pseudemys floridana.

Pseudemys rubriventris (Le Conte 1830)

Pseudemys extincta $†$ Hay 1908a:356 (nomen dubium)

[Early Pleistocene, Blancan, USA (Florida)]

Comment: Described by Hay (1908a) as similar to extant Pseudemys rubriventris, and Preston (1979) agreed. We tentatively synonymize it with $P$. rubriventris pending further analysis.

Trachemys scripta scripta (Thunberg in Schoepff 1792)

Emys euglypha † Leidy 1889a:97 (nomen dubium) [Pleistocene, USA (Florida)], Trachemys euglypha, Pseudemys euglypha

Comment: Synonymized with Trachemys scripta by 
000e.44 Conservation Biology of Freshwater Turtles and Tortoises • Chelonian Research Monographs, No. 5

Weaver and Robertson (1967), and with T. s. scripta based on its geographic provenance.

Trachemys sculpta † Hay 1908a:351 (nomen dubium)

[Pleistocene, USA (Florida)], Pseudemys sculpta

Comment: Described by Hay (1908a) as being very similar to Pseudemys bisornatus (Cope 1878). Redescribed as distinct by Gilmore (1930). Synonymized with Trachemys scripta by Weaver and Robertson (1967), and with T. s. scripta based on its provenance.

Trachemys delicata † Hay 1916a:66 (nomen dubium) [Pleistocene, USA (Florida)], Pseudemys delicata

Comment: Synonymized with Trachemys scripta by Weaver and Robertson (1967), and with T. s. scripta based on its provenance.

\section{Trachemys scripta elegans (Wied 1839)}

Emys petrolei $\uparrow$ Leidy 1868a:176 [Late Pleistocene,

Rancholabrean, USA (Texas)], Pseudemys petrolei,

Chrysemys petrolei, Chrysemys scripta petrolei,

Trachemys petrolei, Pseudemys scripta petrolei,

Trachemys scripta petrolei

Comment: Treated by Weaver and Robertson (1967) as

a valid extinct subspecies of Chrysemys (= Trachemys) scripta. Preston (1979) suggested that P. bisornatus and T. trulla were possibly synonyms of a valid $T$. s. petrolei. Jackson (1988) considered the recognition of Pleistocene subspecies of Trachemys scripta unwarranted based on lack of sufficient morphologic differentiation; this taxon was synonymized with $T$. s. elegans based on its geographic provenance. Holman (1995) agreed that the distinctness of this subspecies was tenuous.

Pseudemys bisornatus $\dagger$ Cope 1878:228 [Pleistocene, USA

(Texas)], Pseudemys bisornata, Chrysemys scripta

bisornata, Pseudemys scripta bisornata, Trachemys

scripta bisornata, Trachemys scripta bisornatus,

Trachemys bisornata, Trachemys bisornatus

Comment: Recognized by Preston (1966) as a valid extinct subspecies of Pseudemys (= Trachemys) scripta while synonymizing Emys petrolei with T. s. elegans. Jackson (1988) considered the recognition of Pleistocene subspecies of Trachemys scripta unwarranted; this taxon was synonymized with T. s. elegans based on its provenance. The questionable validity of this taxon was discussed further by Holman (1995).

Trachemys trulla $\dagger$ Hay 1908a:355 (nomen dubium)

[Pleistocene, USA (Texas)], Pseudemys trulla

Comment: The type material is a mixture of primarily Trachemys scripta and one epiplastron of Terrapene carolina, and was synonymized with $T$. scripta by Preston (1979), and with T. s. elegans based on its provenance.

\section{EMYdinae}

Emys or Actinemys marmorata Baird and Girard 1852

Clemmys hesperia $\dagger$ Hay 1903:238 [Miocene-Pliocene, USA (Oregon)]

Comment: Synonymized with Clemmys marmorata (=Emys or Actinemys marmorata) by Brattstrom and Sturn (1959).

Emys or Emydoidea blandingii (Holbrook 1838)

Emys twente $i \uparrow$ Taylor 1943:250 [Pleistocene, USA

(Kansas)]
Comment: Synonymized by Preston and McCoy (1971).

Emys orbicularis orbicularis (Linnaeus 1758)

Emys turfa $†$ Meyer 1835:67 [Holocene, subfossil, Germany]

Comment: Synonymized by Boulenger (1889), Kurck (1917), and Fritz (1992).

Clemmys schlotheimii $\uparrow$ Fitzinger 1835:127 (nomen nudum) [Pleistocene, Germany]

Comment: Synonymized by Karl (2006) and Karl and Paust (2014).

Trionyx schlotheimii $\uparrow$ Fitzinger 1835:128 (nomen nudum)

[Pleistocene, Germany]

Comment: This taxon was not included on TTWG (2014); we include it here based on synonymization by Geinitz (1877) as Cistudo europaea (=Emys orbicularis), and by Karl and Paust (2014).

Emys lutaria borealis $\dagger$ Nilsson 1841:208 [Holocene,

Boreal (Atlantic), subfossil, Sweden]

Comment: Synonymized by Nilsson (1860), Boulenger (1889), and Fritz (1992). Additional Swedish and European subfossil material described by Kurck (1917).

Testudo (Emys) canstadiensis $\dagger$ Plieninger 1847:208 (nomen oblitum) [Pleistocene, Germany]

Comment: This taxon was included under the synonymy of Testudo hermanni on TTWG (2014), based on presumed synonymy by Auffenberg (1974); however, the specimen is actually an Emys orbicularis, and we correct it here based on synonymization by Karl and Tichy (2002).

Cistudo anhaltina $\uparrow$ Giebel 1866:1 [Holocene, subfossil, Germany]

Comment: Synonymized by Kurck (1917) and Fritz (1995a).

Emys orbicularis galloitalica Fritz 1995a

Testudo purgotii $\uparrow$ Ceselli 1846:24 (nomen oblitum) [Late Pleistocene, Italy]

Comment: This overlooked taxon was not included in TTWG (2014); we include it here based on Kotsakis (1982) and Fritz (1995b), who identified it as Emys orbicularis and noted that Italian fossil specimens were larger than modern E. o. galloitalica, and that the name $T$. purgotii was available if subspecific designation was needed for the Pleistocene taxon. Though $T$. purgotii has nomenclatural priority over E. o. galloitalica, it has never been used since its description in 1846, and is therefore a nomen oblitum.

Emys latens $\uparrow$ Portis 1890:16 (nomen dubium) [Late Pliocene to Early Pleistocene, Villafranchian, Italy] Comment: Synonymized by Chesi (2009) and Rook et al. (2013).

Emys major $\uparrow$ Portis 1890:16 (nomen dubium) [Late Pliocene to Early Pleistocene, Villafranchian, Italy] Comment: Synonymized by Chesi (2009) and Rook et al. (2013).

Terrapene carolina carolina (Linnaeus 1758)

Cistudo eurypygia $†$ Cope 1870b:124 [Pleistocene, USA

(Maryland)], Terrapene eurypygia

Comment: Synonymized by Milstead (1965).

Toxaspis anguillulatus $\dagger$ Cope 1899:196 [Pleistocene, USA (Pennsylvania)], Terrapene anguillulatus 
Comment: Synonymized with Cistudo eurypygia by Hay (1908a).

Testudo munda $\dagger$ Hay 1920:86 [Pleistocene, USA

(Tennessee)]

Comment: Described based on fragmentary material as a Testudinidae, it was reexamined and determined to be an Emydidae and synonymized with Terrapene carolina by Auffenberg (1963).

Terrapene carolina bauri Taylor 1895

Terrapene innoxia $\dagger$ Hay 1916a:61 [Pleistocene, USA

(Florida)]

Comment: Synonymized with $T$. canaliculata $(=T$. $c$. major) by Barbour and Stetson (1931), but with $T$. $c$. bauri by Auffenberg (1958).

Trachemys nuchocarinata $\dagger$ Hay 1916a:70 (nomen dubium) [Pleistocene, USA (Florida)]

Comment: Synonymized by Auffenberg (1958).

Terrapene singletoni $\uparrow$ Gilmore 1927:1 [Pleistocene, USA (Florida)]

Comment: Synonymized with $T$. canaliculata $(=T . c$. major) by Barbour and Stetson (1931), but with T. $c$. bauri by Auffenberg (1958).

Terrapene carolina major (Agassiz 1857)

Cistudo marnochii $†$ Cope 1878:229 [Pliocene-Pleistocene, USA (Texas)], Terrapene marnochii

Comment: Considered by Milstead (1965) to be an intermediate form between $T$. $c$. putnami and $T$. $c$. triunguis, but closer to T.c. putnami.

Terrapene putnami $\dagger$ Hay 1906:30 [Pliocene? to Late Pleistocene?, USA(Florida)], Terrapene carolina putnami Comment: Terrapene putnami was described by Hay (1906) from a single fossil hypoplastron with imprecise stratigraphic data, originally stated to be Pliocene, but later assumed to be Late Pleistocene. Auffenberg (1958) recognized putnami as a valid extinct subspecies of $T$. carolina, and Auffenberg (1967b) described apparent hybridization between T. c. putnami and fossil specimens of T. c. bauri and T. c. major. Holman (1995) tentatively recognized T. c. putnami as a valid extinct subspecies that had hybridized with other extant subspecies of T. carolina. Through difficulty of identification, T. putnami has come to inappropriately represent virtually all eastern North American fossil Terrapene material from the Miocene to the late Pleistocene (Ehret et al. 2013). This has become problematic because molecular analyses of extant taxa have suggested that T. putnami should either be synonymized with $T$. carolina major (Butler et al. 2011), or retained as a separate taxon, as an extinct subspecies of T. carolina (Martin et al. 2013). To facilitate resolution of the relationships among living and fossil turtles of the $T$. carolina complex, Ehret et al. (2013) proposed to the ICZN the designation of a more or less complete neotype specimen for T. putnami, with precise locality and stratigraphic data. The TTWG (2014) chose to maintain T.putnami as a listed synonym of T. carolina major pending an ICZN ruling and further research on the relationships of extant and fossil taxa, but the extinct taxon T. putnami appears to be distinct at the species level (Bourque, unpubl. data).
Terrapene canaliculata $\dagger$ Hay 1907:850 [Pliocene-Early Pleistocene, USA (Georgia)]

Comment: Redescribed by Gilmore (1927). Synonymized with T. c. major by Barbour and Stetson (1931), and with T. c. putnami by Auffenberg (1958).

Terrapene formosa $\dagger$ Hay 1916a:57 [Late Pleistocene, USA (Florida)]

Comment: Synonymized with T. c. putnami by Barbour and Stetson (1931); considered by Auffenberg (1958) to be intermediate between T.c. carolina and T. c. bauri.

Terrapene antipex $\uparrow$ Hay 1916a:58 [Late Pleistocene, USA (Florida)]

Comment: Synonymized with T. canaliculata by Gilmore (1927) and with T.c. putnami by Auffenberg (1958).

Terrapene carolina triunguis (Agassiz 1857)

Terrapene whitneyi $\dagger$ Hay 1916b:8 [Pleistocene, USA

(Texas)]

Comment: Synonymized by Milstead (1965).

Terrapene bulverda $\dagger$ Hay 1920:133 [Pleistocene, USA (Texas)]

Comment: Synonymized by Oelrich (1953) and Milstead (1956).

Terrapene impressa $\dagger$ Hay 1924:245 [Pleistocene, USA (Texas)], Terrapene impensa Comment: Synonymized by Oelrich (1953) and Milstead (1956).

Terrapene llanensis $\uparrow$ Oelrich 1953:35 [Late Pleistocene, Sangamonian, USA (Kansas)]

Comment: Synonymized with $T$. canaliculata by Milstead (1956) and designated an intergrade between $T$. c. triunguis and T. c. putnami by Milstead (1967).

Terrapene ornata ornata (Agassiz 1857)

Terrapene longinsulae $\uparrow$ Hay 1908b:166 [Late Miocene or Early Pliocene to possibly Pleistocene, USA (Kansas)], Terrapene ornata longinsulae

Comment: Treated as a valid extinct subspecies of $T$. ornata by Milstead (1967). Synonymized with T. ornata by Joyce et al. (2012), who noted that the holotype may have originated from either Kansas or Nebraska and could be anywhere from Early Miocene to Late Pleistocene in age.

\section{_GEOEMYDIDAE}

\section{Geoemydinae}

Batagur affinis affinis (Cantor 1847)

Batagur siebenrocki $\dagger$ Jaekel 1911:76 [Pleistocene, Trinil

Beds, Indonesia (Java)]

Comment: Synonymized with Batagur baska by Karl (1987) prior to the taxonomic split between $B$. baska and $B$. affinis. Synonymization updated to reflect current taxonomy and distribution of Batagur.

\section{Batagur dhongoka (Gray 1832)}

Batagur durandi $\uparrow$ Lydekker 1885:192 [Late Pliocene to Early Pleistocene, Siwaliks, India (Punjab)] Comment: Synonymized with Kachuga dhongoka (= Batagur dhongoka) by Boulenger (1889). 
Batagur kachuga (Gray 1831a)

Batagur bakeri $\dagger$ Lydekker 1885:190 [Late Pliocene to Early Pleistocene, Siwaliks, India (Punjab)] Comment: Synonymized with Kachuga lineata (= Batagur kachuga) by Boulenger (1889).

Cuora flavomarginata flavomarginata (Gray 1863)

Terrapene culturalia $\dagger$ Yeh 1961:59 [Holocene, Neolithic, subfossil, China (Shandong)], Emydoidea culturalia Comment: Assigned to Emydoidea by Milstead (1965); synonymized with Cuora flavomarginata by McCoy and Richmond (1966).

Geoclemys hamiltonii (Gray 1830b)

Clemmys palaeindica $\uparrow$ Lydekker 1885:178 [Late Pliocene to Early Pleistocene, Siwaliks, India (Punjab)] Comment: Synonymized with Damonia hamiltonii (= Geoclemys hamiltonii) by Boulenger (1889).

Geoclemys sivalensis $\dagger$ Tewari and Badam 1969:555 [Early Pleistocene, Upper Siwaliks, India (Punjab)] Comment: Synonymized by Das (1991).

Hardella thurjii (Gray 1831b)

Batagur falconeri $\uparrow$ Lydekker 1885:187 [Late Pliocene to Early Pleistocene, Siwaliks, India (Punjab)], Hardella falconeri

Comment: Synonymized with Hardella thurgi (= Hardella thurjii) by Boulenger (1889).

Batagur cautleyi $\uparrow$ Lydekker 1885:194 [Late Pliocene to Early Pleistocene, Siwaliks, India (Punjab)]

Comment: Synonymized with Hardella thurgi (= Hardella thurjii) by Boulenger (1889).

Clemmys watsoni $\uparrow$ Lydekker 1886:540 [Late Pliocene to Early Pleistocene, Siwaliks, India (Gujrat)]

Comment: This taxon was inadvertently not included on TTWG (2014); we include it here based on synonymization by Lydekker (1889b) and Boulenger (1889).

Geoemyda pilgrimi $\uparrow$ Prasad and Satsangi 1967 [Late Pliocene to Early Pleistocene, Siwaliks, India (Himachal Pradesh)] Comment: This taxon was inadvertently not included on TTWG (2014); we include it here based on synonymization by Das (1994).

\section{Mauremys nigricans (Gray 1834a)}

Geoclemys palaeannamitica $\dagger$ Bourret 1941:10

[Holocene, Neolithic, subfossil, Vietnam], Chinemys palaeannamitica

Comment: Recognized as distinct by Bour (1980), but synonymized with Chinemys nigricans (= Mauremys nigricans) by Pritchard (1994).

Mauremys reevesii (Gray1831b)

Chinemys pani $\uparrow$ Tao 1985:45 [Pleistocene, Chi-Ting, Taiwan] Comment: Described as being very similar to Chinemys reevesii (= Mauremys reevesii).

\section{Mauremys sinensis (Gray 1834a)}

Testudo anyangensis $\dagger$ Ping 1930:217 [Holocene, Neolithic, subfossil, China (Henan)], Pseudocadia anyangensis Comment: Provisionally synonymized with Mauremys mutica by McDowell (1964), synonymized with Ocadia sinensis (= Mauremys sinensis) by Zhao and Adler (1993) without justification, but confirmed by Pritchard (1994).

Ocadia sinensis changwui $\uparrow$ Tao 1988:229 [Late

Pleistocene, Taiwan]

Comment: Synonymized with Ocadia sinensis (= Mauremys sinensis) by Zhao and Adler (1993).

Melanochelys tricarinata (Blyth 1856)

Nicoria tricarinata sivalensis $\dagger$ Lydekker 1889b:100 [Late Pliocene to Early Pleistocene, Siwaliks, India (Punjab)], Nicoria sivalensis

Comment: Synonymized with Nicoria (= Melanochelys) tricarinata by Lydekker (1889c).

Melanochelys trijuga indopeninsularis (Annandale 1913)

Clemmys sivalensis $\dagger$ Lydekker 1885:170 (nomen dubium) [Late Pliocene to Early Pleistocene, Siwaliks, India

(Punjab)], Bellia sivalensis

Comment: Synonymized with Geoemyda (= Melanochelys) trijuga by Smith (1931), and with M.t. indopeninsularis based on its geographic provenance.

Clemmys hydaspica $\uparrow$ Lydekker 1885:172 (nomen dubium) [Late Pliocene to Early Pleistocene, Siwaliks, India

(Punjab)], Clemmys hydraspica

Comment: Synonymized with Bellia sivalensis (= Clemmys sivalensis) by Lydekker (1889a), with Geoemyda (= Melanochelys) trijuga by Smith (1931), and with M.t.indopeninsularis based on its provenance.

Clemmys theobaldi $\uparrow$ Lydekker 1885:173 (nomen dubium)

[Late Pliocene to Early Pleistocene, Siwaliks, India

(Punjab)], Bellia theobaldi

Comment: Synonymized with Geoemyda (= Melanochelys) trijuga by Smith (1931), and with M.t. indopeninsularis based on its provenance.

Clemmys punjabiensis $\dagger$ Lydekker 1885:175 (nomen dubium) [Late Pliocene to Early Pleistocene, Siwaliks, India (Punjab)]

Comment: Synonymized with Bellia theobaldi (= Clemmys theobaldi) by Lydekker (1889a), with Geoemyda (= Melanochelys) trijuga by Smith (1931), and with M.t.indopeninsularis based on its provenance.

Orlitia borneensis Gray 1873a

Batagur signatus $\dagger$ Jaekel 1911:77 [Pleistocene, Trinil

Beds, Indonesia (Java)]

Comment: Synonymized by Karl (1987).

Pangshura tecta (Gray 1830a)

Emys namadicus $\uparrow$ Theobald 1860:295 (nomen nudum)

[Tertiary, Nerbudda, India], Emys namadica

Comment: Listed as a synonym of Kachuga tecta (= Pangshura tecta) by Boulenger (1889) and Lydekker (1889b).

\section{_TeSTUdinIDAe}

Gopherus berlandieri (Agassiz 1857)

Gopherus auffenbergi $\uparrow$ Mooser 1972:61 [Late Pleistocene, Mexico (Aguascalientes)], Xerobates auffenbergi Comment: This taxon was synonymized with $G$. berlandieri by Reynoso and Montellano-Ballesteros (2004), but treated as distinct and most closely related to G. berlandieri by Bramble and Hutchison (2014) and 
Franz (2014), but without detailed analysis.

Gopherus flavomarginatus Legler 1959

Gopherus huecoensis $\uparrow$ Strain 1966:24 [Early Pleistocene, Blancan, USA (Texas)], Gopherus huacoensis Comment: This taxon was synonymized with $G$. flavomarginatus by Bramble (1982) and Reynoso and Montellano-Ballesteros (2004), but treated as distinct and most closely related to G. flavomarginatus by Bramble and Hutchison (2014) and Franz (2014), but without detailed analysis. It may well be distinct and further analysis is clearly needed.

Gopherus polyphemus (Daudin 1801)

Testudo atascosae † Hay 1902:383 (nomen dubium) [Pleistocene, USA (Texas)], Gopherus atascosae Comment: Synonymized by Bramble (1982).

Gopherus praecedens $\uparrow$ Hay 1916a:55 [Late Pleistocene, USA (Florida)]

Comment: Synonymized by Auffenberg (1974).

Testudo hermanni hermanni Gmelin 1789

Testudo globosa † Portis 1890:3 [Late Pliocene to Early Pleistocene, Villafranchian, Italy], Eurotestudo globosa Comment: Synonymized by Lapparent de Broin et al. (2006c) and Rook et al. (2013).

Testudo oriens $\uparrow$ Portis 1890:9 [Late Pliocene to Early Pleistocene, Villafranchian, Italy]

Comment: Synonymized by Lapparent de Broin et al. (2006c) and Rook et al. (2013).

Testudo seminota $\uparrow$ Portis 1890:10 [Late Pliocene to Early Pleistocene, Villafranchian, Italy]

Comment: Synonymized by Lapparent de Broin et al. (2006c) and Rook et al. (2013).

Testudo marginata Schoepff 1793

Testudo marginata cretensis $\dagger$ Bachmayer, Brinkerink, and Symeonidis 1975:111 [Pleistocene, Greece (Crete)] Comment: Described as endemic to Crete, this taxon was previously recognized as subspecifically distinct, and specimens have been recorded from as recently as the Late Pleistocene (Georgalis and Kear 2013). However, according to analysis of fossil material by Vlachos (2015), taxonomic morphologic distinction from mainland T. marginata is not justified, and the taxon is therefore hereby synonymized pending further analysis (Delfino, pers. comm.).

\section{TrionyChIDAE}

\section{Cyclanorbinae}

\section{Lissemys ceylonensis (Gray 1856a)}

Lissemys punctata sinhaleyus $\dagger$ Deraniyagala 1953:5 (nomen dubium) [Late Pleistocene, Ratnapura Beds, Sri Lanka] Comment: This taxon was described from a single hypoplastron very similar to L. ceylonensis; taxonomic distinction is not demonstrably justified, and the taxon is hereby synonymized pending further analysis.

\section{TrionychinaE}

Amyda cartilaginea (Boddaert 1770)

Trionyx trinilensis $\dagger$ Jaekel 1911:78 [Pleistocene, Trinil

Beds, Indonesia (Java)]

Comment: Synonymized with Trionyx cartilagineus (= Amyda cartilaginea) by Karl (1987); agreed by van Dijk (unpubl. data).

Chitra chitra javanensis McCord and Pritchard 2003

Chitra selenkae † Jaekel 1911:80 (nomen suppressum) [Pleistocene, Trinil Beds, Indonesia (Java)]

Comment: Synonymized with Chitra indica by Karl (1987) and with Chitra chitra by McCord and Pritchard (2003), who noted that $C$. selenkae was essentially a nomen oblitum; the name was later suppressed by the ICZN (2005).

Nilssonia hurum (Gray 1830b)

Trionyx hurum sivalensis $\dagger$ Lydekker 1889b:9 [Late Pliocene to Early Pleistocene, Siwaliks, India (Punjab)], Trionyx sivalensis

Comment: Described by Lydekker (1885) as an unnamed Trionyx sp. and later designated a named variety of Trionyx hurum (Lydekker 1889b). We tentatively synonymize it with Nilssonia hurum pending further analysis.

Pelochelys cantorii Gray 1864

Chitra minor $\dagger$ Jaekel 1911:80 [Pleistocene, Trinil Beds, Indonesia (Java)]

Comment: Synonymized with Chitra indica by Karl (1987) and with Pelochelys cantorii by McCord and Pritchard (2003).

Rafetus swinhoei (Gray 1873b)

Pelochelys taihuensis $\uparrow$ Zhang 1984:71 [Holocene, Neolithic, subfossil, China (Zhejiang)]

Comment: Synonymized by Farkas (1992).

Trionyx liupani $\uparrow$ Tao 1986:28 [Late Pleistocene, Taiwan] Comment: Synonymized by Farkas (1992).

\section{- Pleurodira}

Chelidae

\section{Chelodininae}

Elseya lavarackorum (White and Archer 1994) Emydura lavarackorum $\uparrow$ White and Archer 1994:159 [Pleistocene to Modern, Australia (Queensland)], Elseya lavarackorum, Elseya dentata lavarackorum Comment: Recognized as representing a valid extant species by Thomson et al. (1997).

\section{HYdROMEDUSINAE}

Hydromedusa tectifera Cope 1870a

Platemys antiqua $†$ Ameghino 1882:41 (nomen nudum) [Pleistocene or Holocene, Argentina (Buenos Aires)] Comment: Synonymized by de la Fuente (1992).

Platemys fossilis $\uparrow$ Ameghino 1882:41 (nomen nudum) [Pleistocene or Holocene, Argentina (Buenos Aires)] Comment: Synonymized by de la Fuente (1992).

Platemys laevis $\dagger$ Ameghino 1882:41 (nomen nudum) 
000e.48 Conservation Biology of Freshwater Turtles and Tortoises • Chelonian Research Monographs, No. 5

[Pleistocene or Holocene, Argentina (Buenos Aires)] Comment: Synonymized by de la Fuente (1992).

Platemys robusta $†$ Ameghino 1882:41 (nomen nudum)

[Pleistocene or Holocene, Argentina (Buenos Aires)]

Comment: Synonymized by de la Fuente (1992).

\section{Pelomedusidae}

Pelusios sinuatus (Smith 1838)

Sternothaerus rudolphi $\uparrow$ Arambourg 1947:461 [Pleistocene, Ethiopia (Lake Turkana)], Pelusios rudolphi

Comment: Synonymized with Pelusios sinuatus by Broin (1969) after reexamination of the original type material of rudolphi and extensive new material of fossil and extant sinuatus.

$$
* * * * * * * * *
$$

\section{APPENDIX III \\ "Pleistocene" Taxa Now Considered Older}

The following named fossil taxa, sometimes considered to be of possible Pleistocene or Plio-Pleistocene origin, are more likely to represent older, possibly earlier Pliocene or Miocene taxa, and may or may not be considered valid.

\section{- Cryptodira}

\section{Testudinidae}

Chelonoidis elata (Gervais 1877) (nomen dubium)

(Late Miocene to Early Pleistocene?)

Solimões Giant Tortoise

Brazil (Acre)

Size: "very large, similar to Colossochelys atlas"

Testudo elata $\dagger$ Gervais 1877:283 (nomen dubium)

[Late Miocene or Early Pleistocene, Solimões

Formation, Brazil (Acre)], Geochelone (Che-

lonoidis) elata, Geochelone elata, Chelonoidis elata

Comment: The Solimões Formation, where the type was collected, has sometimes been considered to be Early Pleistocene, but has recently been shown to be Miocene (Latrubesse et al. 2010). Oliveira and Romano (2007) considered this name to be a nomen dubium.

Homopus fenestratus Cooper and Broadley 1990 (Late Neogene; possibly Pliocene to Early Pleistocene) Fenestrated Tortoise

South Africa

Size: CL ca. $9 \mathrm{~cm}$

Homopus fenestratus $\uparrow$ Cooper and Broadley 1990:41 [Late Neogene, Plio-Pleistocene?, South Africa (Cape)]

Comment: The collection data on this specimen was imprecise and its stratigraphy very uncertain. We consider it tentatively an earlier Pliocene taxon.

Testudo kalganensis Gilmore 1931

(Tertiary; Pliocene to Early Pleistocene?)

Kalgan Tortoise

China (Hebei)

Size: CL ca. 27-28 cm
Testudo kalganensis $\dagger$ Gilmore 1931:247 [Tertiary, Plio-Pleistocene?, Kalgan region, North China (Hebei)], Gopherus kalganensis, Geochelone (Hesperotestudo) kalganensis, Hesperotestudo kalganensis, Protestudo kalganensis

Comment: The collection data on this specimen associated it with the "Nantienmen" Cretaceous beds, however, a good argument for it not being that old was made by Gilmore (1931), who assigned it questionably to the Tertiary. Williams (1950) noted similarities between this species and two species of Gopherus, which seems to have lead to Auffenberg (1974) to place it in the subgenus Hesperotestudo. He also restricted the questionable age range of the species to the Plio-Pleistocene. Crumly (1983) expressed doubts that the species was that recent, so its inclusion in this checklist is dubious from an age perspective. It would seem that comprehensive reassessment of the fossil site would be required to have confidence in its age (Crumly, pers. comm.). Assignment of this species to the genus Hesperotestudo was also called into question by Crumly (1983), a point reiterated by Meylan and Sterrer (2000), hence we keep it in the genus Testudo. Chkhikvadze (1989) considered this species within his genus Protestudo.

Titanochelon schafferi (Szalai 1931)

(Late Miocene)

Samos Giant Tortoise

Greece (Samos Island)

Size: CL ca. 185-200 cm

Testudo schafferi $\uparrow$ Szalai 1931:1 [Late Miocene, Greece (Samos)], Geochelone schafferi, Cheirogaster schafferi, Titanochelon schafferi

Comment: This taxon is now known to occur only in its type locality (Late Miocene of Samos Island, Greece). All other known later occurences of gigantic tortoises from the Pliocene and Pleistocene of Greece are now believed to represent distinct taxa, such as the case of the Lesvos giant tortoise (Kear and Georgalis 2009; Georgalis and Kear 2010, 2013).

\section{- Pleurodira}

\section{_Chelidae}

\section{Chelinae}

Chelus macrococcygeanus (Barbosa Rodrigues 1892) (nomen dubium)

(Miocene to Early Pleistocene?)

Loreto Solimões Matamata

Peru (Loreto)

Size: undetermined

Colossoemys macrococcygeana $\uparrow$ Barbosa Rodrigues 1892:44 (nomen dubium) [Miocene, Solimões, Peru (Loreto)], Emys macrococcygeana, Emys macrocygea, Chelus macrococcygeanus

Comment: Kuhn (1964) misspelled the name as Emys macrocygea and stated that the type material consisted of an admixture of turtle and crocodile bones from the Pleistocene and Late Tertiary. The Solimões Formation, where the type was collected, has sometimes been considered to be Early Pleistocene, but has recently 
been shown to be Miocene (Latrubesse et al. 2010). Oliveira and Romano (2007) considered this name to be a nomen dubium, and noted that the limited fragmentary type material had been lost. This taxon is probably synonymous with the Miocene species Chelus lewisi (Wood 1976), as Bocquentin et al. (2001) assigned material from the same formation (Solimões of Venezuela and Acre, Brazil), to that species, but the name is a nomen dubium and nomen oblitum and should not replace $C$. lewisi through priority.

Chelus quaternarius (Barbosa Rodrigues 1892) (nomen dubium)

(Miocene to Early Pleistocene?)

Acre Solimões Matamata

Brazil (Acre)

Size: "ca. same size as Podocnemis unifilis"

Emys quaternaria $\dagger$ Barbosa Rodrigues 1892:42 (nomen dubium) [Miocene, Solimões, Acre, Brazil], Chelus quaternarius, Podocnemis quaternaria

Comment: Same as for C. macrococcygeanus. Most likely synonymous with $C$. macrococcygeanus and Miocene $C$. lewisi, but is a nomen dubium and nomen oblitum and should not replace $C$. lewisi through priority.

Phrynops paranaensis (Wieland 1923)

(Late Miocene to Early Pliocene?)

Parana Sideneck Turtle

Argentina (Entre Rios)

Size: undetermined

Parahydraspis paranaensis $\dagger$ Wieland 1923:6 [Late Miocene or Early Pliocene, Formación Ituzaingó, Argentina], Phrynops paranaensis

Comment: Previously hypothesized to be from the Late Pliocene or Early Pleistocene and most similar to members of the Phrynops geoffroanus complex (Rhodin and Mittermeier 1983; Argañaraz and Piña 2000) and tentatively placed by several authors in the synonymy of Phrynops geoffroanus (e.g., TTWG 2014). This species is instead most likely Late Miocene (Tortonian) in origin (Cione et al. 2000), and unlikely to be synonymous with any modern Phrynops (de la Fuente, unpubl. data).

$* * * * * * * * *$.

\section{APPENDIX IV \\ Indeterminate Pleistocene Fossil Taxa}

The following named fossil taxa, considered to be of possible Pleistocene or Plio-Pleistocene origin, are generally considered to be relatively unidentifiable nomina dubia. With further study some of these may become recognizable as distinct and valid.

\section{- Cryptodira}

\section{_ CheloniIDae}

“Chelone” gastaldii Portis 1880 (nomen dubium)

(Late Pliocene to Early Pleistocene)

Gastaldi's Sea Turtle

Italy

Size: undetermined
Chelone gastaldii $\uparrow$ Portis 1880:115 (nomen dubium) [Late Pliocene to Early Pleistocene, Villafranchian, Italy]

Comment: Based on an internal mold of a skull, Lapparent de Broin (2001) listed this species as Cheloniidae gen. indet.

“Chelone” murua De Vis 1905 (nomen dubium)

(Pleistocene?)

Murua Sea Turtle

Papua New Guinea (Woodlark Island [Murua])

Size: "larger than living species"

Chelone murua $\dagger$ De Vis 1905:30 (nomen dubium)

[Quaternary, Papua New Guinea (Woodlark Island)]

Comment: Described from probable Pleistocene deposits along with a dugong and a narrow-snouted crocodile (see Molnar 1982), and differentiated from extant Chelone virgata (= Chelonia mydas) and hawksbills (= Eretmochelys imbricata) on the basis of its larger shell size and lack of contact between the costal ribs and the marginals. Reassessed by Gaffney (1981), who assigned it to Cheloniidae, gen. indet. It is unlikely that this taxon represents a valid species, but it has not been adequately compared to living Cheloniidae, and has not been formally synonymized.

“Chelone” simonellii Porta 1898 (nomen dubium)

(Late Pliocene to Early Pleistocene)

Simonelli's Sea Turtle

Italy

Size: undetermined

Chelone simonellii $\uparrow$ Porta 1898:116 (nomen

dubium) [Late Pliocene to Early Pleistocene, Villafranchian, Italy]

Comment: Lapparent de Broin (2001) listed this species as Cheloniidae gen. indet.

“Chelone" sismondai Portis 1880 (nomen dubium)

(Late Pliocene to Early Pleistocene)

Sismonda's Sea Turtle

Italy

Size: undetermined

Chelone sismondai $\uparrow$ Portis 1880:117 (nomen dubium) [Late Pliocene to Early Pleistocene, Villafranchian, Italy]

Comment: Lapparent de Broin (2001) listed this species as Cheloniidae gen. indet.

"Chelone" sordellii Strobel in Porta 1898 (nomen dubium) (Late Pliocene to Early Pleistocene)

Sordelli's Sea Turtle

Italy

Size: undetermined

Chelone sordellii $\uparrow$ Strobel in Porta 1898:111 (nomen dubium) [Late Pliocene to Early Pleistocene, Villafranchian, Italy], Archaeochelonia sordellii

Comment: Lapparent de Broin (2001) listed this species as Cheloniidae gen. indet.

“Chelone” strobeli Porta 1898 (nomen dubium) (Late Pliocene to Early Pleistocene) 
Strobel's Sea Turtle

Italy

Size: undetermined

Chelone strobeli $\uparrow$ Porta 1898:105 (nomen dubium)

[Late Pliocene to Early Pleistocene, Villafranchian, Italy]

Comment: Lapparent de Broin (2001) listed this species as Cheloniidae gen. indet.

“Pliochelys" derelicta Portis 1890 (nomen dubium)

(Late Pliocene to Early Pleistocene)

Valdarno Sea Turtle

Italy

Size: undetermined

Pliochelys derelicta $\uparrow$ Portis 1890:17 (nomen dubium) [Late Pliocene to Early Pleistocene, Villafranchian, Italy]

Comment: Described from a single small carapace fragment, Portis (1890) originally thought this taxon was a side-neck turtle (his family Chelydidi), but later (Boulenger in Portis 1896) synonymized it with the modern cheloniid, Thalassochelys caretta. Kotsakis (1980) agreed, listing it as a synonym under Caretta caretta, but Lapparent de Broin (2001) and Chesi (2009) listed it as Cheloniidae gen. indet., as noted also by Rook et al. (2013).

\section{TestudinIDae}

“Testudo" suttoensis Szalai 1934 (nomen dubium)

(Late Pleistocene)

Sutto Tortoise

Hungary

Size: "small"

Testudo süttöensis $†$ Szalai 1934:131 (nomen $d u$ bium) [Late Pleistocene, Travertine, Hungary], Testudo suttoensis

Comment: This species was not recognized by Lapparent de Broin (2001), but was listed in an archaeological context by Pazonyi (2013). The taxon was founded on very fragmented extremity bones, e.g. humerus, femur, coracoid and shell fragments only, and needs reassessment. It may actually represent the modern emydid turtle Emys orbicularis (Karl, pers. comm.). Diacritical marks in taxonomic names are not acceptable under the ICZN, thereby requiring emendation of süttöensis to suttoensis.

“Testudo” sellovii (Weiss 1830) (nomen dubium)

(Pleistocene)

Southern Cone Giant Tortoise

Uruguay, Argentina?

Size: "giant"

Testudinites sellovii $\uparrow$ Weiss 1830:293 (nomen dubium) [Pleistocene, Uruguay], Testudo sellovii, Chelonoidis sellovii

Testudo sellowi $\uparrow$ Paula Couto 1948:1 (nomen novum) [Pleistocene, Uruguay], Geochelone (Chelonoidis) sellowi, Geochelone sellowi, Chelonoidis sellowi

Comment: The generic name "Testudinites" was an old combination form using the suffix -ites for describing fossils of Testudo, and under ICZN Rules (Art. 20) has no validity as a separate generic name, being referred instead back to the stem name, Testudo. Also, the original collector was named Sellow, so Paula Couto (1948) changed the spelling of the specific name in order to correspond to his name's spelling, but this was an unjustified emendation. Based on the plate in Weiss (1830) and reproduced by Paula Couto (1948), the fragmentary nature of the holotype of $T$. sellovii precludes assignment to the genus Chelonoidis or identification as a new species (de la Fuente, pers. comm.).

\section{TrionychIDAE}

\section{TrionYCHINAE}

“Trionyx” kazusensis Otsuka 1969 (nomen dubium)

(Early Pleistocene)

Kazusa Softshell

Japan (Kyushu)

Size: "larger than Pelodiscus sinensis"

Trionyx kazusensis † Otsuka 1969:61 (nomen

dubium) [Early Pleistocene, Japan (Kyushu)]

Comment: Species established on the basis of a few isolated or fragmentary shell components, a scapula, and an incompelete ilium; distinguished from Pelodiscus sinensis in having a larger size, thicker shell, quadrate first neural, and deep and wide pits on the shell. However, no diagnostic features for its generic allocation were noted in the materials, and further work is needed.

\section{- Pleurodira}

\section{Chelidae}

“Hydraspis” arenarius Rusconi 1934 (nomen dubium) (Late Pliocene to Early Pleistocene)

Sand Sideneck Turtle

Argentina

Size: undetermined

Hydraspis arenarius $\dagger$ Rusconi 1934:32 (nomen dubium) [Late Pliocene to Early Pleistocene, Argentina]

Comment: Considered unidentifiable beyond generic level by de la Fuente (1992; unpubl. data); possibly a $\mathrm{Hy}$ dromedusa or Phrynops, and possibly Miocene in origin.

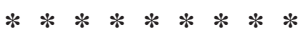

\section{LITERATURE CITED}

Abbazzi,L.,Carboni,S.,Delfino,M.,Gallai,G.,Lecca,L., and Rook, L. 2008. Fossil vertebrates (Mammalia and Reptilia) from Capo Mannu Formation (Late Pliocene, Sardinia, Italy), with description of a new Testudo (Chelonii, Testudinidae) species. Rivista Italiana di Paleontologia e Stratigrafia 114:119-132.

Acuña-Mesén, R.A. and Laurito, C.A. 1996. Nueva especie de Rhinoclemmys Fitzinger, 1836 (Chelonii, Cryptodira) del Cenozoico tardío de Costa Rica. Ameghiniana 33(3):271-278.

ADAMs, A.L. 1877. On gigantic land-tortoises and a small freshwater species from the ossiferous caverns of Malta, together with a list of their fossil fauna; and a note on chelonian remains from the rockcavities of Gibraltar. Quarterly Journal of the Geological Society of London 33:177-191. 
ADLER, K. 1968. Turtles from archeological sites in the Great Lakes region. Michigan Archaeologist 14:147-163.

AdLER, K. 1970. The influence of prehistoric man on the distribution of the box turtle. Annals of the Carnegie Museum 41:263-280.

Agassiz, L. 1857. Contributions to the Natural History of the United States of America. First Monograph. Vol. I. Part I. Essay on Classification.PartII.NorthAmerican Testudinata.Boston:Little,Brown and Co., Vol. I, pp. 1-452.

Agustí, J., Vekua, A., Oms, O., LoRdKIPANIDZe, D., Bukhsianidze, M., KILADZE, G., AND Rook, L. 2009. The Pliocene-Pleistocene succession of Kvabebi (Georgia) and the background to the early human occupation of Southern Caucasus. Quaternary Science Reviews 28:3275-3280.

AHL, E. 1926. Über eine ausgestorbene Riesenschildkröte der Insel Teneriffa. Zeitschrift der Deutschen Geologischen Gesellschaft 77(4):575-580.

AleKPerov, A.M. 1978. Zemnovodnye i presmykayuschiesya Azerbaydzhana. [Amphibians and reptiles of Azerbaijan]. Baku: Elm, 264 pp.

Almera, D.J. AND Bofill, A.P. 1903. Consideraciones sobre los restos fósiles cuaternarios de la caverna de Gracia (Barcelona). Memorias de la Real Academia de Ciencias y Artes de Barcelona 4(33):95-112.

Ameghino, F. 1882. Catálogo explicativo de las colecciones de Antroplogía, prehistoria y de paleontología de Florentino Ameghino. Buenos Aires: Catálogo de la Sección de la Provincia de Buenos Aires en la Exposición Continental SudAmericana,AnexoA:35-42.

Anadón, J.D., Graciá, E., Botella, F., Giménez, A., Fahd, S., And FRITZ, U. 2015. Individualistic response to past climate changes: niche differentiation promotes diverging Quaternary range dynamics in the subspecies of Testudo graeca. Ecography 38:001-011.

Anderson, C. 1925. Notes on the extinct chelonian Meiolania, with a record of a new occurrence. Records of the Australian Museum 14:223-242.

Annandale, N. 1913. The tortoises of Chota Nagpur. Records of the Indian Museum 9(5):63-78.

ARAmBourg, C. 1947. Contribution à l'étude géologique et paléontologique du bassin du lac Rodolphe et de la basse vallée de l'Omo. In: Arambourg, C. (Ed.). Mission scientifique de l'Omo. Vol. 1: Géologie etAnthropologie.Paris:Editions du Muséum,pp.231-562.

Archer,W.,Braun,D.R.,Harris,J.W.K.,McCoy,J.T., ANDRichmond, B.G. 2014. Early Pleistocene aquatic resource use in the Turkana Basin. Journal of Human Evolution 77:74-87.

Argañaraz, B. And PiÑa, C.I. 2000. Quelonios de la Formación Ituzaingó (Mioceno superior-Plioceno), en Villa Urquiza, Entre Ríos, Argentina. In: Aceñolaza, F.G. and Herbst, R. (Eds.). El Neógeno de Argentina. Correlación Geológica 14:239-244.

ARNOLD, E.N. 1979. Indian Ocean giant tortoises: their systematics and island adaptations. Philosophical Transactions of the Royal Society of London 286B:127-145.

AUFFENBERG, W. 1958. Fossil turtles of the genus Terrapene in Florida. Bulletin of the Florida State Museum 3:53-92.

AufFENBERG, W. 1962. A new species of Geochelone from the Pleistocene of Texas. Copeia 1962(3):627-636.

AufFenBERG, W. 1963. Fossil testudinine turtles of Florida, genera Geochelone and Floridemys. Bulletin of the Florida State Museum, Biological Sciences 7(2):53-97.

AufFENBERG, W. 1967a. Notes on West Indian tortoises. Herpetologica 23(1):34-44.

AufFENBERG, W. 1967b. Further notes on fossil box turtles of Florida. Copeia 1967(2):319-325.

AufFENBERG, W. 1974. Checklist of fossil land tortoises (Testudinidae). Bulletin of the Florida State Museum, Biological Sciences
18:121-251.

AufFEnBERG, W. 1981. The fossil turtles of Olduvai Gorge, Tanzania, Africa. Copeia 1981(3):509-522.

AufFENBERG,W.1988.Anew species of Geochelone (Testudinata: Testudinidae) from the Pleistocene of Florida (U.S.A.). ActaZoologica Cracoviensia 31:591-604.

Austin, J.J. AND ARNOLD, E.N. 2001. Ancient mitochondrial DNA and morphology elucidate an extinct island radiation of Indian Ocean giant tortoises (Cylindraspis). Proceedings of the Royal Society of London 268B:2515-2523.

Austin, J.J., ARnold, E.N., AND BouR, R. 2003. Was there a second adaptive radiation of giant tortoises in the Indian Ocean? Using mitochondrial DNA to investigate speciation and biogeography of Aldabrachelys (Reptilia, Testudinidae). Molecular Ecology 12:1415-1424.

Avery, G.A., Kandel, A.W., Klein, R.K., Conard, N.J., AND CruZURIBE, K.C. 2004. Tortoises as food and taphonomic elements in palaeo «landscapes». In: Brugal, J.-P. and J. Desse, J. (Eds.). Petits Animaux et Sociétés Humaines. Du Complément Alimentaire aux Ressources Utilitaires: XXIVe rencontres internationales d'archéologie et d'histoire d'Antibes. Antibes: Editions APDCA, pp. 147-161.

AwORER,L.AND RAMCHURN, R. 2003. The relationships between length and weight of the Aldabra giant tortoise, Dipsochelys dussumieri, in Mauritius. Phelsuma 11:52-58.

BACHMAYER,F.,BRINKERINK, J.P., AND SYMEONIDIS, N. 1975.Pleistozäne Schildkröten aus Höhlen der Insel Kreta. Annales Géologiques des Pays Helléniques 27:100-121.

BAIRD,S.F.AND GIRARD,C.1852.Descriptions of new species of reptiles, collected by the U.S. Exploring Expedition under the command of Capt. Charles Wilkes, U.S.N. First Part.-Including the species from the western coast of America. Proceedings of the Acadademy of Natural Sciences of Philadelphia 1852:174-177.

Barbosa Rodrigues, J. 1892. Les reptiles fossiles de la vallée de l'Amazone. Vellosia - Contribuições do Museu Botanico do Amazonas 2:41-56.

Barbour, E.H. AND Stetson, H.C. 1931. A revision of the Pleistocene species of Terrapene of Florida. Bulletin of the Museum of Comparative Zoology 72:293-299.

Barley, A.J., Spinks, P.Q., Thomson, R.C., and Shaffer, H.B. 2010. Fourteen nuclear genes provide phylogenetic resolution for difficult nodes in the turtle tree of life. Molecular Phylogenetics and Evolution 55:1189-1194.

Barnosky, A.D., Koch, P.L., Feranec, R.S., Wing, S.L., and Shabel, A.B. 2004. Assessing the causes of Late Pleistocene extinctions on the continents. Science 306:70-75.

Batsch, A.J.G.C. 1788. Versuch einer Anleitung zur Kenntniss und Geschichte der Thiere und Mineralien. Erster Theil. Allgemeine Geschichte der Natur; besondre der Säugthiere, Vögel, Amphibien und Fische. Jena: Akademischen Buchhandlung, 528 pp.

BATE, D.M.A. 1914. On remains of a gigantic land tortoise (Testudo gymnesicus n. sp.) from the Pleistocene of Menorca. Geological Magazine, n.s. 1:100-107.

BATTISTIN, R. AND CREMERS, G. 1972. Geomorphology and vegetation of Isles Glorieuses. Atoll Research Bulletin 159:1-10.

BAUR, G. 1889. The gigantic land tortoises of the Galapagos Islands. American Naturalist 23:1039-1057.

BAur, G. 1893. Notes on the classification and taxonomy of the Testudinata. Proceedings of the American Philosophical Society 31:210-225.

BEECH,M.2000.Preliminary reporton the faunal remains froman Ubaid settlement on Dalma Island, United Arab Emirates. In: Mashkour, M. et al.(Eds.). Archaeozoology of the Near East. IVb. Groningen, 
Netherlands: ARC, Publicatie 32, pp. 68-78.

BeECH, M. 2002. Faunal remains from site H3, As-Sabiyah: an Arabian Neolithic site in Kuwait. Paper, 6th ICAZ Archaeozoologists of Southwest Asia (ASWA) Working Group Meeting. University College, London: Institute of Archaeology.

Bellwood,P.(Ed.).2013. The Global Prehistory of Human Migration. Chichester, UK: Wiley Blackwell, 432 pp.

BERGOUNIOUX,F.-M. 1935. Contribution à l'étude paléontologique des chéloniens: chéloniens fossiles du bassin d'Aquitaine. Mémoires de la Société Géologique de France, n.s. 25:1-216.

Bergounioux, F.M. 1958. Les reptiles fossiles du Tertiaire de la Catalogne. Estudios Geologicos Madrid 14(39):129-219.

BEYIN, A. 2011.Upper Pleistocene human dispersals out of Africa: a review of the current state of the debate. International Journal of Evolutionary Biology 2011(615094):1-17.

Blain,H.-A.,Agustí,J.,LordKIPANIDZe,D.,Rook,L., And Delfino, M. 2014. Paleoclimatic and paleoenvironmental context of the Early Pleistocene hominins from Dmanisi (Georgia, Lesser Caucasus) inferred from the herpetofaunal assemblage. Quaternary Science Reviews 105:136-150.

Blasco, R. 2008. Human consumption of tortoises at Level IV of Bolomor Cave (Valencia, Spain). Journal of Archaeological Science 35:2839-2848.

Blasco,R.,Blain,H.-A.,Rosell,J.,Díez,J.C.,Huguet,R.,Rodríguez, J.,Arsuaga,J.L.,DeCAStro,J.M.B., And Carbonell,E.2011.Earliest evidence for human consumption of tortoises in the European Early Pleistocene from Sima del Elefante, Sierra de Atapuerca, Spain. Journal of Human Evolution 61:503-509.

Blyth, E. 1856. Notabilia contained in the collections presented by Capt. Berdmore and Mr. Theobald. Journal of the Asiatic Society of Bengal 24:711-723.

Bocquentin, V.J., GuILHERMe, E., AND Negri, F.R. 2001. Duas espécies do gênero Chelus (Pleurodira, Chelidae) no Mioceno Superior PliocenoInferior daAmazôniaSul-Ocidental.Revista Universidade Guarulhos 6(6):50-55.

BoDA,A. 1927.Clemmydopsis sopronensis, n.g.,n.sp. aus der unteren pannonischen Stufe von Sopron in Ungarn. Centralblatt für Mineralogie, Geologie und Paläontologie, B, Stuttgart 1927:375-383.

BodDAERT, P. 1770. Brief van de kraakbeenige schildpad. Epistola de testudine cartilaginea. Amsterdam: Kornelis van Tongerlo, 39 pp.

Bogachev, M. 1960. Novaja ponticeskaja cerepachia iz Kryma. Vopr. Geolg. Buren. Glob. Nef. 10:88-92. [In Russian]

Boivin, N., Crowther, A., Helm, R., AND Fuller, D.Q. 2013. East Africa and Madagascar in the Indian Ocean world. Journal of World Prehistory 26:213-281.

Bonfiglio, L., Marra, A.C., AND Masini, F. 1999. The contribution of Quaternary vertebrates to palaeonvironmental and palaeoclimatological reconstructions in Sicily. In: Hart, M.B. (Ed.). Climates: PastandPresent.London: Geological Society, Special Publications, 181:171-184.

Boulenger, G.A. 1887. On the systematic position of the genus Miolania, Owen (Ceratochelys, Huxley).Proceedings of the Zoological Society of London 1887:554-555.

Boulenger, G.A. 1889. Catalogue of the Chelonians, Rhynchocephalians, and Crocodiles in the British Museum (Natural History). London: Trustees of the Museum, $311 \mathrm{pp}$.

Boulenger, G.A. 1891. On some chelonian remains preserved in the Museum of the Royal College of Surgeons. Proceedings of the Zoological Society of London 1891:4-8.

Bour,R.1980.Position systematique de Geoclemys palaeannamitica Bourret,1941 (Reptilia-Testudines-Emydidae).Amphibia-Reptilia 1(2):149-159.

Bour, R. 1981. Histoire de la tortue terrestre de Bourbon. Bulletin de
l'Académie de La Réunion 25:97-147.

Bour, R. 1983. Trois populations endémiques du genre Pelusios (Reptilia, Chelonii, Pelomedusidae) aux îles Seychelles; relations avec les espèces africaines et malgaches. Bulletin du Muséum National d'Histoire Naturelle, Paris (4)5A:343-382.

Bour, R. 1984. Données sur la répartition géographique des tortues terrestres et d'eau douce aux îles Maurice et Rodrigues. Bulletin of the Mauritius Insitute 10(1):75-102.

Bour, R. 1985a. Una nova tortuga terrestre del Pleistocè d'Eivissa: la tortuga de la Cova de Ca Na Reia. Endins, Mallorca 10-11:57-62.

Bour, R. 1985b. Les tortues terrestres géantes des îles de l'océan Indien occidental: données géographiques, taxinomiques et phylogénétiques. In: de Broin, F. and Jimenez-Fuentes, E. (Eds.). Studia Palaeocheloniologica I. Studia Geologica Salmanticensia, Vol. Especial 1 [1984]:17-76.

Bour,R. 1988.Tortues et insularité: les tortues des Seychelles.Bulletin de la Société Zoologique de France 112:401-418.

Bour, R. 1994. Recherches sur des animaux doublement disparus: les tortues géantes subfossiles de Madagascar. Mémoires et Travaux de l'Institut de Montpellier 19:1-123.

Bour, R. 2006. An unnamed tortoise from the Seychelles Islands. Emys 13(3):24-30.

Bour, R. 2007. Les tortues des Mascareignes. Chéloniens 6:12-21.

Bour, R. 2013. Actualités chez les tortues des Seychelles. Chéloniens 29:27-41.

Bour, R., Fretey, T., And CheKe, A.S. 2014a. Philibert Marragon (1749-1826) and the Mémoire sur l'Isle de Rodrigue (1795). Bibliotheca Herpetologica 10(2):5-32.

Bour, R., Mourer-Chauvire, C., And Ribes, S. 2014b. Morphology and paleontological exploration (up to 2000) of the extinct tortoises of the Mascarenes islands. In: Gerlach, J. (Ed.). Western Indian Ocean Tortoises: Ecology, Diversity, Evolution, Conservation, Palaeontology. Manchester: Siri Scientific Books, pp. 121-202.

BouRn, D.M. AND COE, M.J. 1978. The size, structure and distribution of the giant tortoise population of Aldabra. Philosophical Transactions of the Royal Society of London 282:139-175.

BOURRET,R. 1941.Note surun crâne de tortue fossile.Comptes Rendus des Séances du Conseil de Recherches Scientifiques de l'Indochine 1940-1941. 1941(1):9-11.

Bover, P., Quintana, J., And Alcover, J.A. 2008. Three islands, three worlds: paleogeography and evolution of the vertebrate fauna from the Balearic Islands. Quaternary International 182:135-144.

BRAMBLE, D.M. 1982. Scaptochelys: generic revision and evolution of gopher tortoises. Copeia 1982(4):852-867.

Bramble, D.M. AND Hutchison, J.H. 2014. Morphology, taxonomy, and distribution of North American tortoises: an evolutionary perspective. In: Rostal, D.C., McCoy, E.D., and Mushinsky, H.R. (Eds.). Biology and Conservation of North American Tortoises. Baltimore: Johns Hopkins University Press, pp. 1-12.

Braithwaite, C.J.R., TAYlor, J.D., AND KenNedy, W.J. 1973. The evolution of an atoll: the depositional and erosional history of Aldabra. Philosophical Transactions of the Royal Society of London 266B:307-340.

Brattstrom, B.H. AND Sturn, A. 1959. A new species of fossil turtle from the Pliocene of Oregon, with notes on other fossil Clemmys from western North America. Bulletin of the Southern California Academy of Sciences 58:65-71.

Braun,D.R.,Harris,J.W.K.,Levin,N.E.,McCoy,J.T.,Herries,A.I.R., BAMford, M.K., Bishop, L.C., Richmond, B.G., AND KibunJIA, M. 2010. Early hominin diet included diverse terrestrial and aquatic animals 1.95 Ma in East Turkana, Kenya. PNAS (Proceedings of the National Academy of Sciences) 107(22):10002-10007.

Bravo, T. and CoEllo, J. 1975. Sedimentos con sienitas nefelínicas 
en Tenerife. Estudios Geologicos 31:501-511.

BRINKMAN, D.B., Li, J., AND Ye, X. 2008. Order Testudines. In: Li, J., $\mathrm{Wu}, \mathrm{X}$., and Zhang, F.(Eds.). The Chinese Fossil Reptiles and their Kin. Beijing: Science Press, 2nd ed., pp. 35-102.

BROADLEY,D.G. 1997.Anew species of Psammobates (Reptilia: Testudinidae) from the early Pleistocene of South Africa. Palaeontologia Africana 34:111-114.

BROADLEY,D.G. 2007. Description of an anomalous tortoise (Reptilia: Testudinidae)from the EarlyHolocene ofZimbabwe.Palaeontologia Africana 42:109-113.

BRoIN, F. DE. 1969. Sur la présence d'une tortue, Pelusios sinuatus (A. Smith) au Villafranchien Inférieur du Tchad. Bulletin de la Société Géologique de France (7)11:909-916.

BRoIN, F. DE. 1990. Les tortues. In: Allibert C., Argant A., and Argant, J. Le site de Dembeni (Mayotte, Archipel des Comores). Etudes de l'Ocean Indien, 11. Archipel des Comores, 1. Maore et Ngazidja, pp. 136-142.

BRoom, R. 1929. On the extinct Galápagos tortoise that inhabited Charles Island. Zoologica (New York) 9(8):313-320.

Brumm, A., Jensen, G.M., van den Bergh, G.D., Morwood, M.J., KurniaWAn, I.,AzIz, F., AND Storey, M. 2010. Hominins on Flores, Indonesia, by one million years ago. Nature 464:748-752.

Burenhult, G. 2000. Die ersten Menschen. Augsburg: Bechtermünz, $240 \mathrm{pp}$.

Burke, A.C., Anderson, M., Weld, A., And Gaffney, E.S. 1983. The reconstruction and casting of a large extinct turtle, Meiolania. Curator 26(1):5-25.

Burleigh, R. AND ARnold, E.N. 1986. Age and dietary differences of recently extinct Indian Ocean tortoises Geochelone sensu lato revealed by carbon isotope analysis. Proceedings of the Royal Society of London, Biological Sciences 227B:137-144.

BuRLEIGH,R.,MATtHEWs,K., ANDAMBERS,J.1982.British Museum natural radiocarbon measurements XIV. Radiocarbon 24(3):229-261.

Burstein, S.M. 1989. Agatharchides of Cnidus: on the Erythraean Sea. London: The Hakluyt Society, 202 pp.

Butler, J.M., Dodd, C.K., JR., Aresco, M., And Austin, J.D. 2011. Morphological and molecularevidence indicates that the GulfCoast box turtle (Terrapene carolina major) is not a distinct evolutionary lineage in the Florida Panhandle. Biological Journal of the Linnean Society 102:889-901.

CANTOR,T.1847.Catalogue of reptiles inhabiting the Malayan peninsula and islands. Journal of the Asiatic Society of Bengal 16:607-656, 897-952, 1026-1078.

CARLSON, L.A. 1999. Aftermath of a feast: human colonization of the southern Bahamian Archipelago and its effects on the indigenous fauna. Ph.D. Thesis, University of Florida, Gainesville.

CARR,A.F.,JR.1938a.Pseudemysnelsoni, a new turtle fromFlorida.Occasional Papers of the Boston Society of Natural History 8:305-310.

CARR,A.F., JR. 1938b. A new subspecies of Pseudemys floridana with notes on the floridana complex. Copeia 1938(3):105-109.

Case,T.J.,Bolger,D.T., and Richman,A.D. 1998.Reptilian extinctions over the last ten thousand years. In: Fiedler, P.L. and Kareiva, P.M. (Eds.). Conservation Biology: for the Coming Decade. Springer, pp. 157-186.

Cautley, P.T. 1838. Note on a fossil ruminant genus allied to Giraffidae in the Siwalik hills. Journal of the Asiatic Society of Bengal 7(2):658-660.

Ceselli, L. 1846. Sopra una tartaruga fossile trovata alle Acque Caje di Viterbo: lettera al sig. Prof. Sebastiano Purgotti. Rome: Salviucci, 26 pp.

Chere, A.S. And Bour, R. 2014. Unequal struggle - how humans displaced the dominance of tortoises in island ecosystems. In: Gerlach, J. (Ed.). Western Indian Ocean Tortoises: Ecology, Diversity,
Evolution,Conservation,Palaeontology.Manchester: SiriScientific Books, pp. 31-120.

Cheke, A.S. And Hume, J.P. 2008. Lost Land of the Dodo: An Ecological History of Mauritius, Réunion and Rodrigues. London: T. and A.D. Poyser, 464 pp.

CHESI, F. 2009. Il registro fossile italiano dei cheloni. Ph.D. Thesis, Università di Firenze, Italy.

Chesi, F., Delfino, M., Abbazzi,L., Carboni, S., LeCCa, L., and Rook, L. 2007. New fossil vertebrate remains from San Giovanni di Sinis (Late Pleistocene, Sardinia): the last Mauremys (Reptilia, Testudines) in the central Mediterranean. Rivista Italiana di Paleontologia e Stratigrafia 113(2):287-297.

Chesi, F., Delfino, M., AND Rook, L. 2009. Late Miocene Mauremys (Testudines, Geoemydidae) from Tuscany (Italy): evidence of terrapin persistence after a mammal turnover. Journal of Paleontology 83:379-388.

Chevalier,A.,Joleaud,L., And Petit,G. 1935.Les dépôts quaternaires de l'ancien cratère de Pedra de Lume (île de Sal, archipel du CapVert). Comptes Rendus des Séances de l'Académie des Sciences, Paris 200:1334-1335.

ChHibBer,H.L. 1934.Geology of Burma.London:Macmillan,538 pp.

ChKHIKvadze, V.M. 1979. [Comparison of turtles of faunas of Kuchurgan and Kvabebi]. Tbilisi: XXII Nauchnaya Sessiya Instituta Paleobiologii, pp. 7-9. [In Russian]

ChkHIKvadze, V.M. 1983. Iskopayemye cherepakhi Kavkaza i Severnogo Prichernomorya. [Fossil turtles of the Caucasus and the northern Black Sea region]. Tbilisi: Metsniereba, 149 pp. [In Russian]

ChkHIKvadZe, V.M. 1989. Neogenovye cherepakhi SSSR. [Neogene turtles of the USSR]. Tbilisi: Metsniereba, 104 pp. [In Russian]

Chrhikvadze, V.M. 2007. A brief catalogue of fossil turtles of the North Eurasia. Problems of Paleobiology (Tbilisi) 2:126-137. [In Russian]

Chrhikvadze, V.M. 2010. Annotated catalogue of Paleogene, Neogene and Recent turtles of Northern Eurasia. Georgian National Museum, Proceedings of the Natural and Prehistoric Section 2:96-113. [In Russian]

Chow M.-C. 1961. A new Pleistocene turtle from Hsiangfeu, Shanxi. Acta Paleontologica Sinica, Peking 9(4):426-430. [In Chinese]

Chow, M. And YeH, S.-K. 1958. Anew species of Trionyx from Yushe, Shansi. Vertebrata Palasiatica 2(1):51-55. [In Chinese]

Cione, A.L.,Azpelicueta, M.M., Bond, M., Carlini, A.A., Casciotta, J.R., Cozzuol, M.A., dE la Fuente, M., Gasparini, Z., Goin, F.J., Noriega, J., Scillato-Yané, G.J., Soibelzon, L., Tonni, E.P., VERZI, D., AND VucETICH, M.G. 2000. Miocene vertebrates from Entre Ríos province, eastern Argentina. In: Aceñolaza, F.G. and Herbst, R. (Eds.).El Neógeno de Argentina.Correlación Geológica 14:191-237.

Cione, A.L., Tonn, E.P., And Soibelzon, L. 2003. The broken zig-zag: Late Cenozoic large mammal and tortoise extinction in South America. Revista del Museo Argentino de Ciencias Naturales 5(1):1-19.

CisNeros,J.C.2005.NewPleistocene vertebrate fauna fromEl Salvador. Revista Brasileira de Paleontologia 8(3):239-255.

Claude, J., Naksri, W., Boonchai, N., Buffetaut, E., Duangkrayom, J., Laojumpon, C., Jintasakul, P., Lauprasert, K., Martin, J., SutEethorn, V., AND Tong, H. 2011. Neogene reptiles of northeastern Thailand and their paleogeographical significance. Annales de Paléontologie 97:113-131.

Clausen, C.J., Cohen, A.D., Emiliani, C., Holman, J.A., and Stipp, J.J. 1979. Little Salt Spring, Florida: a unique underwater site. Science 203:609-614.

CoE,M.J.,BouRn,D., ANDSwingland,I.R. 1979. The biomass, production and carrying capacity of giant tortoises on Aldabra.Philosophi- 
cal Transactions of the Royal Society of London 286B:163-176.

Congdon, J.D., Dunham, A.E., and Van Loben Sels, R.C. 1993. Delayed sexual maturity and demographics of Blanding's turtles (Emydoidea blandingii): implications for conservation and management of long-lived organisms. Conservation Biology 7(4):826-833.

Congdon, J.D., Dunham, A.E., and Van Loben Sels, R.C. 1994. Demographics of common snapping turtles (Chelydra serpentina): implications forconservation and management of long-lived organisms. American Zoologist 34(3):397-408.

Cooper, M.R. AND Broadley, D.G. 1990. A new species of fossil Homopus (Cryptodira: Testudinidae) from South Africa. Studia Palaeocheloniologica 3(4):41-55.

Cope, E.D. 1864. On the limits and relations of the Raniformes. Proceedings of the Academy of Natural Sciences of Philadelphia 16:181-183.

Cope, E.D. 1868a. An examination of the Reptilia and Batrachia obtained by the Orton expedition to Equador and the upper Amazon, with notes on other species. Proceedings of the Academy of Natural Sciences of Philadelphia 20:96-140.

Cope,E.D. 1868b. On the origin of genera.Proceedingsof the Academy of Natural Sciences of Philadelphia 20:242-300.

Cope, E.D. 1870a. Seventh contribution to the herpetology of tropical America. Proceedings of the American Philosophical Society 11(1869)[1870]:147-169.

Cope, E.D. 1870b. Synopsis of the extinct Batrachia, Reptilia and Aves of North America. Transactions of the American Philosophical Society 14(1869)[1870]:1-252.

Cope,E.D.1878.Description of new Vertebrata from the upperTertiary formations of the West. Proceedings of the American Philosophical Society 17:219-231.

Cope, E.D. 1892a. A contribution to the vertebrate palaeontology of Texas. Proceedings of the American Philosophical Society 30:123-131.

Cope, E.D. 1892b. A contribution to the knowledge of the fauna of the Blanco beds of Texas. Proceedings of the Academy of Natural Sciences, Philadelphia 1892:226-229.

Cope, E.D. 1893. A preliminary report on the vertebrate paleontology of the Llano Estacado. Annual Reports of the Geological Survey of Texas 4:1-136.

Cope, E.D. 1899. Vertebrate remains from Port Kennedy bone deposit. Journal of the Academy of Natural Sciences, Philadelphia (2)11:193-267.

Crawford, N.G.,Parham,J.F., Sellas, A.B.,Faircloth, B.C., Glenn, T.C.,Papenfuss, T.J.,Henderson, J.B., Hansen, M.H., and Simison, B.W. 2015. A phylogenomic analysis of turtles. Molecular Phylogenetics and Evolution 83:250-257.

Crumly, C.R. 1983. An annotated checklist of the fossil tortoises of China and Mongolia. Proceedings of the Biological Society of Washington 96(3):567-580.

Cuvier, G.L.C.F.D. 1824. Recherches sur les Ossemens Fossiles, ou l'on rétablit les caractères de plusieurs animaux dont les révolutions du globe ont détruit les espèces. Paris: Dufour et d'Ocagne, Ed. 2, 5(2):1-547.

DanILOV, I.G. 2005. Die fossilen Schildkröten Europas. In: Fritz, U. (Ed.).Handbuch der Reptilien undAmphibienEuropas.Band3/IIIB: Schildkröten(Testudines) II.(Cheloniidae,Dermochelyidae,Fossile Schildkröten Europas). Wiebelsheim:AULA-Verlag,pp. 329-441.

DANILOv, I.G. AND PARHAM, J.F. 2008. A reassessment of some poorly known turtles from the middle Jurassic of China, with comments on the antiquity of extant turtles. Journal of Vertebrate Paleontology 28(2):306-318.

Danilov, I.G., Cernanský, A., Syromyatnikova, E.V., and Joniak, P. 2012. Fossil turtles of Slovakia: new material and a review of the previous record. Amphibia-Reptilia 33:423-442.

Danilov, I.G., Cherepanov, G.O., AND ViteK, N.S.2013.Chelonological studies of L.I. Khosatzky with his annotated bibliography on turtles. Proceedings of the Zoological Institute Russian Academy of Sciences 317(4):382-425.

DAs, I. 1991. The taxonomic status of the Pleistocene turtle Geoclemys sivalensis. Journal of Herpetology 25(1):104-106.

DAs, I. 1994. The identity of the Plio-Pleistocene turtle, Geoemyda pilgrimi Prasad and Satsangi, 1967 (Testudines: Cryptodira: Bataguridae). Hamadryad 19:41-46.

DAs, I. 1997. A reassessment of Hardella isoclina Dubois, 1908 (Testudines: Bataguridae) from the Trinil Beds of the Javan Pleistocene. Herpetological Journal 7(2):71-73.

Daudin, F.M. 1801. Histoire Naturelle, Générale et Particulière des Reptiles. Tome Second. Paris: Imprimerie F. Dufart, 432 pp.

DE LA Fuente, M.S. 1992. Las tortugas Chelidae del Terciario superior y Cuaternariodel territorioArgentino.Ameghiniana 29(3):211-229.

DE la Fuente, M.S. 1999. A review of the Pleistocene reptiles of Argentina: taxonomic and palaeoenvironmental considerations. In: Rabassa, J. and Salemme, M. (Eds.). Quaternary of South America and Antarctic Peninsula. Rotterdam: A.A. Balkema, pp. 109-136.

DE VIS, C.W. 1894. The lesser chelonians of the Nototherian drifts. Proceedings of the Royal Society of Queensland 10:123-127.

DE VIS, C.W. 1897. The extinct freshwater turtles of Queensland. Annals of the Queensland Museum 3:1-7.

DE VIs, C.W. 1905. Fossil vertebrates from New Guinea. Annals of the Queensland Museum 6:26-31.

Delfino, M. And de Vos, J. 2014. A giant crocodile in the Dubois Collection from the Pleistocene of Kali Gedeh (Java). Integrative Zoology 9:141-147.

Delfino,M.,Luján, À.H.,CARmona,R.L.,AndAlba,D.2012.Revision of the extinct Pleistocene tortoise Testudo lunellensis Almera and Bofill, 1903 from Cova de Gràcia (Barcelona, Spain). AmphibiaReptilia 33:215-225.

Depéret, C. 1885. Description géologique du Bassin Tertiare du Roussillon. Annales des Sciences Géologiques 17:1-272.

Deraniyagala,P.E.P. 1953.AColored Atlas of Some Vertebrates from Ceylon. Vol. 2. Tetrapod Reptilia. Ceylon Natural History Museum Publication, $101 \mathrm{pp}$.

DietL,G.P.AndFlessa, K.W.2011.Conservation paleobiology:putting the dead to work. Trends in Ecology and Evolution 26(1):30-37.

Dirzo, R., Young, H.S., Galetti, M., Ceballos, G., IsaAc, N.J.B., and Collen, B. 2004. Defaunation in the Anthropocene. Science 345:401-406.

DodD, C.K.,JR. 2001. NorthAmerican Box Turtles: A Natural History. Norman, OK: University of Oklahoma Press, $231 \mathrm{pp}$.

DorofF, A.M. AND KeITH, L.B. 1990. Demography and ecology of an ornate box turtle (Terrapene ornata) population in south-central Wisconsin. Copeia 1990(2):387-399.

DuboIs, E. 1908. Das geologische Alter der Kendeng- oder TrinilFauna.Tijdschrift vanhetKoninklijk NederlandschAardrijkskundig Genootschap (2)25:1235-1270.

DumÉRIL, A.M.C. 1805 ["1806"]. Zoologie Analytique, ou Méthode Naturelle de Classification des Animaux. Paris: Perronneau, 344 pp. [Published Nov 1805].

DuméRIL, A.M.C. AND BiBron, G. 1835. Erpétologie Générale ou Histoire Naturelle Complète des Reptiles. Tome Second. Paris: Roret, $680 \mathrm{pp}$.

Durrell, G. 1977. Golden Bats and Pink Pigeons: A Journey to the Flora and Fauna of a Unique Island. New York: Simon and Schuster, $190 \mathrm{pp}$.

Edwards, D.L., Benavides, E., Garkick, R.C., Gibbs, J.P., Russello, M.A., Dion, K.B., Hyseni, C., Flanagan, J.P., Tapia, W., and 
CACCONE,A.2013.The genetic legacy of Lonesome George survives: giant tortoises with Pinta Island ancestry identified in Galápagos. Biological Conservation 157:225-228.

EHRET, D.J. AND BouRQue, J.R. 2011. An extinct map turtle Graptemys (Testudines,Emydidae) from the late Pleistocene of Florida. Journal of Vertebrate Paleontology 31:575-587.

Ehret, D.J., Bourque, J.R., AND Hulbert, R.C., JR. 2013. Case 3628. Terrapene putnami Hay,1906(Testudines,Emydidae):replacement of the holotype by designation of a neotype. Bulletin of Zoological Nomenclature 70(3):193-198.

ERnst, C.H. 1988. Chrysemys. Catalogue of American Amphibians and Reptiles 438:1-8.

FALCONER, H. AND CAUTLEY, P.T. 1837. On additional fossil species of the order Quadrumana from the Siwalik Hills. Journal of the Asiatic Society of Bengal 6:354-360.

FalConer, H. AND CAUTLEY, P.T. 1844. Communication on the Colossochelys atlas, a fossil tortoise of enormous size from the Tertiary strata of the Siwalk Hills in the north of India. Proceedings of the Zoological Society of London 1844(12):54-84.

FARKAS, B.L. 1992. Wiederentdeckung eines Exemplars von Rafetus swinhoei (Gray, 1873) im Naturhistorischen Museum Wien. Salamandra 28(2):145-152.

FARKAS,B. 1995.Fossil trionychid turtletypesin Hungarian collectionsa preliminary review (Reptilia, Testudines). Annales HistoricoNaturales Musei Nationalis Hungarici 87:57-62.

Filella-Subirà, E., Gàsser-Casanovas, Z., Garcia-Porta, J., and FERRER-FERRER, J.A. 1999. Una puesta fósil de tortuga terrestre en el Pleistoceno de Formentera (Islas Pitiusas, archipiélago Balear). Treballs del Museu de Geologia de Barcelona 8:67-84.

FITZINGER, L.J. 1826. Neue Classification der Reptilien, nach ihren Natürlichen Verwandtschaften nebst einer Verwandtschafts-Tafel und einem Verzeichnisse der Reptilien-Sammlung des k.k. Zoologischen Museum zu Wien. Wien: J.G. Hübner Verlagen, 66 pp.

FITZINGER, L.J. 1835. Entwurf einer systematischen Anordnung der Schildkröten nach den Grundsätzen der natürlichen Methode. Annalen des Wiener Museums der Naturgeschichte 1:105-128.

FItZINGER, L.J. 1843. Systema Reptilium. Fasciculus Primus: Amblyglossae. Vindobonae: Braumuller und Seidel, 106 pp.

FLANNERY, T.F. 1994. The Future Eaters: An Ecological History of the Australasian Lands and People. Port Melbourne: Reed Press, 423 pp.

FRAZIER, J. 2003. Prehistoric and ancient historic interactions between humans andmarine turtles.In:Lutz,P.L.,Musick,J.A., andWyneken, J. (Eds.). The Biology of Sea Turtles. Volume II. Boca Raton, FL: CRC Press, pp. 1-38.

FRANZ, R. 2014. The fossil record for North American tortoises. In: Rostal, D.C., McCoy, E.D., and Mushinsky, H.R. (Eds.). Biology and Conservation of North American Tortoises. Baltimore: Johns Hopkins University Press, pp. 13-24.

FRANZ, R. AND Franz,S.E. 2009.A new fossil land tortoise in the genus Chelonoidis (Testudines: Testudinidae) from the northern Bahamas, with an osteological assessment of other Neotropical tortoises. Bulletin of the Florida Museum of Natural History 49(1):1-44.

FRANZ, R. AND QUITMYER, I.R. 2005. A fossil and zooarchaeological history of the gopher tortoise (Gopherus polyphemus) in the southeastern United States. Bulletin of the Florida Museum of Natural History 45(4):179-199.

Franz, R. AND Woods, C.A. 1983. A fossil tortoise from Hispaniola. Journal of Herpetology 17(1):79-81.

Franz, R., Carlson, L.A., Owen, R.D., and Steadman, D. 2001. Fossil tortoises from the Turks and Caicos Islands, B.W.I. In: Clark-Simpson, C.A. and Smith, G.W. (Eds.). Proceedings of the 8th Symposium on the Natural History of the Bahamas, pp. 27-31. FRITZ, U. 1992. Zur innerartlichen Variabilität von Emys orbicularis
(Linnaeus, 1758). 2. Variabilität in Osteuropa und Redefinition von Emys orbicularis orbicularis (Linnaeus, 1758) und E. o. hellenica (Valenciennes, 1832) (Reptilia, Testudines: Emydidae). Zoologische Abhandlungen, Staatliches Museum für Tierkunde Dresden 47(5):37-77.

FRITZ, U. 1995a. Zur innerartlichen Variabilität von Emys orbicularis (Linnaeus, 1758).5a.Taxonomie in Mittel-Westeuropa, aufKorsika, Sardinien, der Apenninen-Halbinsel und Sizilien und Unterartengrupppen von E. orbicularis (Reptilia: Testudines: Emydidae). Zoologische Abhandlungen, Staatliches Museum für Tierkunde Dresden 48:185-242.

FRITZ, U. 1995b. Kritische Übersicht der Fossilgeschichte der Sumpfschildkröten-Gattung Emys A.Duméril, 1806 (Reptilia:Testudines: Emydidae). Zoologische Abhandlungen, Staatliches Museum für Tierkunde Dresden 48:243-264.

FrITZ, U. AND FARKAS, B. 1996. The proper generic allocation of Clemmys mehelyi Kormos, 1911 (Reptilia, Testudines). Fragmenta Mineralogica et Palaeontologica 18:103-105.

Fritz, U., HundsdöRfer, A.K., Siroky, P., Auer, M., KAMi, H., LeHMann, J., Mazanaeva, L.F., Türkozan, O., And Wink, M. 2007. Phenotypic plasticity leads to incongruence between morphologybased taxonomy and genetic differentiation in western Palearctic tortoises (Testudo graeca complex; Testudines, Testudinidae). Amphibia-Reptilia 28:97-121.

Froyd, C.A., COFFey, E.E.D., van DER KnAAP, W.O., van LeEUWEN, J.F.N., TYE,A., AND WILLIS, K.J. 2014. The ecological consequences of megafaunal loss: giant tortoises and wetland biodiversity. Ecology Letters 17:144-154.

GADOw, H. 1894. On the remains of some gigantic land-tortoises, and of an extinct lizard, recently discovered in Mauritius. Transactions of the Zoological Society of London 13(8):313-324.

GAFFNEY,E.S.1981.Areview of the fossil turtles of Australia.American Museum Novitates 2720:1-38.

GAFFNEY, E.S. 1983. The cranial morphology of the extinct horned turtle, Meiolania platyceps, from the Pleistocene of Lord Howe Island, Australia. Bulletin of the American Museum of Natural History 175(4):326-479.

GAFFNEY,E.S. 1984. Historical analysis of theories of chelonian relationship. Systematic Zoology 33:283-301.

GAFFNEY, E.S. 1985. The cervical and caudal vertebrae of the cryptodiran turtle, Meiolania platyceps, from the Pleistocene of Lord Howe Island, Australia. American Museum Novitates 2805:1-29.

GAFFNEY, E.S. 1992. Ninjemys; a new name for "Meiolania" oweni (Woodward), a horned turtle from the Pleistocene of Queensland. American Museum Novitates 3049:1-10.

GAFFNEY, E.S. 1996. The postcranial morphology of Meiolania platyceps and areview of the Meiolaniidae. Bulletin of the American Museum of Natural History 229:1-166.

GAFFNEY, E.S. AND BARTHOLOMAI, A. 1979. Fossil trionychids of Australia. Journal of Paleontology 53:1354-1360.

GafFney, E.S. And Jenkins, F.A. 2010. The cranial morphology of Kayentachelys, an Early Jurassic cryptodire, and the early history of turtles. Acta Zoologica 91:335-368.

GAFFNEY,E.S. AND MCNamara, G. 1990. A meiolaniid turtle from the Pleistocene of northern Queensland. Memoirs of the Queensland Museum 28(1):107-113.

GAFFNEY,E.S. AND MEYLAn,P.A. 1988.Aphylogeny of turtles.In: Benton, M.J.(Ed.). The Phylogeny and Classification of the Tetrapods, Volume I: Amphibians, Reptiles, Birds. Systematics Association Special Volume No. 35A:157-219.

GAFFNEY,E.S.,BALOUET,J.C.,ANDBROIN,F.DE.1984.New occurrences of extinct meiolaniid turtles in New Caledonia. American Museum Novitates 2800:1-6. 
Gaffney, E.S., Rich, T.H., Vickers-Rich, P., Constantine, A., V Acca, R., AND Kool, L. 2007. Chubutemys, a new eucryptodiran turtle from the early Cretaceous of Argentina, and the relationships of the Meiolaniidae. American Museum Novitates 3599:1-35.

Gaffney, E.S., Meylan, P.A., Wood, R.C., Simons, E., and Campos, D. DE A. 2011. Evolution of the side-necked turtles: the family Podocnemididae. Bulletin of the American Museum of Natural History 350:1-237.

Galbreath, E.C. 1948. A new extinct emydid turtle from the Lower Pliocene of Oklahoma.Univeersity ofKansas Publications, Museum of Natural History 1(16):265-280.

Garrick,R.C.,BenaVides,E.,Russello,M.A.,GibBs,J.P.,PoulaKakis, N., Dion, K.B., Hyseni, C., Kajdacsi, B., Márquez, L., Baran, S., Ciofi, C., TAPIA, W., AND CACCone, A. 2012. Genetic rediscovery of an 'extinct' Galápagos giant tortoise species. Current Biology 22:R10-R11.

GeEr, A. van der, Lyras, G., Vos, J. De, AND Dermitzakis, M. 2010. Evolution ofIsland Mammals:Adaptation and Extinction ofPlacental Mammals on Islands. Chichester, UK: Wiley-Blackwell, 479 pp.

GeINITZ, E. 1877. Die angebliche Trionyx schlotheimii im diluvialen Kalktuff von Burgtonna ist eine Cistudo europaea. Neues Jahrbuch fürMineralogie, Geognosie, Geologie und Petrefaktenkunde, Stuttgart 1877:278-279.

Geoffroy Saint-Hilaire, E. 1809. Mémoire sur les tortues molles. Nouveau Bulletin des Sciences, par la Société Philomatique de Paris 1(22):363-367.

Georgalis, G.L. And Kear, B.P. 2010. New records of fossil turtles from Greece. Journal of Vertebrate Paleontology, SVP Program and Abstracts Book, p. 95.

Georgalis, G.L. and Kear, B.P. 2013. The fossil turtles of Greece: an overview of taxonomy and distribution. Geobios 46:299-311.

Gerlach, J. 2004. Giant Tortoises of the Indian Ocean. The genus Dipsochelys inhabiting the Seychelles Islands and the extinct giants of Madagascar and the Mascarenes. Frankfurt: Edition Chimaira, 207 pp.

GERLACH,J. 2008. Redescription of the skull of the extinct Madagascan giant tortoise, Dipsochelys abrupta. Chelonian Conservation and Biology 7(2):251-255.

Gerlach, J. 2014. Ecology and status of Western Indian Ocean Aldabrachelys giant tortoises. In: Gerlach, J. (Ed.). Western Indian Ocean Tortoises: Ecology, Diversity, Evolution, Conservation, Palaeontology. Manchester: Siri Scientific Books, pp. 229-251.

Gerlach, J. and Rioux PaQuette, S. 2014. Evolution of the tortoises of the Western Indian Ocean. In: Gerlach, J. (Ed.). Western Indian Ocean Tortoises: Ecology, Diversity, Evolution, Conservation, Palaeontology. Manchester: Siri Scientific Books, pp. 9-30.

Gerlach, J., Rocamora, G., Gane, J., Jolliffe, K., and Vanherck, L. 2013. Giant tortoise distribution and abundance in the Seychelles Islands: past, present, and future. Chelonian Conservation and Biology 12(1):70-83.

GervaIs, P. 1877. Tortue gigantesque fossile au Brésil. Journal de Zoologie (Paris) 6:283-285.

GibBard, P.L., Head, M.J., Walker, M.J.C., and The Subcommittee ON Quaternary Stratigraphy. 2010. Formal ratification of the Quaternary System/Period and the Pleistocene Series/Epoch with a base at 2.58 Ma. Journal of Quaternary Science 25(2):96-102.

GibBons, A. 2015. Deep roots for the genus Homo. Science 347:10561057.

GibBs, J.P., Sterling, E.J., AND Zabala, F.J. 2010. Giant tortoises as ecological engineers: along-termquasi-experimentin the Galápagos Islands. Biotropica 42:208-214.

Gibis, J.P., Hunter, E.A., Shoemaker, K.T., TAPia, W.H., And CAYot, L.J. 2014. Demographic outcomes and ecosystem implications of giant tortoise reintroduction to Española Island, Galapagos. PLoS ONE 9(10):e110742.

GiEBel,C.G. 1866.Cistudoanhaltinan.sp.ausderLatdorfer Braunkohle. Zeitschrift für die Gesammten Naturwissenschaften 27:1-11.

Gilmore, C.W. 1923. A new fossil turtle, Kinosternon arizonense, from Arizona. Proceedings of the United States National Museum 62:1-8.

GILMORE, C.W. 1927. On fossil turtles from the Pleistocene of Florida. Proceedings of the United States National Museum 71:1-10.

Gilmore, C.W. 1930. A nearly complete shell of the extinct turtle Trachemys sculpta. Proceedings of the United States National Museum 77:1-8.

Gilmore, C.W. 1931. Fossil turtles of Mongolia. Bulletin of the American Museum of Natural History 59:213-257.

Gilmore, C.W. 1933. A new species of extinct turtle from the Upper Pliocene of Idaho. Proceedings of the United States National Museum 82(9):1-7.

Gmelin, J.F. 1789. Caroli a Linné, Systema Naturae per regna tria naturae secundum classes, ordines, genera,species, cum characteribus, differentiis, synonymis, locis.Ed. 13. Tom. I.Pars III.Leipzig: G.E. Beer, Ed. 13, 1(3):1033-1516.

GMIRA, S. 1993. Une nouvelle espèce de tortue Testudininei (Testudo kenitrensis n. sp.) de l'inter Amirien-Tensiftien de Kénitra (Maroc). Comptes Rendus de l'Académie des Sciences, Paris, Serie II, 316(5):701-707.

Gmira, S., Lapparent de Broin, F. de, Geraads, D., Lefèvre, D., MohiB, A., and Raynal, J.-P. 2013. Les tortues du Pliocène d'Ahl al Oughlam (Casablanca, Maroc) et de localités mio-pliocènes avoisinantes. Geodiversitas 35(3):691-733.

GRANDIDIER, A. 1868. Sur les découvertes zoologiques faites récemment à Madagascar. Annales des Sciences Naturelles. Zoologie et Paléontologie, Paris (5)10:375-378.

GRAY, J.E. 1825. A synopsis of the genera of reptiles and amphibia, with a description of some new species. Annals of Philosophy (2)10:193-217.

GrAY, J.E. 1830a. Illustrations of Indian Zoology, chiefly selected from the collection of Major-General Hardwicke. Vol. I, Part 2, pl. 72. London: Treuttel, Wurtz, Treuttel, Jun. and Richter. [Published Mar 1830].

Gray, J.E. 1830b. A Synopsis of the Species of the Class Reptilia. In: Griffith E. and Pidgeon, E. The Class Reptilia arranged by the Baron Cuvier, with specific descriptions. In: Griffith, E. (Ed.). The Animal Kingdom Arranged in Conformity with its Organization, by the Baron Cuvier, with Additional Descriptions of all the Species Hitherto Named, and of many not before Noticed. Vol. 9. Reptilia. Supplement. London: Whittaker, Treacher, and Co., 110 pp. [Part 26, published Dec 1830].

GraY, J.E. 1831a. Illustrations of Indian Zoology, chiefly selected from the collection of Major-General Hardwicke. Vol. I, Part 5, pl. 74. London: Treuttel, Wurtz, Treuttel, Jun. and Richter. [Published Jan 1831].

GraY, J.E. 1831b. Synopsis Reptilium; or Short Descriptions of the Species of Reptiles.PartI._Cataphracta.Tortoises, Crocodiles, and Enaliosaurians.London: Treuttel, Wurz, and Co., 85 pp. [Published May 1831].

GRAY, J.E. 1832. Illustrations of Indian Zoology, chiefly selected from the collection of Major-General Hardwicke. Vol. II, Part 11, pl. 60. London: Adolphus Richter and Co. [Published Jul 1832].

GrAY, J.E. 1834a. Characters of several new species of freshwater tortoises (Emys) from India and China. Proceedings of the Zoological Society of London 1834(2):53-54.

GRAY,J.E.1834b. Characters of two new genera of reptiles (Geoemyda and Gehyra). Proceedings of the Zoological Society of London 
1834(2):99-101.

GraY, J.E. 1854. Description of a new genus and some new species of tortoises. Proceedings of the Zoological Society of London 1852[1854]:133-135.

GraY, J.E. 1856a. On some new species of freshwater tortoises from North America, Ceylon and Australia, in the collection of the British Museum. Proceedings of the Zoological Society of London 1855[1856](23):197-202. [Published Feb 1856].

GraY,J.E. 1856b ["1855"]. Catalogue of Shield Reptiles in the Collection of the British Museum. Part I. Testudinata (Tortoises). London: British Museum, 79 pp. [Published Mar 1856].

GRAY, J.E. 1863. Observations on the box tortoises, with the descriptions of three new Asiatic species. Proceedings of the Zoological Society of London 1863:173-179.

GRAY,J.E. 1864. Revision of the species of Trionychidae found in Asia and Africa, with the descriptions of some new species. Proceedings of the Zoological Society of London 1864:76-98.

Gray, J.E. 1867. Description of a new Australian tortoise (Elseya latisternum). Annals and Magazine of Natural History (3)20:43-45.

GRAY,J.E. 1869a. Notes on the families and genera of tortoises (Testudinata), and on the characters afforded by the study of their skulls. Proceedings of the Zoological Society of London 1869:165-225.

GraY, J.E. 1869b. Description of Mauremys laniaria, a new freshwater tortoise. Proceedings of the Zoological Society of London 1869:499-500.

GRAY,J.E. 1872a. Notes on the mud-tortoises of India (Trionyx, Geoffroy). Annals and Magazine of Natural History (4)10:326-340.

GraY,J.E. 1872b.Appendix to the Catalogue of Shield Reptiles in the Collection of the British Museum. Part I. Testudinata (Tortoises). London: British Museum, 28 pp.

GRAY, J.E. 1873a. On a new freshwater tortoise from Borneo (Orlitia borneensis).Annals and Magazine of Natural History (4)11:156-157.

GraY, J.E. 1873b. Notes on the tortoises of the 'Zoology of Mexico' of MM.A. Duméril and Bocourt. Annals and Magazine of Natural History (4)12:109-114.

GrAY, J.E. 1873c. Notes on the genera of turtles (Oiacopodes), and especially on their skeletons and skulls. Proceedings of the Zoological Society of London 1873:395-411.

GRIFFITHS, C. 2014. Rewilding in the Western Indian Ocean. In: Gerlach, J. (Ed.). Western Indian Ocean Tortoises: Ecology, Diversity, Evolution,Conservation,Palaeontology.Manchester: SiriScientific Books, pp. 325-349.

Griffiths, C.J.,Jones,C.G.,Hansen,D.M.,Puttoo,M.,TAtayah, R.V., MÜLLER,C.B.,ANDHARRIS,S.2010.The use of extantnon-indigenous tortoises as a restoration tool to replace extinct ecosystem engineers. Restoration Ecology 18(1):1-7.

Griffiths, C.J., Hansen, D., Jones, C., Zuël, N., and Harris, S. 2011. Resurrecting extinct interactions with extant substitutes. Current Biology 21:1-4.

GrifFITHS,C.J.,ZUËL,N.,Jones,C.G.,AhamUd,Z.,ANDHARris,S.2013a. Assessing the potential to restore historic grazing ecosystems with tortoise ecological replacements. Conservation Biology 27:690-700.

Griffiths, O., ANDRE, A., AND MeunIER, A. 2013b. Tortoise breeding and 're-wilding' on Rodrigues Island. In: Castellano, C.M., Rhodin, A.G.J., Ogle, M., Mittermeier, R.A., Randriamahazo, H., Hudson, R., and Lewis, R.E. (Eds.). Turtles on the Brink in Madagascar: Proceedings of Two Workshops on the Status, Conservation, and Biology of Malagasy Tortoises and Freshwater Turtles. Chelonian Research Monographs 6:171-177.

Grosman, L., Munro, N.D., AND Belfer-Cohen, A. 2008. A 12,000year-old Shaman burial from the southern Levant (Israel). PNAS (Proceedings of the NationalAcademy of Sciences) 105(46):1766517669.
Gross,M.2004.Sumpfschildkröten(Clemmydopsisturnauensis(Meyer, 1847); Bataguridae) aus der Tongrube Mataschen (Pannonium, Steiermark). Joannea Geologie und Paläontologie 5:131-147.

GüNTHER, A.C.L.G. 1873. Preliminary notice of some extinct tortoises from the islands of Rodriguez and Mauritius. Annals and Magazine of Natural History (4)11:397.

GÜNTHER,A.C.L.G. 1875.Descriptions of the living and extinct races of gigantic land-tortoises. Parts I and II. Introduction, and the tortoises of the Galapagos Islands. Philosophical Transactions of the Royal Society of London 165:251-284.

GüNTHER, A.C.L.G. 1877. The Gigantic Land-Tortoises (Living and Extinct) in the Collection of the British Museum. London: Taylor and Francis, 96 pp.

Hansen,D.M.,Donlan,C.J.,GrifFiths, C.J.,ANDCAMPBell,K.J.2010. Ecological history and latent conservation potential: large and giant tortoises as a model for taxon substitutions. Ecography 33:272-284.

Harrison, T. 2011. Tortoises (Chelonii, Testudinidae). In: Harrison, T. (Ed.). Paleontology and Geology of Laetoli: Human Evolution in Context. Vol. 2: Fossil Hominins and the Associated Fauna. Springer Science, Vertebrate Paleobiology and Paleoanthropology, pp. 479-503.

HARTWEG,N.1938.Kinosternon flavescens stejnegeri, a new turtle from northern Mexico. Occasional Papers of the Museum of Zoology, University of Michigan 371:1-5.

Hasegawa, Y. 1981. Pleistocene hinged terrapin from the Tsukumi Limestone Quarry, Oita-ken, Japan. Science Reports of the Yokohama National University (2)28:19-23.

Hasegawa, Y. and Ota, M. 1980. Report on a Pleistocene terrapin, Cyclemys from Katayama Marble Quarry, Mine City, Japan. Science Reports of the Yokohama National University (2)27:47-52.

HaSEGaWA, Y.,TARU,H., AND Matsushima, Y. 2007.Nauman's elephant and associated with Ocadia assemblage. In: Inuzuka, N. (Ed.). Jubilee Publication in Commemoration of Professor Kamei Tadao's 80th Birthday, pp. 141-144.

Hastings, A.K., Krigbaum, J., Steadman, D.W., and Albury, N.A. 2014. Domination by reptiles in a terrestrial food web of the Bahamas prior to human occupation. Journal of Herpetology 48(3):380-388.

HAY, O.P. 1902. Descriptions of two new species of extinct tortoise, one new. Proceedings of the Academy of Natural Sciences, Philadelphia 54:383-388.

HAY, O.P. 1903. Two new species of fossil turtles from Oregon. University of California Publications, Bulletin of the Department of Geological Sciences 3:237-241.

HaY, O.P. 1906. Descriptions of two new genera (Echmatemys and Xenochelys) and two new species (Xenochelys formosa and Terrapene putnami) of fossil turtles. Bulletin of the American Museum of Natural History 22(3):27-31.

HAY, O.P. 1907. Description of seven new species of turtles from the Tertiary of the United States. Bulletin of the American Museum of Natural History 23:847-863.

HAY, O.P. 1908a. The Fossil Turtles of North America. Carnegie Institution of Washington, Publication 75:1-568.

HAY, O.P. 1908b. Descriptions of five species of North American fossil turtles, four of which are new. Proceedings of the United States National Museum 35:161-169.

HAY, O.P. 1916a. Descriptions of some Floridian fossil vertebrates, belonging mostly to the Pleistocene. Annual Report of the Florida State Geological Survey 8:39-76.

HAY, O.P. 1916b. Descriptions of some fossil vertebrates found in Texas. Bulletin of the University of Texas 71:3-24.

HAY, O.P. 1917a. On a collection of fossil vertebrates made by Dr. F.W. Dragin in the Equus beds of Kansas. Kansas University Science Bulletin 10:39-51. 
HAY, O.P. 1917b.Vertebrata mostly from stratumno. 3, at Vero,Florida, together with descriptions of new species. Ninth Annual Report for the Florida State Geological Survey, pp. 43-68.

HaY, O.P. 1920. Descriptions of some Pleistocene Vertebrata found in the United States. Proceedings of the U.S. National Museum 58:83-146.

HaY, O.P. 1923. Characteristics of sundry fossil vertebrates. PanAmerican Geologist 39:114-120.

HAY,O.P.1924. The Pleistocene of the middle region of North America and its vertebrated animals. Carnegie Institution of Washington, Publication 322:1-374.

HAYNES, G. (Ed.). 2009. American Megafaunal Extinctions at the End of the Pleistocene. Springer, $201 \mathrm{pp}$.

HENDRICKSON, J.R. 1965. Reptiles of the Galápagos. Pacific Discovery 18(5):28-36.

HENNESSY, E. 2014. The molecular turn in conservation: genetics, pristine nature, and the rediscovery of an extinct species of Galápagos giant tortoise. Annals of the Association of American Geographers 105(1):87-104.

Hennig, G.J., Herr, W., Weber, E., AND XiRotiris, N.I. 1981. ESRdating of the fossil hominid cranium from Petralona Cave, Greece. Nature 292:533-536.

Hervet, S. 2004. A new genus of 'Ptychogasteridae' (Chelonii, Testudinoidea) from the Geiseltal (Lutetian of Germany). Comptes Rendus Palevol 3:125-132.

Hervet, S. 2006. The oldest European ptychogasterid turtle (Testudinoidea) from the lowermost Eocene amber locality of Le Quesnoy (France, Ypresian, MP7). Journal of Vertebrate Paleontology 26(4):839-848.

HIRAYAMA, R.2007.Revision of the systematics of the fossil turtles from Japan.In:Inuzuka, N.(Ed.). Jubilee Publication in Commemoration of Professor Kamei Tadao's 80th Birthday, pp. 145-153.

HiraYAma, R. AND IsAJ, S. 2010. Additional turtle fossils from the Kiyokawa Formation of the Shimosa Group (Middle Pleistocene) at Sodegaura City, Chiba Prefecture, Japan. Journal of the Natural History Museum and Institute, Chiba 11(1):29-35.

HiRAYAMA, R., KANEKO, N., AND OKAZAKI, H. 2007. Ocadia nipponica, a new species of aquatic turtle (Testudines: Testudinoidea: Geoemydidae) from the Middle Pleistocene of Chiba Prefecture, central Japan. Paleontological Research 11:1-19.

HIRSCH, K.F. AND LÓPEZ-JURADO, L.F. 1987. Pliocene chelonian fossil eggs from Gran Canaria, Canary Islands. Journal of Vertebrate Paleontology 7:96-99.

HolbROOK, J.E. 1838. North American Herpetology; or, a Description of the Reptiles Inhabiting the United States. Ed. 1, Vol. 3. Philadelphia: J. Dobson, 122 pp.

Holman, J.A. 1972. Amphibians and reptiles. In: Skinner, M.F. and Hibbard,C.W.(Eds.).Early Pleistocenepre-glacial and glacial rocks and faunas of north-central Nebraska. Bulletin of the American Museum of Natural History 148(1):55-148.

HoLmAn,J.A.1991.NorthAmerican Pleistoceneherpetofaunal stability and its impact on the interpretation of modern herpetofaunas: an overview. In: Purdue, J.R., Klippel, W.E., and Styles, B.W. (Eds.). Beamers, Bobwhites, and Blue-points: Tributes to the Career of Paul W. Parmalee. Illinois State Museum of Science Papers No. 23, pp. 227-235.

Holman, J.A. 1995. Pleistocene Amphibians and Reptiles in North America. New York: Oxford University Press, Oxford Monographs on Geology and Geophysics, No. 32, 243 pp.

Holman, J.A. And Clausen, C.J. 1984. Fossil vertebrates associated with Paleo-Indian artifact at Little Salt Spring, Florida. Journal of Vertebrate Paleontology 4:146-154.

Hoogmoed, M.S.,Gassó Miracle, M.E., and V an Den Hoek Ostende,
L.W.2010. Type specimens of recent and fossil Testudines and Crocodylia in the collections of the Netherlands Centre for Biodiversity Naturalis, Leiden, the Netherlands. Zoologische Mededelingen, Leiden 84:159-199.

HoOIJER, D.A. 1948. Pleistocene vertebrates from Celebes. II. Testudo margae nov. spec. Proceedings of the Koninklijke Nederlandsche Akademie van Wetenschappen, Amsterdam 51(9):1169-1182.

HoolJer, D.A. 1963. Geochelone from the Pleistocene of Curaçao, Netherlands Antilles. Copeia 1963(3):579-580.

HooIJer, D.A. 1971. A giant land tortoise, Geochelone atlas (Falconer and Cautley), from the Pleistocene of Timor. Proceedings of the Koninklijke Nederlandsche Akademie van Wetenschappen, Ser. B, Phys. Sci. 74(5):504-525.

HooIJER, D.A. 1972. Pleistocene vertebrates from Celebes: XIV. Additions to the Archidiskodon-Celebochoerus fauna. Zoologische Mededelingen, Leiden 46:1-16.

HoolJer, D.A. 1982. The extinct giant land tortoise and the pygmy stegodont of Indonesia. Modern Quaternary Research in Southeast Asia 7:171-176.

Hume, J.P. 2014. Fossil discoveries in Rodrigues and Mauritius. In: Gerlach,J.(Ed.).WesternIndian Ocean Tortoises:Ecology,Diversity, Evolution,Conservation,Palaeontology.Manchester: Siri Scientific Books, pp. 203-228.

HunTER,E.A.,GiBBS,J.P.,CAYOT,L.J.,AND TAPIA,W.2013.Equivalency of Galápagos giant tortoises used as ecological replacement species to restore ecosystem functions. Conservation Biology 27:701-709.

Hutchison, J.H. 2008. History of fossil Chelydridae. In: Steyermark, A.C.,Finkler,M.S.,andBrooks,R.J.(Eds.).Biology of the Snapping Turtle (Chelydra serpentina). Baltimore: Johns Hopkins University Press, pp. 14-30.

Hutchison, J.H. AND WeEms, R.E. 1998. Paleocene turtle remains from South Carolina. Transactions of the American Philosophical Society 88:165-195.

HutTerer,R.,García-TALAVERA,F.,LÓPEZ-MartínEZ,N., ANDMichauX, J. 1998. New chelonian eggs from the Tertiary of Lanzarote and Fuerteventura and a review of fossil tortoises of the Canary Islands (Reptilia, Testudinidae). Vieraea 26:139-161.

HuXley, T.H. 1887. Preliminary note on the fossil remains of a chelonian reptile, Ceratochelys sthenurus, from Lord Howe's Island, Australia. Proceedings of the Royal Society 42:232-238.

INDES, F. 1869. Sur la formation des tufs des environs de Rome et sur une caverne à ossements au Monte delle Gioie. Bulletin de la Société Géologique de France (2)26:11-28.

InTERnATIONAl COMMISSION ON ZOOLOGICAL NomenClature [ICZN]. 1986. Opinion 1377. Chelydra osceola Stejneger, 1918 given nomenclatural precedence over Chelydra laticarinata Hay, 1916 and Chelydra sculpta Hay, 1916 (Reptilia, Testudines). Bulletin of Zoological Nomenclature 43:33-34.

InTERNATIONAL COMMISSION ON ZOOLOGICAL NOMENCLATURE [ICZN]. 2005b. Opinion 2119 (Case 3277). Chitra chitra Nutaphand, 1986 (Reptilia, Testudines): specific name given precedence over Chitra selenkae Jaekel, 1911. Bulletin of Zoological Nomenclature 62(2):118-119.

IVERSON,J.B. 1979. On the validity of Kinosternonarizonense Gilmore. Copeia 1979(1):175-177.

IVERSON, J.B. 1981. Biosystematics of the Kinosternon hirtipes species group (Testudines: Kinosternidae). Tulane Studies in Zoology 23:1-74.

IVERSON, J.B. 1982. Biomass in turtle populations: a neglected subject. Oecologia 55:69-76.

IverSON, J.B., Higgins, H., SirulnIK, A., AND GrifFIThS, C. 1997. Local and geographic variation in the reproductive biology of the snapping turtle (Chelydra serpentina). Herpetologica 53(1):96-117. 
JACKSON, C.G., JR. 1964. The status of Deirochelys floridana Hay with comments on the fossil history of the genus. Tulane Studies in Geology 2(3):103-106.

JACKSON, C.G., JR. 1974. The status of Trachemys jarmani Hay with clarification of the fossil record of Deirochelys. Copeia 1974:536537.

JACKSON, D.R. 1975. A Pleistocene Graptemys (Reptilia: Testudines) from the Santa Fe River of Florida. Herpetologica 31:213-219.

JACKSON, D.R. 1978. Chrysemys nelsoni. Catalogue of American Amphibians and Reptiles 210:1-2.

JACKSON, D.R. 1988. A re-examination of fossil turtles of the genus Trachemys (Testudines: Emydidae). Herpetologica 44:317-325.

JAEKEL, O. 1911. Die fossilen Schildkrötenreste von Trinil. In: Selenka, M.L. and Blanckenhorn, M.(Eds.). Die Pithecanthropus-Schichten auf Java. Geologische und Paläontologische Ergebnisse der TrinilExpedition(1907 und 1908).Leipzig:WilhelmEngelmann,pp.75-81.

JAIN, S.L. 1986. New pelomedusid turtle (Pleurodira: Chelonia) remains from Lameta Formation (Maastrichtian) at Dongargaon, Central India, and a review of pelomedusids from India. Journal of the Palaeontological Society of India 31:63-75.

JASS, C.N., CoBB, T.P., AND BeLL, C.J. 2014. Regional, depositional, and chronologic comparisons of Pleistocene turtle richness in North America. Chelonian Conservation and Biology 13(1):16-26.

Jiménez Fuentes, E., CARdoso, J.L., And CRespo, E.G. 1999. Presencia de Agrionemys (=Testudo) hermanni (Gmelin, 1789) en el Paleolítico Medio de la Gruta Nova da Columbeira (Bombarral, Provincia de Estremadura, Portugal). Studia Geologica Salamanticensia 34:123-139.

JoHnston, C.S. 1937. Osteology of Bysmachelys canyonensis, a new turtle from the Pliocene of Texas. Journal of Geology 45:439-447.

Joordens, J.C.A., Wesselingh, F.P., De Vos, J., Vonhof, H.B., AND KROON, D. 2009. Relevance of aquatic environments for hominins: a case study from Trinil (Java,Indonesia). Journal of Human Evolution 57:656-671.

Joyce, W.G. 2007. Phylogenetic relationships of Mesozoic turtles. Bulletin of the Peabody Museum of Natural History 48(1):3-102.

JoyCE, W.G. AND Lyson, T.R. 2010. Pangshura tatrotia, a new species of pondturtle(Testudinoidea)from the Pliocene Siwaliks of Pakistan. Journal of Systematic Palaeontology 8(3):449-458.

Joyce, W.G., Lucas, S.G., Scheyer, T.M., Heckert, A.B., AND Hunt, A.P. 2009. A thin-shelled reptile from the Late Triassic of North America and the origin of the turtle shell. Proceedings of the Royal Society B 276:507-513.

Joyce, W.G.,Petričević, A., Lyson, T.R., AND CZAPLewski, N.J. 2012. A new box turtle from the Miocene/Pliocene boundary (Latest Hemphillian) of Oklahoma and a refined chronology of box turtle diversification. Journal of Paleontology 86:177-190.

Joyce, W.G., Parham, J.F., Lyson, T.R., Warnock, R.C.M., AND Donoghue, P.C.J. 2013. A divergence dating analysis of turtles using fossil calibrations: an example of best practices. Journal of Paleontology 87:612-634.

JuLIEN, A.J. 1878. Gigantic land tortoises. Nature 19:30-31 .

KARL, H.-V. 1983.APliocene Geoemyda species (Testudines, Emydidae) from Wetterau (Hessonia, FRG). Zoologischer Anzeiger 210:375-380.

KARL, H.V. 1987. Revision der fossilen Schildkröten (Reptilia, Testudines) von Jawa. Gothaer Museumsheft 14:37-44.

KARL, H.-V. 1995. Über einen fossilen Schildkrötenrest (Reptilia, Testudines) von Kuba. Mitteilungen aus dem Geologisch-Paläontologischen Institut der Universität Hamburg 78:129-137.

KARL, H.-V. 1999. Die Zoogeographie der känozoischen Weichschildkröte Trionyx triunguis Forskäl 1775 (Testudines: Trionychidae). Joannea Geologie und Paläontologie 1:27-60.
KARL,H.-V.2006.Literaturbericht220 Jahre Paläocheloniologie-über die älteste wissenschaftliche Publikation fossiler Schildkrötenreste. Zentralblatt für Geologie und Paläontologie 2(3/4):361-374.

KARL,H.-V.2012.Human consumption of turtles of the Homorudolfensis site Uraha (Malawi, East Africa). Archaeofauna 21:253-264.

KarL, H.-V. AND Paust, E. 2014. Die Geschichte der Europäischen Sumpfschildkröte in Deutschland 2: Checkliste zur prähistorischen Verbreitung der Europäischen Sumpfschildkröte (Emys orbicularis L., 1758) in Thüringen. Mainzer Naturwissenschaftliches Archiv $51: 145-165$

KarL,H.-V. AND StaESche, U. 2007. Fossile Riesen-Landschildkröten von den Philippinen und ihre paläogeographische Bedeutung. Geologische Jahrbucher 98:171-197.

KARL, H.-V. AND Tichy, G. 2002. Erstnachweis von Testudo hermanni Gmelin 1789 aus dem Pleistozän Zentraleuropas nördlich derAlpen (Testudines; Testudinidae). Revue de Paléobiologie 21:781-787.

Karl, H.-V., Gröning, E., Brauckmann, C., Reich, M., and Gehler, A. 2012. Revision of Chelydra strausi Schmidt, 1966 (Testudines: Chelydridae: Chelydropsinae) from the Late Pliocene of Willershausen, Germany). Studia Palaeocheloniologica 4:217-230.

KEAR, B.P. AND GEORGALIS, G.L. 2009. Evolution of gigantic tortoises from the Neogene of Europe. Journal of Vertebrate Paleontology, SVP Program and Abstracts Book, pp. 123-124.

Khosatzky, L.I. 1946. Some new species of the genus Clemmys Ritgen (Testudines, Reptilia) from the Pliocene of the Ukraine. Comptes Rendus (Doklady) del'Academie des Sciences de l'URSS 52(7):617-620.

KHOSATZKY,L.I.1948. New species of the genus Testudo Linne (Testudines, Reptilia) from the Pliocene of Ukraine. Byulleten' Komissii po Izucheniyu Chetvertichnogo Perioda 11:92-96. [In Russian]

KHOSATZKY, L.I. 1956. Otstatki bolotnoj cerepachi iz pliocena Stravropolja. [Remains of the European pond turtle from the Pliocene of Stavropolye].Ezhegodnik VsesoyuznogoPaleontologicheskogo Obshchestva 15:321-327. [In Russian]

KHOSATZKу,L.I. 1982.Reptiles.In: StratigrafiyaSSSR.Chetvertichnaya Sistema. Polutom 1. Moscow: Nedra, pp. 252-262. [In Russian]

KhosatzKy, L.I. And MŁynarski, M. 1966a. Fossil tortoises of the genus Geoemyda Gray, 1834 (s. lat.) of Europe. Acta Zoologica Cracoviensia 11(13):397-421.

KhosatzKy, L.I. And MŁynarski, M. 1966b. Agrionemys - nouveau genre de tortues terrestres (Testudinidae). Bulletin Academie Polonaise Sciences II 14(2):123-125.

KHOSATZKY,L.I. AND REDKOZUBOV, O.I. 1986.Anew species of freshwaterturtle from thePliocene of south of Moldavia.IzvestiyaAkademii Nauk Moldavskoy SSR Seriya Biologicheskikh i Khimicheskikh Nauk 6:74. [In Russian]

KHOSATZKY,L.I. AND REDKOZUBOv, O.I. 1989.Neogenovye cherepakhi Moldavii [Neogene turtles of Moldavia]. Shtiintsa, Kishinev, 94 pp. [In Russian]

Kinaston, R., Buckley, H., Valentin, F., Bedford, S., Spriggs, M., HAWKIns, S., AND HERRSCHER,E. 2014.Lapitadiet in RemoteOceania: new stable isotope evidence from the 3000-year-old Teouma site, Efate Island, Vanuatu. PLOS ONE 9(3)e90376:1-18.

KLEIN, R.G. AND CRUZ-URIBE, K. 1983. Stone Age population numbers and average tortoise size at Bynesdranskop Cave 1 and Die Kelders Cave 1, Southern Cave Province, South Africa. South African Archaeological Bulletin 38:26-30.

Klein, R.G. And Cruz-Uribe, K. 2000. Middle and Later Stone Age large mammal and tortoise remains from Die Kelders Cave 1, Western Cape Province, South Africa. Journal of Human Evolution 38:169-195.

Knauss, G.E., Joyce, W.G., Lyson, T.R., and Pearson, D. 2011. A new kinosternoid from the Late Cretaceous Hell Creek Formation 
of North Dakota and Montana and the origin of the Dermatemys mawii lineage. Palaeontologische Zeitschrift 85:125-142.

Kormos, T. 1911. Une nouvelle espèce de tortue (Clemmys Méhelyi n. sp.) du Pléistocène hongrois. Földtani Közlöny Budapest 41:506-512.

KotsaKIs, T. 1980. Revision des tortues (Emydidae, Testudinidae, Trionychidae) du Plio-Pléistocene de Valdarno supérieur (Toscane, Italie). Quaternaria 22:11-37.

Kotsakis, T. 1982. Gli anfibi e i rettili dei Pleistocene del Lazio (Italia centrale). [Amphibians and reptiles of the Pleistocene of Latium, central Italy]. Geologica Romana 20(1981):57-67.

Kretzol, M. AND Poulianos, N. 1981. Remarks on the middle and lower Pleistocene vertebrate fauna in the Petralona Cave. Anthropos 8:57-72.

KuHN,O. 1964.Testudines.In:Westphal,F.(Ed.).Fossilium Catalogus I: Animalia, Pars 107. Gravenhage: W. Junk, 299 pp.

KURCK, C. 1917.Den forntida utbredningen af kärrsköldpaddan Emys orbicularis (Lin.) i Sverige, Danmark och angränsande länder. [The ancient distribution of the pond turtle Emys orbicularis (Lin.) in Sweden, Denmark and adjacent countries]. Lunds Universitets Årsskrift (N.F.) (2)13:1-129. [In Swedish]

LAPPARENT DE BROIN,F. DE. 2000. African chelonians from the Jurassic to the present.A preliminary catalog of the African fossil chelonians. Palaeontologica Africana 36:43-82.

LAPPARENT de BRoIN, F. DE. 2001. The European turtle fauna from the Triassic to the present. Dumerilia 4(3):155-217.

LAPPARENT DEBRoIN,F.DE.2002.Agiant tortoise from the LatePliocene of Lesvos Island (Greece) and its possible relationships. Annales Géologiques des Pays Helléniques 39:99-130.

LapparentdeBroin,F.de,Bour,R.,Parham,J.F.,AndPeräLä,J.2006a. Eurotestudo, a new genus for the species Testudo hermanni Gmelin, 1789 (Chelonii, Testudinidae).Comptes Rendus Palevol 5:803-811.

Lapparent de Broin, F. de, Bour, R., ANd PerÄLÄ, J. 2006b. Morphological definition of Eurotestudo (Testudinidae, Chelonii): first part. Eurotestudo (Chelonii, Testudinidae), définition, approche morphologique: première partie.Annales dePaléontologie 92:255-304.

Lapparent de Broin, F. DE, Bour, R., ANd Perälä, J. 2006c. Morphological definition of Eurotestudo (Testudinidae, Chelonii): second part.Eurotestudo (Chelonii,Testudinidae), définition, approche morphologique.Deuxième partie.Annalesde Paléontologie 92:325-357.

Latrubesse, E.M., Cozzuol, M., Silva-Caminha, S.A.F. DA, Rigsby, C.A., Absy, M.L., AND JARAmILlo, C. 2010. The Late Miocene paleogeography of the Amazon Basin and the evolution of the Amazon River system. Earth-Science Reviews 99:99-124.

LAWVER, D.R. AND JACKSON, F.D. 2014. A review of the fossil record of turtle reproduction: eggs, embryos, nests and copulating pairs. Bulletin of thePeabody Museum of Natural History 55(2):215-236.

LAZELL, J.D., JR. 1993. Tortoise, cf. Geochelone carbonaria, from the Pleistocene of Anguilla, northern Lesser Antilles. Journal of Herpetology 27(4):485-486.

LE, M. AND MCCoRd, W.P. 2008. Phylogenetic relationships and biogeographical history of the genus Rhinoclemmys Fitzinger, 1835 and the monophyly of the turtlefamily Geoemydidae(Testudines: Testudinoidea).Zoological Journal of the Linnean Society 153:751-767.

Le ConTe, J. 1830. Description of the species of North American tortoises.Annals of the Lyceum of Natural History,New York 3:91-131.

LEGLER, J.M. 1959. A new tortoise, genus Gopherus, from northcentral Mexico. University of Kansas Publications of the Museum of Natural History 11(5):335-343.

LEGLER, J.M. AND CANN, J. 1980. A new genus and species of chelid turtle from Queensland,Australia.Contributions in Science, Natural History Museum of Los Angeles County 324:1-18.

LeGuAT, F. 1707 [“1708”]. Voyages et avantures de François Leguat, et de ses compagnons, en deux îsles désertes des Indes orientales. London: David Mortier, Vol. 1, 164 pp., Vol. 2, 180 pp.

LEIDY, J. 1868a. Notice of some vertebrate remains from Harden Co., Texas. Proceedings of the Academy of Natural Sciences of Philadelphia 1868:174-176.

LeIDY, J. 1868b. Notice on some vertebrate remains from the West Indian Islands. Proceedings of the Academy of Natural Sciences of Philadelphia 1868:178-180.

LEIDY, J. 1877. Description of vertebrate remains, chiefly from the phosphate beds of South Carolina. Journal of the Academy of Natural Sciences of Philadelphia (2)8:209-261.

LEIDY, J. 1889a. Fossil vertebrates from Florida. Proceedings of the Academy of Natural Sciences of Philadelphia 1889:96-97.

LEIDY, J. 1889b. Description of vertebrate remains from Peace Creek, Florida. Transactions of the Wagner Free Institute of Science of Philadelphia 2:19-31.

Li, X., Harbottle, G., Zhang, J., And Wang, C. 2003. The earliest writing? Sign use in the seventh millennium BC at Jiahu, Henan Province, China. Antiquity 77:31-44.

LinNAEus, C. 1758. Systema Naturae, per RegnaTria Naturae, secundum Classes, Ordines, Genera, Species, cum Characteribus, Differentiis, Synonymis, Locis. Tomus I. Editio Decima, Reformata. [10th Ed.]. Holmiae [Stockholm]: Laurentii Salvii, 824 pp.

Loomis, F.B. 1927. A giant tortoise from Florida. American Journal of Science (5)13:435-439.

López-Jurado, L.F. AND MATEO, J.A. 1993. A new giant land tortoise from the Pliocene of Gran Canaria (Canary Islands). Revista Española de Herpetología 7:107-111.

López-Jurado, L.F., Mateo, J.A., ANd García-Márquez, M. 1998. La tortuga fósil de la isla de Sal (Archipiélago de Cabo Verde). Revista Española de Herpetología 12:111-114.

Loveridge, A. AND Williams, E.E. 1957. Revision of the African tortoises and turtles of the suborder Cryptodira. Bulletin of the Museum of Comparative Zoology 115(6):163-557.

LYDEKKER, R. 1885. Indian Tertiary and post-Tertiary Vertebrata. Siwalik and Nerbada Chelonia. Memoirs of the Geological Survey of India, Palaeontologia Indica (10)3:155-208.

LYDEKKER, R. 1886. On a new emydine chelonian from the Pliocene of India. Quarterly Journal of the Geological Society of London 42:540-541.

LYDEKKER,R. 1889a.Notes on Siwalik and NarbadaChelonia. Records of the Geological Survey of India 22:56-58.

LYDEKKER, R. 1889b. Catalogue of the Fossil Reptilia and Amphibia in the British Museum. Part III. Chelonia.London: British Museum of Natural History, 239 pp.

LYDEKKER, R. 1889c. On the tortoises described as Chaibassia. Journal of the Asiatic Society of Bengal 58:327-333.

Macarovici, N. and Vancea, S. 1960. Sur le restes tortues de la faune de Malusteni de la Moldavie meridionale (Roumanie). Analele Stiintifice ale Universitatii “Al. I. Cuza” 6(2):377-386.

MacPhee, R.D.E. (Ed.). 1999. Extinctions in Near Time: Causes, Contexts, and Consequences. New York: Kluwer Academic / Plenum Publishers, 394 pp.

MahÉ,J. AND SouRdat, M. 1972. Sur l'extinction des Vertébrés subfossiles et l'aridification du climat dans le Sud-Ouest de Madagascar. Description des gisements.Datations absolues.Bulletin delaSociété Géologique de France (7)14:295-309.

Martin, B.T., Bernstein, N.P., BirkhEad, R.D., KoukL, J.F., MussMANN, S.M., AND PlACYK, J.S., JR. 2013. Sequence-based molecular phylogenetics and phylogeography of the American box turtles (Terrapene spp.) with support from DNA barcoding. Molecular Phylogenetics and Evolution 68(1):119-134.

Mashkaryan, V., Vamberger, M., Arakelyan, M., Hezaveh, N., 
Carretero, M.A., Corti, C.,Harris, D.J., ANd Fritz,U. 2013.Gene flow among deeply divergent mtDNA lineages of Testudo graeca (Linnaeus, 1758) in Transcaucasia.Amphibia-Reptilia34:337-351.

McCord, W.P. ANd PRITCHARd, P.C.H. 2003. A review of the softshell turtles of the genus Chitra, with the description of new taxa from Myanmar and Indonesia (Java). Hamadryad 27(1)(2002) [2003]:11-56.

McCoy, C.J. AND Richmond, N.D. 1966. The identity of the Chinese box turtle, Terrapene culturalia. Copeia 1966(4):886.

McDowell, S.B. 1964. Partition of the genus Clemmys and related problems in the taxonomy of the aquatic Testudinidae. Proceedings of the Zoological Society of London 143:239-279.

McFarlane, D.A. and Debrot, A.O. 2001. A new species of extinct oryzomyine rodent from the Quaternary of Curaçao, Netherlands Antilles. Caribbean Journal of Science 37:182-184.

McFarlane, D.A. AND LundBerg, J. 2002. A middle Pleistocene age and biogeography for the extinct rodent Megalomys curazensis from Curaçao, Netherlands Antilles. Caribbean Journal of Science 38:278-281.

Mercadal, B. and Pretus Real, J.J. 1980. Nuevo yacimiento de Testudo gymnesicus Bate, 1914 en la isla de Menorca. Bolleti de la Societat d'Historia Natural de les Balears 24:15-22.

Merrem, B. 1820. Versuch eines Systems der Amphibien. Tentamen Systematis Amphibiorum. Marburg: J.C. Krieger, 191 pp.

MeYER, H. von. 1835. Mittheilungen an Professor Bronn gerichtet. Neues Jahrbuch für Mineralogie, Geognosie, Geologie und Petrefaktenkunde, Stuttgart 1835:63-69.

Meylan, P.A. 1995. Pleistocene amphibians and reptiles from the Leisey Shell Pit, Hillsborough County, Florida. Bulletin of the Florida Museum of Natural History 37(1)(9):273-297.

Meylan, P.A. And Auffenberg, W. 1987. The chelonians of the Laetolil Beds. In: Leakey, M.D. and Harris, J.M. (Eds.). Laetoli, a Pliocene Site in Northern Tanzania. Oxford: Oxford University Press, pp. 62-78.

Meylan, P.A. And Sterrer, W. 2000. Hesperotestudo (Testudines: Testudinidae) from the Pleistocene of Bermuda, with comments on the phylogenetic position of the genus. Zoological Journal of the Linnean Society 128:51-76.

Mikulíček, P., JANDZIK, D., Fritz, U., Schneider, C., AND ŠIroký, P. 2013.AFLPanalysis shows high incongruence between genetic differentiation and morphology-based taxonomy in a widely distributed tortoise. Biological Journal of the Linnean Society 108(1):151-160.

Milne-Edwards, A. 1868. Sur des découvertes zoologiques faites récemment à Madagascar par M. Alfred Grandidier. Comptes Rendus Hebdomadaires des Séances de l'Académie des Sciences, Paris 67:1165-1167.

Mirstead, W.W. 1956. Fossil turtles of Friesenhahn Cave, Texas, with the description of a new species of Testudo.Copeia 1956(3):162-171.

MilsteAd, W.W. 1965. Notes on the identities of some poorly known fossils of box turtles (Terrapene). Copeia 1965(4):513-514.

Milstead, W.W. 1967. Fossil box turtles (Terrapene) from central North America, and box turtles of eastern Mexico. Copeia 1967(1):168-179.

MŁYNARSKI, M. 1964. Die jungpliozäne Reptilienfauna von Rebielice Królewskie, Polen. Senckenbergiana Biologica 45(3/5):325-347.

MŁYNARSKI, M. 1966. Die fossilen Schildkröten in den ungarischen Sammlungen. Acta Zoologica Cracoviensia 11(8):224-288.

MŁynarski, M. 1976. Handbuch der Palaeoherpetologie. Part 7. Testudines. Stuttgart: Gustav Fisher, 130 pp.

MŁYNARSKI, M. 1980. Die Schildkröten des Steinheimer Beckens II. Chelydridae mit einem Nachtrag zu den Testudinoidea. Palaeontographica 8(2) Suppl. B:1-35.

MolnaR, R.E. 1982. A longirostrine crocodilian from Murua
(Woodlark), Solomon Sea. Memoirs of the Queensland Museum 20:675-685.

Moodie, K.B. and Van Devender, T.R. 1979. Extinction and extirpation in the herpetofauna of the southern high plains with emphasis on Geochelone wilsoni (Testudinidae). Herpetologica 35:198-206.

Mooser, O. 1972. A new species of Pleistocene fossil tortoise, genus Gopherus, from Aguascalientes, Aguascalientes, Mexico. Southwestern Naturalist 17(1):61-65.

MOOSER, O. 1980.Pleistocene fossil turtles from Aguascalientes, State of Aguascalientes. Universidad Nacional Autónoma de México, Instituto de Geología, Revista 4(1):63-66.

MorAFKA, D.J. 1988. Historical biogeography of the Bolson tortoise. In: Morafka, D.J. and McCoy, C.J.(Eds.). The ecogeography of the Mexican Bolson tortoise (Gopherus flavomarginatus): derivation of its endangered status and recommendations for its conservation. Annals of Carnegie Museum 57(1):47-72.

MorafKa, D.J. AND Berry, K.H. 2002. Is Gopherus agassizii a desert-adapted tortoise, or an exaptive opportunist? Implications for tortoise conservation. Chelonian Conservation and Biology 4(2):263-287.

Morales Pérez,J.V.and SANChIS SERRA,A.2009.The Quaternary fossil record of the genus Testudo in the Iberian Peninsula.Archaeological implications and diachronic distribution in the western Mediterranean. Journal of Archaeological Science 36(5):1152-1162.

Morwood,M.J.,O’Sullivan,P.B.,Aziz,F., andRaza,A.1998.Fissiontrack ages of stone tools and fossils on the east Indonesian island of Flores. Nature 392:173-176.

Mudar, K. and Anderson, D. 2007. New evidence for Southeast Asian Pleistocene foraging economies: faunal remains from the early levels of Lang Rongrien Rockshelter, Krabi, Thailand. Asian Perspectives 46(2):298-334.

Muns,D.R.,Pandolfi,J.M.,Simmons, K.R., andSchumann,R.R. 2012. Sea-level history of past interglacial periods from uranium-series dating of corals, Curacao, Leeward Antilles islands. Quaternary Research 78(2):157-169.

MunRo, N.D. AND Grosman,L. 2010. Early evidence (ca. 12,000 B.P.) for feasting at a burial cave in Israel. PNAS (Proceedings of the National Academy of Sciences) 107(35):15362-15366.

Murchison, C. 1868. Palaeontological Memoirs and Notes of the late Hugh Falconer, A.M., M.D., with a Biographical Sketch of the Author. Vol. I. Fauna Antiqua Sivalensis. London: Hardwicke, 590 pp.

NAKSRI, W., Lu, L., AND Tong, H. 2014. A revision of Testudo tungia Yeh, 1963 from the Lower Pleistocene Gigantopithecus cave, Liucheng, Guangxi Province, China. Journal of Science and Technology, Mahasarakham University 33:386-392.

NiLsson, S. 1841. Beskrifning öfver en i Skåne funnen fossil sköldpadda, jemförd med andra i Svensk jord funna qvarlefvor af samma djurordning. [Description of a fossil turtle found in Skåne, compared with other Swedish remains of the same order of animals]. Kongliga Svenska Vetenskaps-Academiens Handlingar 1839[1841]:194-211. [In Swedish]

Nilsson, S. 1860. Skandinawisk Fauna. Tredje Delen: Amfibierna. Andra Upplagan. Skandinawisk Herpetologi, eller Beskrifning öfwer de sköldpaddor, ödlor, ormar och grodor, som förekomma i Swerige och Norrige, jemte deras lefnadssätt, födoämnen, nytta och skada. Lund: Berlingska Boktryck., 140 pp. [In Swedish]

North-CoOmBes, A. 1986. Histoire des tortues de terre de Rodrigues et le mouvement maritime de l'ile de 1601 à 1808 . Port-Louis, Mauritius: Service Bureau, 75 pp.

OELRICH,T.M. 1952.Anew Testudo from the UpperPliocene of Kansas with additional notes on associated Rexroad mammals. Transactions of the Kansas Academy of Sciences 55(3):300-311.

OELRICH, T.M. 1953. A new boxturtle from the Pleistocene of south- 
western Kansas. Copeia 1953(1):33-38.

Oliveira, G.R. DE AND Romano, P.S.R. 2007. Histórico dos achados de tartarugas fósseis do Brasil. Arquivos do Museu Nacional, Rio de Janeiro 65(1):113-133.

OLIVER, J.R. 2008. The archaeology of agriculture in ancient Amazonia. In: Silverman, H. and Isbell, W.H. (Eds.). Handbook of South American Archaeology. New York: Springer, pp. 185-216.

Olson, S.L. and Meylan, P.A. 2009. A second specimen of the Pleistocene Bermuda tortoise, Hesperotestudo bermudae Meylan and Sterrer. Chelonian Conservation and Biology 8(2):211-212.

Olson, S.L. AND PREGILL, G.K. 1982. Introduction to the paleontology of Bahaman vertebrates. In: Olson, S.L. (Ed.). Fossil vertebrates from the Bahamas. Smithsonian Contributions to Paleobiology, no. 48 , pp. 1-7.

Olson, S.L., Pregill, G.K., And Hilgartner, W.B. 1982. Studies on fossils and extant vertebrates from San Salvador (Watling's) Island, Bahamas. Smithsonian Contributions to Zoology 508:1-15.

O'ReILly,D.J.W., VON DEN Driesch,A., AND Voeun, V.2006.Archaeology and archaeozoology of Phum Snay: a late prehistoric cemetery in northwestern Cambodia. Asian Perspectives 45(2):188-211.

OTsuKa, H. 1969. Pleistocene vertebrate fauna from the Kuchinotsu Group of west Kyushu (part III-V). Reports of the Faculty of Science, Kagoshima University 2:53-84.

OTSUKA, H. AND TAKAHASHI, A. 2000. Pleistocene vertebrate faunas in the Ryukyu Islands: their migration and extinction. Tropics 10:25-40.

OTsuka, H., NaKamuRA, T., AND OTA, T. 2008. ${ }^{14} \mathrm{C}$ ages of vertebrate fossil beds in the Ryukyu Islands, south Japan. Summaries of Researches Using AMS at Nagoya University 19:135-153.

Owen, R. 1886a. Description of fossil remains of two specimens of a Megalanian genus (Meiolania, Ow.), from Lord Howe's Island. Proceedings of the Royal Society of London 1886(40):315-316.

OwEn, R. 1886b. Description of fossil remains of two species of Megalanian genus (Meiolania) from "Lord Howe Island." Philosophical Transactions of the Royal Society of London 177:471-480.

PARHAM, J.F. 2008. Rediscovery of an "extinct" Galápagos tortoise. Proceedings of the National Academy of Sciences of the USA 105:15227-15228.

PARRIS,D.C. AND DAESCHLER, E. 1995. Pleistocene turtles of Port Kennedy Cave (late Irvingtonian), Montgomery County, Pennsylvania. Journal of Paleontology 69(3):563-568.

Paula Couto, C. DE. 1948. Sobre os vertebrados fósseis da coleção Sellow, do Uruguai. Boletim Departamento Nacional da Produção Mineral Divisão de Geologia e Mineralogia, Rio de Janeiro 125:1-14.

Pazonyi,P.2013.Archaeological sites of the SüttóTravertine Complex (Hungary) with stratigraphical and paleoecological implications from their faunas. Quaternary International, doi.org/10.1016/j. quaint.2013.05.019.

Pedrono, M. 2008. The Tortoises and Turtles of Madagascar. Kota Kinabalu: Natural History Publications (Borneo), 147 pp.

Pedrono, M., Griffiths, O., Clausen, A., Smith, L., Griffiths, C., WiLMÉ, L., AND BuRNEY, D. 2013. Using a surviving lineage of Madagascar's vanished megafauna for ecological restoration. Biological Conservation 159:501-506.

Peres, C.A. And Nascimento, H.S. 2006. Impact of game hunting by the Kayapó of south-eastern Amazonia: implications for wildlife conservation in tropical forest indigenous reserves. Biodiversity and Conservation 15:2627-2653.

Pérez-García, A. and Vlachos, E. 2014. New generic proposal for the European Neogene large testudinids (Cryptodira) and the first phylogenetic hypothesis for the medium and large representatives of the European Cenozoic record.Zoological Journal of the Linnean Society 172:653-719.
Peters, K.F. 1868. Zur Kenntniss der Wirbelthiere aus den Miocänschichten von Eibiswald in Steiermark. I. Die Schildkrötenreste. Sitzungsberichte der Akademie der Wissenschaften in Wien, Mathematisch-Naturwissenschaftliche Klasse 57(1):72-74.

PidoplichKo, I.G. AND TARASHChUK, V.I. 1960. A new genus of bigheaded turtle from the Pontian deposits in the environs of Odessa. Zbirnik Prats Zoologichnego Muzeyu AN URSR 29:105-110. [In Ukrainian]

Ping, C. 1930. Notes on the shell of a land tortoise from the ancient ruins of Annyang. Bulletin of the Fan Memorial Institute of Biology 1(13):217-226.

Plieninger, T. 1847. Verzeichnis der Reptilien Württembergs. Jahreshefte des Vereins für Vaterländische Naturkunde, Württemberg 3:194-208.

PORTA,V.A.1898. NuoviChelonii fossilidelPiacentino.RivistaItaliana di Paleontologia 4:105-122.

PoRTIS,A. 1880. Di alcuni fossili terziarii del Piemonte e della Liguria, appartenentiall'ordine deiChelonii.Memorie dellaRealeAccademia delle Scienze di Torino (2)32:113-134.

PorTIs, A. 1890.I Rettili Pliocenici del Valdarno Superiore e di Alcune Altre Localitá Plioceniche di Toscana. Firenze: Le Monnier, 32 pp.

PorTIs, A. 1896. Contribuzioni alla storia fisica del bacino di Roma e studii sopra l'estensione da darsi al Pliocene superiore. II. Rome.

Poulakakis, N., Glaberman, S., Russello, M., Beheregaray, L.B., Ciofi, C., Powell, J.R., and Caccone, A. 2008. Historical DNA analysis reveals living descendants of an extinct species of Galápagos tortoise. Proceedings of the National Academy of Sciences 105:15464-15469.

Poulakakis, N., Russello, M., Geist, D., and Caccone, A. 2012. Unravelling the peculiarities of island life: vicariance, dispersal, and the diversification of the extinct and extant giant Galápagos tortoises. Molecular Ecology 21:160-173.

Prasad, K.N. and Satsangi, P.P. 1967. On a new chelonian from the Siwalik beds of Himachal Pradesh. Records of the Geological Survey of India 95:533-536.

Pregill, G. 1981. Late Pleistocene herpetofaunas from Puerto Rico. University of Kansas Museum of Natural History Miscellaneous Publications 71:1-72.

Preston, R.E. 1966. Turtles of the Gilliland faunule from the Pleistocene of Knox County, Texas. Papers of the Michigan Academy of Science, Arts, and Letters 51:221-239.

PRESTON, R.E. 1979. Late Pleistocene cold-blooded vertebrate faunas from the mid-Continental United States. I. Reptilia, Testudines, Crocodilia. University of Michigan Museum of Paleontology, Papers on Paleontology, No. 19, 53 pp.

Preston, R.E. AND McCoy, C.J. 1971. The status of Emys twentei (Reptilia: Testudinidae) based on new fossil records from Kansas and Oklahoma. Journal of Herpetology 5:23-30.

PRITCHARD,P.C.H.1994.Comments on Chinemyspalaeannamitica and certain otherchelonian taxabased upon material from archaeological sites. Chelonian Conservation and Biology 1(2):131-137.

PritchaRd,P.C.H. 1996. The Galápagos Tortoises: Nomenclatural and Survival Status. Chelonian Research Monographs No. 1, 85 pp.

Pritchard, P.C.H., RabetT, R.J., AND PIPER, P.J. 2009. Distinguishing species of geoemydid and trionychid turtles from shell fragments: evidence from the Pleistocene at Niah Caves,Sarawak. International Journal of Osteoarchaeology 19:531-550.

Quintana, J., Kohler, M., And Moya-Sola, S. 2011. Nuralagus rex, gen. et sp. nov., an endemic insular giant rabbit from the Neogene of Minorca. Journal of Vertebrate Paleontology 31(2):231-240.

QuoY, J.R.C. AND GAIMARD, J.P. 1824a. Description d'une nouvelle espèce de tortue et de trois espèces nouvelles de scinques. Bulletin des Sciences Naturelles et de Géologie, Paris 1:90-91. 
QuOY, J.R.C. And GAIMARD, J.P. 1824b. Sous-genre Tortue de TerreTestudo Brongn. Tortue Noire-Testudo nigra N. In: Freycinet, M.L. de. Voyage Autour du Monde, Entrepris par le Ministère et conformément aux instructions de s. exc. M. le Vicomte du Bouchage, Secrétaire d'Etat au Département de la Marine, Exécuté sur les corvettes de S.M.l'Uranie et la Physicienne, pendant les années 1817-1820. Zoologie. Paris: Pillet Aîné, pp. 174-175.

RAFINESQUE, C.S. 1815. Analyse de la Nature ou Tableau de l'Univers et des Corps Organisés. Palermo: 223 pp.

RAFINESQUE, C.S. 1832. Description of two new genera of soft shell turtles of North America.Atlantic Journal and Friend of Knowledge $1: 64-65$.

RAY,C.E. 1964. A small assemblage of vertebrate fossils from Spring Bay, Barbados. Journal of the Barbados Museum and Historical Society 31(1):11-22.

ReDKozUBov, O.I. 1988. Nowyj wid presnowodnoj cerepachi iz erchnepliozenowych otlozenij Moldawii. [A new pond turtle from the Upper Pliocene deposits of Moldova]. Izvestiya Akademii Nauk Moldavsk.SSR Ser.Biol.Khim.Nauk 1988(4):74-75. [In Russian]

REDKOZUBOv, O.I. 1994. New findings of fossil remains of turtles from the locality near village Salchiya (Moldova). Bul.Acad. Sti. Repub. Mold. Sti. Biol. Si Chim. 6:27-29.

Reyes-Velasco, J.,Iverson, J.B., And Flores-Villela, O. 2013. The conservation status of several endemic Mexican kinosternid turtles. Chelonian Conservation and Biology 12:203-208.

Reynoso, V.-H. and Montellano-Ballesteros, M. 2004. A new giant turtle of the genus Gopherus (Chelonia: Testudinidae) from the Pleistocene of Tamaulipas, México, and a review of the phylogeny and biogeography of gopher tortoises. Journal of Vertebrate Paleontology 24(4):822-837.

RHoDIN, A.G.J. 1986. Analysis of prehistoric turtle bone remains from Cedar Swamp, Westborough, Worcester County, Massachusetts. Archaeological Quarterly 8(2):2-9.

Rhodin, A.G.J. 1992. Chelonian zooarchaeology of eastern New England: turtle bone remains from Cedar Swamp and other prehistoric sites. Bulletin of the Massachusetts Archaeological Society 53(1):21-30.

RHodin, A.G.J. 1995. Archaeological turtle bone remains from Concord Shell Heap. Bulletin of the Massachusetts Archaeological Society 56(2):71-82.

Rhodin, A.G.J. And Largy, T. 1984. Prehistoric occurrence of the redbelly turtle (Pseudemys rubriventris) at Concord, Middlesex County, Massachusetts. Herpetological Review 15(4):107.

Rhodin, A.G.J. AND MittermeIER, R.A. 1983. Description of Phrynops williamsi, a new species of chelid turtle of the South American $P$. geoffroanus complex. In: Rhodin, A.G.J. and Miyata, K. (Eds.). Advances inHerpetology and Evolutionary Biology.Essaysin Honor of Ernest E. Williams. Cambridge, MA: Museum of Comparative Zoology, pp. 58-73.

Rödder, D., Lawing, A.M., Flecks, M., Ahmadzadeh, F., Dambach, J., Engler, J.O., Habel, J.C., Hartmann, T., Hörnes, D., Ihlow, F., Schidelko, K., Stiels, D., AND Polly, P.D. 2013. Evaluating the significance of paleophylogeographic species distribution models in reconstructing Quaternary range-shifts of Nearctic chelonians. PLoS ONE 8(10):e72855, doi:10.1371/journal.pone.0072855.

Rook, L., Croitor, R., Delfino, M., Ferretti, M.P., Gallai, G., AND Pavia, M. 2013. The Upper Valdarno Plio-Pleistocene vertebrate record: an historical overview, with notes on palaeobiology and stratigraphic significance of some important taxa. Italian Journal of Geosciences 132:104-125.

Roosevelt, A.C., Lima da Costa, M., Lopes Machado, C., Michab, M., Mericer, N., Valladas, H., Feathers, J., Barnett, W., Imazio da Silveira, M., Henderson, A., Silva, J., Chernoff, B., Reese,
D.S., Holman, J.A., Toth, N., And Shick, K. 1996. Paleoindian cave dwellers in the Amazon: the peopling of the Americas. Science 272:373-384.

RothsCHILD, W. 1915. On the gigantic land tortoises of the Seychelles and Aldabra-Madagascar group with some notes on certain forms of the Mascarene group. Novitates Zoologicae 22:418-442.

Rusconi, C. 1934. Tercera noticia sobre los vertebrados fósiles de las arenas puelchenses de Villa Ballester. Anales de la Sociedad Científica Argentina 117:19-37.

Russello,M.A.,Beheregaray,L.B.,GibBs,J.P.,Fritts,T.,HaVavill, N., Powell,J.R., AND CACCONE,A. 2007.Lonesome George is not alone among Galápagos tortoises. Current Biology 17(9):R317-R318.

Russello, M., Poulakakis, N., Gibbs, J., Tapia, W., Benavides, E., Powell, J., AND CACCone, A. 2010. DNA from the past informs $e x$ situ conservation for the future: an "extinct" species of Galápagos tortoise identified in captivity. PLoS ONE 5:7.

SACCO, F. 1889. I Cheloni astiani del Piemonte. Memorie della Reale Accademia delle Scienze di Torino (2)39:427-461.

SANDOM,C., FAurby, S., SANDEL, B., AND SvennING, J.-C. 2014. Global lateQuaternary megafauna extinctions linked to humans, notclimate change. Proceedings of the Royal Society B 281:20133254. http:// dx.doi.org/10.1098/rspb.2013.3254.

Schmid, H. 1966. Eine Entwicklungsreihe bei Schildkröten der Gattung Chelydra. Neues Jahrbuch für Geologie und Paläontologie, Abhandlungen 125:19-28.

SCHNEIDER, J.G. 1783. Allgemeine Naturgeschichte der Schildkröten, nebst einem systematischen Verzeichnisse der einzelnen Arten und zwei Kupfern. Leipzig: J.G. Müller, 364 pp.

ScHOEPFF,J.D. 1792.Historia Testudinum Iconibus Illustrata.Erlangae: Ioannis Iacobi Palm, 136 pp. [Fascicles Iand II,pp. 1-32,pls. 1-10].

SCHOEPFF,J.D. 1793. Historia Testudinum Iconibus Illustrata.Erlangae: Ioannis Iacobi Palm, 136 pp. [Fascicles III and IV, pp. 33-80, pls. 11-16, 17B-20].

SCHWEIGGER, A.F. 1812. Prodromus monographiae Cheloniorum. Königsberger Archiv für Naturwissenschaft und Mathematik 1:271-368, 406-462.

SCOTESE,C.R.2013.Map Folio 2,LastGlacial Maximum(Pleistocene, $21 \mathrm{ky})$. PALEOMAP PaleoAtlas for ArcGIS, vol. 1, Cenozoic Paleogeographic, Paleoclimatic and Plate Tectonic Reconstructions, PALEOMAP Project, Evanston, IL.

SERB,J.M.,PhilliPs,C.A.,ANDIVERSOn,J.B.2001.Molecularphylogeny and biogeography of Kinosternon flavescens based on complete mitochondrial control region sequences. Molecular Phylogenetics and Evolution 18:149-162.

SETIYABUdi, E. 2006. Palaeontological study of fossil giant tortoises from the Indonesian islands. Unpublished M.Sc. Thesis, University of Kagoshima, Japan.

Setryabudi, E. 2009. An early Pleistocene giant tortoise (Reptilia; Testudines; Testudinidae) from the Bumiayu area, Central Java, Indonesia. Journal of Fossil Research 42(1):1-11.

Sharapov, S., Amiranashvili, N.G., and Chkhikvadze, V.M. 1988. Novyi vid pozlepliotsenovoi sukhoputnoi cherepakhi iz Tadzhikistana. [A new late Pliocene species of tortoise from Tajikistan]. Doklady Akademii Nauk Tadzhikskoy SSR 31(8):545-547. [In Russian]

SHIKAMA, T. 1949. The Kuzuï ossuaries: geological and palaeontological studies of the limestone fissure deposits in Kuzuü, Totigi Prefecture. Scientific Reports of Tohoku University, 2nd Series (Geology) 23:1-201.

ShiKAma, T. ANd OKAFuJ, G. 1964. On a new Cyclemys from Akiyoshi, Japan. Science Reports of Yokohama University (2)(11):59-67.

SiEBENROCK, F. 1906. Schildkröten von Ostafrika und Madagaskar. In: Voeltzkow, A. Reise in Ost-Afrika in den Jahren 1903-1905 mit 
Mitteln der Hermann und Elise geb. Heckmann-Wentzel-Stiftung. Wissenschaftliche Ergebnisse, Systematischen Arbeiten, Stuttgart 2:1-40.

Simpson, G.G. 1937. New reptiles from the Eocene of South America. American Museum Novitates 927:1-3.

SMITH,A. 1838. Illustrations of the Zoology of South Africa; consisting chiefly of Figures and Descriptions of the Objects of Natural History collected during an Expedition into the Interior of South Africa, in the years 1834, 1835, and 1836. Part No. 1. London: Smith, Elder and Co., 23 pp., 10 pls. [Reptilia, plate 1].

SмIтн, M.A. 1931. The Fauna of British India, including Ceylon and Burma.ReptiliaandAmphibia.Vol.I.Loricata,Testudines.London: Taylor and Francis, 185 pp.

SNow, D.W. 1964. The giant tortoises of the Galápagos Islands: their present status and future chances. Oryx 7:277-290.

Sommer, R.S.,Persson,A., Wiesere,N., and Fritz, U. 2007. Holocene recolonization and extinction of the pond turtle,Emysorbicularis $(\mathrm{L}$., 1758), in Europe. Quaternary Science Reviews 26:3099-3107.

Sommer, R.S.,Lindevist, C.,Persson,A.,Bringsøe,H.,Rhodin,A.G.J., Schneeweiss, N., Siroky, P., Bachmann, L., AND Fritz, U. 2009. Unexpected early extinction of the European pond turtle (Emys orbicularis) in Sweden and climatic impact on its Holocene range. Molecular Ecology 18:1252-1262.

Sommer, R.S., Fritz, U., Seppä, H., Ekström, J., Persson, A., AND LILJEGREN, R. 2011. When the pond turtle followed the reindeer: effect of the last extreme global warming event on the timing of faunal change in Northern Europe. Global Change Biology 17:2049-2053.

SONDAAR,P.Y.1981.The Geochelone faunas of the Indonesian archipelago and their paleogeographical and biostratigraphical significance. Modern Quaternary Research in Southeast Asia 6:111-120.

SONDAAR,P.Y.1987.Pleistocene man and extinctions of islandendemics. Mémoires de la Société Géologique de France, N.S. 150:159-165.

SondaAr, P.Y., Van Den Bergh, G.D., Mubroto, B., Aziz, F., De Vos, J., AND BATU, U.L. 1994. Middle Pleistocene faunal turnover and colonization of Flores (Indonesia) by Homo erectus. Comptes Rendues de l'Academie des Sciences, Paris 319(II):1255-1262.

Souza-Mazurek, R.R. de, Pedrinho, T., Feliciano, X., Hilário, W., GERÔNCIO, S., AND MARCELO, E. 2000. Subsistence hunting among the WaimiriAtroari Indians in central Amazonia,Brazil.Biodiversity and Conservation 9:579-596.

SPETH, J.D. AND TChernov, E. 2003. Paleoclimatic and behavioral implications of Middle Paleolithic tortoise use at Kebara Cave (Israel). In: Patou-Mathis, M. and Bocherens, H. (Eds.). Le role de l'environnement dans les comportements des chasseurs-cueilleurs prehistoriques. BAR International Series 1105, pp. 9-21.

StARKey,D.E.,ShafFer,H.B.,BurKe,R.L.,Forstner,M.R.J.,Iverson, J.B.,JANZEN,F.J.,RHODIN,A.G.J.,ANDULTSCH, G.R.2003.Molecular systematics, phylogeography, and the effects of Pleistocene glaciation in the painted turtle (Chrysemys picta) complex. Evolution 57(1):119-128.

STEADMAN,D.W., 1986. Holocene vertebrate fossilsfrom IslaFloreana, Galápagos.Smithsonian Contributions toZoology,No.413,103 pp.

Steadman, D.W., Franz, R., Morgan, G.S., Albury, N.A., Kakuk, B., Broad, K., Franz, S.E., Tinker, K., Pateman, M.P., Lott, T.A., JARZEN, D.M., AND DilChER, D.L. 2007. Exceptionally well preserved late Quaternary plant and vertebrate fossils from a blue hole on Abaco, The Bahamas. PNAS (Proceedings of the National Academy of Sciences) 105(50):19897-19902.

Steadman, D.W., Albury, N.A., Maillis, P., Mead, J.I., SlapcinSKy, J., Krysko, K.L., Singleton, H.M., and Franklin, J. 2014. Late-Holocene faunal and landscape change in the Bahamas. The Holocene 24(2):220-230.
STEele, T.E. 2010.A unique hominin menu dated to 1.95 million years ago. PNAS (Proceedings of the National Academy of Sciences) 107(24):10771-10772.

SteELE, T.E. AND KLEIN, R.G. 2006.Mollusk and tortoise size as proxies for stone age population density in South Africa: implications for the evolution of human cultural capacity. MUNIBE (AntropologiaArkeologia) Homenaje a Jesús Altuna 57(1):221-237.

SteJNEGER, L. 1918. Description of a new lizard and a new snapping turtle from Florida. Proceedings of the Biological Society of Washington 31:89-92.

STERLI, J. 2008. A new, nearly complete stem turtle from the Jurassic of South America with implications for turtle evolution. Biology Letters 2008:1-4.

STERLI, J. 2010. Phylogenetic relationships among extinct and extant turtles: the position of Pleurodira and the effects of the fossils on rooting crown-group turtles. Contributions to Zoology 79 (3): 93-106.

Sterli, J. AND DE la Fuente, M.S. 2013. New evidence from the Palaeocene of Patagonia (Argentina) on the evolution and palaeobiogeography of Meiolaniformes (Testudinata, new taxon name). Journal of Systematic Palaeontology 11(7):835-852.

Stiner, M.C., Munro, N.D., Surovell, T.A, Tchernov, E., AND BarYosef, O. 1999. Paleolithic population growth pulses evidenced by small animal exploitation. Science 283:190-194.

Stiner, M.C., Munro, N.D., AND Surovell, T.A. 2000. The tortoise and the hare. Small-game use, the broad-spectrum revolution, and Paleolithic demography. Current Anthropology 41(1):39-79.

Stoddart, D.R., Peake, J.F., Gordon, C., and Burleigh, R. 1979. Historical records of Indian Ocean giant tortoise populations. Philosophical Transactions of the Royal Society ofLondon 286B:147-158.

STRAIN, W.S. 1966. Blancan mammalian fauna and Pleistocene formations, Hudspeth County, Texas. Bulletin of the Texas Memorial Museum 10:1-31.

Strauch,A. 1865. Die Vertheilung der Schildkröten über den Erdball. Einzoogeographischerversuch.Mémoires del'Académie Impériale des Sciences de St.-Pétersbourg (7)8(13):1-207.

StUART, C.L. AND MEakin, P.R. 1983. A note on the effect of fire on a population of angulate tortoises, Chersina angulata (Cryptodira: Testudinidae), with an estimate of biomass. Journal of the Herpetological Association of Africa 29:7-8.

StUCKAs, H., Gemel, R., AND Fritz, U. 2013. One extinct turtle species less: Pelusios seychellensis is not extinct, it never existed. PLoS ONE 8(4):e57116.

SucKow, G.A.1798.Anfangsgründe dertheoretischenundangewandten Naturgeschichte der Thiere. Dritter Theil. Von den Amphibien. Leipzig: Weidmannischen Buchhandlung, 298 pp.

Surovell, T., Waguespack, N., ANd Brantingham, P.J. 2005. Global archaeological evidence for proboscidean overkill.PNAS (Proceedings of the National Academy of Sciences) 102(17):6231-6236.

Swingland, I.R. AND CoE, M. 1979. The natural regulation of giant tortoise populations on Aldabra Atoll: recruitment. Philosophical Transactions of the Royal Society of London 286B:177-188.

SwINTON, W.E. 1939.Anew fresh-water tortoise from Burma. Records of the Geological Survey of India 74:548-551.

SzalaI, T. 1931. Schildkrötenstudien. I. Testudo schafferi nov. sp., eine Riesenschildkröte aus dem Pliozan von Samos. Annalen des Naturhistorischen Museums in Wien 46:153-157.

SzalaI, T. 1934. Die fossilen Schildkröten Ungarns. Folia Zoologica et Hydrobiologia 6:97-142.

TAGLIAFERRO,N.1914. On the occurrence of a new gigantic land tortoise at Corradino, Malta. Archivum Melitense 2:76-79.

Takahashi, A., Otsuka, H., And Hirayama, R. 2003. A new species of the genus Manouria (Testudines: Testudinidae) from the Upper Pleistocene of the Ryukyu Islands, Japan.Paleontological Research 
7(3):195-217.

TAKAHASHI,A., KaTO, T., AND OTA,H. 2007.Anew species of the genus Geoemyda (Chelonii: Geoemydidae) from the Upper Pleistocene of Tokunoshima Island, the central Ryukyus, Japan. Current Herpetology 26(1):1-11.

Takahashi, A., Otsuka, H., and Ota, H. 2008. Systematic review of Late Pleistocene turtles (Reptilia: Chelonii) from the Ryukyu Archipelago, Japan, with special reference to paleogeographical implications. Pacific Science 62(3):395-402.

TAO,H-J.1985.New fossil turtles, Chinemys pani $\mathrm{n}$. sp.(Testudinidae) from the Chi-Ting Formation (Pleistocene), Tainan District, Taiwan Island. Journal of the Taiwan Museum 38(1):43-52.

TAO, H-J. 1986. Report of a new fossil soft-shelled turtle, Trionyx liupani from Taiwan, with comparative study to the living species, Trionyx sinensis (Wiegmann). Journal of the Taiwan Museum 39(2):21-41.

TAO,H-J. 1988. New fossil turtle, Ocadia sinensis changwui n. subsp., from Late Pleistocene, Taiwan Strait. Acta Zoologica Taiwanica 2:229-240.

TARASHCHUK, V.I. 1971.Turtles of Neogene and Anthropogene deposits of Ukraine. Report I, family of big-headed turtles (Platysternidae). Vestnik Zoologii 2:56-62. [In Russian]

TAYLOR, E.H. 1943. An extinct turtle of the genus Emys from the Pleistocene of Kansas. University of Kansas Science Bulletin 29(II)(3):249-254.

Taylor, J.D., Braithwaite, C.J.R., Peake, J.F., and Arnold, E.N. 1979. Terrestrial faunas and habitats of Aldabra during the late Pleistocene. Philosophical Transactions of the Royal Society of London 286B:47-66.

TAYLOR, W.E. 1895. The box turtles of North America. Proceedings of the United States National Museum 17:573-588.

Telepneva, V.P. 1964. New data on Pliocene turtles of Moldavia and Ukraine [Abstract]. Leningrad: Voprosy gerpetologii. Materialy gerpetologicheskoy konferentsii, Leningrad State University, p. 70. [In Russian]

TEWARI,B.S. AND BADAM, G.L.1969.Anew species of fossil turtle from the UpperSiwaliks of Pinjore,India.Palaeontologica 12(4):555-558.

THEOBALD, W., JR. 1860. On the Tertiary and alluvial deposits of the central portion of the Nerbudda Valley. Memoirs of the Geological Survey of India 2:279-298.

Theobald, W., JR. 1868. Catalogue of Reptiles in the Museum of the Asiatic Society of Bengal. Journal of the Asiatic Society, Extra Number, 88 pp.

Theobald, W., JR. 1879. On the marginal bone of an undescribed tortoise from the Upper Siwaliks near Nila, in the Potwar, Punjab. Records of the Geological Survey of India 12:186-187.

Thomas, T.M., Granatosky, M.C., Bourque, J.R., Krysko, K.L., Moler, P.E., Gamble, T., Suarez, E., Leone, E., Enge, K.M., AND RoMAN,J.2014. Taxonomic assessment of Alligator Snapping Turtles (Chelydridae:Macrochelys), with the description of two new species from the southeastern United States. Zootaxa 3786(2):141-165.

Thompson, J.C. AND HenshiLwood, C.S. 2014. Nutritional values of tortoises relative to ungulates from the Middle Stone Age levels at Blombos Cave, South Africa: implications for foraging and social behaviour. Journal of Human Evolution 67:33-47.

Thomson, S.A. 2000. Arevision of the fossil chelid turtles (Pleurodira) described by C.W. DeVis (1897). Memoirs of the Queensland Museum 43:593-598.

Thomson, S., White, A., And Georges, A. 1997. Re-evaluation of Emydura lavarackorum: identification of a living fossil. Memoirs of the Queensland Museum 42(1):327-336.

TownSEND, C.H. 1925. The Galapagos tortoises in their relation to the whaling industry: a study of old logbooks. Zoologica 4(3):55-135.
Truett, J. And Phillips, M. 2009. Beyond historic baselines: restoring Bolson Tortoises to Pleistocene range. Ecological Restoration 27(2):144-151.

Tuma, M. And Stanford, C.B. 2014. History of human interaction with North American tortoises. In: Rostal, D.C., McCoy, E.D., and Mushinsky, H.R. (Eds.). Biology and Conservation of North American Tortoises. Baltimore: Johns Hopkins University Press, pp. 143-148.

Turtle Conservation Coalition[Rhodin,A.G.J.,Walde,A.D.,Horne, B.D., van DiJK, P.P., Blanck, T., and Hudson, R. (Eds.)]. 2011. Turtles in Trouble: The World's 25+MostEndangered Tortoises and Freshwater Turtles-2011. Lunenburg, MA: IUCN/SSC Tortoise and Freshwater Turtle Specialist Group, Turtle Conservation Fund, Turtle Survival Alliance, Turtle Conservancy, Chelonian Research Foundation, Conservation International, Wildlife Conservation Society, and San Diego Zoo Global, 54 pp.

Turtle Taxonomy Working Group [van Dijk, P.P., Iverson, J.B. RHodin, A.G.J., SHaffer, H.B., AND Bour, R.]. 2014. Turtles of the world, 7th edition: annotated checklist of taxonomy, synonymy, distribution with maps, and conservation status. In: Rhodin,A.G.J., Pritchard, P.C.H., van Dijk, P.P., Saumure, R.A., Buhlmann, K.A., Iverson, J.B., and Mittermeier, R.A. (Eds.). Conservation Biology of Freshwater Turtles and Tortoises: A Compilation Project of the IUCN/SSC Tortoise and Freshwater Turtle Specialist Group. Chelonian Research Monographs 5(7):000.329-479.

Turvey, S.T. (Ed.). 2009. Holocene Extinctions. New York: Oxford University Press, 352 pp.

VAILLANT, L. 1885. Remarques complémentaires sur les tortues gigantesques de Madagascar. Comptes Rendus hebdomadaires des Séances de l'Académie des Sciences, Paris 100:874-877.

VAILlANT,L. 1898. Dessins inédits de chéloniens tirés des manuscrits de Commerson. Bulletin du Musée National d'Histoire Naturelle, Paris 4:133-139.

van DEN BerGH, G.D. 1999. The Late Neogene elephantoid-bearing faunas of Indonesia and their palaeozoogeographic implications; a study of the terrestrial faunal succession of Sulawesi, Flores and Java, including evidence for early hominid dispersal east of Wallace's Line. Scripta Geologica 117:1-419.

van den Bergh, G.D., de Vos, J., and SondaAr, P.Y. 2001. The Late Quaternary palaeogeography of mammal evolution in the Indonesian Archipelago. Palaeogeography, Palaeoclimatology, Palaeoecology 171:385-408.

van den Bergh, G.D., MeIJer, H.J.M., Due, R.A., Morwood, M.J., Szabo, K., Ostende, L.W.V.D.H., Sutikna, T., Saptomo, E.W., PIPER, P.J., AND DoBney, K.M. 2009. The Liang Bua faunal remains: a 95 k.yr. sequence from Flores, East Indonesia. Journal of Human Evolution 57(5):527-537.

Van Denburgh, J. 1907. Expedition of the California Academy of Sciences to the Galapagos Islands, 1905-1906. I. Preliminary descriptions of four new races of gigantic land tortoises from the Galapagos Islands. Proceedings of the California Academy of Sciences (4)1:1-6.

Van Denburgh, J. 1914. Expedition of the California Academy of Sciences to the Galapagos Islands, 1905-1906. X. The gigantic land tortoises of the Galapagos Archipelago. Proceedings of the California Academy of Sciences (4)2(1):203-374.

VAN DER GeER, A., Lyras, G., DE Vos, J., AND Dermitzakis, M. 2010. Evolution of IslandMammals:AdaptationandExtinction of Placental Mammals on Islands. Sussex: Wiley-Blackwell, 496 pp.

van Der Sluis, L.G., Hollund, H.I., Buckley, M., De Louw, P.G.B., RIJSDIJK, K.F., AND KARS, H. 2014. Combining histology, stable isotope analysis and ZooMS collagen fingerprinting to investigate the taphonomic history and dietary behaviour of extinct giant tortoises 
from the Mare aux Songes deposit on Mauritius. Palaeogeography, Palaeoclimatology, Palaeoecology 416:80-91.

van DiJK, P.P., Stuart, B.L., AND Rhodin, A.G.J. (Eds.). 2000. Asian Turtle Trade: Proceedings of a Workshop on Conservation and Trade of Freshwater Turtles and Tortoises in Asia. Chelonian Research Monographs No. 2, 164 pp.

Vlachos, E. 2015. The fossil chelonians of Greece. Systematics Evolution - Stratigraphy - Palaeoecology. Ph.D. Dissertation, Scientific Annals of the School of Geology, Aristotle University of Thessaloniki, Greece 173, 479 pp.

Waguespack, N.M. and Surovell, T.A. 2003. Clovis hunting strategies, or how to make out on plentiful resources. American Antiquity 68(2):333-352.

WEAVER, W.G.,JR. AND RoBERTSON,J.S. 1967.A re-evaluation of fossil turtles of the Chrysemys scripta group. Tulane Studies in Geology 5(2):53-66.

WebB, D.S. and Perrigo, S. 1984. Late Cenozoic vertebrates from Honduras and El Salvador. Journal of Vertebrate Paleontology 4:237-254.

Wei Feng, Wu Wei-tang, Xu Yu-bin, and Zhang Ming-hua. 1975. First discovery of Testudo in Cheking. Vertebrata Palasiatica 13(2):118-121.

WeIss, C.S. 1830. Über das südliche Ende des Gebirgszuges von Brasilien in der Provinz S. Pedro do Sul und der Banda oriental oder dem Staate von Monte Video; nach den Sammlungen des Herrn Fr. Sellow. Abhandlungen der Königlichen Akademie der Wissenschaften zu Berlin 1827[1830]:217-293.

Wells, R.W. and Wellington, C.R. 1985. A classification of the Amphibia and Reptilia of Australia. Australian Journal of Herpetology, Supplementary Series 1:1-61.

White, A.W. 2001. A new Eocene soft-shelled turtle (Trionychidae) from Murgon, south-eastern Queensland. Memoirs of the Association of Australasian Palaeontologists 25:37-43.

WhItE, A.W. AND ARChER, M. 1994. Emydura lavarackorum, a new Pleistocene turtle (Pleurodira: Chelidae) from fluviatile deposits at Riversleigh, northwestern Queensland. Records of the South Australian Museum 27(2):159-167.

White, A.W., Worthy, T.H., Hawkins, S., Bedford, S., AND Spriggs, M. 2010. Megafaunal meiolaniid horned turtles survived until early human settlement in Vanuatu, Southwest Pacific. PNAS (Proceedings of the National Academy of Sciences) 107(41):15512-15516.

WIED, M. ZU. 1839. Reise in das innere Nord-America in den Jahren 1832 bis 1834. Erster Band. Coblenz: J. Hoelscher, 653 pp.

Wieland, G.R. 1923. A new Parana pleurodiran. American Journal of Science (5)5:1-14.

Williams, E.E. 1950. Testudo cubensis and the evolution of Western Hemisphere tortoises. Bulletin of the American Museum of Natural History 95:1-36.

Williams, E.E. 1952. A new fossil tortoise from Mona Island, West Indies, and a tentative arrangement of the tortoises of the world. Bulletin of the American Museum of Natural History 99:545-560.

Williams, E.E. 1957. Hardella isoclina Dubois redescribed. Zoologische Mededelingen 35:235-240.

Wood, R.C. 1970. A review of the fossil Pelomedusidae (Testudines, Pleurodira) of Asia. Breviora 357:1-24.

Wood,R.C. 1976.Two new species of Chelus (Testudines: Pleurodira) from the Late Tertiary of northernSouthAmerica.Breviora 435:1-26.

Wood, R.C. 1983. Kenyemys williamsi, a fossil pelomedusid turtle from the Pliocene of Kenya. In: Rhodin, A.G.J. and Miyata, K. (Eds.). Advances in Herpetology and Evolutionary Biology. Essays in Honor of Ernest E. Williams. Cambridge, MA: Museum of Comparative Zoology, pp. 74-85.

Wood, R.C. 2003. Fossil turtles from Lothagam. In: Leakey, M.V. and Harris, J.M. (Eds.). Lothagam: The Dawn of Humanity in Eastern Africa. New York: Columbia University Press, pp. 115-136.

WOODWARD,A.S.1888. Note on the extinctreptilian genera Megalania, Owen, and Meiolania, Owen. Annals and Magazine of Natural History (6)1:85-89.

Worthy, T.H., Anderson, A.J., AND Molnar, R.E. 1999. Megafaunal expression in a land without mammals - the first fossil faunas from terrestrial deposits in Fiji (Vertebrata: Amphibia, Reptilia, Aves). Senckenbergiana Biologica 79(2):237-242.

Ye, X. 1994. Fossil and Recent Turtles of China. Beijing: Science Press, $112 \mathrm{pp}$.

Yен Н-к. 1961. The first discovery of a box-turtle in China. Vertebrata Palasiatica 5:58-64.

Yeн H-к. 1963a. The fossil turtles of China. Palaeontologica Sinica, ser. C 6(3):1-112.

Yен H-к. 1963b. A new Quaternary Testudo from Gigantopithecus Cave, Liucheng, Kwangsi. Vertebrata Palasiatica 7:223-235.

Zacarías,G.G.,DEla Fuente,M.S.,FernándeZ,M.S., ANDZuRITA,A.E. 2013. Nuevaespecie de tortugaterrestre gigante del género Chelonoidis Fitzinger, 1835(Cryptodira: Testudinidae), del miembroinferior de la formación Toropí/ Yupoí (Pleistoceno Tardío/Lujanense), Bella Vista, Corrientes, Argentina. Ameghiniana 50(3):298-318.

Zachos, J., Pagani, M., Sloan, L., Thomas, E., AND Billups, K. 2001. Trends, rhythms, and aberrations in global climate 65 Ma to present. Science 292:686-693.

Zhang M. 1984. [A new species of Pelochelys from Zhejiang, with subfossil description]. Acta Herpetologica Sinica 3(4):71-76. [In Chinese]

Zhao, E. And Adler, K. 1993. Herpetology of China. Society for the Study of Amphibians and Reptiles, Contributions to Herpetology, No. 10, 522 pp.

Zug, G.R. 1969. Fossil chelonians, Chrysemys and Clemmys, from the Upper Pliocene of Idaho. Great Basin Naturalist 29:82-87.

\section{Citation Format for this Account:}

Turtle Extinctions Working Group [Rhodin, A.G.J., Thomson, S., Georgalis, G., Karl, H.-V., Danilov, I.G., Takahashi, A., DE la Fuente, M.S., Bourque, J.R., Delfino, M., Bour, R., Iverson, J.B., SHAFFER, H.B., AND VAN DiJK, P.P.]. 2015. Turtles and tortoises of the world during the rise and global spread of humanity: first checklist and review of extinct Pleistocene and Holocene chelonians. In: Rhodin, A.G.J., Pritchard, P.C.H., van Dijk, P.P., Saumure, R.A., Buhlmann, K.A., Iverson, J.B., and Mittermeier, R.A. (Eds.). Conservation Biology of Freshwater Turtles and Tortoises: A Compilation Project of the IUCN/SSC Tortoise and Freshwater Turtle Specialist Group. Chelonian Research Monographs 5(8):000e.1-66. 